\title{
UICN
}

\section{Directrices para la aplicación de las categorías de gestión de áreas protegidas}

Editado por Nigel Dudley

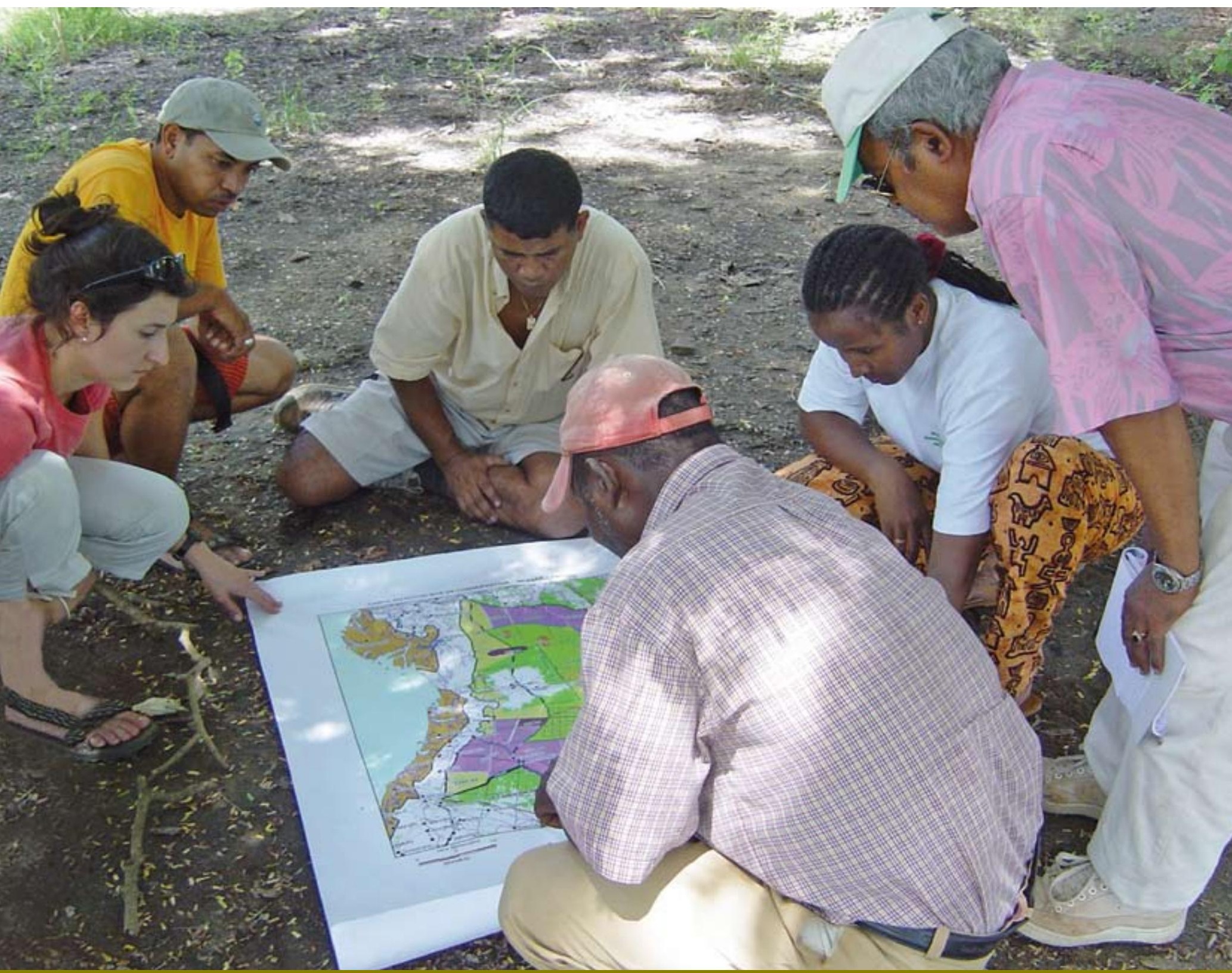




\section{Directrices para la aplicación de las categorías de gestión de áreas protegidas}




\section{UICN}

La UICN (Unión Internacional para la Conservación de la Naturaleza), fundada en 1948, agrupa a Estados soberanos, agencias gubernamentales y una diversa gama de organizaciones no gubernamentales, en una alianza única: más de 1000 miembros diseminados en cerca de 160 países. Como Unión, la UICN busca influenciar, alentar y ayudar a los pueblos de todo el mundo a conservar la integridad y la diversidad de la naturaleza, y a asegurar que todo uso de los recursos naturales sea equitativo y ecológicamente sustentable. La UICN fortalece el trabajo de sus miembros, redes y asociados, con el propósito de realzar sus capacidades y apoyar el establecimiento de alianzas globales para salvaguardar los recursos naturales a nivel local, regional y global.

Website: www.iucn.org

\section{La Comisión Mundial de Áreas Protegidas (CMAP)}

La Comisión Mundial de Áreas Protegidas (CMAP) es la red de liderazgo mundial de especialistas y directores de áreas protegidas, con más de 1300 miembros en 140 países. La CMAP es una de las 6 comisiones voluntarias de la UICN. Es administrada por el Programa de Áreas Protegidas, ubicado en la sede mundial de la UICN en Gland, Suiza. La misión de la CMAP, dentro de la misión de la UICN, es la de promover el establecimiento y gestión eficaz de una red mundial representativa de áreas protegidas terrestres y marinas.

Website: www.iucn.org/themes/wcpa

\section{Consejería de Medio Ambiente de la Junta de Andalucia}

La Consejería de Medio Ambiente de la Junta de Andalucía es la administración responsable del gobierno regional de Andalucía en la conservación de la naturaleza, la aplicación de las normas y políticas ambientales sobre el uso y gestión de recursos naturales, la declaración y gestión de las Áreas Protegidas de su territorio, así como la definición, desarrollo e implantación de la estrategia y políticas de mitigación y adaptación en materia de cambio climático.

\section{Fundación Biodiversidad}

La Fundación Biodiversidad es una organización fundacional, sin ánimo de lucro, fundada en el año 1998 a raíz de los compromisos adquiridos por España tras la ratificación del Convenio sobre Diversidad Biológica. Su actividad se desarrolla en el ámbito de la conservación, estudio y uso sostenible de la biodiversidad, así como la cooperación internacional al desarrollo. A través de la Cooperación Internacional, la Fundación Biodiversidad consigue aunar esfuerzos y crear sinergias, así como promover la colaboración con organismos, instituciones y programas nacionales e internacionales. 


\section{Directrices para la aplicación de las categorías de gestión de áreas protegidas}

Editado por Nigel Dudley 
La designación de entidades geográficas y la presentación del material en este libro no implican la expresión de ninguna opinión por parte de la UICN o de otra organización participante respecto a la condición jurídica de ningún país, territorio o área, o de sus autoridades, o referente a la delimitación de sus fronteras y límites.

Los puntos de vista que se expresan en esa publicación no reflejan necesariamente los de la UICN o de otra organización participante. La UICN y las organizaciones participantes declinan cualquier error u omisión en la traducción de este documento de la versión original en inglés al español.

\section{Publicado por:}

Derechos reservados:

Citación:

\section{ISBN:}

Traducción al español: Fotografías de la cubierta:

Diagramado por:

Producido por:

Impreso por:

Disponible en:

\section{UICN, Gland, Suiza}

(C) 2008 Unión Internacional para la Conservación de la Naturaleza y de los Recursos Naturales

Se autoriza la reproducción de esta publicación con fines educativos y otros fines no comerciales sin permiso escrito previo de parte de quien detenta los derechos de autor con tal de que se mencione la fuente.

Se prohíbe reproducir esta publicación para la venta o para otros fines comerciales sin permiso escrito previo de quien detenta los derechos de autor.

Dudley, N. (Editor) (2008). Directrices para la aplicación de las categorias de gestión de áreas protegidas. Gland, Suiza: UICN. x + 96pp.

978-2-8317-1088-4

José Puente, revisado por Isabel Moyano Ramos y Pedro Rosabal

Cubierta anterior: Debate con comunidades locales cerca de Morondava, Madagascar sobre la zonificación en una área propuesta como protegida para conservar especies del árbol baobab. (C) Nigel Dudley

Cubierta posterior: Nueva Caledonia (C Dan Laffoley

Bookcraft Ltd, Stroud, Reino Unido

Servicio de publicaciones de UICN

Page Bros, Norwich, Reino Unido

UICN (Unión Internacional para

la Conservación de la Naturaleza)

Servicio de publicaciones

Rue Mauverney 28

1196 Gland

Suiza

Tel +41229990000

Telefax +41229990020

books@iucn.org

www.iucn.org/publications

También existe a disposición un catálogo de las publicaciones de la UICN. 


\section{Índice}

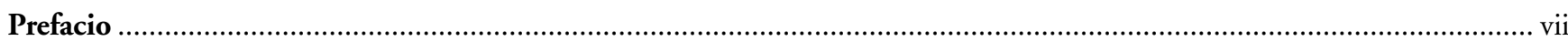

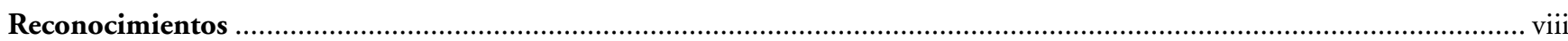

Introducción

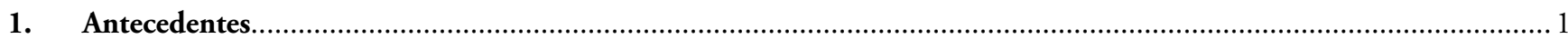

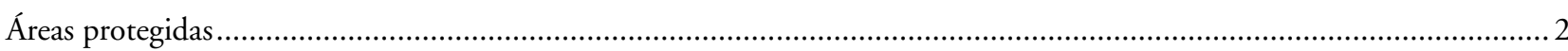

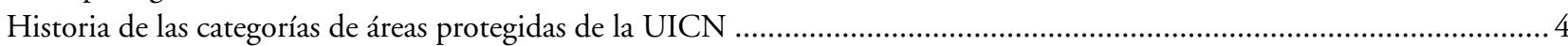

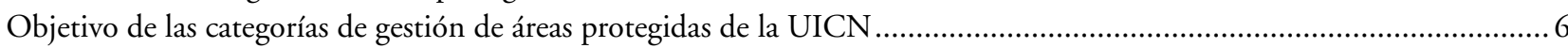

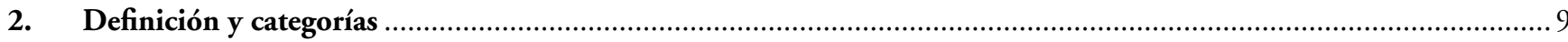

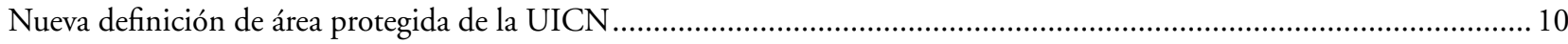

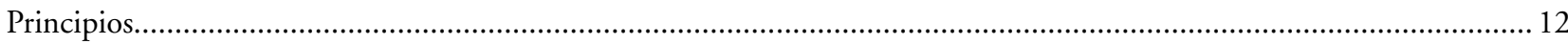

Definición de sistema de áreas protegidas y de enfoque de ecosistema .................................................................. 12

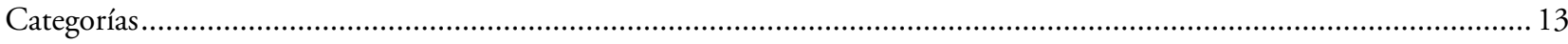

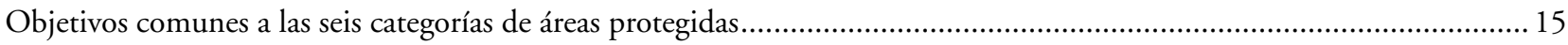

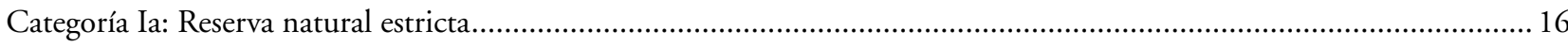

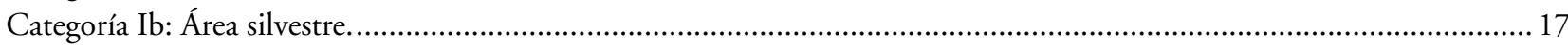

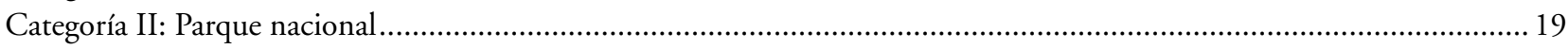

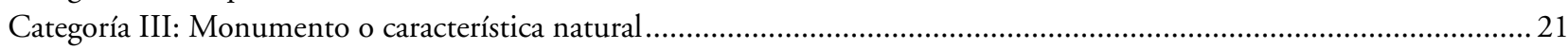

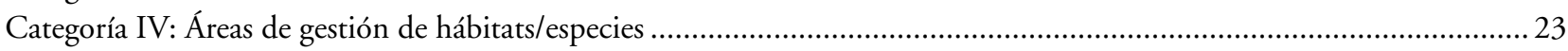

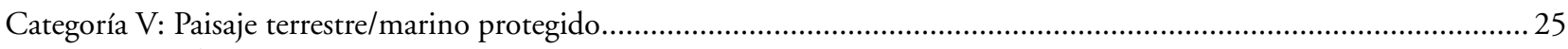

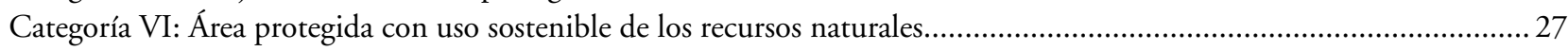

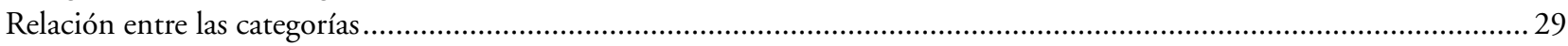

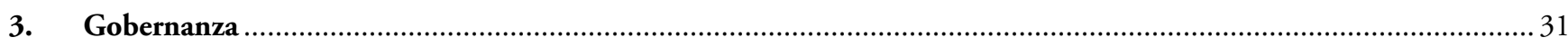

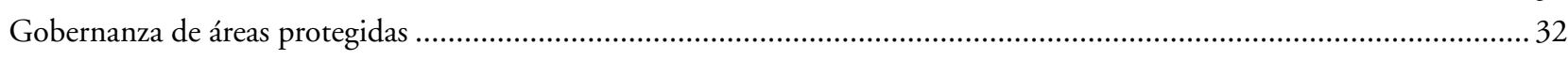

Gobernanza por parte de pueblos indígenas y comunidades locales ..................................................................... 34

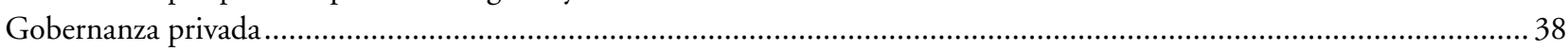

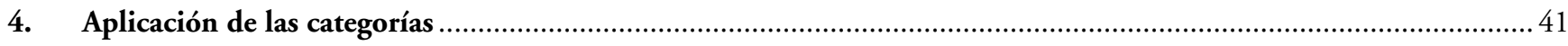

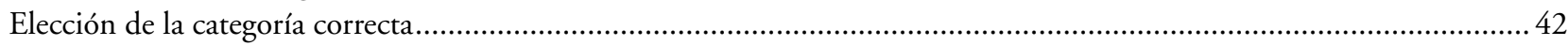

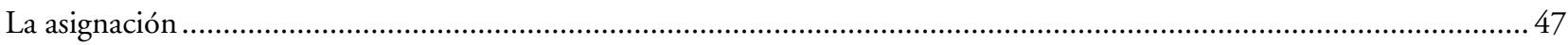

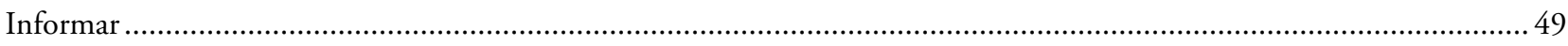

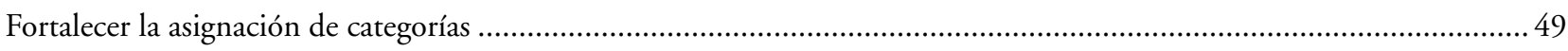

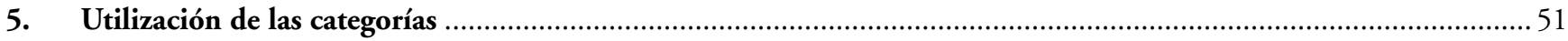

Utilización de las categorías de áreas protegidas de la UICN como herramienta de planificación de la conservación ......... 52

Planificar para afrontar el cambio climático .................................................................................................5

Utilización de las categorías de áreas protegidas de la UICN como herramienta para las políticas de conservación ............56

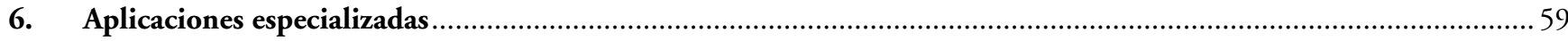

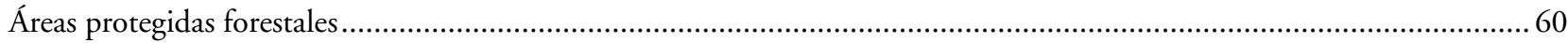

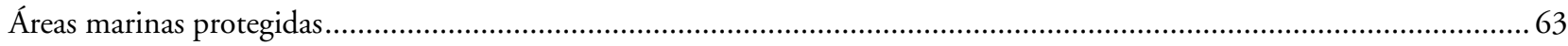

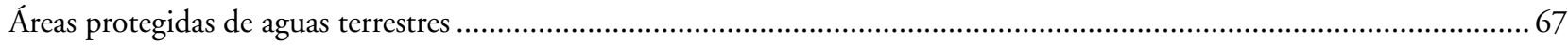

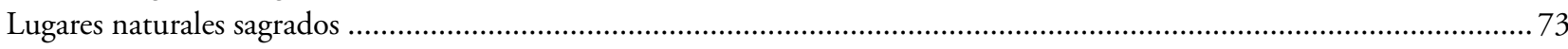

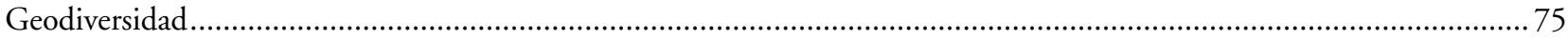

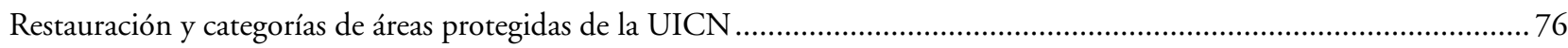

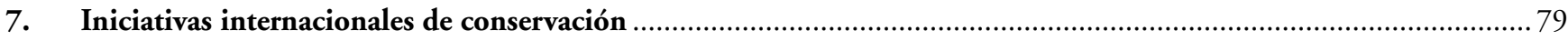

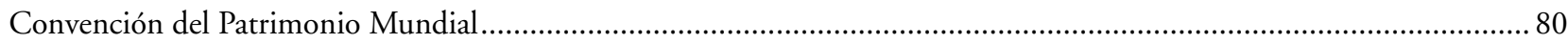

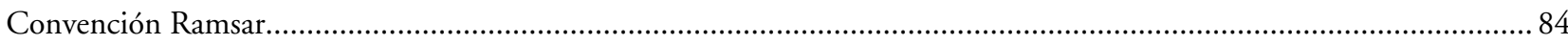

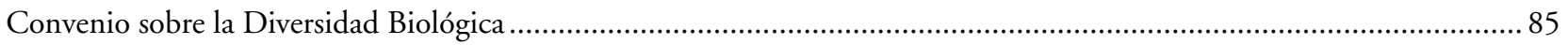




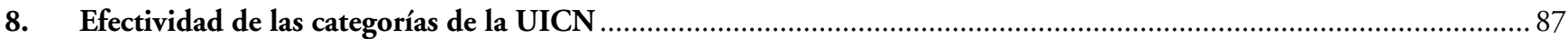

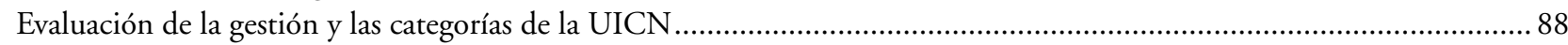

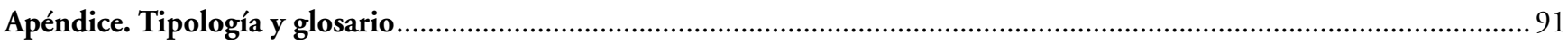

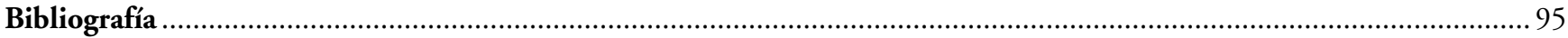

Tablas

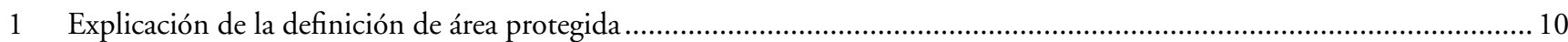

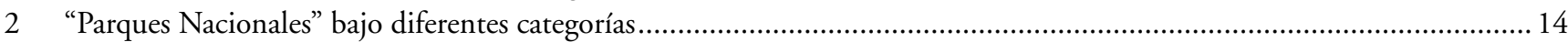

3 "La matriz de área protegida de la UICN": un sistema de clasificación de áreas protegidas que comprende tanto la

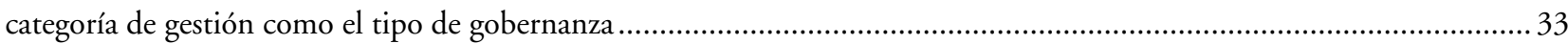

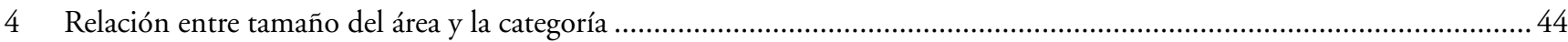

5 Análisis de Fortalezas-Debilidades-Oportunidades-Amenazas por categorías en condiciones de cambio climático............. 55

6 Ejemplos de Áreas Protegidas Forestales, y también de bosques bien conservados que no son Áreas

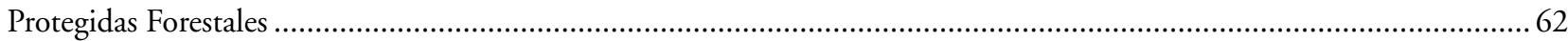

7 Distinción entre áreas de conservación de conectividad como corredores biológicos, puntos conectores y zonas de amortiguamiento dentro y fuera de las áreas protegidas forestales.........................................................63

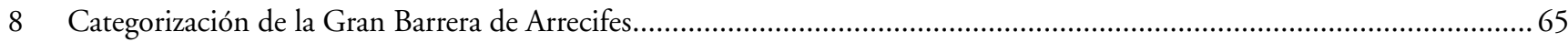

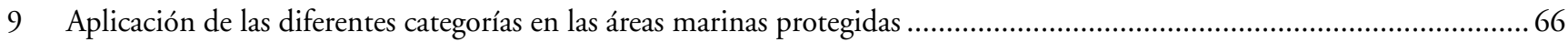

10 Ejemplos de áreas protegidas de distintas categorías destinadas a la protección de aguas terrestres ................................. 70

11 Compatibilidad de distintas estrategias de protección de aguas terrestres con las categorías de la UICN......................... 71

12 Categorías de áreas más adecuadas para distintos tipos de ecosistemas de humedales terrestres .....................................72

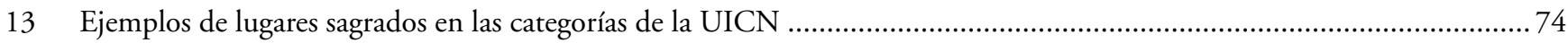

14 Ejemplos de geodiversidad en distintas categorías de áreas de la UICN ..............................................................76

15 Indicaciones de posibles categorías de áreas protegidas de la UICN para distintos aspectos de la geodiversidad ................ 76

16 Guía indicativa para la restauración en diferentes categorías de la UICN ...........................................................77

17 Cambios de relación entre los sitios naturales Patrimonio Mundial y las áreas protegidas con el tiempo ......................... 81

18 Elementos del marco de trabajo del CMAP para la evaluación de la eficacia de la gestíon de áreas protegidas................... 88

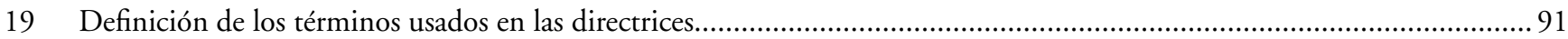

\section{Figuras}

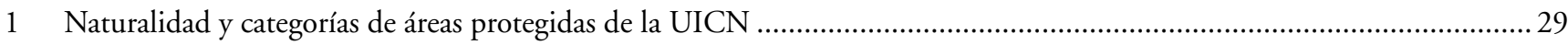

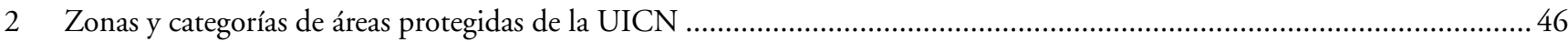

3 Proceso para la asignación de categorías de áreas protegidas .............................................................................49

4 Frecuencia de la incidencia de las categorías de Áreas Protegidas de la UICN en los sitios naturales de Patrimonio Mundial de biodiversidad y de no-biodiversidad. 


\section{Prefacio}

Las áreas protegidas siguen siendo la piedra angular de prácticamente todas las estrategias nacionales e internacionales de conservación, ya que además cuentan con el apoyo de gobiernos e instituciones internacionales como el Convenio sobre la Diversidad Biológica. Sin duda, constituyen el núcleo fundamental de los esfuerzos para proteger las especies amenazadas del mundo y cada vez más se reconoce su papel esencial no sólo como proveedores esenciales de servicios de ecosistema y recursos biológicos, sino como elementos fundamentales en las estrategias de mitigación al cambio climático. Además, en ocasiones se han probado fundamentales para proteger ciertas comunidades humanas amenazadas y lugares de gran valor cultural y espiritual. Dado que las áreas protegidas cubren el doce por ciento de la superficie emergida del planeta, el sistema de áreas protegidas representa un compromiso sin precedentes hacia el futuro, un faro de esperanza, en lo que a veces parece ser una carrera desalentadora hacia el declive ambiental y social.

Las áreas protegidas no son en modo alguno entidades uniformes, antes bien, abarcan un amplio abanico de objetivos y están administradas por un gran número de actores muy diversos. Así, podemos encontrar un número de sitios cuyo acceso está totalmente prohibido debido a su enorme importancia y fragilidad, pero también otro tipo de áreas protegidas que engloban territorios y espacios marinos tradicionalmente habitados, donde la acción humana ha moldeado los paisajes culturales con una alta biodiversidad. En algunos casos, la propiedad y la gestión de los sitios están en manos de los gobiernos, mientras que en otros esta propiedad y gestión corresponde a particulares, empresas privadas, comunidades y grupos religiosos. De esta forma, vamos reconociendo que hay una variedad mucho más rica y amplia de gobernanza que la que habíamos asumido hasta ahora.
Las categorías de gestión de las áreas protegidas de la UICN constituyen un marco internacional de referencia, reconocido por el Convenio sobre la Diversidad Biológica, para categorizar la variedad de modos de gestión de las áreas protegidas. Resumir la serie casi infinita de enfoques en seis categorías no puede entenderse sino como una aproximación. Pero la profundidad del interés y la pasión del debate que suscita la revisión de estas categorías muestran que para muchos conservacionistas y otros actores, representan un marco general clave que ayuda a moldear la gestión y las prioridades de las áreas protegidas en todo el mundo.

No nos hemos apresurado en esta revisión. Comenzó con un proyecto consultivo de investigación de dos años, que, presentado al Congreso Mundial de la Conservación de Bangkok en el año 2004, dio lugar a una resolución para elaborar las directrices que se presentan en este libro. Durante estos años, la UICN ha realizado consultas a un número enorme de miembros en reuniones especiales, congresos, debates electrónicos y mediante lo que en ocasiones resultaba ser una correspondencia interminable. Somos conscientes de que los resultados no son perfectos, una tarea por lo demás imposible. Pero creemos que la interpretación de la definición de área protegida y las categorías aquí que se presentan constituyen la opinión de la gran mayoría de los miembros de la UICN. De manera importante, se complementan con los tipos de gobernanza de la UICN, demostrando el creciente interés de la Unión por las cuestiones de gobernanza.

En los próximos años, trabajaremos para promocionar el sistema de categorías, para traducir las directrices a más idiomas y para asegurar que se apliquen eficazmente, con el propósito de maximizar el potencial del sistema global de áreas protegidas para que se prolongue a lo largo del tiempo. 


\section{Reconocimientos}

La revisión de las directrices de la UICN ha seguido un largo y exhaustivo proceso de consultas dentro de la UICN. Por ello, estamos profundamente agradecidos a los miembros de la UICN, La Comisión Mundial de Áreas Protegidas de la UICN y el grupo de Trabajo de Categorías por su ayuda en la redacción y el consenso del texto final. Esta publicación es el resultado de dicha revisión y ha sido posible gracias a la generosa aportación económica de la Fundación Biodiversidad de España. La Fundación Biodiversidad es una fundación sin ánimo de lucro constituida en 1998 en cumplimiento de los compromisos asumidos por España tras la ratificación del Convenio sobre la Diversidad Biológica. Desarrolla actividades en el campo de la conservación, estudio y uso sostenible de la biodiversidad, así como cooperación internacional para el desarrollo. Mediante la cooperación internacional la Fundación Biodiversidad intenta unir esfuerzos y crear sinergias, así como promover la colaboración con organizaciones, instituciones y programas nacionales e internacionales.

En primer lugar queremos mostrar nuestro agradecimiento a todos aquellos que han realizado comentarios al proyecto Emplear un Lenguaje Común., que tuvo como resultado un informe final redactado por Kevin Bishop, Nigel Dudley, Adrian Phillips y Sue Stolton, quienes desarrollaron la investigación previa que llevó a la revisión de las categorías. El presente informe del proyecto incluye una lista completa de reconocimientos, pero nos gustaría agradecer especialmente a Natalia Danilina, Vicepresidente de la CMAP para Eurasia Septentrional, por organizar la traducción de todo el informe al ruso.

A continuación, nuestro profundo agradecimiento a todos aquellos que redactaron informes que les fueron encargados de forma independiente sobre la aplicación de las categorías y asimismo realizaron sugerencias para la versión revisada. Entre ellos: Robin Abell, José Antonio Atauri, Christian Barthod, Charles Besancon, Harry Biggs, Luigi Boitani, Grazia BorriniFeyerabend, Peter Bridgewater, Jessica Brown, Phillip Bubb, Neil Burgess, José Courrau, Roger Crofts, Nick Davidson, Jon Day, Phillip Deardon, Benita Dillon, Charlie Falzon, Lucy Fish, Pete Frost, Roberto Gambino, John Gordon, Craig Groves, David Harmon, Marc Hockings, Sachin Kapila, Cyril Kormos, Ashish Kothari, Dan Laffoley, Harvey Locke, Stephanie Mansourian, Josep-Maria Mallarach, Claudio Maretti, Carole Martinez, Kenton Miller, Brent Mitchell, John Morrison, C. Niel, Gonzalo Oviedo, Jeffrey Parrish, Andrew Parsons, Marc Patry, Jean-Marie Petit, Adrian Phillips, Kent Redford, Liesbeth Renders, Carlo Rondinini, Deborah Bird Rose, Fausto Sarmiento, David Sheppard, Daniela Talamo, Daniel Vallauri, Bas Verschuuren, John Waugh y Bobby Wishitemi. Algunos de estos artículos fueron producidos con fondos de BP y estamos muy agradecidos por este apoyo.
Una parte vital de este proceso de revisión fue la realización de la Cumbre sobre Categorías de la UICN, celebrada en Almería, España (7-11 de mayo de 2007). La Cumbre sobre Categorías fue organizada y realizada con el apoyo económico e institucional de la Junta de Andalucía, la Fundación Biodiversidad y el Centro de la UICN de Cooperación del Mediterráneo. La Consejería de Medio Ambiente de la Junta de Andalucía proporcionó apoyo técnico y logístico en forma de estudios de caso y actividades de campo durante la Cumbre, que contribuyeron sustancialmente al éxito de la misma. La Consejería de Medio Ambiente de la Junta de Andalucía es el organismo público del gobierno autonómico de Andalucía responsable de la conservación de la naturaleza, la aplicación de las normativas y políticas medioambientales sobre el uso y la gestión de los recursos naturales, la declaración y gestión de áreas protegidas, así como la definición, desarrollo e implementación de la mitigación del cambio climático y de las estrategias y políticas de adaptación al mismo.

Un gran número de personas dedicó una semana de su tiempo a debatir la revisión de las categorías durante la Cumbre sobre Categorías de la UICN. Estamos especialmente agradecidos a los siguientes expertos por su participación: Tarek Abulhawa, Andrés Alcántara, Germán Andrade, Alexandru Andrasanu, Suade Arancli, Margarita Astralaga, José Antonio Altauri, Jim Barborak, Brad Barr, Christian Barthod, Louis Bélanger, Charles Besancon, Ben Böer, Grazia Borrini-Feyerabend, Peter Bridgewater, Tom Brooks, Jessica Brown, Susana Calvo Roy, Sonia Castaneda, Carles Castell Puig, Miguel Castroviejo Bolívar, Peter Cochrane, Peter Coombes, José Courrau, Botella Coves, Roger Crofts, Marti Domènech I Montagut, Marc Dourojeanni, Holly Dublin, Nigel Dudley, Abdellah El Mastour, Ernest Enkerlin Hoeflicj, Reinaldo Estrada, Jordi FalgaronaBosch, Antonio Fernández de Tejada González, Georg Frank, Roberto Gambino, Javier Garat, Sarah Gindre, Craig Groves, José Romero Guirado, Manuel Francisco Gutiérrez, Heo HagYoung, Marc Hockings, Rolf Hogan, Bruce Jeffries, Vicente Jurado, Ali Kaka, Sachin Kapila, Seong-II Kim, Cyril Kormos, Meike Kretschmar, Zoltan Kun, Dan Laffoley, Kari Lahti, Maximo Liberman Cruz, Harvey Locke, Axel Loehken, Arturo Lopez, Elena López de Montenegro, Nik Lopoukhine, Ibanez Luque, Maher Mahjoub, Josep Maria Mallarach, Moses Mapesa, Claudio Maretti, Vance Martin, María Teresa Martín Crespo, Carole Martinez, Baldomero Martinez, Julia Marton-Lefevre, Mehrasa Pehrdadi, Rosa Mendoza Castellón, Kenton Miller, Susan Miller, Carmen Miranda, Fernando Molina, Sophie Moreau, Gérard Moulinas, Marta Múgica, Eduard Müller, Anread Müseler, Olav Nord-Varhaug, Juan Carlos Orella, Gonzalo Oviedo, Ana Pena, Milagros Pérez Villalba, Christine 
Pergent-Martini, Rosario Pintos Martin, Anabelle Plantilla, Francisco Quiros, Mohammed Rafiq, Tamica Rahming, Anitry Ny Aina Ratsifandrihamanana, Kent Redford, Manuel Rodríguez de Los Santos, Pedro Rosabal, Juan Carlos Rubio García, Alberto Salas, Francisco Sánchez, Ana Elena Sánchez de Dios, José Luis Sánchez Morales, Mohammed Seghir Melouhi, Peter Shadie, David Sheppard, Sue Stolton, Gustavo Suárez de Freitas, Daniela Talamo, Tony Turner, Rauno Väisänen, Tafe Veselaj, Nestor Windevoxhel y Stephen Woodley.

Asimismo, se celebraron reuniones nacionales para discutir las categorías en la II Conferencia de Parques del Patrimonio de la ASEAN y en la IV Conferencia Regional de Áreas Protegidas del Sudeste Asiático celebrada en Sabah, Malasia; en asociación con el Centro Mundial de Monitorización de la Conservación del PNUMA en Nairobi, Kenya; en el Segundo Congreso Latinoamericano de Parques de Bariloche, Argentina y en la Reunión Europea de la CMAP de Barcelona, España. Estamos muy agradecidos a los organizadores, incluyendo a Christi Nozawa, Anabelle Plantilla, Geoffrey Howard, Sue Stolton, Carmen Miranda y Roger Crofts. También queremos expresar nuestro agradecimiento a todos aquellos que participaron en los talleres y cuyas ideas contribuyeron a las directrices finales.

Igualmente, se celebraron reuniones en el Consejo Internacional de Minería y Metales (ICCM) y la Asociación Internacional de la Industria Petrolera sobre Conservación Ambiental (IPIECA), ambas en Londres y en una reunión especial de representantes de la industria con la UICN en Gland, Suiza, y damos las gracias a los organizadores de dichos eventos.

Nos han enviado numerosos comentarios relativos a la definición de área protegida, las directrices en su conjunto o parte de las mismas y muchos han contribuido al-debate. Entre los que han enviado comentarios por escrito o han participado en las reuniones organizadas se encuentran, además de los anteriormente citados: Mike Appleton, Alberto Arroyo, Andrea Athanus, Tim Badman, John Benson, Juan Bezaury, Stuart Blanch, Andrer Bouchard, José Briha, Kenneth Buk, Eduardo Carqueijeiro, Brian Child, Thomas Cobb, Nick Conner, Marina Cracco, Adrian Davey, Fekadu Desta, Jean Pierre d'Huart, Paul Eagles, Joerg Elbers, Neil Ellis, Penny Figgis, Frauke Fisher, James Fitzsimmons, Gustavo Fonseca, Alistair Gammell, George Gann, Brian Gilligan, Fernando Ghersi, Hugh Govan, Mary Grealey, Michael Green, Larry Hamilton, Elery Hamilton Smith, Alan Hemmings, John Hough, Pierre Hunkeler, Glen Hvengaard, Tilman Jaeger, Jan Jenik, Graeme Kelleher, Richard Kenchington, Saskia de Koning, Linda Krueger, Barbara Lausche, Richard Leakey, Mary Kay LeFevour, Li Lifeng, Heather MacKay, Brendan Mackey, Dave MacKinnon, Vinod Mathur, Nigel Maxted, Jeffrey McNeely, Mariana Mesquita, Paul Mitchell, Russ Mittermeier, Geoff
Mosley, Fulori Nainoca, Juan Oltremari, Sarah Otterstrom, Thymio Papayanis, Jamie Pittock, Sarah Pizzey, Dave Pritchard, Allen Putney, Joanna Robertson, Jaime Rovira, Tove Maria Ryding, Heliodoro Sánchez, Andrej Sovinc, Rania Spyropoulou, Erica Stanciu, David Stroud, Surin Suksawan, Martin Taylor, Djafarou Tiomoko, Joseph Ronald Toussaint, Frank Vorhies, Daan Vreugdenhil, Haydn Washington, Sue Wells, Rob Wild, Graeme Worboys, Eugene Wystorbets y Edgard Yerena. Hemos recibido también numerosas respuestas colectivas que reflejan las de un grupo de especialistas, una institución o una ONG.

David Sheppard, Pedro Rosabal, Kari Lahti, y Tim Badman del Programa de Áreas Protegidas (PAP) de la UICN han aportado contribuciones técnicas y orientación sobre políticas en todo este proceso; Delwyn Dupuis, Anne Erb y Joanna Erfani han proporcionado también asistencia y apoyo administrativo muy necesarios desde la sede de la UICN de Gland. Nik Lopoukhine, Presidente de la CMAP, ha sido constante en su apoyo a este proceso, al igual que los miembros de la Junta Directiva de la CMAP. En particular Trevor Sandwith, Roger Crofts y Marc Hockings han realizado lecturas detalladas del texto completo y Grazia Borrini-Feyerabend y Ashish Kothari han comentado las numerosas versiones del capítulo de gobernanza. El asesoramiento técnico y sobre políticas proporcionado por Gonzalo Oviedo, Asesor Senior de la UICN sobre Políticas Sociales ha sido fundamental en relación con las cuestiones de gobernanza y pueblos indígenas.

Peter Cochrane y Sarah Pizzey de Parks Australia organizaron y apoyaron un largo viaje a cinco estados de Australia para discutir las categorías con decenas de profesionales que trabajan en áreas protegidas, tanto en reuniones como sobre el terreno. Esto supuso una gran aportación a nuestra comprensión de los retos y oportunidades de establecer unas nuevas directrices y de probar nuestras ideas.

El trabajo sobre la categoría $\mathrm{Ib}$ ha sido impulsado por el Grupo de Trabajo de Vida Silvestre presidido por Vance Martin, y Cyril Kormos ha asumido el liderazgo en el trabajo sobre categorías. La posición sobre la categoría V de la UICN ha sido desarrollada en mayor profundidad en dos reuniones del grupo de trabajo especial dedicado a los enfoques de paisaje, generosamente financiadas por el gobierno catalán y por un consorcio de la agencia de conservación del Reino Unido: Natural England, Patrimonio Natural de Escocia y el Countryside Council for Wales. Jessica Brown preside el grupo de trabajo, organizó las reuniones, con la ayuda de Jordi Falgarone y Andy Brown respectivamente. La posición sobre la categoría VI se ha desarrollado mediante el trabajo de un nuevo Grupo de Trabajo de la Categoría VI presidido por Claudio Maretti y en una reunión celebrada en el marco del Congreso Latinoamericano y del Caribe de Parques de Bariloche, Argentina. 


\section{Introducción}

Estas directrices se presentan para ayudar a la aplicación de las categorías de gestión de áreas protegidas de la UICN que clasifican las áreas protegidas en función de sus objetivos de gestión. Las categorías están reconocidas por organismos internacionales como las Naciones Unidas y por muchos gobiernos nacionales como el estándar global para la definición de áreas protegidas y como tales están siendo progresivamente incorporadas a las legislaciones nacionales. Por ejemplo, el Programa de trabajo de Áreas Protegidas del CDB "reconoce que el valor de un único sistema internacional de clasificación para las áreas protegidas y el beneficio de ofrecer información que sea comparable entre los distintos paises y regiones, y por ello da la bienvenida a los actuales esfuerzos de la Comisión Mundial de Areas Protegidas de la UICN para refinar el sistema de categorías de la UICN..."

Las directrices proporcionan toda la claridad posible en relación al significado y la aplicación de las categorías. Describen la definición y las categorías y abordan su aplicación en distintos biomas y con distintos enfoques de gestión.

La intención original del sistema de Categorías de Gestión de Áreas Protegidas de la UICN era crear un entendimiento común sobre las áreas protegidas tanto entre países como dentro de ellos. Esto está planteado en la introducción de las Directrices por el entonces Presidente de la CPNAP (Comisión de Parques Nacionales y Áreas Protegidas, hoy en día Comisión Mundial de Áreas Protegidas), P.H.C. (Bing) Lucas escribió lo siguiente: "Estas directrices tiene un significado especial ya que están dirigidas a todos los que están involucrados en las áreas protegidas, proporcionando un lenguaje común mediante el cual los gestores, planificadores, investigadores, politicos y grupos ciudadanos pueden intercambiar información y puntos de vista" (UICN 1994).

Tal como señaló Phillips (2007) las Directrices de 1994 también estaban dirigidas a: "reducir la confusión en el uso de muchos términos diferentes para describir las áreas protegidas; proporcionar estándares internacionales para una contabilidad global y regional y para las comparaciones entre paises, emplear un marco de referencia común para la recogida, procesamiento y divulgación de datos de áreas protegidas; y en general, mejorar la comunicación y comprensión mutua entre todos aquellos involucrados en la conservación".

Este uso de las categorías de áreas protegidas como vehículo para "emplear un lenguaje común" se ha ampliado consistentemente desde la adopción de las directrices en 1994. En particular, ha habido varios casos de aplicación del sistema de categorías en política a todos los niveles: internacional, regional y nacional. Las actuales directrices cubren por tanto una gama más amplia de cuestiones y son más detalladas que la versión de 1994. Cuando sea necesario, se complementarán por guías más detalladas para cada una de las categorías, su aplicación en determinados biomas y otras áreas especializadas. Tras un largo proceso de consultas dentro de la UICN y con los miembros, se han realizado varios cambios adicionales desde 1994, incluyendo la definición de área protegida y de algunas de las categorías.

\section{¿Debería ser "área protegida" un término inclusivo o exclusivo?}

Una cuestión fundamental relativa a la definición y las categorías de las áreas protegidas es si el término "área protegida" debería ser un término general que puede abarcar una gama muy amplia de tipos de gestión de territorios y aguas que de forma incidental tienen algún valor para la conservación de la biodiversidad y el paisaje, o debería ser un término más preciso que describa una forma concreta de sistema de gestión especialmente dirigido a la conservación. Los países difieren en su interpretación, lo que hace que las comparaciones a veces resulten difíciles: algunos de los espacios que "cuentan" como áreas protegidas en un país determinado no serán necesariamente considerados como tales en otros. La UICN ha intentado alcanzar algún tipo de consenso en esta cuestión con los principales actores clave vinculados a este tema. Aunque reconocemos que es cuestión de cada país el determinar lo que describe como área protegida, la opinión mayoritaria entre los miembros de la UICN y otros parece ser hacer la definición general más estricta.

Una implicación es que no todas las áreas que son valiosas para la conservación - por ejemplo bosques bien gestionados, áreas de usos sostenibles, áreas de entrenamiento militar o varias formas de designación del paisaje - serán reconocidas como "áreas protegidas" por la UICN. No es nuestra intención restar importancia o socavar dichos esfuerzos más generales para la gestión sostenible. Reconocemos que dichos enfoques de gestión son valiosos para la conservación, pero quedan fuera de la definición de área protegida de la UICN que se presenta en estas directrices. 


\section{Antecedentes}

La primera sección de las directrices plantea el escenario presentando lo que significa el término "área protegida" para la UICN. Aborda la historia de las categorías de áreas protegidas de la UICN, incluyendo el presente proceso de revisión de las directrices. Explica después los objetivos fundamentales de las categorías para la UICN.

Finalmente, se incluye un glosario para asegurar una comprensión consistente. 


\section{Áreas protegidas}

Las áreas protegidas son esenciales para la conservación de la biodiversidad. Son la piedra angular de prácticamente todas las estrategias nacionales e internacionales de conservación, están destinadas a mantener ecosistemas naturales operativos, actuar como refugios para las especies y mantener procesos ecológicos incapaces de sobrevivir en los entornos terrestres y marítimos con un mayor nivel de intervención. Las áreas protegidas actúan como indicadores que nos permiten entender las interacciones humanas con el mundo natural. Frecuentemente constituyen la última esperanza con la que contamos para impedir la extinción de muchas especies amenazadas o endémicas. Son complementarias de otras medidas destinadas a conseguir la conservación y el uso sostenible de la biodiversidad fuera de las áreas protegidas de acuerdo con directrices del CDB como los Principios de Malawi y Addis Abeba (CDB VII/11-12). La mayoría de las áreas protegidas se encuentran en ecosistemas naturales o casi naturales, o que se están restaurando para recuperar dicha condición, aunque existen excepciones. Muchas contienen rasgos de la historia y los procesos del planeta mientras que otras documentan la sutil interrelación entre las actividades humanas y la naturaleza en los paisajes culturales. Las áreas protegidas de mayor tamaño y más naturales también proporcionan un espacio para la evolución y la futura adaptación ecológica, ambas de una creciente importancia bajo condiciones de rápido cambio climático.

Dichos espacios también benefician directamente a los seres humanos. Las personas - tanto los que viven en áreas protegidas y en áreas limítrofes como otras de más lejos - se benefician de las oportunidades de entretenimiento y renovación existentes en los parques nacionales y áreas silvestres, del potencial genético de las especies silvestres, y de los servicios medioambientales proporcionados por los ecosistemas naturales como el suministro de agua. Muchas áreas protegidas son también esenciales para las sociedades humanas vulnerables y conservan espacios de gran valor como son los lugares naturales sagrados. Aunque muchas de las áreas protegidas son establecidas por los gobiernos nacionales, son cada vez más las establecidas por comunidades locales, pueblos indígenas, ONG medioambientales, personas físicas y jurídicas y otros.

Existe un interés enorme y creciente en el mundo natural, y las áreas protegidas nos proporcionan la oportunidad de interactuar con la naturaleza de una forma que resulta cada vez más difícil en otras zonas. Nos ofrecen un espacio del que de otra forma careceríamos en un planeta cada vez más gestionado y poblado.

Las áreas protegidas también representan un compromiso con las generaciones futuras. La mayoría de la gente cree que tenemos la obligación ética de evitar la pérdida de especies causada por nuestras propias acciones y esto se defiende en las enseñanzas de las principales confesiones religiosas del mundo (Dudley et al. 2006). La protección de paisajes terrestres y marinos icónicos también se considera importante también desde una perspectiva cultural más amplia, y las áreas protegidas emblemáticas son tan importantes para el patrimonio de un país como por ejemplo, edificios famosos tales como la Catedral de Notre Dame o el Taj Mahal, las selecciones nacionales de fútbol o las obras de arte.

\section{Desarrollo del sistema mundial de áreas protegidas}

Hoy en día alrededor de un diez por ciento de la superficie terrestre del mundo cuenta con algún tipo de protección. A lo largo de los últimos 40 años el área total protegida se ha incrementado desde un área de la superficie del Reino Unido a un área de la superficie de Sudamérica. Sin embargo, persisten importantes retos. Muchas áreas protegidas aún no se han implementado o gestionado en su totalidad. Las áreas protegidas marinas son mucho más escasas que las áreas protegidas terrestres y de aguas continentales, aunque se están realizando esfuerzos para rectificar dicha situación. La inmensa mayoría de las áreas protegidas han sido identificadas y documentadas durante el siglo veinte, en el que casi con total seguridad, es el mayor y más rápido cambio consciente de la gestión del territorio de toda la historia (aunque no tan grande como la degradación del territorio en gran medida no planificada que se ha producido en el mismo período). Este cambio de valores está aún por reconocer y comprender. Se siguen estableciendo áreas protegidas, que recibieron un impulso en 2004 a raíz del Convenio sobre la Diversidad Biológica (CDB), donde se aprobó un ambicioso Programa de Trabajo de Áreas Protegidas, basado en las conclusiones clave del V Congreso Mundial de Parques de la UICN, ${ }^{1}$ con el fin de completar sistemas de áreas protegidas ecológicamente representativos en todo el mundo, este cuenta con casi cien objetivos con periodos de cumplimiento claramente determinados. Ello resulta necesario porque aunque el ritmo de crecimiento ha sido impresionante, muchas áreas protegidas han sido establecidas en zonas remotas, despobladas o poco habitadas como montañas, campos helados o tundras, y sigue existiendo un déficit en algunos ecosistemas de bosques o pastizales, en desiertos y zonas semidesérticas, en masas de agua dulce, y especialmente en áreas costeras y marinas. Muchas de las especies salvajes vegetales y animales del mundo no cuentan con poblaciones viables dentro de las áreas protegidas y una considerable proporción se encuentra fuera de las áreas protegidas (Rodrigues et al. 2004). Por ello es probable que se sigan estableciendo áreas protegidas en el futuro. Un importante avance de la última década es la creciente profesionalidad en la selección de áreas protegidas, mediante el uso de técnicas como el análisis de la brecha ecológica (Dudley y Parrish 2006). 
$\mathrm{Al}$ mismo tiempo, se ha producido un rápido incremento en nuestra comprensión de cómo se deben gestionar las áreas protegidas. En la carrera para el establecimiento de áreas protegidas, a menudo para salvar fragmentos de zonas terrestres y acuáticas naturales de la repentina acometida del desarrollo, con frecuencia se establecieron áreas protegidas sin un cuidado análisis de las habilidades y capacidades necesarias para mantenerlas. El conocimiento se está desarrollando rápidamente a todos los niveles de la gestión, desde los planificadores de alto nivel hasta los guarda parques y personal de campo, y existe una red de voluntarios cada vez más sofisticada preparada para apoyar el desarrollo de sistemas de áreas protegidas. Paralelamente, muchas comunidades locales y pueblos tradicionales e indígenas están empezando a ver las áreas protegidas como una forma de proteger espacios que son importantes para ellos, por ejemplo, lugares naturales sagrados o áreas gestionadas con fines medioambientales como la disponibilidad de agua limpia o el mantenimiento de las existencias de pesca.

\section{La diversidad de la protección}

El término "área protegida" resume por tanto lo que a veces es una amplísima gama de designaciones de áreas terrestres y marinas, de las cuales las más conocidas son parque natural, reserva natural, área silvestre, área de gestión de vida silvestre y área de paisaje protegido pero puede incluir también conceptos como áreas conservadas por la comunidad. Lo más importante es que el término abarca una amplia gama de enfoques de gestión, desde espacios altamente protegidos en los que se permite la entrada a muy poca gente, a parques en los que se hace énfasis en la conservación pero los visitantes son bienvenidos, hasta enfoques mucho menos restrictivos en los que la conservación se integra en los estilos de vida humanos tradicionales ( $\mathrm{y}$ a veces no tan tradicionales) o incluso tiene lugar junto con una extracción limitada y sostenible de los recursos. En algunas áreas protegidas se prohíben actividades como la recolección de alimentos, la caza o la extracción de recursos naturales, mientras que en otras, dichas actividades se admiten e incluso constituyen una parte esencial de la gestión. Los enfoques de gestión en las áreas protegidas terrestres, de aguas continentales o marinas también pueden diferir significativamente y dichas diferencias se explicarán pormenorizadamente más adelante, en las directrices.

La variedad refleja el reconocimiento de que la conservación no se consigue por las mismas vías en todas las situaciones, y que lo que puede ser deseable o factible en un lugar podría ser contraproducente o políticamente imposible en otro. Las áreas protegidas son el resultado de un bienvenido énfasis en las consideraciones a largo plazo y en el cuidado del mundo natural, pero a veces suponen un precio a pagar por aquellos que viven dentro de las áreas protegidas o en sus proximidades, en términos de pérdida de derechos, tierras o acceso a recursos. Existe una presión creciente y muy justificada para que se tengan en cuenta las necesidades humanas a la hora de establecer áreas protegidas, y a veces éstas tienen que valorarse frente a las necesidades de conservación. Mientras que en el pasado los gobiernos a menudo tomaban primero las decisiones sobre áreas protegidas y sólo luego informaban a la población, hoy en día se tiende a poner énfasis en debatir con los agentes implicados y en tomar decisiones conjuntas en relación a cómo deben delimitarse y gestionar dichos espacios. Estas negociaciones no resultan nunca fáciles pero normalmente producen resultados más sólidos y duraderos tanto para la conservación como para las sociedades.

La UICN reconoce que existen muchos enfoques válidos a la hora de establecer y gestionar áreas protegidas y que éstos pueden realizar aportaciones significativas a las estrategias de conservación. Esto no quiere decir que todos sean igualmente útiles en todos los casos: la habilidad a la hora de seleccionar y combinar distintos enfoques de gestión resulta a menudo clave para desarrollar un sistema de áreas protegidas que funcione eficazmente. Algunas situaciones requieren una protección muy estricta, otras pueden funcionar, o les puede ir mejor, con enfoques de gestión menos restrictivos o con la aplicación diferenciada de distintas estrategias de gestión dentro de una única área protegida.

\section{Descripción de los diferentes enfoques}

En un intento de describir los diferentes enfoques y darles sentido a los mismos, la UICN ha aprobado una definición de lo que es y lo que no es un área protegida, y después ha identificado seis categorías de áreas protegidas diferentes, basándose en los objetivos de gestión, de las cuales una está subdividida en dos partes. Aunque el objetivo original de las categorías era en su mayoría razonablemente modesto, ya que consistía en la recogida de datos e información sobre las áreas protegidas, con el tiempo se han convertido en una herramienta más compleja. En la actualidad, las categorías encierran la filosofía de la UICN respecto a las áreas protegidas y también ayudan a proporcionar un marco en el cual pueden combinarse distintas estrategias de conservación, junto con sistemas de gestión de apoyo fuera de las áreas protegidas, para un enfoque coherente de conservación de la naturaleza. Las categorías de la UICN se emplean hoy en día para objetivos tan diversos como la planificación, el establecimiento de normativas y la negociación de usos del suelo y el agua. El presente documento describe dichas categorías y explica cómo pueden utilizarse para planificar, implementar y evaluar estrategias de conservación.

Una advertencia: existe una sorprendente variedad de áreas protegidas - en términos de tamaño, ubicación, enfoques de gestión y objetivos. Cualquier intento de concentrar una colección tan rica en media docena de pequeñas cajas sólo puede aspirar a ser aproximada. La definición de áreas protegidas de la UICN y sus categorías no son una camisa de fuerza, sino un marco para orientar una mejor aplicación de las categorías. 


\section{Historia de las categorías de áreas protegidas de la UICN}

A medida que a lo largo del siglo XX se establecían áreas protegidas en el sentido moderno del término en un país tras otro, cada estado desarrolló su propio enfoque de gestión e inicialmente no existieron ni estándares ni terminología comunes. De ahí que se emplearan muchos términos diferentes para describir las áreas protegidas y que existieran diversos sistemas internacionales de áreas protegidas establecidos por convenios globales (por ej., sitios de Patrimonio Mundial) y acuerdos regionales (por ej., espacios Natura 2000 en Europa).

El primer esfuerzo para esclarecer la terminología tuvo lugar en 1933 en la Conferencia Internacional para la Protección de la Fauna y la Flora Silvestre celebrada en Londres. En ella se establecieron cuatro categorías de áreas protegidas: parque natural, reserva natural estricta, reserva de flora y fauna y reserva con prohibición de caza y recolección. En 1942 la Convención del Hemisferio Occidental sobre Protección de la Naturaleza y Conservación de la Vida Silvestre también incorporó cuatro tipos: parque natural, reserva nacional, monumento nacional y reserva natural estricta (Holdgate 1999).

En 1962, la recién formada Comisión de Parques Nacionales y Áreas Protegidas de la UICN (CPNAP), actualmente la Comisión Mundial de Áreas Protegidas (CMAP), preparó una Lista Mundial de Parques Nacionales y Reservas Equivalentes, para la Primera Conferencia Mundial de Parques Nacionales celebrada en Seattle, con un documento sobre nomenclatura redactado por C. Frank Brockman (1962). En 1966 la UICN redactó una segunda versión de lo que vendría a ser conocido como la Lista de la ONU de Areas Protegidas, empleando un sistema de clasificación simple: parques nacionales, reservas naturales y monumentos naturales. En 1972 la Segunda Conferencia Mundial de Parques Nacionales solicitó a la UICN que "definiera los diferentes objetivos para los que se establecen áreas protegidas; y desarrollase unos estándares y una nomenclatura apropiados para dichas áreas" (Elliott 1974).

Estos son los antecedentes de la decisión de la CPNAP de desarrollar un sistema de categorías de áreas protegidas. Un informe de grupo de trabajo (UICN 1978) determinó que el sistema de categorización debería: mostrar cómo los parques nacionales pueden complementarse con otros tipos de áreas protegidas; ayudar a los estados a desarrollar categorías de gestión que reflejen sus necesidades; ayudar a la UICN a recoger y analizar datos sobre áreas protegidas; eliminar ambigüedades e inconsistencias; y asegurar que "independientemente de la nomenclatura empleada por los estados... un área de conservación pueda ser reconocida y categorizada en función de los objetivos para los cuales de hecho se gestiona". Se propusieron diez categorías, definidas principalmente por los objetivos de gestión, todas ellas consideradas de igual importancia, sin ser ninguna de ellas de forma inherente más valiosa que las demás:
Grupo A: Categorías para las cuales la CPNAP asumirá una responsabilidad especial:

I Reserva científica

II Parque nacional

III Monumento nacional/hito nacional

IV Reserva de conservación de la naturaleza

V Paisaje protegido

Grupo B: Otras categorías de importancia para la UICN pero no exclusivamente dentro del ámbito de la CPNAP:

VI Reserva de recursos

VII Reserva antropológica y

VIII Área de gestión multi-usos

Grupo C: Categorías que forman parte de programas internacionales:

IX Reserva de la biosfera

X Sitio Patrimonio Mundial (natural)

Sin embargo, las limitaciones del sistema pronto se hicieron visibles. No incluía una definición de área protegida; se utilizaban distintos términos para describir toda la serie de diez categorías; una única área protegida podría encontrase en más de una categoría: y el sistema carecía de una dimensión marina.

\section{Revisión y propuestas de nuevas categorías}

En 1984, la CPNAP estableció un grupo de trabajo para actualizar las categorías, que elaboró un informe en 1990, donde se aconsejaba que se construyese un nuevo sistema acerca de la categorías I-V de 1978, y que se abandonasen las categorías VI-X (Eidsvik 1990). La CPNAP lo sometió al Congreso Mundial de Parques de 1992, celebrado en Caracas, Venezuela. En un taller de tres días de duración celebrado en dicho congreso, se propuso mantener una categoría que fuese similar a la anterior categoría VIII de áreas protegidas en las que el uso sostenible de los recursos naturales constituyese un objetivo en sí mismo. El Congreso dio su apoyo a esta propuesta y en Enero de 1994, la Asamblea General de la UICN de Buenos Aires aprobó el nuevo sistema. Las directrices fueron publicadas por la UICN y con posterioridad por el Centro Mundial de Monitoreo de la Conservación (CMMC) en el mismo año (UICN 1994). Estas directrices establecieron la definición de "área protegida" - $U n$ área terrestre o marina especialmente dedicada a la protección y el mantenimiento de la diversidad biológica, y de los recursos naturales y culturales asociados, gestionada mediante medios legales o efectivos de cualquier otro tipo - y seis categorías:

\section{Áreas gestionadas principalmente con fines de:}

I Protección estricta [Ia) Reserva natural estricta y Ib) Área Natural Silvestre]

II Conservación y protección del ecosistema (Parque nacional)

III Conservación de los rasgos naturales (Monumento natural) 
IV

Conservación mediante gestión activa (Área de gestión de hábitats/especies)

V Conservación de paisajes terrestres y marinos y ocio (Paisaje terrestre y marino protegido)

VI Uso sostenible de los recursos naturales (por ej., Área protegida con gestión de los recursos)

Las directrices de 1994 se basan en una serie de principios fundamentales: la base de la categorización es el objetivo de gestión; la asignación a una categoría no supone una valoración de la eficacia de la gestión; el sistema de categorías es internacional; la designación nacional de las áreas protegidas puede variar; todas las categorías son importantes; y se implica una gradación de la intervención humana.

\section{Evolución desde 1994}

Desde la publicación de las directrices, la UICN ha promovido de forma activa la comprensión y utilización del sistema de categorías; ha participado en publicaciones sobre cómo aplicar las directrices en contextos específicos tanto geográficos como de otro tipo (por ej., EUROPARC y UICN 1999; Bridgewater et al. 1996) y en una publicación específica de directrices para las áreas protegidas de la categoría V (Phillips 2002). El sistema de categorías ha sido la base de una declaración sobre la posición de la CMAP sobre minería y áreas protegidas, que fue incorporada a una recomendación (número 2.82) aprobada en el Congreso Mundial de la Naturaleza de UICN que tuvo lugar en Amán en 2000.

La UICN logró que se aprobara el sistema por el Convenio sobre Diversidad Biológica en la VII Conferencia de las Partes del CDB celebrada en Kuala Lumpur en Febrero de 2004. En el Congreso Mundial de Parques de Durban (2003) y en el Congreso Mundial de la Naturaleza de Bangkok (2004), se realizaron propuestas para incorporar la dimensión de gobernanza a las categorías.

Finalmente, la UICN apoyó un proyecto de investigación de la Universidad de Cardiff, Reino Unido, sobre el uso y los resultados del sistema de 1994: Emplear un Lenguaje Común. El borrador de los resultados se discutió en el Congreso Mundial de Parques de 2003 y fue publicado en el Congreso Mundial de la Naturaleza de 2004 (Bishop et al. 2004). También se publicó un resumen de los documentos en PARKS en 2004 (UICN 2004). Este proyecto contribuyó a la creación del Grupo de Trabajo sobre Categorías de la CMAP y al inicio de un proceso de revisión que ha tenido por resultado un nuevo conjunto de directrices.

\section{El proyecto actual de revisión}

Las actuales directrices son el resultado de un intenso proceso de consulta y revisión, coordinado por un grupo de trabajo específicamente designado por la CMAP, que trabaja conjuntamente con los socios de la CMAP así como con las otras cinco comisiones de la UICN. El grupo de trabajo redactó su plan de trabajo original a partir de los resultados del proyecto Emplear un Lenguaje Común, pero con un mandato más amplio de la UICN que consistía en analizar todos los aspectos de las categorías. Durante 18 meses realizó una intensa labor de recogida de información, debate y consulta con las diferentes partes implicadas que pueden resumirse en varios estadios:

- Investigación: Un gran número de personas, tanto de la red de la CMAP como ajena a ella, ha realizado aportaciones a la revisión de las directrices mediante la redacción de documentos de trabajo, que analizan diferentes aspectos de las directrices. Se redactaron alrededor de 40 documentos que iban desde documentos de discusión y cuestionamiento a documentos con propuestas específicas o propuestas de texto de las nuevas directrices. En conjunto, conforman un importante recurso que analiza la forma en la que una gama de objetivos de gestión de áreas protegidas contribuyen a la conservación.

- Reuniones y debate: El grupo de trabajo no solo celebró una serie de reuniones en todo el mundo sino que también participó en otras reuniones ya convocadas, para brindar a todos la oportunidad de plantear sus opiniones, esperanzas e inquietudes en relación con los distintos enfoques de gestión de áreas protegidas. Entre las reuniones clave se pueden citar las siguientes:

- Categoría V: reunión conjunta con el Grupo de Trabajo de Paisajes de la CMAP en Cataluña, España en 2006, apoyado por el gobierno de Cataluña para desarrollar una postura sobre los enfoques de la categoría $\mathrm{V}$ y los paisajes, seguida de otra reunión del Grupo de Trabajo celebrada en North Yorkshire, Inglaterra, en 2008;

- Categoría VI: reunión en Brasil para prepara un documento de posicionamiento y planificar un manual técnico en 2007;

- Europa: debate en la Reunión Europea de la CMAP de Barcelona para recoger las opiniones de los socios europeos de la CMAP en 2007.

- África Meridional y Oriental: taller de dos días sobre gobernanza celebrado en Nairobi en 2006 en colaboración con PNUMA-WCMC(Programa dede las Naciones Unidas para el Medio AmbienteCentro Mundial para la Monitorización de la Conservación) al que asistieron representantes de 13 estados africanos;

- Sudeste Asiático: taller de dos días sobre gobernanza y categorías en la conferencia regional celebrada en Kota Kinabalu, Sabah, Malasia en 2007 con representantes de 17 países;

- América Latina: debate en el Congreso Latinoamericano de Áreas Protegidas, celebrado en Bariloche, Argentina en 2007, centrado en cuestiones específicas de la categorías VI, áreas protegidas marinas y reservas indígenas; 
- Consejo Internacional de Minería y Metales: presentación seguida de un debate, que originó un documento de trabajo de los miembros del ICMM en 2007.

- También tuvieron lugar una serie de reuniones de menor envergadura,. Entre las que se encuentran las celebradas con el Comité de la UICN del Reino Unido, el Consejo de Áreas Ecológicas de Canadá, el Programa Científico de Conservación de WWF, Conservation International, la UNESCO, con partes implicadas de la industria en la sede de la UICN, etc.

- Asimismo, se celebró una cumbre global sobre áreas protegidas en España en Mayo de 2007, que contó con la financiación y el apoyo técnico de la Junta de Andalucía, el Ministerio de Medio Ambiente de España y la Fundación Biodiversidad. A ella asistieron más de cien expertos de todo el mundo, dedicando cuatro días a debatir una amplia gama de cuestiones relativas a las categorías. Aunque el objetivo de la reunión no era la toma de decisiones, se desarrollaron varias posturas de consenso durante la reunión que contribuyeron a fijar el texto de las directrices revisadas.

- Página web: El grupo de trabajo cuenta con una página web propia en el sitio web de la CMAP, en la cual se encuentran todos los documentos relevantes: www.UICN. org/themes/wcpa/theme/categories/about.html

- E-forum: En la fase previa a la cumbre la UICN y el grupo de trabajo coordinaron un debate por internet sobre las categorías abierta a todo el mundo, que proporcionó una serie de valiosísimas aportaciones para las fases ulteriores del proceso de revisión.

Se preparó un Borrador de las directrices para la reunión del Comité Rector de la Comisión Mundial de Áreas Protegidas celebrada en Septiembre del 2007, que fue revisado tras los comentarios realizados por los miembros del Comité Rector. Los diversos borradores se redactaron únicamente en inglés, una limitación determinada por la escasez de fondos, aunque el texto completo de las directrices estará publicado en inglés, francés y español, con resúmenes en otros idiomas. Las directrices fueron puestas a disposición de todos los miembros de la CMAP y de cualquier otra parte interesada para recabar sus comentarios, muchos de los cuales han sido incorporados al texto. Se realizó por separado una consulta relativa a la definición de área protegida.

El Comité Rector de la CMAP se reunió de nuevo en Abril de 2008 en Cuidad del Cabo y debatió el borrador en detalle, tanto en plenario como en grupos separados para tratar cuestiones específicas. Las decisiones finales sobre que proponer a los miembros de la UICN fueron tomadas por el presidente de la CMAP en los que resultó necesario.

\section{Objetivo de las categorías de gestión de áreas protegidas de la UICN}

La UICN considera que las categorías de gestión de áreas protegidas constituyen un importante estándar global para la planificación, establecimiento y gestión de áreas protegidas; esta sección esboza los principales usos reconocidos para las mismas. Los mismos se han ampliado ya que las directrices originales sobre categorías fueron publicadas en 1994 y la lista de usos potenciales es mayor. Por otra parte, las categorías son empleadas a veces como herramientas más allá de sus objetivos originales, quizás en ausencia de otras alternativas, y debemos distinguir entre los usos que apoya la UICN, aquellos ante los que es neutral, y aquellos a los que se opone.

\section{Objetivos que la UICN apoya y fomenta activamente}

Facilitar la planificación de áreas protegidas y de sistemas de áreas protegidas

- Proporcionar un instrumento para la planificación de sistemas de áreas protegidas y de ejercicios de planificación de la conservación más amplios, a escala bioregional o ecoregional;

- Animar a los gobiernos y otros titulares y gestores de áreas protegidas a desarrollar sistemas de áreas protegidas con una gama de objetivos de gestión adaptados a las condiciones nacionales y locales;

- Dar reconocimiento a distintos acuerdos de gestión y modelos de gobernanza.

\section{Mejorar la gestión de la información sobre áreas protegidas}

- Proporcionar estándares internacionales para contribuir a la recogida de datos y producción de informes sobre esfuerzos de conservación a escala global y regional, para facilitar las comparaciones entre países y establecer un marco para evaluaciones globales y regionales;

- Proporcionar un marco para la recogida, tratamiento y divulgación de datos sobre áreas protegidas;

- Mejorar la comunicación y la comprensión mutua entre todos aquellos implicados en la conservación;

- Reducir la confusión surgida a raíz de la adopción de muchos términos diferentes para describir los mismos tipos de áreas protegidas en distintas partes del mundo.

\section{Ayudar a regular las actividades en áreas protegidas}

- Utilizar las categorías como directrices a nivel nacional e internacional para regular las actividades, por ej., mediante la prohibición de ciertas actividades en determinadas categorías de acuerdo con los objetivos de gestión de cada área protegida. 


\section{Objetivos que cada vez son más comunes, que la UICN apoya y para los cuales está dispuesta a proporcionar asesoramiento}

- Servir de base para la legislación - un número creciente de países están utilizando las categorías de la UICN como base de la categorización legal de áreas protegidas;

- Establecer los presupuestos - algunos países determinan sus presupuestos anuales para áreas protegidas en función de su categoría;

- Utilizar las categorías como herramienta de reivindicación - las ONGs utilizan las categorías como herramienta en sus campañas para promover objetivos de conservación y un nivel adecuado de usos humanos;
- Interpretar o clarificar la tenencia y gobernanza de tierras algunas comunidades locales y pueblos indígenas están utilizando las categorías como herramienta para ayudar a establecer sistemas de gestión tales como reservas indígenas;

- Proporcionar herramientas para ayudar a planificar sistemas de áreas protegidas que consideren una gama de objetivos de gestión y formas de gobernanza.

\section{Objetivos a los que se opone la UICN}

- Utilizar las categorías como excusa para la expulsión de los pueblos de sus tierras tradicionales;

- Modificar las categorías para reducir la protección del medio ambiente;

- Utilizar las categorías para abogar por propuestas de desarrollo insensible al medio ambiente en áreas protegidas. 

2. Definición y categorías

La presente sección delimita y explica la definición de la UICN de un área protegida, un sistema de áreas protegidas y las seis categorías. La definición se explica término a término y debería aplicarse con unos principios que la acompañan. Las categorías se describen por su objetivo principal, otros objetivos, rasgos distintivos, papel en el paisaje terrestre o marino, elementos únicos y acciones que son compatibles o incompatibles. 


\section{Nueva definición de área protegida de la UICN}

Se indica la nueva definición de la UICN que se explica término a término

Los miembros de la UICN han trabajado conjuntamente para redactor una nueva definición de área protegida que a continuación se indica. El primer borrador de esta nueva definición se preparó en una reunión sobre categorías celebrada en Almería, España en Mayo de 2007 y desde entonces ésta ha sido depurada y revisada por muchas personas de UICN-CMAP.
Un área protegida es: "Un espacio geográfico claramente definido, reconocido, dedicado y gestionado, mediante medios legales $u$ otros tipos de medios eficaces para conseguir la conservación a largo plazo de la naturaleza y de sus servicios ecosistémicos y sus valores culturales asociados".

Para aplicar el sistema de categorías, el primer paso consiste en determinar si el espacio concreto cumple esta condición, y el segundo en decidir la categoría más adecuada.

Esta definición reúne muchas cosas en una breve frase. La tabla 1 analiza cada término y/o frase en detalle y amplia su significado.

Tabla 1. Explicación de la definición de área protegida

\begin{tabular}{|c|c|c|}
\hline Término & Explicación & Ejemplos y detalles adicionales \\
\hline $\begin{array}{l}\text { Espacio } \\
\text { geográfico } \\
\text { claramente } \\
\text { definido }\end{array}$ & $\begin{array}{l}\text { Incluye áreas terrestres, de aguas continentales, } \\
\text { marinas y costeras o una combinación de dos o más } \\
\text { de ellas. El término "espacio" es tridimensional, por } \\
\text { ej., cuando el espacio situado sobre un área protegida } \\
\text { se encuentra protegido frente a aeronaves en vuelo } \\
\text { a baja altura o en áreas protegidas marinas cuando } \\
\text { se encuentra protegida una cierta profundidad de } \\
\text { agua o el lecho marino se encuentra protegido pero la } \\
\text { masa de agua situada sobre el mismo no lo está; a la } \\
\text { inversa, a veces el espacio subterráneo no se encuentra } \\
\text { protegido (por ej., es susceptible de actividades } \\
\text { mineras). "Claramente definido" implica un área definida } \\
\text { espacialmente con límites demarcados y acordados. } \\
\text { Estos límites pueden estar a veces definidos por } \\
\text { características físicas que pueden desplazarse con el } \\
\text { tiempo (por ej., márgenes fluviales) o por acciones de } \\
\text { gestión (por ej., zonas vedadas al uso). }\end{array}$ & $\begin{array}{l}\text { Reserva de la Naturaleza de Wolong } \\
\text { en China (categoría la, terrestre); } \\
\text { Parque Nacional del Lago Malawi en } \\
\text { Malawi (categoría II, principalmente agua } \\
\text { dulce); Reserva Marina de Masinloc } \\
\text { and Oyon Bay en Filipinas (categoría } \\
\text { la, principalmente marina) son ejemplos } \\
\text { de áreas en biomas muy diferentes pero } \\
\text { todas ellas son áreas protegidas. }\end{array}$ \\
\hline Reconocido & $\begin{array}{l}\text { Implica que la protección puede incluir una gama de } \\
\text { formas de gobernanza declaradas por colectivos así } \\
\text { como las identificadas por los estados, pero dichos } \\
\text { espacios tienen que estar reconocidos de alguna } \\
\text { manera (especialmente mediante su inclusión en la } \\
\text { Base de Datos Mundial de Áreas Protegidas - World } \\
\text { Database on Protected Areas (WDPA)). }\end{array}$ & $\begin{array}{l}\text { El Área Protegida Indígena (API) de } \\
\text { Anindilyakwa ha sido autodeclarada } \\
\text { por las comunidades aborígenes de la } \\
\text { península Groote Eylandt, una de las } \\
\text { muchas APls autodeclaradas reconocidas } \\
\text { por el gobierno. }\end{array}$ \\
\hline Dedicado & $\begin{array}{l}\text { Implica la existencia de un compromiso específico } \\
\text { vinculante con la conservación a largo plazo, } \\
\text { mediante por ejemplo: } \\
\text { - Convenios y acuerdos internacionales } \\
\text { - Leyes nacionales, provinciales o locales } \\
\text { - Ley consuetudinaria } \\
\text { - Convenios de ONGs } \\
\text { - Acuerdos de fundaciones y empresas privadas } \\
\text { - Planes de certificación. }\end{array}$ & $\begin{array}{l}\text { Parque Nacional del Monte Cradle - } \\
\text { Lago St Clair en Tasmania, Australia } \\
\text { (categoría II, estado); Santuario } \\
\text { de Pesca de Nabanka en Filipinas } \\
\text { (área conservada por la comunidad); } \\
\text { Reserva de la Bahía de Port Susan en } \\
\text { Washington, EEUU (privada); todas ellas } \\
\text { son áreas protegidas pero su estructura } \\
\text { legal difiere considerablemente. }\end{array}$ \\
\hline Gestionado & $\begin{array}{l}\text { Se han tomado medidas activas para conservar } \\
\text { los valores naturales (y posiblemente otros) por los } \\
\text { cuales se ha establecido el área protegida; téngase } \\
\text { en cuenta que "gestionado" puede incluir la decisión } \\
\text { de dejar el área intocada si ésta es la mejor estrategia } \\
\text { de conservación. }\end{array}$ & $\begin{array}{l}\text { Existen muchas opciones posibles. Por } \\
\text { ejemplo el Parque Nacional Kaziranga } \\
\text { en India (categoría II) se gestiona } \\
\text { principalmente mediante controles de la } \\
\text { caza furtiva y la eliminación de especies } \\
\text { invasoras; las islas del Parque Nacional } \\
\text { Archipiélago en Finlandia se gestionan } \\
\text { utilizando métodos agrarios tradicionales } \\
\text { y manteniendo las especies asociadas a } \\
\text { las praderas. }\end{array}$ \\
\hline
\end{tabular}


Tabla 1. Explicación de la definición de área protegida (cont.)

\begin{tabular}{|c|c|c|}
\hline Término & Explicación & Ejemplos y detalles adicionales \\
\hline $\begin{array}{l}\text { Medios } \\
\text { legales u } \\
\text { otros tipos } \\
\text { de medios } \\
\text { eficaces }\end{array}$ & $\begin{array}{l}\text { Significa que las áreas protegidas tienen que haber } \\
\text { sido legisladas (es decir, reconocidas por la normativa } \\
\text { legal vigente), reconocidas mediante convenios o } \\
\text { acuerdos internacionales, o gestionadas de alguna } \\
\text { u otra manera mediante medios eficaces pero no } \\
\text { legalizados formalmente, como por ejemplo, mediante } \\
\text { normas tradicionales reconocidas como las que } \\
\text { regulan el funcionamiento de las áreas conservadas } \\
\text { por comunidades o los acuerdos de organizaciones } \\
\text { no gubernamentales legalmente constituidas. }\end{array}$ & $\begin{array}{l}\text { El Parque Nacional de Flinders } \\
\text { Range en Australia está gestionado } \\
\text { por la autoridad estatal de Australia } \\
\text { Meridional; la Reserva de la } \\
\text { Naturaleza de Attenborough en } \\
\text { el Reino Unido está gestionada por } \\
\text { la Nottinghamshire Wildlife Trust en } \\
\text { asociación con la empresa gravera } \\
\text { propietaria del espacio; y el Parque } \\
\text { Nacional Alto Fragua Indiwasi en } \\
\text { Colombia está gestionado por los } \\
\text { pueblos Ingano. }\end{array}$ \\
\hline $\begin{array}{l}\text {... para } \\
\text { conseguir }\end{array}$ & $\begin{array}{l}\text { Implica un cierto nivel de eficacia - un elemento } \\
\text { nuevo que no estaba presente en la definición de } \\
1994 \text { pero que ha sido demandado por muchos } \\
\text { gestores de áreas protegidas entre otros. Aunque la } \\
\text { categoría será al final determinada por los objetivos, } \\
\text { la eficacia de la gestión será progresivamente } \\
\text { registrada en la Base de Datos Mundial de Áreas } \\
\text { Protegidas y con el tiempo pasará a convertirse } \\
\text { en un importante criterio para la identificación y } \\
\text { reconocimiento de áreas protegidas. }\end{array}$ & $\begin{array}{l}\text { El Convenio para la Diversidad } \\
\text { Biológica requiere a las Partes la } \\
\text { realización de evaluaciones de la } \\
\text { eficacia de la gestión. }\end{array}$ \\
\hline Largo plazo & $\begin{array}{l}\text { Las áreas protegidas deberían ser gestionadas a } \\
\text { perpetuidad y no como una estrategia de gestión a } \\
\text { corto plazo o temporal. }\end{array}$ & $\begin{array}{l}\text { Las medidas temporales como la } \\
\text { financiación a corto plazo del abandono } \\
\text { de tierras agrícolas, las rotaciones } \\
\text { en la gestión comercial de bosques o } \\
\text { las zonas pesqueras temporalmente } \\
\text { protegidas no constituyen áreas } \\
\text { protegidas reconocidas por la UICN. }\end{array}$ \\
\hline Conservación & $\begin{array}{l}\text { En el contexto de la presente definición, conservación } \\
\text { se refiere al mantenimiento in situ de los ecosistemas } \\
\text { y hábitats naturales y seminaturales y de poblaciones } \\
\text { viables de especies en su entorno natural, y en el } \\
\text { caso de especies domésticas o cultivadas (ver la } \\
\text { definición de agrobiodiversidad en el Apéndice), } \\
\text { en los entornos en los que han desarrollado sus } \\
\text { propiedades distintivas. }\end{array}$ & $\begin{array}{l}\text { El Parque Nacional de Yellowstone } \\
\text { en los Estados Unidos (categoría II) } \\
\text { centra sus objetivos de conservación } \\
\text { especialmente en el mantenimiento de } \\
\text { poblaciones viables de osos y lobos, } \\
\text { pero con el fin más amplio de preservar } \\
\text { todo el ecosistema funcional. }\end{array}$ \\
\hline Naturaleza & $\begin{array}{l}\text { En este contexto naturaleza siempre se refiere a } \\
\text { biodiversidad a nivel genético, de especie y de } \\
\text { ecosistema, y a menudo también a geodiversidad, } \\
\text { formas del relieve y a valores naturales más amplios. }\end{array}$ & $\begin{array}{l}\text { El Parque Nacional del Bosque } \\
\text { Impenetrable de Bwindi en Uganda } \\
\text { (categoría II) está gestionada } \\
\text { principalmente para proteger los } \\
\text { bosques de montaña naturales y } \\
\text { especialmente al gorila de montaña. } \\
\text { La Reserva Nacional Natural de Isla } \\
\text { de Rum en Escocia (categoría IV) } \\
\text { fue establecida para proteger rasgos } \\
\text { geológicos únicos. }\end{array}$ \\
\hline $\begin{array}{l}\text { Servicios } \\
\text { ecosistémicos } \\
\text { asociados }\end{array}$ & $\begin{array}{l}\text { Aquí significa servicios ecosistémicos que están } \\
\text { relacionados con el objetivo de conservación de } \\
\text { la naturaleza pero no interfieren con éste. Aquí se } \\
\text { incluyen servicios de aprovisionamiento de agua o } \\
\text { alimentos; servicios de regulación como el control } \\
\text { de inundaciones, sequía, degradación de suelos, y } \\
\text { enfermedades; servicios de apoyo como formación } \\
\text { de suelo o ciclos de nutrientes; y servicios culturales } \\
\text { como recreativos, espirituales, religiosos y otros } \\
\text { beneficios no materiales. }\end{array}$ & $\begin{array}{l}\text { Muchas áreas protegidas también } \\
\text { proporcionan servicios de ecosistema: } \\
\text { por ej., el Parque Nacional de Gunung } \\
\text { Gede en Java, Indonesia (categoría II) } \\
\text { contribuye al suministro de agua potable } \\
\text { a Yakarta; y el Parque Nacional de } \\
\text { Sundarbans en Bangladesh (categoría } \\
\text { IV) ayuda a proteger la costa frente a } \\
\text { inundaciones. }\end{array}$ \\
\hline
\end{tabular}


Tabla 1. Explicación de la definición de área protegida (cont.)

\begin{tabular}{|l|l|l|}
\hline Término & Explicación & Ejemplos y detalles adicionales \\
\hline $\begin{array}{l}\text { Valores } \\
\text { culturales }\end{array}$ & $\begin{array}{l}\text { Incluye a todos aquellos que no interfieren con el } \\
\text { objetivo de conservación (todos los valores culturales } \\
\text { de un área protegida deberían cumplir este criterio), } \\
\text { incluyendo especialmente: } \\
\bullet \quad \text { aquellos que contribuyen al resultado de } \\
\text { conservación (por ej, las prácticas de gestión } \\
\text { tradicionales de las cuales dependen especies } \\
\text { clave); }\end{array}$ & $\begin{array}{l}\text { Muchas áreas protegidas contienen } \\
\text { lugares sagrados, por ej., en el } \\
\text { Parque Nacional de Nyika en Malawi } \\
\text { se encuentran un estanque, una } \\
\text { cascada y una montaña sagrados: La } \\
\text { aquellos que se encuentran de por si } \\
\text { amenazados. }\end{array}$ \\
& $\begin{array}{l}\text { proporcionar madera para los templos } \\
\text { en Japón ha producido algunos de los } \\
\text { bosques más antiguos del país, como } \\
\text { el bosque primigenio protegido situado } \\
\text { en las afueras de Nara. Los bosques } \\
\text { de Kaya de la zona costera de Kenya } \\
\text { se encuentran protegidos tanto por su } \\
\text { biodiversidad como por sus valores } \\
\text { culturales. }\end{array}$ \\
\hline
\end{tabular}

\section{Los aspectos tridimensionales de las áreas protegidas}

En algunos casos es necesario considerar en las áreas protegidas los impactos de las actividades humanas en tres dimensiones. Entre tales cuestiones se incluyen las siguientes: proteger el espacio aéreo de un área protegida de perturbaciones causadas por el vuelo de aviones, helicópteros o globos aerostáticos a baja altura. Cuestiones que afectan específicamente a las aguas marinas y continentales son la pesca, el dragado, el submarinismo o el ruido submarino. Varios países han consagrado esta escala tridimensional en la legislación de áreas protegidas; por ejemplo, Cuba prohíbe las actividades mineras bajo áreas protegidas. La UICN anima a los gobiernos a considerar una norma general para salvaguardar las áreas protegidas frente a actividades intrusivas sobre y/o bajo la superficie terrestre y acuática. Anima a los gobiernos a garantizar la realización de evaluaciones sobre los efectos potenciales de dichas actividades antes de tomar cualquier decisión relativa a si éstas deben ser autorizadas o si deben aplicar determinados límites o condiciones.

\section{Principios}

La definición debe aplicarse en el contexto de una serie de principios que la acompañan y que a continuación se indican

- Para la UICN, solo aquellas áreas en las que el principal objetivo es la conservación de la naturaleza pueden considerarse áreas protegidas; se pueden incluir muchas áreas con otros objetivos al mismo nivel, pero en caso de conflicto la conservación de la naturaleza será la prioridad;

- Las áreas protegidas deben impedir, o eliminar cuando sea necesario, cualquier explotación o práctica de gestión que sea negativa para los objetivos para los que ha sido designada;

- La selección de la categoría deberá basarse en el/los objetivo/s primarios establecidos para cada área protegida

- El sistema no pretende ser jerárquico;

- Todas las categorías contribuyen a la conservación pero los objetivos deben ser seleccionados en función de cada caso concreto; no todas las categorías resultan de la misma utilidad en todos los casos;

- Cualquiera de las categorías puede existir bajo cualquier de las formas de gobernanza y vice versa;

- La diversidad de enfoques de gestión resulta deseable y debería fomentarse, ya que refleja las múltiples formas en las que comunidades de todo el mundo expresan el valor universal del concepto de área protegida;

- La categoría deberá ser modificada si la evaluación muestra que los objetivos declarados a largo plazo no se ajustan a la categoría asignada;

- Sin embargo, la categoría no refleja la eficacia de la gestión;

- El objetivo de las áreas protegidas debería ser mantener, o idealmente, aumentar el grado de naturalidad del ecosistema que está siendo protegido;

- La definición y las categorías de las áreas protegidas no deberán ser utilizadas como excusa para desposeer a las personas de sus tierras.

\section{Definición de sistema de áreas protegidas y de enfoque de ecosistema}

Las categorías deberán aplicarse en el contexto de sistemas nacionales de áreas protegidas o de otro tipo y como parte del enfoque de ecosistema 
La UICN hace énfasis en que las áreas protegidas no deberían verse como entidades aisladas, sino como parte de entornos de conservación más amplios, que incluyan tanto sistemas de áreas protegidas como enfoques para la conservación de ecosistemas más amplios que se implementan en todo el paisaje terrestre y marino. La siguiente sección ofrece definiciones generales de ambos conceptos.

\section{Sistema de áreas protegidas}

El objetivo fundamental de un sistema de áreas protegidas es la eficacia en la conservación de la biodiversidad in situ. La UICN ha planteado que el éxito a largo plazo de la conservación in situ requiere que el sistema global de áreas protegidas incluya una muestra representativa de cada uno de los diferentes ecosistemas del mundo (Davey 1998). UICN/CMAP caracteriza un sistema de áreas protegidas como aquel que cuenta con cinco elementos relacionados entre si (Davey 1998 con adiciones):

- Representatividad, totalidad y equilibrio: incluyendo ejemplos de la máxima calidad de toda la gama de tipos de medio ambiente de un país; incluye la medida en que las áreas protegidas proporcionan una muestra equilibrada de los tipos de entornos que pretenden representar.

- Adecuación: integridad, suficiencia de extensión espacial y disposición de las áreas que contribuyen al sistema, junto con una gestión eficaz, para respaldar la viabilidad de los procesos medioambientales y/o especies, poblaciones y comunidades que conforman la biodiversidad del país.

- Coherencia y complementariedad: contribución positiva de cada área protegida al conjunto de objetivos de conservación y desarrollo sostenible definidos por el país.

- Consistencia: aplicación de los objetivos, políticas y clasificaciones de gestión en condiciones comparables de forma estandarizada, de manera que quede claro para todos el propósito que persigue cada área protegida en el marco del sistema y se maximicen las posibilidades de que su gestión y uso contribuyan a los objetivos del sistema.

- Rentabilidad, eficiencia y equidad: equilibrio adecuado entre los costes y los beneficios, y la debida equidad en su distribución; incluye la eficacia: el número y la superficie mínimos de áreas protegidas necesarios para alcanzar los objetivos del sistema.

En 2004 el Programa de Trabajo de Áreas Protegidas del CDB proporcionó algunos criterios para los sistemas de áreas protegidas dentro del objetivo general del programa de establecer y mantener "sistemas nacionales y regionales de áreas protegidas integrales, gestionados eficazmente y ecológicamente representativos".

\section{Enfoques de ecosistema}

La UICN cree que las áreas protegidas deberían estar integradas en sistemas coherentes de áreas protegidas, y que dichos sistemas deberían estar a su vez integrados en enfoques más amplios de conservación y usos del suelo/agua, que incluyan tanto tierras como aguas protegidas y una amplia gama de enfoques de gestión sostenible. Esto está en línea con los Principios de Malawi del CDB (CDB/COP 4, 1998) que subraya la importancia de las estrategias de uso sostenible. Estas estrategias de conservación de más amplia escala reciben diversas denominaciones: "enfoques a escala de paisaje", "enfoques bioregionales" o "enfoques ecosistémicos". Cuando dichos enfoques incluyen la conservación de territorios que conectan las áreas protegidas se emplea el término "conservación en conectividad". Cada una de las áreas protegidas debería por tanto y cuando fuera posible contribuir a planes nacionales y regionales de gestión de áreas protegidas nacionales como a otros planes más amplios de conservación.

El enfoque de ecosistema constituye un marco más amplio para la planificación y el desarrollo de la conservación y la gestión de usos del suelo/agua de forma integrada. En dicho contexto las áreas protegidas encajan como un instrumento importante - quizás el más importante - de dicho enfoque.

El CDB define el enfoque de ecosistema como: "una estrategia para la gestión integrada de los recursos terrestres, acuáticos y vivos que promueve la conservación y el uso sostenible de forma equitativa ..." (CDB 2004).

\section{Categorías}

Cada una de las categorías se describe por su parte mediante una serie de apartados:

- Objetivo(s) primario(s)

- Otros objetivos

- Rasgos distintivos

- Papel en el paisaje terrestre o marino

- ¿Qué hace singular a la categoría?

- Cuestiones a tener en cuenta 


\section{Denominación de las áreas protegidas}

El sistema de categoría se introdujo en gran medida para ayudar a estandarizar las descripciones de lo que constituye un área protegida concreta. Las denominaciones de las áreas protegidas, con excepción de las de categoría II, están más o menos relacionadas con el objetivo principal de gestión de la categoría.

Se encontró que el término "Parque Nacional", que existía mucho antes del sistema de categorías, se ajustaba especialmente bien a las áreas protegidas de gran tamaño bajo la categoría II. Sin embargo, es cierto que muchos de los parques nacionales existentes en todo el mundo tienen objetivos muy diferentes a los de la categoría II. De hecho algunos países han clasificado sus parques nacionales en otras categorías de la UICN (ver Tabla 2 a continuación).

Tabla 2. "Parques Nacionales" bajo diferentes categorías

\begin{tabular}{|l|l|l|r|l|}
\hline Catégoria & Nombre & Ubicación & Superficie (ha) & Fecha \\
\hline Ia & Parque Nacional de Dipperu & Australia & 11.100 & 1969 \\
\hline II & Parque Nacional de Guanacaste & Costa Rica & 32.512 & 1991 \\
\hline III & Parque Nacional de Yozgat Camligi & Turquía & 264 & 1988 \\
\hline IV & Parque Nacional de Pallas Ounastunturi & Finlandia & 49.600 & 1938 \\
\hline V & Parque Nacional de Snowdonia & Gales, RU & 214.200 & 1954 \\
\hline VI & Parque Nacional Expedition & Australia & 2.930 & 1994 \\
\hline
\end{tabular}

Es importante señalar que el hecho de que un gobierno haya denominado o pretenda denominar un área parque nacional, esto no quiere decir que tenga que ser gestionado de acuerdo con las directrices de la categoría II. Por el contrario, se debe identificar y aplicar el sistema de gestión más adecuado; el nombre o denominación concreta que se aplique a dicha área es una cuestión que debe decidir el gobierno o los agentes implicados correspondientes.

Lo que sigue es un marco de referencia. Aunque algunas de las áreas protegidas encajarán de forma natural en alguna de las categorías, en otros casos la distinción será menos obvia y requerirá un análisis en profundidad de las opciones. Dado que la asignación de la categoría depende del objetivo de gestión, dependerá más de lo que la autoridad de gestión pretende para el espacio concreto que de cualquier conjunto de criterios fijos e inamovibles. Existen algunas herramientas disponibles para ayudar a tomar la decisión respecto a la categoría, pero en muchos casos la decisión final será cuestión de la apreciación colectiva.

Además, dado que el sistema es global, es inevitable que sea bastante general. La UICN anima a los países a añadir más detalles a la definición de las categorías para ajustarlas a sus condiciones específicas si resultase de utilidad, siempre dentro de los directrices generales que a continuación se explican. Varios países ya lo han hecho o se encuentran en proceso de hacerlo y la UICN apoya dicho proceso.

\section{Paisajes terrestres/marinos naturales y culturales}

Hay que señalar que pocas, si es que existe alguna, de las zonas terrestres, de aguas continentales y litorales marinos permanecen totalmente sin ser afectadas por las actividades humanas directas, que también tienen su impacto sobre los océanos del mundo a través de la presión pesquera y la contaminación. Si se incorporan los efectos de la contaminación atmosférica transfronteriza y el cambio climático, se ha modificado todo el planeta. Por lo tanto se deduce que los términos "natural" y "cultural" son aproximaciones. En cierta medida podríamos afirmar que todas las áreas protegidas existen en paisajes "culturales" ya que las prácticas culturales han modificado la ecología e influido en ella, a menudo durante milenios. Sin embargo, esto no resulta de gran ayuda para distinguir entre formas muy diferentes de funcionamiento del ecosistema. Por ello se emplean los términos tal como sigue:

Áreas naturales o no modificadas son aquellas que conservan un conjunto completo o casi completo de especies nativas del área, dentro de un ecosistema que funciona de forma más o menos natural.

Las áreas culturales han experimentado cambios más sustanciales, por ejemplo han albergado actividades agrícolas, pastoreo intensivo permanente o gestión forestal que han alterado la composición de la estructura del bosque. Es muy posible que la composición de las especies y el funcionamiento del ecosistema se hayan alterado sustancialmente. Sin embargo, los paisajes culturales siguen albergando una amplia gama de especies y en algunos casos éstas han llegado a depender de la gestión cultural.

El empleo de términos como "natural" y "no modificado" no pretende ocultar o negar la custodia y actividad desde hace mucho tiempo de pueblos indígenas o tradicionales en muchas de las áreas protegidas; de hecho, muchas de ellas siguen siendo valiosas para la biodiversidad debido a esta forma de gestión. 


\section{Objetivos comunes a las seis categorías de áreas protegidas}

La definición implica un conjunto de objetivos comunes para las áreas protegidas; por su parte las categorías definen la existencia de diferencias en los enfoques de gestión. Los siguientes objetivos pueden o deberían aplicarse a todas las categorías de áreas protegidas; es decir, no distinguen a una categoría de las demás.

\section{Los objetivos de todas las áreas protegidas deberían ser:}

- Conservar la composición, estructura, función y potencial evolutivo de la biodiversidad;

- Contribuir a las estrategias de conservación regionales (como reservas clave, zonas tampón, corredores, zonas de parada para especies migratorias, etc.);

- Mantener la diversidad de paisajes o hábitats, y de las especies y ecosistemas asociados;

- Ser de un tamaño suficiente como para asegurar la integridad y el mantenimiento a largo plazo de los objetivos de conservación especificados o ser susceptibles de ampliación para alcanzar dicha meta;

- Mantener los valores que le han sido asignados a perpetuidad;

- Funcionar de acuerdo con un plan de gestión y de un programa de monitoreo y evaluación que sirva de apoyo a una gestión adaptativa;

- Contar con un sistema de gobernanza claro y equitativo.

\section{Cuando corresponda, ${ }^{2}$ otros objetivos de las áreas protegidas deberían incluir:}

- Conservar rasgos significativos del paisaje, la geomorfología y la geología;

- Proporcionar servicios reguladores del ecosistema, incluyendo la mitigación de los impactos del cambio climático;
- Conservar áreas naturales o paisajes de importancia nacional e internacional con fines culturales, espirituales o científicos;

- Beneficiar a las comunidades residentes o locales en consistencia con los demás objetivos de gestión;

- Proporcionar beneficios recreativos consecuentes con los objetivos de gestión;

- Facilitar las actividades de investigación científica de bajo impacto y el monitoreo ecológico relacionado y consecuente con los valores del área protegida;

- Utilizar estrategias de gestión adaptativas para mejorar la eficacia de la gestión y la calidad de la gobernanza a los largo del tiempo;

- Ayudar a ofrecer oportunidades educativas (incluyendo las relativas a enfoques de gestión);

- Contribuir a desarrollar el apoyo público a la protección.

Deberá tenerse en cuenta que los miembros de la UICN adoptaron una recomendación en el Congreso Mundial de Conservación de Amán, Jordania en Octubre de 2000, que sugería que no deberían emprenderse actividades mineras en las áreas protegidas de las categorías I-IV de la UICN. La recomendación 2.82 incluye una sección que: "Hace un llamamiento a los Estados Miembros de la UICN a prohibir por ley toda la exploración y extracción de recursos minerales en las áreas protegidas que correspondan a las categorias de gestión de áreas protegidas I-IV de la UICN”. La recomendación también incluye un apartado relativo a las áreas protegidas de categoría V y VI: "en las categorías Vy VI la exploración y la extracción localizada sólo serán aceptadas cuando la naturaleza y el volumen de las actividades mineras propuestas indiquen la compatibilidad de las actividades del proyecto minero con los objetivos de las áreas protegidas". Tal recomendación no es de ninguna forma vinculante para los gobiernos; actualmente algunos prohíben las actividades mineras en las áreas protegidas I-IV mientras que otros no lo hacen.

Se hace esta distinción porque no todas las áreas protegidas poseen una geología significativa, servicios de ecosistema, oportunidades de sustento locales, etc, de forma que estos objetivos no son universales pero son adecuados cuando se presenta la oportunidad. Las siguientes páginas describen los rasgos distintivos de cada categoría de gestión suplementarios a los objetivos básicos. En algunos casos se pueden mencionar objetivos como la investigación científica o los recreativos porque son objetivos principales de una categoría concreta. 


\section{Categoría la: Reserva natural estricta}

Las áreas de Categoría la son áreas estrictamente protegidas reservadas para proteger la biodiversidad así como los rasgos geológicos/geomorfológicos en las cuales las visitas, el uso y los impactos están estrictamente controlados y limitados para asegurar la protección de los valores de conservación. Estas áreas protegidas pueden servir como áreas de referencia indispensables para la investigación científica y el monitoreo.

Antes de seleccionar una categoría se debe comprobar que el espacio cumple la definición de área protegida que se indica en la página 10 .

\section{Objetivo primario}

- Conservar a escala regional, nacional o global ecosistemas, especies (presencia o agregaciones) y/o rasgos de geodiversidad extraordinarios: dichos atributos se han conformado principalmente o exclusivamente por fuerzas no humanas y se degradarían o destruirían si se viesen sometidos a cualesquiera impactos humanos que no fueran muy ligeros.

\section{Otros objetivos}

- Conservar ecosistemas, especies y rasgos de geosistemas en un estado tan poco modificado por actividades humanas recientes como sea posible;

- Garantizar ejemplos del entorno natural para la investigación científica, el monitoreo y la educación ambiental, incluyendo áreas de referencia para la investigación en las que se prohíba cualquier acceso;

- Minimizar las perturbaciones mediante una planificación e implementación adecuada de la investigación y demás actividades permitidas;

- Conservar los valores culturales y espirituales asociados a la naturaleza.

\section{Rasgos distintivos}

En términos generales el área debería:

- Contar con un conjunto bastante completo de las especies nativas esperadas en densidades ecológicamente significativas o con capacidad para alcanzarlas mediante procesos naturales o intervenciones mínimas de gestión;

- Contar con el conjunto completo de ecosistemas nativos, con procesos ecológicos básicamente intactos o con capacidad para restaurarlos con una mínima intervención de la gestión;

- Estar libres de intervenciones directas significativas de los seres humanos modernos que pudieran comprometer los principios de conservación especificados para el área concreta, lo que normalmente implica la limitación del acceso de personas y la exclusión de asentamientos;

- No requerir una intervención sustancial y permanente para alcanzar sus objetivos de conservación;

- Cuando sea posible, estar rodeada de territorios con usos del suelo que contribuyan a alcanzar los objetivos de conservación especificados para el área;

- Ser adecuada como espacio de monitoreo de referencia para la investigación del impacto relativo de las actividades humanas;

- Ser gestionada para un nivel bajo de visitas;

- Ser susceptible de gestionarse de forma que se garantice una perturbación mínima (especialmente relevante para ambientes marinos).

El área podría ser de importancia religiosa o espiritual (como, por ej., un lugar natural sagrado) siempre y cuando la conservación de la biodiversidad esté identificada como el objetivo primario. En este caso área puede contener lugares así que podrían ser visitados por un número reducido de personas participantes en actividades religiosas que fueran consistentes con los objetivos de gestión de la misma.

\section{Papel en el paisaje terrestre/marino}

Las áreas de Categoría Ia son un componente vital de entre las herramientas de la conservación. A medida que la tierra se ve cada vez más afectada por las actividades humanas, quedan cada vez menos áreas en las que dichas actividades se encuentren estrictamente limitadas. Sin la protección que acompaña a la designación Ia, pronto no quedaría ninguno de estos territorios. Como tales, estas áreas contribuyen de forma significativa a la conservación ya que:

- Protegen parte de la riqueza de la tierra que no sobreviviría fuera de estos entornos estrictamente protegidos;

- Proporcionan puntos de referencia para permitir la evaluación y monitoreo a largo plazo de los impactos derivados de los cambios inducidos por el hombre fuera de dichas áreas (por ej., la contaminación);

- Proporcionan áreas en las que pueden estudiarse los ecosistemas en un entorno tan prístino como sea posible;

- Protegen servicios de ecosistemas;

- Protegen lugares naturales que también cuentan con significación religiosa y cultural.

\section{¿Qué hace que la categoría la sea única?}

La adjudicación de la categoría es una cuestión de elección, dependiendo de los objetivos de gestión a largo plazo, a menudo con varias opciones alternativas que podrían aplicarse en un espacio concreto. La siguiente tabla esboza algunas de las principales razones por las que se puede escoger la Categoría Ia en situaciones concretas frente a otras categorías con objetivos similares. 


\begin{tabular}{|c|c|}
\hline \multicolumn{2}{|c|}{$\begin{array}{l}\text { La Categoría la difiere de las demás categorías por } \\
\text { las siguientes razones: }\end{array}$} \\
\hline $\begin{array}{l}\text { Categoría } \\
\text { lb }\end{array}$ & $\begin{array}{l}\text { Las áreas protegidas de categoría lb } \\
\text { normalmente son más extensas y están } \\
\text { protegidas menos estrictamente de los } \\
\text { visitantes que la categoría la: aunque } \\
\text { no están sujetas normalmente al turismo } \\
\text { masivo, pueden estar abiertas a un } \\
\text { número limitado de personas que viajan } \\
\text { por si mismas, ya sea pie o en barco, } \\
\text { lo que no siempre ocurre en el caso de } \\
\text { las la. }\end{array}$ \\
\hline $\begin{array}{l}\text { Categoría } \\
\text { II }\end{array}$ & $\begin{array}{l}\text { Las áreas protegidas de categoría II } \\
\text { normalmente combinan la protección } \\
\text { del ecosistema con usos recreativos en } \\
\text { zonas determinadas, a una escala que no } \\
\text { se ajusta a la categoría I. }\end{array}$ \\
\hline $\begin{array}{l}\text { Categoría } \\
\text { III }\end{array}$ & $\begin{array}{l}\text { Las áreas protegidas de categoría III } \\
\text { normalmente están centradas en un } \\
\text { rasgo natural concreto de tal forma que } \\
\text { el objetivo principal de la gestión es el } \\
\text { mantenimiento de dicho rasgo, mientras } \\
\text { que los objetivos de las la normalmente } \\
\text { abarcan a ecosistemas y procesos } \\
\text { ecológicos completos. }\end{array}$ \\
\hline $\begin{array}{l}\text { Categoría } \\
\text { IV }\end{array}$ & $\begin{array}{l}\text { Las áreas protegidas de categoría IV } \\
\text { protegen fragmentos de ecosistemas } \\
\text { o hábitats que a menudo requieren } \\
\text { intervenciones de gestión continuas para } \\
\text { mantenerse. Por el contrario, las áreas de } \\
\text { categoría la deberían ser en gran medida } \\
\text { autosustentables y sus objetivos excluyen } \\
\text { estas actividades de gestión y las tasas } \\
\text { de visitas comunes en la categoría IV. } \\
\text { Asimismo, las áreas protegidas de la } \\
\text { categoría IV a menudo se establecen } \\
\text { para proteger especies o hábitats } \\
\text { concretos y no los objetivos ecológicos } \\
\text { específicos de la categoría la. }\end{array}$ \\
\hline $\begin{array}{l}\text { Categoría } \\
\text { V }\end{array}$ & $\begin{array}{l}\text { Las áreas protegidas de categoría V } \\
\text { normalmente son paisajes terrestres o } \\
\text { marinos que han sido alterados por los } \\
\text { seres humanos durante centenares o } \\
\text { incluso miles de años y que dependen de } \\
\text { una intervención continua para mantener } \\
\text { sus características, incluyendo la } \\
\text { biodiversidad. Muchas áreas protegidas } \\
\text { de categoría V contienen asentamientos } \\
\text { humanos permanentes. Todo lo anterior } \\
\text { es incompatible con la categoría la. }\end{array}$ \\
\hline $\begin{array}{l}\text { Categoría } \\
\text { VI }\end{array}$ & $\begin{array}{l}\text { Las áreas protegidas de categoría VI } \\
\text { contienen áreas naturales en las que } \\
\text { la conservación de la biodiversidad va } \\
\text { unida al uso sostenible de los recursos } \\
\text { naturales, la que resulta incompatible } \\
\text { con la categoría la. Sin embargo, existen } \\
\text { áreas protegidas de categoría VI de gran } \\
\text { tamaño que pueden contener áreas de } \\
\text { categoría la dentro de sus límites como } \\
\text { parte de una de sus zonas de gestión. }\end{array}$ \\
\hline
\end{tabular}

\section{Cuestiones a tener en cuenta}

- Existen pocos espacios terrestres o marinos en el mundo que no muestren la huella de acciones humanas pasadas, aunque en muchos casos los habitantes humanos originales ya no estén presentes. En muchos casos las áreas de categoría Ia requieren por tanto un proceso de restauración. Esta restauración debería realizarse por medio de procesos naturales o intervenciones limitadas en el tiempo: si resultara necesaria una intervención continua el área encajaría mejor en otra categoría como la IV o la V.

- Existen pocas áreas que no se encuentren bajo algún tipo de propiedad legal o al menos tradicional, de forma que encontrar espacios que excluyan la actividad humana resulta a menudo problemático.

- Algunas actividades humanas tienen un alcance regional o global que no se ve obstaculizado por los límites de las áreas protegidas. Esto es evidente en el caso del cambio climático o la contaminación atmosférica así como en el caso de enfermedades nuevas y emergentes. En una ecología cada vez más modificada, puede resultar cada vez más difícil mantener áreas prístinas mediante la no intervención.

- Muchos lugares naturales sagrados son gestionados de forma análoga a las áreas protegidas de categoría Ia por razones espirituales y culturales, y pueden estar ubicados dentro de áreas protegidas de categoría tanto $\mathrm{V}$ como VI.

\section{Categoría lb: Área silvestre}

Las áreas protegidas de categoría lb son generalmente áreas no modificadas o ligeramente modificadas de gran tamaño, que retienen su carácter e influencia natural, sin asentamientos humanos significativos o permanentes, que están protegidas y gestionadas para preservar su condición natural.

Antes de seleccionar una categoría se debe comprobar que el espacio cumple la definición de área protegida que se indica en la página 10.

\section{Objetivo primario}

- Proteger la integridad ecológica a largo plazo de áreas naturales no perturbadas por actividades humanas significativas, libres de infraestructuras modernas y en las que predominan las fuerzas y procesos naturales, de forma que las generaciones presentes y futuras tengan la oportunidad de experimentar dichas áreas.

\section{Otros objetivos}

- Proporcionar acceso público a unos niveles y de un tipo tales que se mantenga la calidad silvestre del área para las generaciones presentes y futuras; 
- Permitir a las comunidades indígenas mantener su estilo de vida y costumbres tradicionales basados en un entorno silvestre, viviendo en densidades bajas y utilizando los recursos disponibles de forma compatible con los objetivos de conservación;

- Proteger los correspondientes valores culturales y espirituales y los beneficios no materiales para las poblaciones indígenas y no indígenas, como la soledad, el respeto a lugares sagrados, el respeto a los antepasados, etc.;

- Permitir actividades educativas y de investigación científica de bajo impacto y mínimamente invasivas, cuando dichas actividades no puedan desarrollarse fuera del área silvestre.

\section{Rasgos distintivos}

En términos generales el área debería:

- Estar libres de infraestructuras modernas y actividades de desarrollo e industrias extractivas, entre ellas, pero no exclusivamente, carreteras, oleoductos, antenas de telefonía móvil, plataformas de petróleo y gas, terminales marítimas de gas natural licuado, otras estructuras permanentes, minería, plantas hidroeléctricas, extracción de petróleo y gas, agricultura incluyendo pastoreo intensivo, pesca comercial, aeronaves en vuelo a baja altura, etc., preferiblemente sin acceso motorizado o con acceso muy restringido.

- Caracterizarse por un alto grado de naturalidad: que contengan un alto porcentaje de la extensión original del ecosistema, conjuntos de fauna y flora nativas completos o casi completos, reteniendo sistemas predador-presa intactos e incluyendo grandes mamíferos.

- Ser de un tamaño suficiente para proteger la biodiversidad; mantener procesos ecológicos y servicios de ecosistema, mantener refugios ecológicos, servir de tampón frente a los impactos del cambio climático; y mantener procesos evolutivos.

- Ofrecer excelentes oportunidades para la soledad que se puedan disfrutar una vez que se ha llegado al área mediante medios de desplazamiento simples, silenciosos y que no sean molestos (por ej., acceso no motorizado o si es motorizado, que esté muy limitado a cuando sea estrictamente necesario y consecuente con los objetivos biológicos citados anteriormente).

- Estar libres de usos o presencia humanos inadecuados o excesivos, ya que se reducirían sus valores silvestres y en último caso impedirían que un área cumpliera los criterios biológicos y culturales citados anteriormente. Sin embargo, la presencia humana no debería ser el factor determinante a la hora de decidir el establecimiento de un área de categoría Ib. Los objetivos clave son un estado biológico intacto y la ausencia de infraestructuras permanentes, industrias extractivas, agricultura, uso motorizado, y otros indicadores de tecnología moderna o duradera.

Sin embargo, pueden incluir:

- Áreas algo alteradas que pueden ser restauradas a un estado silvestre, y áreas pequeñas que pueden ampliarse o que podrían jugar un papel importante en una estrategia más amplia de protección de la vida silvestre, como parte de un sistema de áreas protegidas que incluya áreas silvestres, si los objetivos de gestión de dichas áreas más pequeñas o alteradas en cierta medida son consecuentes con los objetivos citados anteriormente.

Cuando la integridad biológica de un área silvestre esté asegurada y el objetivo primario indicado anteriormente se cumple, el énfasis de la gestión del área protegida podrá trasladarse a otros objetivos como la protección de valores culturales o su uso recreativo, pero siempre y cuando los objetivos primarios estén asegurados.

\section{Papel en el paisaje terrestre/marino}

En muchos aspectos las áreas silvestres desempeñan un papel similar al de los parques nacionales de categoría II a la hora de proteger grandes ecosistemas funcionales (o al menos, áreas en las que muchos aspectos de un ecosistema puedan prosperar). Entre los papeles que pueden desempeñar se encuentran los siguientes:

- Proteger áreas generalmente no alteradas en las que puedan continuar los procesos ecosistémicos, como la evolución, sin obstáculos humanos, incluyendo el desarrollo del turismo masivo;

- Proteger servicios ecosistémicos compatibles;

- Proteger especies y comunidades ecológicas concretas que requieran grandes áreas de hábitats sin perturbaciones;

- Proporcionar un "fondo" de especies para ayudar a poblar áreas gestionadas de forma sostenible situadas alrededor del área protegida;

- Proporcionar un espacio para que un número limitado de visitantes pueda experimentar un entorno silvestre;

- Proporcionar posibilidades de respuesta al cambio climático incluyendo el movimiento de biomas. 


\section{¿Qué hace que la categoría lb sea única?}

\begin{tabular}{|c|c|}
\hline \multicolumn{2}{|c|}{$\begin{array}{l}\text { La categoría lb difiere de las demás categorías por } \\
\text { las siguientes razones: }\end{array}$} \\
\hline $\begin{array}{l}\text { Categoría } \\
\text { la }\end{array}$ & $\begin{array}{l}\text { Las áreas de categoría la son áreas } \\
\text { estrictamente protegidas, generalmente } \\
\text { con visitas humanas muy limitadas. } \\
\text { A menudo (pero no siempre) son } \\
\text { relativamente pequeñas en contraste con } \\
\text { las Ib. Normalmente no hay habitantes } \\
\text { humanos en la categoría la, y existen } \\
\text { usos de comunidades indígenas y locales } \\
\text { en muchas áreas protegidas lb. }\end{array}$ \\
\hline $\begin{array}{l}\text { Categoría } \\
\text { II }\end{array}$ & $\begin{array}{l}\text { Las áreas protegidas de categoría lb y } \\
\text { II son a menudo similares en términos } \\
\text { de tamaño y su objetivo es proteger } \\
\text { ecosistemas funcionales. Sin embargo, } \\
\text { mientras que la categoría II normalmente } \\
\text { incluye (o prevé incluir) el uso por } \\
\text { visitantes, incluyendo las infraestructuras } \\
\text { necesarias, en la lb el uso por visitantes } \\
\text { está más limitado y restringido a aquellos } \\
\text { que cuenten con capacidad y equipo para } \\
\text { sobrevivir sin ayuda. }\end{array}$ \\
\hline $\begin{array}{l}\text { Categoría } \\
\text { III }\end{array}$ & $\begin{array}{l}\text { El objetivo de la categoría III es proteger } \\
\text { un rasgo natural concreto, lo que no es } \\
\text { objetivo de la categoría Ib. Las áreas } \\
\text { protegidas de categoría III normalmente } \\
\text { son bastante pequeñas y como las de } \\
\text { categoría II su objetivo es atraer visitantes } \\
\text { en grandes cantidades; por el contrario, } \\
\text { los espacios lb son normalmente más } \\
\text { grandes y no pretenden atraer más que a } \\
\text { visitantes especializados. }\end{array}$ \\
\hline $\begin{array}{l}\text { Categoría } \\
\text { IV }\end{array}$ & $\begin{array}{l}\text { Las áreas protegidas de categoría IV son } \\
\text { normalmente relativamente pequeñas } \\
\text { y desde luego no son ecosistemas } \\
\text { funcionales completos, y la mayoría } \\
\text { requiere intervenciones continuadas para } \\
\text { mantener su biodiversidad: todas estas } \\
\text { características son las opuestas a las } \\
\text { condiciones de las lb. }\end{array}$ \\
\hline $\begin{array}{l}\text { Categoría } \\
\text { V }\end{array}$ & $\begin{array}{l}\text { Las áreas protegidas de categoría } \\
\text { V comprenden paisajes culturales } \\
\text { terrestres y marinos, modelados por } \\
\text { la intervención humana (normalmente } \\
\text { durante mucho tiempo) y habitualmente } \\
\text { contienen importantes comunidades } \\
\text { humanas asentadas en ellas. Las de } \\
\text { categoría lb deberían contar con un } \\
\text { estado tan natural como sea posible } \\
\text { y sólo contendrían paisajes culturales } \\
\text { si la intención fuera restaurarlos a } \\
\text { condiciones casi naturales. }\end{array}$ \\
\hline
\end{tabular}

Categoría $\quad$ El objetivo de la categoría VI es

VI establecer divisiones por zonas y regímenes de gestión para apoyar un uso sostenible; aunque las áreas silvestres a veces incluyan usos tradicionales limitados por pueblos indígenas, esto es accesorio a sus objetivos de gestión y no una parte intrínseca de los mismos.

\section{Cuestiones a tener en cuenta}

- Algunas áreas silvestres incluyen el pastoreo por pueblos nómadas y puede ser necesario hacer distinciones entre pastoreo intensivo y no intensivo; sin embargo, esto puede suponer un reto si dichos pueblos quieren aumentar las densidades de ganado.

\section{Categoría II: Parque nacional}

Las áreas protegidas de categoría II son grandes áreas naturales 0 casi naturales establecidas para proteger procesos ecológicos a gran escala, junto con el complemento de especies y ecosistemas característicos del área, que también proporcionan la base para oportunidades espirituales, científicas, educativas, recreativas y de visita que sean ambiental y culturalmente compatibles.

Antes de seleccionar una categoría se debe comprobar que el espacio cumple la definición de área protegida que se indica en la página 10 .

\section{Objetivo primario}

- Proteger la biodiversidad natural junto con la estructura ecológica subyacente y los procesos ambientales sobre los que se apoya, y promover la educación y el uso recreativo. ${ }^{3}$

\section{Otros objetivos}

- Gestionar el área para perpetuar, en un estado tan natural como sea posible, ejemplos representativos de regiones fisiográficas, comunidades bióticas, recursos genéticos y procesos naturales singulares;

- Mantener poblaciones viables y ecológicamente funcionales y conjuntos de especies nativas a densidades suficientes como para conservar la integridad del ecosistema y su plasticidad y resistencia a largo plazo;

- Contribuir en particular a la conservación de especies que requieren territorios grandes para su supervivencia, así como procesos ecológicos regionales y rutas migratorias;

\footnotetext{
3 Téngase en cuenta que la denominación "parque nacional" no está exclusivamente vinculada a la Categoría II. En todas las categorías existen espacios denominados parques nacionales (e incluso existen algunos parques nacionales que ni siquiera son áreas protegidas). Esta denominación se utiliza aquí porque describe áreas protegidas de Categoría II de muchos países. El hecho de que a un área se le llame "parque nacional" es independiente de su enfoque de gestión. En concreto, el término "parque nacional" nunca debería emplearse como forma de desposeer a la gente de sus tierras.
} 
- Gestionar el uso por visitantes con fines de inspiración, educativos, culturales y recreativos a un nivel en el que no cause una degradación biológica o ecológica significativa de los recursos naturales;

- Tener en cuenta las necesidades de los pueblos indígenas y las comunidades locales, incluyendo el uso de los recursos para su subsistencia, en la medida en que esto no afecte negativamente al objetivo de gestión primario;

- Contribuir a las economías locales mediante el turismo.

\section{Rasgos distintivos}

Las áreas de categoría II son generalmente de gran tamaño y conservan un ecosistema funcional, aunque para conseguirlo, el área protegida tenga que complementarse mediante una gestión en sintonía con las áreas circundantes.

- El área deberá contener ejemplos representativos de las principales regiones naturales, y de las características biológicas y ambientales del paisaje, en los que las especies animales y vegetales, hábitats y lugares de geodiversidad tengan un especial significado espiritual, científico, educativo, recreativo o turístico.

- El área deberá contar con el suficiente tamaño y calidad ecológica como para mantener funciones y procesos ecológicos que permitan a las especies y comunidades nativas sobrevivir a largo plazo con una intervención mínima de la gestión.

- La composición, estructura y funcionamiento de la biodiversidad deberá estar en gran medida en un estado "natural" o contar con el potencial para ser restaurada a dicho estado, con un riesgo relativamente bajo de sufrir invasiones de especies no-nativas.

\section{Papel en el paisaje terrestre/marino}

La categoría II proporciona oportunidades de conservación a gran escala en las que los procesos ecológicos naturales pueden continuar a perpetuidad, permitiendo una evolución continua. A menudo son puntos de apoyo claves para el diseño y desarrollo de corredores biológicos a gran escala u otras iniciativas de conservación en conectividad necesarias para ésas especies (tanto para las que requieren grandes territorios para su supervivencia como para especies migratorias) que no pueden ser conservadas enteramente en una única área protegida. Sus papeles clave son por tanto:

- Proteger procesos ecológicos a gran escala que no podrían ser abarcados por áreas protegidas más pequeñas o en los paisajes culturales;
- Proteger servicios ecosistémicos compatibles;

- Proteger especies y comunidades concretas que requieren grandes extensiones de hábitats no alterados;

- Proporcionar un fondo de especies para ayudar a poblar áreas gestionadas de forma sostenible situadas alrededor del área protegida;

- Integrarse con el uso de la tierra o el agua de los alrededores para contribuir a los planes de conservación a gran escala;

- Informar y concienciar a los visitantes sobre la necesidad y el potencial de los programas de conservación;

- Apoyar un desarrollo económico compatible, especialmente mediante usos recreativos y turismo, que pueda contribuir a las economías nacionales, y especialmente a las comunidades locales.

Las áreas de categoría II deberían estar protegidas de manera más estricta cuando las funciones ecológicas y las especies nativas estén relativamente intactas; los paisajes que las rodean pueden tener distintos niveles de usos para el consumo o no consumistas pero idealmente deberían servir como zonas de amortiguamiento del área protegida.

\section{¿Qué hace que la categoría II sea única?}

\begin{tabular}{|l|l|}
\hline \multicolumn{2}{|l|}{$\begin{array}{l}\text { La categoría II difiere de las demás categorías por } \\
\text { las siguientes razones: }\end{array}$} \\
\hline $\begin{array}{l}\text { Categoría } \\
\text { la }\end{array}$ & $\begin{array}{l}\text { La categoría II normalmente no se } \\
\text { encuentra tan estrictamente conservada } \\
\text { como la categoría la y puede incluir } \\
\text { infraestructuras y visitas turísticas. } \\
\text { Sin embargo, las áreas protegidas de } \\
\text { categoría II a menudo cuentan con } \\
\text { zonas centrales en las que el número de } \\
\text { visitas está estrictamente controlado, que } \\
\text { pueden equipararse a la categoría la. }\end{array}$ \\
\hline $\begin{array}{l}\text { Categoría } \\
\text { Ib }\end{array}$ & $\begin{array}{l}\text { Las visitas en la categoría II son } \\
\text { normalmente distintas a las de las áreas } \\
\text { silvestres, con más infraestructuras } \\
\text { de soporte (caminos, carreteras, } \\
\text { alojamientos) y por lo tanto un número } \\
\text { de visitantes probablemente mayor. } \\
\text { Las áreas protegidas de categoría II a } \\
\text { menudo cuentan con zonas centrales } \\
\text { en las que el número de visitas está } \\
\text { estrictamente controlado, que pueden } \\
\text { equipararse a la categoría lb. }\end{array}$ \\
\hline Categoría & $\begin{array}{l}\text { La gestión en la categoría III se centra en } \\
\text { un único rasgo natural, mientras que en la } \\
\text { categoría II se centra en mantener todo el } \\
\text { ecosistema. }\end{array}$ \\
\hline III
\end{tabular}




\begin{tabular}{|l|l|}
\hline IV & $\begin{array}{l}\text { El objetivo de la categoría II es mantener } \\
\text { la integridad ecológica a escala de } \\
\text { ecosistema, mientras que el de la } \\
\text { categoría IV es proteger hábitats y } \\
\text { especies concretas. En la práctica, } \\
\text { las áreas de categoría IV raramente } \\
\text { son lo suficientemente grandes como } \\
\text { para proteger todo un ecosistema y la } \\
\text { distinción entre las categorías II y IV es } \\
\text { por tanto una cuestión de extensión: las } \\
\text { áreas de categoría IV son normalmente } \\
\text { bastante pequeñas (humedales } \\
\text { concretos, fragmentos de bosques, } \\
\text { aunque con algunas excepciones), } \\
\text { mientras que las de categoría II } \\
\text { normalmente son mucho mayores y al } \\
\text { menos bastante autosustentables. }\end{array}$ \\
\hline Categoría & $\begin{array}{l}\text { Las áreas protegidas de categoría II } \\
\text { son esencialmente sistemas naturales } \\
\text { o en vías de ser restaurados a sistemas } \\
\text { naturales mientras que las de la categoría } \\
\text { V son paisajes naturales y el objetivo es } \\
\text { mantenerlos en dicho estado. }\end{array}$ \\
\hline Categoría & $\begin{array}{l}\text { Normalmente la categoría II no permite } \\
\text { el uso de recursos excepto para la } \\
\text { subsistencia o usos recreativos. }\end{array}$ \\
VI &
\end{tabular}

\section{Cuestiones a tener en cuenta}

- Los conceptos de naturalidad están desarrollándose rápidamente y algunas áreas que anteriormente han sido consideradas como naturales están empezando a ser considerados paisajes culturales - por ej., los paisajes de sabanas en los se ha empleado el fuego para mantener mosaicos de vegetación y con ello poblaciones de animales para su caza. Los límites entre lo que se considera y gestiona como categoría II y categoría $\mathrm{V}$ pueden por ello cambiar con el tiempo.

- La comercialización de suelo y agua en la categoría II está planteando retos en muchas partes del planeta, en parte porque existe la percepción política de que los recursos están “inmovilizados” en los parques nacionales, existiendo una creciente presión a favor de mayores usos recreativos y mayor permisividad para los operadores turísticos, desarrollo de programas de acuicultura continental y marina, y tendencias hacia la privatización de dichas áreas.

- Están emergiendo una serie de cuestiones como las relativas a las poblaciones asentadas en áreas propuestas para su designación bajo la categoría II, desalojamiento de poblaciones, compensaciones (incluyendo las destinadas a las comunidades pesqueras desalojadas de las áreas protegidas marinas y costeras), opciones de medios de vida alternativos y cambios de los enfoques de gestión.

\section{Categoría III: Monumento o característica natural}

Las áreas protegidas de categoría III se establecen para proteger un monumento natural concreto, que puede ser una formación terrestre, una montaña submarina, una caverna submarina, un rasgo geológico como una cueva o incluso un elemento vivo como una arboleda antigua. Normalmente son áreas protegidas bastante pequeñas y a menudo tienen un gran valor para los visitantes.

Antes de seleccionar una categoría se debe comprobar que el espacio cumple la definición de área protegida que se indica en la página 10 .

\section{Objetivo primario}

- Proteger específicos rasgos naturales sobresalientes y la biodiversidad y los hábitats asociados a ellos.

\section{Otros objetivos}

- Proporcionar protección a la biodiversidad en paisajes terrestres o marinos que en ausencia de ella sufrirían cambios sustanciales; ${ }^{4}$

- Proteger lugares naturales específicos con valores espirituales y/o culturales cuando estos también cuentan con valores de biodiversidad;

- Conservar los valores espirituales y culturales tradicionales del lugar.

\section{Rasgos distintivos}

Las áreas protegidas de categoría III son normalmente espacios relativamente pequeños que se centran en uno o varios rasgos naturales prominentes y a su ecología asociada más que en un ecosistema más amplio. Se gestionan de forma muy similar a las de categoría II. El término "natural" que aquí se emplea puede referirse tanto a rasgos completamente naturales (el uso más frecuente) pero a veces también a rasgos que se han visto influenciados por los seres humanos. En este caso estos espacios deberían poseer atributos importantes asociados a la biodiversidad, que deberían reflejarse como una prioridad en sus objetivos de gestión si se pretende clasificarlos como área protegida y no como lugar histórico o espiritual. Las áreas protegidas de categoría III pueden incluir:

- Rasgos geológicos y geomorfológicos naturales: como saltos de agua, acantilados, cráteres, cuevas, lechos fluviales fósiles, dunas de arena, formaciones rocosas, valles y elementos marinos como montañas submarinas o formaciones de coral;

- Rasgos naturales con influencia cultural: como asentamientos en cuevas y caminos antiguos;

Téngase en cuenta que la protección de lugares culturales concretos a menudo puede ofrecer refugios de hábitat natural o seminatural en áreas que de no ser así habrían sufrido modificaciones sustanciales - por ej., árboles antiguos situados alrededor de los templos. 
- Lugares naturales-culturales: como las muchas formas de lugares sagrados (bosques sagrados, fuentes, saltos de agua, montañas cuevas submarinas, etc.) de importancia para uno o varios grupos de creyentes;

- Lugares culturales asociados con la ecología: en los que la protección de un lugar cultural también protege a una biodiversidad importante y significativa, como lugares arqueológicos/históricos que están inextricablemente vinculados a un área natural.

Los atributos de conservación natural de las áreas protegidas de categoría III son de dos tipos principales:

- Biodiversidad relacionada de forma especial con las condiciones ecológicas asociadas al rasgo natural - como las zonas de caída de agua pulverizada de un salto de agua, las condiciones ecológicas de cuevas o especies vegetales confinadas en acantilados.

- Biodiversidad que sobrevive porque la presencia de valores culturales o espirituales del lugar han mantenido un hábitat natural o seminatural en lo que es un ecosistema modificado - como algunos lugares naturales sagrados o lugares históricos que cuentan con áreas naturales asociadas. En estos casos los criterios clave de su inclusión como área protegida serán: (i) valor del lugar como aportación a la conservación a escala más amplia y (ii) priorización de la conservación de la biodiversidad dentro de los planes de gestión.

Se ha sugerido que la categoría III proporciona un enfoque de gestión natural para muchos lugares naturales sagrados como las cuevas sagradas. Aunque se pueden encontrar lugares naturales sagrados en todas las categorías y pueden beneficiarse de una amplia gama de enfoques de gestión, pueden ser especialmente susceptibles de ser gestionados como monumentos naturales.

\section{Papel en el paisaje terrestre/marino}

El objetivo real de la categoría III es proteger lo inusual más que proporcionar componentes lógicos dentro de un enfoque más amplio de la conservación, por lo que su papel en el paisaje o en las estrategias ecorregionales puede ser a veces oportunista más que planificado. En otros casos (por ej., sistemas de cuevas) dichos lugares pueden jugar un papel ecológico clave dentro de planes de conservación más amplios:

- Los monumentos naturales importantes a veces pueden proporcionar un incentivo y una oportunidad para la educación ambiental/cultural incluso en áreas en las que hay resistencia a otras formas de protección debido a las presiones de la población o el desarrollo, como en el caso de lugares sagrados o culturales importantes y en estos casos las categoría III puede conservar muestras de hábitat cultural en lo que son paisajes culturales o fragmentados.

\section{¿Qué hace que la categoría III sea única?}

Dado que su objetivo es la protección de un elemento concreto, quizás sea la categoría III la más influida de todas por la percepción humana de lo qué es valioso en el paisaje terrestre o marino más que por cualquier otra evaluación más cuantitativa. Ésta resulta menos aplicable a las áreas protegidas de categoría III designadas por rasgos geológicos en los que es posible una identificación sistemática. La gestión se centra normalmente en la protección y mantenimiento de rasgos naturales concretos.

El hecho de que un área contenga un monumento natural importante no significa inexorablemente que sea gestionada como categoría III; por ejemplo, el Gran Cañón en Arizona es gestionado como categoría II a pesar de ser uno de los monumentos naturales más famosos del mundo, porque también es un área extensa y diversa con actividades recreativas asociadas lo que hace que encaje mejor en un modelo de categoría II. La categoría III se ajusta mejor cuando la protección del rasgo natural o fisiográfico es el objetivo único o el predominante.

\begin{tabular}{|c|c|}
\hline \multicolumn{2}{|c|}{$\begin{array}{l}\text { La categoría III difiere de las demás categorías por } \\
\text { las siguientes razones: }\end{array}$} \\
\hline $\begin{array}{l}\text { Categoría } \\
\text { la }\end{array}$ & \multirow{2}{*}{$\begin{array}{l}\text { La categoría III no está confinada a } \\
\text { paisajes naturales y prístinos sino que } \\
\text { podría establecerse en áreas que son } \\
\text { paisajes culturales o fragmentados. A } \\
\text { menudo se fomentan las visitas y los } \\
\text { usos recreativos y la investigación y } \\
\text { la monitorización están limitadas a la } \\
\text { comprensión y el mantenimiento del } \\
\text { rasgo natural concreto. }\end{array}$} \\
\hline $\begin{array}{l}\text { Categoría } \\
\text { lb }\end{array}$ & \\
\hline $\begin{array}{l}\text { Categoría } \\
\text { II }\end{array}$ & $\begin{array}{l}\text { El énfasis de la gestión de la categoría } \\
\text { III no reside en la protección del } \\
\text { ecosistema en su conjunto sino de } \\
\text { rasgos naturales concretos. Por lo } \\
\text { demás la categoría III es similar a la } \\
\text { categoría II y se gestiona de forma } \\
\text { similar aunque a una escala mucho } \\
\text { menor tanto en tamaño como en } \\
\text { complejidad de la gestión. }\end{array}$ \\
\hline $\begin{array}{l}\text { Categoría } \\
\text { IV }\end{array}$ & $\begin{array}{l}\text { El énfasis de la gestión de la categoría III } \\
\text { no reside en la protección de especies o } \\
\text { hábitats clave sino de rasgos naturales } \\
\text { concretos. }\end{array}$ \\
\hline $\begin{array}{l}\text { Categoría } \\
\text { V }\end{array}$ & $\begin{array}{l}\text { La categoría III no está confinada a } \\
\text { paisajes culturales y las prácticas de } \\
\text { gestión se centran en una protección más } \\
\text { estricta del rasgo concreto que en el caso } \\
\text { de la categoría V. }\end{array}$ \\
\hline $\begin{array}{l}\text { Categoría } \\
\text { VI }\end{array}$ & $\begin{array}{l}\text { El objetivo de la categoría III no es el uso } \\
\text { sostenible de los recursos. }\end{array}$ \\
\hline
\end{tabular}




\section{Cuestiones a tener en cuenta}

- A veces puede resultar difícil averiguar los atributos de conservación de los lugares de categoría III, especialmente en los casos en los que pueden existir presiones para aceptar estos lugares dentro de un sistema de áreas protegidas para ayudar a proteger valores culturales o espirituales.

- No todos los monumentos naturales son permanentes aunque algunos árboles sagrados has sobrevivido durantes más de mil años, al final morirán - de hecho muchos árboles son considerados sagrados en parte por lo viejos que son. No está claro lo que ocurre con un área protegida de categoría III si su monumento natural clave desaparece o se degrada.

- A veces resulta difícil trazar los límites entre un monumento natural y un lugar cultural, especialmente cuando se incluyen restos arqueológicos en la categoría III.

- Algunos "monumentos" evidentes pueden requerir la protección de un ecosistema más amplio para sobrevivir por ejemplo un salto de agua puede requerir la protección de toda la cuenca para mantener su flujo.

\section{Categoría IV: Áreas de gestión de hábitats/especies}

El objetivo de las áreas protegidas de categoría IV es la protección de hábitats o especies concretas y su gestión refleja dicha prioridad. Muchas áreas protegidas de categoría IV van a necesitar intervenciones activas habituales para abordar las necesidades de especies concretas o para mantener hábitats, pero esto no es un requisito de la categoría.

Antes de seleccionar una categoría se debe comprobar que el espacio cumple la definición de área protegida que se indica en la página 10 .

\section{Objetivo primario}

- Mantener, conservar y restaurar especies y hábitats. ${ }^{5}$

\section{Otros objetivos}

- Proteger patrones de vegetación u otros rasgos biológicos mediante enfoques de gestión tradicionales;

- Proteger fragmentos de hábitats como elementos de las estrategias de conservación del paisaje terrestre o marino;

- Desarrollar la educación pública y el aprecio por las correspondientes especies y/o hábitats;
- Proporcionar un medio por medio del cual los residentes urbanos puedan tener un contacto regular con la naturaleza.

\section{Rasgos distintivos}

Las áreas protegidas de categoría IV normalmente ayudan a proteger o restaurar: 1) especies de flora de importancia internacional, nacional o local; 2) especies de fauna de importancia internacional, nacional o local incluyendo la fauna residente y la migratoria; y/o 3) hábitats. El tamaño del área puede variar pero a menudo son relativamente pequeñas; sin embargo este no es un rasgo distintivo. La gestión puede variar dependiendo de las necesidades. La protección puede ser suficiente para mantener hábitats y/o especies concretas. Sin embargo, dado que las áreas protegidas de categoría IV a menudo incluyen fragmentos de un ecosistema, estas áreas pueden no ser autosustentables y pueden requerir intervenciones de gestión activas y de forma habitual para asegurar la supervivencia de hábitats concretos y/o cubrir las necesidades de especies concretas. Son posibles una serie de enfoques:

- Protección de una especie particular: proteger especies objeto concretas, que habitualmente se encuentran amenazadas (por ej., una de las últimas poblaciones que subsisten);

- Protección de hábitats: mantener o restaurar hábitats que a menudo son fragmentos de ecosistemas;

- Gestión activa para mantener especies particulares: mantener poblaciones viables de especies concretas, lo que puede incluir la creación y mantenimiento de hábitats artificiales (como la creación de arrecifes artificiales), alimentación suplementaria u otros sistemas de gestión activa;

- Gestión activa de ecosistemas naturales o seminaturales: mantener hábitats naturales o seminaturales que o son demasiado pequeños o están demasiado profundamente afectados como para ser autosustentables, por ej., si no hay herbívoros naturales puede ser necesario reemplazarlos por ganado o alimentación directa; o si la hidrología ha sido alterada puede ser neceserios drenajes o riegos artificiales;

- Gestión activa de ecosistemas definidos culturalmente: mantener sistemas de gestión cultural cuando los mismos presentan una biodiversidad asociada singular. La intervención continua resulta necesaria porque el ecosistema ha sido creado o al menos sustancialmente modificado por la gestión. El objetivo primario de gestión es el mantenimiento de la biodiversidad asociada.

Esto supone una modificación respecto a las directrices de 1994, que definían la Categoría IV como áreas que necesitan intervenciones de gestión de forma habitual. Se ha realizado la modificación porque era la única categoría que se define en función el proceso de gestión y no del objetivo final, y porque esto significaba que las pequeñas reservas destinadas a proteger hábitats o especies particulares tendían a quedar fuera del sistema de categorías. 
Gestión activa significa que el funcionamiento general del ecosistema está siendo modificado mediante por ej., la detención de la sucesión natural, proporcionando alimentación adicional o creando artificialmente hábitats: por ej. la gestión normalmente incluirá mucho más que abordar las amenazas, como la caza furtiva o las especies invasoras, ya que estas actividades tienen lugar virtualmente en todas las áreas de cualquier categoría y por lo tanto no sirven de diagnóstico. Las áreas protegidas de categoría IV son normalmente accesibles al público.

\section{Papel en el paisaje terrestre/marino}

Las áreas protegidas de categoría IV a menudo juegan un papel a la hora de "cubrir las lagunas" de las estrategias de conservación protegiendo especies o hábitats clave en los ecosistemas. Podrían por ejemplo emplearse para:

- Proteger a poblaciones de especies en peligro crítico que necesitan intervenciones de gestión especiales para asegurar su supervivencia continuada;

- Proteger hábitats raros o amenazados, incluyendo fragmentos de hábitats:

- Asegurar zonas de parada (lugares en los que las aves migratorias pueden detenerse y descansar) o zonas de reproducción y cría;

- Proporcionar estrategias y opciones de gestión flexibles en las zonas de amortiguamiento situadas alrededor de áreas más estrictamente protegidas o en los corredores entre las mismas, que son más aceptables para las comunidades locales y otros actores implicados;

- Mantener especies que se han vuelto dependientes de paisajes culturales cuando sus hábitats originales han desaparecido o sufrido alteraciones.

\section{¿Qué hace que la categoría IV sea única?}

La categoría IV proporciona un enfoque de gestión utilizado en áreas que han sufrido modificaciones sustanciales y requieren la protección de los fragmentos restantes, con o sin intervención.

\begin{tabular}{|l|l|}
\hline $\begin{array}{l}\text { La categoría IV difiere de las demás categorias por } \\
\text { las siguientes razones: }\end{array}$ \\
\begin{tabular}{|l|l} 
Categoría \\
la
\end{tabular} & $\begin{array}{l}\text { Las áreas protegidas de categoría } \\
\text { IV no están estrictamente protegidas } \\
\text { frente a usos humanos; puede } \\
\text { existir investigación científica } \\
\text { pero generalmente como objetivo } \\
\text { secundario. }\end{array}$ \\
\hline $\begin{array}{l}\text { Categoría } \\
\text { Ib }\end{array}$ & $\begin{array}{l}\text { Las áreas protegidas de categoría IV no } \\
\text { pueden describirse como "silvestres", tal } \\
\text { como la UICN define el término. Muchas } \\
\text { están sujetas a intervenciones de gestión } \\
\text { que son ajenas al concepto de áreas } \\
\text { silvestres de categoría Ib; aquellas que } \\
\text { permanecen sin gestión son normalmente } \\
\text { demasiado pequeñas para cumplir los } \\
\text { objetivos de la categoría Ib. }\end{array}$ \\
\hline
\end{tabular}

\begin{tabular}{|c|c|}
\hline $\begin{array}{l}\text { Categoría } \\
\text { II }\end{array}$ & $\begin{array}{l}\text { El objetivo de gestión de las áreas } \\
\text { protegidas de categoría IV es la } \\
\text { conservación de especies o hábitats } \\
\text { concretos, y en consecuencia prestan } \\
\text { menor atención a otros elementos del } \\
\text { ecosistema, mientras que el objetivo } \\
\text { de las áreas protegidas de categoría II } \\
\text { es conservar ecosistemas funcionales } \\
\text { completos. Las categoría II y IV } \\
\text { pueden asemejarse mucho en algunas } \\
\text { circunstancias y la distinción se basa en } \\
\text { parte en la cuestión de los objetivos - por } \\
\text { ej., si el objetivo es proteger en la medida } \\
\text { de lo posible todo el ecosistema (categoría } \\
\text { II) o si se centra en proteger unas pocas } \\
\text { especies o hábitats clave (categoría IV). }\end{array}$ \\
\hline $\begin{array}{l}\text { Categoría } \\
\text { III }\end{array}$ & $\begin{array}{l}\text { El objetivo de las áreas de categoría } \\
\text { IV es de una naturaleza más biológica } \\
\text { mientras que el de la categoría III es más } \\
\text { específico del lugar y está más orientado } \\
\text { a la morfología o la cultura. }\end{array}$ \\
\hline $\begin{array}{l}\text { Categoría } \\
\text { V }\end{array}$ & $\begin{array}{l}\text { El objetivo de las áreas protegidas de } \\
\text { categoría IV es la protección de especies o } \\
\text { hábitats específicos mientras que el de la } \\
\text { categoría V es proteger paisajes terrestres/ } \\
\text { marinos con valor para la conservación } \\
\text { de la naturaleza. Las áreas protegidas } \\
\text { de categoría V normalmente poseen } \\
\text { características socioculturales que pueden } \\
\text { estar ausentes en la categoría IV. Cuando } \\
\text { las áreas de categoría IV puedan emplear } \\
\text { enfoques de gestión tradicionales, esto se } \\
\text { hará explícitamente para mantener especies } \\
\text { asociadas o como parte de un plan de } \\
\text { gestión y no de forma más general como } \\
\text { parte de un enfoque de gestión que incluya } \\
\text { una amplia gama de actividades lucrativas. }\end{array}$ \\
\hline $\begin{array}{l}\text { Categoría } \\
\text { VI }\end{array}$ & $\begin{array}{l}\text { Las intervenciones de gestión en las áreas } \\
\text { protegidas de categoría IV se dirigen } \\
\text { principalmente a mantener especies } \\
\text { o hábitats mientras que en las áreas } \\
\text { protegidas de categoría VI se dirigen a } \\
\text { vincular la conservación de la naturaleza al } \\
\text { uso sostenible de los recursos. Como ocurre } \\
\text { con la categoría V, las áreas protegidas de } \\
\text { categoría VI son generalmente mayores } \\
\text { que las de categoría IV. }\end{array}$ \\
\hline
\end{tabular}

\section{Cuestiones a tener en cuenta}

- Muchas áreas protegidas de categoría IV están situadas en paisajes terrestres y marinos con alta densidad de ocupación, en las que la presión humana es relativamente elevada, tanto en términos de usos ilegales potenciales como de visitantes.

- Las áreas protegidas de categoría IV que dependen de intervenciones de gestión regulares necesitan que la autoridad de gestión proporcione recursos adecuados y pueden ser relativamente caras de mantener a menos que la gestión sea asumida de forma voluntaria por las comunidades locales $\mathrm{u}$ otros actores. 
- Dado que habitualmente protegen parte de un ecosistema, una gestión de éxito a largo plazo de las áreas protegidas de categoría IV requiere un monitoreo cuidadoso e incluso un énfasis aún mayor de lo habitual en los enfoques de gestión de ecosistemas en otras partes del paisaje terrestre o marino que sean compatibles con el área de categoría IV.

\section{Categoría V: Paisaje terrestre/marino protegido}

Un área protegida en la que la interacción entre los seres humanos y la naturaleza ha producido un área de carácter distintivo con valores ecológicos, biológicos, culturales y estéticos significativos; y en la que salvaguardar la integridad de dicha interacción es vital para proteger y mantener el área, la conservación de su naturaleza y otros valores.

Antes de seleccionar una categoría se debe comprobar que el espacio cumple la definición de área protegida que se indica en la página 10 .

\section{Objetivo primario}

- Proteger y mantener paisajes terrestres/marinos importantes y la conservación de la naturaleza asociada a ellos, así como otros valores creados por las interacciones con los seres humanos mediante prácticas de gestión tradicionales.

\section{Otros objetivos}

- Mantener una interacción equilibrada entre naturaleza y cultura mediante la protección del paisaje terrestre y/o marino y los enfoques de gestión tradicional, las sociedades, las culturas y los valores espirituales asociados;

- Contribuir a la conservación a escala amplia manteniendo especies asociadas a paisajes culturales y/o proporcionar oportunidades de conservación en paisajes que presentan un elevado nivel de usos;

- Proporcionan posibilidades de disfrute, bienestar y actividades socioeconómicas mediante usos recreativos y el turismo;

- Proporcionar productos naturales y servicios ambientales;

- Proporcionar un marco que sirva de soporte a la participación de la comunidad en la gestión de paisajes terrestres o marinos de gran valor y del patrimonio natural y cultural que contienen;

- Fomentar la conservación de la agrobiodiversidad ${ }^{6}$ y la biodiversidad acuática;

- Actuar como modelos de sostenibilidad para poder aprender lecciones que puedan aplicarse de forma más amplia.

\footnotetext{
6 Ver definición en el Apéndice.
}

\section{Rasgos distintivos}

Las áreas protegidas de categoría $\mathrm{V}$ son el resultado de la interacción biótica, abiótica y humana y deberían mostrar las siguientes características esenciales:

- Paisaje terrestre y/o marino costero o insular de calidad estética elevada y/o distintiva y con hábitats, flora y fauna y rasgos culturales significativos asociados a los mismos;

- Una interacción equilibrada entre las personas y la naturaleza que ha perdurado en el tiempo y sigue contando con integridad, o en los que existe una esperanza razonable de restaurar dicha integridad;

- Patrones exclusivos o tradicionales de uso del suelo, por ej., los que existen en sistemas agrícolas y forestales sostenibles $\mathrm{y}$ asentamientos humanos que han evolucionado en equilibrio con su entorno.

A continuación se indican las características deseables:

- Posibilidades de usos recreativos y turísticos consecuentes con el estilo de vida y las actividades económicas;

- Organización sociales únicas o tradicionales, que se evidencian por las costumbres, modos de sustento y creencias locales;

- Reconocimiento por artistas de cualquier tipo y por las tradiciones culturales (presentes y pasadas);

- Potencial de restauración ecológica y/o paisajística.

\section{Papel en el paisaje terrestre/marino}

Generalmente, las áreas protegidas de categoría $\mathrm{V}$ juegan un importante papel en la conservación a escala de paisaje terrestre/ marino, especialmente como parte de un mosaico de patrones de gestión, de designación de áreas protegidas y de otros mecanismos de conservación:

- Algunas áreas protegidas de categoría V sirven de áreas de amortiguamiento alrededor de un núcleo de una o varias áreas más estrictamente protegidas para garantizar que los usos del suelo y el agua no amenacen su integridad;

- Las áreas protegidas de categoría V también pueden servir de nexo de unión entre varias áreas protegidas.

La Categoría V ofrece aportaciones únicas a la conservación de la diversidad biológica; en concreto:

- Especies o hábitats que han evolucionado en asociación con sistemas de gestión cultural y solo pueden sobrevivir si se mantienen dichos sistemas;

- Proporcionar un marco de referencia cuando los objetivos de conservación tienen que ser alcanzados en un área extensa (por ej., para especies predadoras que se encuentran en la cúspide de la cadena alimentaria) en paisajes con 
altas densidades de ocupación con una amplia gama de modos de tenencia de la tierra, de modelos de gobernanza y de usos del suelo;

- Asimismo, los sistemas tradicionales de gestión a menudo están asociados a elementos importantes de la agrobiodiversidad o la biodiversidad acuática, que sólo pueden conservarse si se mantienen dichos sistemas.

\section{¿Qué hace que la categoría $V$ sea única?}

\section{La categoría $\mathbf{V}$ difiere de las demás categorías por las siguientes razones:}

\begin{tabular}{|l|l|}
\hline $\begin{array}{l}\text { Categoría } \\
\text { la }\end{array}$ & $\begin{array}{l}\text { Se espera que exista intervención } \\
\text { humana. La categoría V no tiene la } \\
\text { investigación entre sus prioridades, } \\
\text { aunque puede ofrecer oportunidades } \\
\text { para estudiar las interacciones entre los } \\
\text { seres humanos y la naturaleza. }\end{array}$ \\
\hline $\begin{array}{l}\text { Categoría } \\
\text { Ib }\end{array}$ & $\begin{array}{l}\text { Las áreas protegidas de categoría V } \\
\text { no son "silvestres" según la definición } \\
\text { de la UICN. Muchas están sujetas a } \\
\text { intervenciones de gestión que son ajenas } \\
\text { al concepto de la categoría Ib. }\end{array}$ \\
\hline
\end{tabular}

Categoría El objetivo de la categoría II es minimizar II la actividad humana con el fin de permitir un "estado tan natural como sea posible". La categoría $V$ incluye la posibilidad de interacción humana continuada.

Categoría La categoría III se centra en rasgos III específicos y valores aislados y hace énfasis en la monumentalidad, la singularidad y/o la rareza de rasgos individuales, mientras que éstos no se requieren para las áreas protegidas de categoría $\mathrm{V}$, que abarca paisajes más extensos y múltiples valores.

Categoría La categoría $\mathrm{V}$ está dirigida a la protección IV general de paisajes terrestres y marinos que son valiosos por su biodiversidad, mientras que la categoría IV está dirigida especialmente a la protección de especies y hábitats concretos. Normalmente las áreas protegidas de categoría $\mathrm{V}$ son más extensas que las de categoría IV.

Categoría La categoría VI subraya la necesidad VI de vincular la conservación en áreas naturales a la vez que se apoyan los medios de vida sostenibles: por su parte la categoría $V$ hace énfasis en los valores de las interacciones a largo plazo entre las personas y la naturaleza en condiciones modificadas. En la categoría $\mathrm{VI}$ el énfasis reside en el uso sostenible de los recursos naturales y servicios ambientales (normalmente caza, pesca, pastoreo), mientras que en la categoría $\mathrm{V}$ el énfasis reside en usos más intensivos (normalmente agrícolas, forestales y turísticos). La categoría VI es normalmente más "natural" que la categoría $\mathrm{V}$.

\section{Cuestiones a tener en cuenta}

- Siendo un modelo relativamente flexible, la categoría $\mathrm{V}$ a veces plantea posibilidades de conservación cuando áreas más estrictamente protegidas no son viables.

- El objetivo de las áreas protegidas de categoría V puede ser mantener las prácticas actuales, restaurar sistemas de gestión históricos, o quizás más frecuentemente, mantener valores paisajísticos clave a la vez que se acomoda al desarrollo y los cambios contemporáneos: se deberán tomar decisiones al respecto en los planes de gestión.

- El énfasis en las interacciones entre las personas y la naturaleza a lo largo del tiempo plantea la cuestión conceptual de cada una de las áreas protegidas de categoría $\mathrm{V}$ : ¿en qué punto del continuo temporal debería centrarse la gestión? Y, en un área establecida para proteger los valores basados en los sistemas de gestión tradicionales ¿qué ocurre cuando las tradiciones cambian o se pierden?

- Dado que las consideraciones sociales, económicas y de conservación son parte íntegra del concepto de categoría $\mathrm{V}$, es importante definir medidas de evaluación de la gestión que permitan medir el éxito en la conservación de estos valores.

- Dado que las personas son los guardianes del paisaje terrestre o marino en las áreas de categoría V, son necesarias directrices claras sobre la medida en que la toma de decisiones puede ser dejada en manos de los habitantes locales y en qué medida debe prevalecer el interés público cuando las necesidades locales y nacionales entran en conflicto.

- ¿Cómo se distingue la categoría V de la gestión sostenible del paisaje en general? ¿Cómo un área con valores excepcionales? ¿Cómo un ejemplo de mejores prácticas de gestión? La categoría $\mathrm{V}$ es quizás la que se está desarrollando más rápidamente de entre todos los enfoques de gestión.

- Siguen existiendo pocos ejemplos de la aplicación de la categoría $\mathrm{V}$ en entornos costeros o marinos en las que el enfoque de "paisaje marino protegido" debería ser la opción de gestión más adecuada, por lo que son necesarios más ejemplos de este tipo (ver, por ej., Holdaway, sin fecha). 


\section{Categoría VI: Área protegida con uso sostenible de los recursos naturales}

Las áreas protegidas de categoría VI conservan ecosistemas y hábitats, junto con los valores culturales y los sistemas tradicionales de gestión de recursos naturales asociados a ellos. Normalmente son extensas, con una mayoría del área en condiciones naturales, en las que una parte cuenta con una gestión sostenible de los recursos naturales, y en las que se considera que uno de los objetivos principales del área es el uso no industrial y de bajo nivel de los recursos naturales, compatible con la conservación de la naturaleza.

Antes de seleccionar una categoría se debe comprobar que el espacio cumple la definición de área protegida que se indica en la página 10 .

\section{Objetivo primario}

- Proteger los ecosistemas naturales y usar los recursos naturales de forma sostenible, cuando la conservación y el uso sostenible puedan beneficiarse mutuamente.

\section{Otros objetivos}

- Promover el uso sostenible de los recursos naturales, considerando las dimensiones ecológica, económica y social;

- Promover beneficios sociales y económicos para las comunidades locales cuando sea relevante;

- Facilitar la seguridad intergeneracional de los medios de vida de las comunidades locales - garantizando así que dichos medios de vida son sostenibles;

- Integrar otros enfoques culturales, sistemas de creencias y visiones del mundo dentro de la gama de enfoques sociales y económicos de conservación de la naturaleza;

- Contribuir al desarrollo y/o mantenimiento de una relación más equilibrada entre los seres humanos y el resto de la naturaleza;

- Contribuir al desarrollo sostenible a nivel nacional, regional y local (en este último caso especialmente para las comunidades locales y/o pueblos indígenas que dependen de recursos naturales protegidos);

- Facilitar la investigación científica y el monitoreo ambiental, principalmente en relación con la conservación y el uso sostenible de los recursos naturales;
- Colaborar en la obtención de beneficios para las personas, especialmente las comunidades locales, que viven dentro o en las proximidades del área protegida designada;

- Facilitar los usos recreativos y un turismo adecuado a pequeña escala.

\section{Rasgos distintivos}

- Las áreas protegidas de categoría VI son singulares dentro del sistema de categorías de la UICN, ya que tienen el uso sostenible de los recursos naturales como medio para conseguir la conservación de la naturaleza, junto y en sinergia con otras acciones comunes a otras categorías como la protección.

- El objetivo de las áreas protegidas de categoría VI es conservar ecosistemas y hábitats junto con los valores culturales y sistemas de gestión de recursos naturales asociados a ellos. Por tanto las áreas protegidas de esta categoría tienden a ser de gran extensión (aunque esto no es obligatorio).

- Esta categoría no está diseñada para albergar actividades de recolección a escala industrial.

- En general, la UICN recomienda que una parte del área se mantenga en condiciones naturales, ${ }^{7}$ lo que en algunos casos puede implicar su definición como una zona vedada o de protección más estricta. Algunos países han establecido este umbral de zonas en condiciones naturales en dos tercios de la extensión total del área protegida; la UICN recomienda que las decisiones se tomen a nivel nacional y a veces incluso para cada una de las áreas protegidas.

\section{Papel en el paisaje terrestre/marino}

- Las áreas protegidas de categoría VI están especialmente adaptadas a la aplicación de enfoques de paisaje.

- Esta es una categoría adecuada para grandes áreas naturales como los bosques tropicales, los desiertos y otras tierras áridas, los sistemas complejos de humedales, aguas costeras y de alta mar, bosques boreales, etc. - no solo por el establecimiento de grandes áreas protegidas en sí, sino también a través de vincular grupos de áreas protegidas, corredores biológicos o redes ecológicas.

- Las áreas protegidas de categoría VI también pueden ser especialmente adecuadas para la conservación de ecosistemas naturales cuando no existen o hay pocas áreas sin ocupación o uso, y cuando dicha ocupación o uso consiste en prácticas tradicionales y de bajo impacto que no han afectado sustancialmente al estado natural del ecosistema.

Téngase en cuenta que esto no excluye necesariamente actividades de bajo nivel como la recolección de productos forestales no madereros. 


\section{¿Qué hace que la categoría VI sea única?}

La adjudicación de la categoría VI depende de los objetivos de gestión a largo plazo y también de las características locales concretas. La siguiente tabla muestra algunas de las razones por las que puede elegirse la categoría VI en situaciones concretas frente a otras categorías.

\begin{tabular}{|c|c|}
\hline \multicolumn{2}{|c|}{$\begin{array}{l}\text { La categoría VI difiere de las demás categorías por } \\
\text { las siguientes razones: }\end{array}$} \\
\hline $\begin{array}{l}\text { Categoría } \\
\text { la }\end{array}$ & $\begin{array}{l}\text { Las áreas protegidas de categoría } \\
\text { VI conservan la biodiversidad, } \\
\text { especialmente a escala de ecosistema } \\
\text { y de paisaje, pero el objetivo no sería } \\
\text { protegerlas estrictamente frente a } \\
\text { la interferencia humana. Aunque la } \\
\text { investigación científica puede ser } \\
\text { importante, sería considerada como } \\
\text { una prioridad sólo cuando se centrase } \\
\text { en los usos sostenibles de los recursos } \\
\text { naturales, ya sea para mejorarlos o para } \\
\text { entender cómo minimizar los riesgos para } \\
\text { la sostenibilidad ecológica. }\end{array}$ \\
\hline $\begin{array}{l}\text { Categoría } \\
\text { lb }\end{array}$ & $\begin{array}{l}\text { En ciertos casos las áreas protegidas de } \\
\text { categoría VI podrían ser consideradas } \\
\text { como próximas al concepto de "silvestre", } \\
\text { sin embargo, promueven explícitamente el } \\
\text { uso de los recursos naturales, a diferencia } \\
\text { de la situación de las áreas silvestres } \\
\text { de categoría lb en las que dichos usos } \\
\text { son mínimos y siempre secundarios a } \\
\text { los objetivos de conservación. También } \\
\text { contribuyen al mantenimiento de los } \\
\text { servicios del ecosistema, pero no } \\
\text { exclusivamente por la conservación de } \\
\text { la naturaleza, ya que el uso sostenible } \\
\text { de los recursos naturales puede } \\
\text { también contribuir a la protección de los } \\
\text { ecosistemas, de grandes hábitats y de los } \\
\text { procesos ecológicos. }\end{array}$ \\
\hline $\begin{array}{l}\text { Categoría } \\
\text { II }\end{array}$ & $\begin{array}{l}\text { El objetivo de las áreas protegidas de } \\
\text { categoría VI es conservar ecosistemas } \\
\text { y hábitats, tan completos y funcionales } \\
\text { como sea posible, así como sus especies, } \\
\text { diversidad genética y los servicios } \\
\text { ambientales asociados a los mismos, } \\
\text { pero difieren de la categoría II en el papel } \\
\text { que juegan en la promoción del uso } \\
\text { sostenible de los recursos naturales. El } \\
\text { turismo puede desarrollarse en las áreas } \\
\text { protegidas de categoría VI pero sólo como } \\
\text { actividad muy secundaria o cuando forme } \\
\text { parte de las estrategias socioeconómicas } \\
\text { de las comunidades locales (por ej., en } \\
\text { relación al desarrollo del ecoturismo). }\end{array}$ \\
\hline
\end{tabular}

\begin{tabular}{|c|c|}
\hline $\begin{array}{l}\text { Categoría } \\
\text { III }\end{array}$ & $\begin{array}{l}\text { Las áreas protegidas de categoría VI } \\
\text { pueden incluir la protección de rasgos } \\
\text { naturales o culturales concretos, } \\
\text { incluyendo las especies y la diversidad } \\
\text { genética, entre sus objetivos, siempre } \\
\text { que el uso sostenible de los recursos } \\
\text { naturales sea parte de sus objetivos, } \\
\text { pero están más orientadas a la } \\
\text { protección de ecosistemas y procesos } \\
\text { ecológicos y al mantenimiento de los } \\
\text { servicios medioambientales mediante la } \\
\text { protección de la naturaleza y el fomento } \\
\text { de enfoques de gestión que conduzcan } \\
\text { al uso sostenible de los recursos } \\
\text { naturales. }\end{array}$ \\
\hline $\begin{array}{l}\text { Categoría } \\
\text { IV }\end{array}$ & $\begin{array}{l}\text { Las áreas protegidas de categoría VI } \\
\text { están orientadas a la protección de } \\
\text { ecosistemas y procesos ecológicos } \\
\text { y al mantenimiento de los servicios } \\
\text { medioambientales mediante la } \\
\text { protección de la naturaleza y el fomento } \\
\text { del uso sostenible de los recursos } \\
\text { naturales. Mientras que las áreas } \\
\text { protegidas de categoría IV tienden a } \\
\text { priorizar la gestión activa, la categoría } \\
\text { VI promueve el uso sostenible de los } \\
\text { recursos naturales. }\end{array}$ \\
\hline $\begin{array}{l}\text { Categoría } \\
\text { V }\end{array}$ & $\begin{array}{l}\text { La categoría } \vee \text { se aplica a áreas en las } \\
\text { que los paisajes se han transformado } \\
\text { como resultado de una larga interacción } \\
\text { con los seres humanos; las áreas de } \\
\text { categoría VI siguen siendo ecosistemas } \\
\text { naturales predominantemente. El énfasis } \\
\text { de la categoría VI reside por tanto en la } \\
\text { protección de los ecosistemas naturales } \\
\text { y los procesos ecológicos mediante la } \\
\text { protección de la naturaleza y el fomento } \\
\text { del uso sostenible de los recursos } \\
\text { naturales. }\end{array}$ \\
\hline
\end{tabular}

\section{Cuestiones a tener en cuenta}

- La protección de los ecosistemas naturales y el fomento del uso sostenible tienen que estar integradas y beneficiarse mutuamente; la categoría VI puede potencialmente demostrar las mejores prácticas de gestión que pueden ser utilizadas más ampliamente.

- Es necesario que las autoridades de gestión desarrollen nuevas capacidades y herramientas para abordar los nuevos retos que surgen de la planificación, monitoreo y gestión de las áreas protegidas de usos sostenibles. 
- Es también necesario desarrollar formas de gobernanza adecuadas para las áreas protegidas de categoría VI en las que a menudo existe una multitud de actores implicados. La conservación a escala de paisaje afecta inevitablemente a un grupo de agentes muy diversos, y requiere acuerdos institucionales delicados y enfoques innovadores de gobernanza.

\section{Relación entre las categorías}

- Las categorías no implican una jerarquía simple en términos de calidad, importancia y naturalidad

- Tampoco son las categorías necesariamente iguales en todas las situaciones, sino que deberían ser seleccionadas para maximizar las posibilidades de conservación y también abordar las amenazas a la conservación

Las categorías no implican una jerarquía simple, ni en términos de calidad o importancia ni de otra forma - por ejemplo el grado de intervención o naturalidad. Sin embargo, todas las categorías tampoco son iguales en el sentido de que sean igualmente útiles en cualquier situación. Uno de los principios asociados a la definición de área protegida es que: "Todas las categorías realizan su contribución a la conservación, pero los objetivos deben ser seleccionados en función de cada situación concreta; no todas las categorías son igualmente útiles en todas las situaciones".

Esto significa que un sistema de áreas protegidas bien equilibrado debería considerar la utilización de todas las categorías, aunque puede darse el caso de que no todas las opciones sean necesarias o prácticas en todas las regiones o países. En la gran mayoría de las situaciones al menos parte de las áreas protegidas deberían estar en las categorías más estrictas, es decir I-IV. La selección de la categoría a menudo supone un reto y debería estar orientada por las necesidades y la urgencia de la conservación de la biodiversidad, las posibilidades de prestación de servicios de ecosistema, las necesidades, deseos y creencias de las comunidades humanas, la estructura de propiedad del suelo, la fuerza de la gobernanza y los niveles de población. Las decisiones relativas a las áreas protegidas normalmente tendrán que sopesar una cierta cantidad de ventajas e inconvenientes resultantes de usos de la tierra que compitan entre si y de los resultados de los procesos de consulta. Es importante dedicar la suficiente atención y ponderación a los objetivos de conservación en los correspondientes procesos de toma de decisiones.

Los enfoques de gestión y las categorías no son necesariamente inmutables en el tiempo y pueden cambiar si cambian las condiciones o si se percibe que un enfoque es erróneo; sin embargo, el cambio de categoría de un área protegida debería estar sujeto a procedimientos que sean al menos tan rigurosos como los empleados en el primer momento en que se establece el área protegida y que se asigna a una determinada categoría.

Mucha gente da por hecho que las categorías implican una gradación de la naturalidad de acuerdo con el orden de I a VI pero la realidad es más compleja tal como se muestra en la Figura 1 a continuación, que intenta comparar la naturalidad media de todas las categorías.

\section{Figura 1. Naturalidad y categorías de áreas protegidas de la UICN}

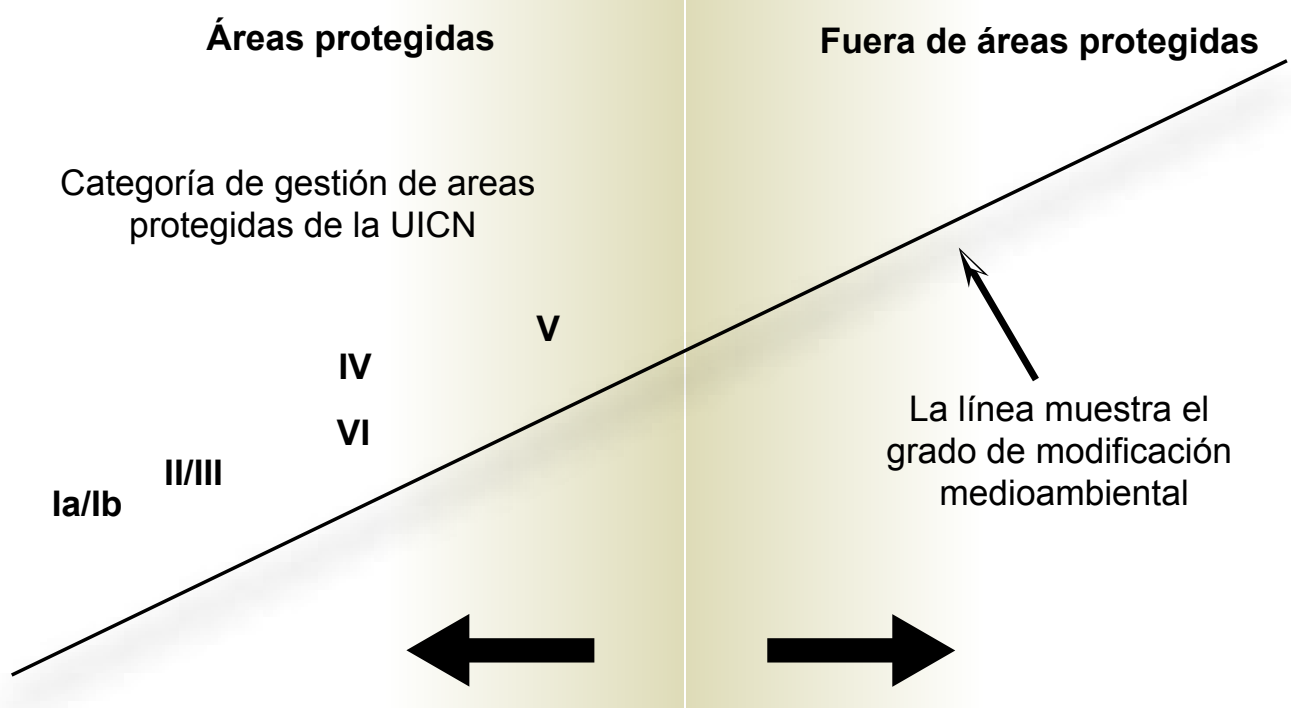

Condiciones más naturales

Condiciones menos naturales 



\section{Gobernanza}

Las categorías no dependen de quién sea el propietario de las áreas protegidas, de quién las controle, o de quién tenga la responsabilidad de su gestión. De todos modos, la gobernanza es muy importante. La UICN ha identificado distintos tipos de gobernanza con el objeto de ayudar en la comprensión, la planificación y el registro de áreas protegidas. Esta sección identifica los tipos de gobernanza de la UICN, explica de qué modo están vinculados a las categorías y analiza cómo la gobernanza por parte de pueblos indígenas, comunidades y empresas privadas puede contribuir con los sistemas de áreas protegidas. 


\section{Gobernanza de áreas protegidas}

La UICN reconoce cuatro grandes tipos de gobernanza de áreas protegidas, cualquiera de los cuales puede asociarse con cualquier objetivo de gestión:

A. Gobernanza por parte del gobierno

B. Gobernanza compartida

C. Gobernanza privada

D. Gobernanza por parte de pueblos indígenas y comunidades locales

Las definiciones de área protegida y categorías de gestión de la UICN son "neutrales" en cuanto a la propiedad o la autoridad administrativa. En otras palabras, la tierra, el agua y los recursos naturales en cualquier categoría de gestión pueden ser de propiedad de, y/o ser gestionadas directamente por agencias gubernamentales, ONGs, comunidades, pueblos indígenas y empresas privadas - por sí solas o conjuntamente. Tanto la UICN como el CDB reconocen la legitimidad de un abanico de tipos de gobernanza. La UICN diferencia cuatro amplios tipos de gobernanza de áreas protegidas, en función de en quién recaiga la toma de decisiones y la autoridad administrativa y la responsabilidad acerca de las áreas protegidas.

Tipo A: Gobernanza por parte del gobierno (a nivel de gobierno central/estatal/subnacional o municipal). Una oficina del gobierno (como puede ser un ministerio o una agencia de parques que responde directamente al gobierno) posee la autoridad, la responsabilidad y la obligación de rendir cuentas sobre la gestión del área protegida, determina sus objetivos de conservación (del mismo modo que son definidos en las categorías de la UICN), desarrolla y aplica su plan de gestión y normalmente también es propietaria de las tierras, del agua y de los recursos relacionados dentro del área protegida. Otras agencias subnacionales y municipales también pueden estar a cargo de lo mencionado anteriormente y/o poseer tierras y recursos en áreas protegidas. En algunos casos, el gobierno posee el control del área protegida - en otras palabras, define los objetivos de gestión del área - pero delega la planificación y/o tareas administrativas diarias a una organización paraestatal, ONG, empresa privada o comunidad. Dentro del marco legal y de gobernanza estatal puede existir, o no, una obligación legal de informar o consultar a los agentes implicados antes de establecer áreas protegidas y hacer o aplicar decisiones administrativas. De todas formas, cada vez son más comunes y generalmente más convenientes los enfoques participativos. Los niveles de responsabilidades también pueden variar en función del país.

Tipo B: Gobernanza compartida. Para compartir (formal e informalmente) la autoridad administrativa y la responsabilidad entre varias partes gubernamentales y no gubernamentales se emplean complejos mecanismos y procesos institucionales. La gobernanza compartida, o cogestión, puede ser de muchas formas. En una gestión "colaborativa” es una agencia la que tiene el poder de toma de decisiones y la responsabilidad, pero se requiere - por ley o norma - que esta agencia informe o consulte a los demás agentes implicados. Se puede reforzar la participación en una gestión colaborativa asignando a grupos de varios agentes implicados la responsabilidad de desarrollar propuestas técnicas para la regulación y gestión del área protegida, que serán finalmente remitidas a la autoridad de toma de decisiones para su aprobación. En una gestión "conjunta", varias partes forman el consejo de gobierno con autoridad de toma de decisiones y responsabilidad. Es posible que las decisiones requieran consenso. En cualquier caso, una vez que se toman decisiones de gestión, su aplicación tiene que delegarse en organismos o personas previamente consensuados. Una forma particular de gobernanza compartida es la de las áreas protegidas transfronterizas, en las que intervienen por lo menos a dos gobiernos y posiblemente otros organismos locales.

Tipo C: Gobernanza privada. La gobernanza privada comprende áreas protegidas bajo el control y/o propiedad de personas, cooperativas, ONGs o corporaciones, gestionadas con o sin ánimo de lucro. Ejemplos típicos son las áreas adquiridas por ONGs explícitamente para su conservación. Muchos propietarios de tierras también persiguen la conservación por su respeto hacia el campo y su deseo de mantener sus valores estéticos y ecológicos. Los planes de incentivos, como los ingresos por ecoturismo y la caza, o la reducción de tasas e impuestos a menudo también apoyan este tipo de gobernanza. En todos estos casos la autoridad de gestión del área protegida y los recursos recae en los dueños, que determinan los objetivos de conservación, desarrollan y aplican planes de gestión y mantienen el poder de decisión, sujetos a la legislación vigente. Las responsabilidades de las áreas protegidas privadas pueden verse limitadas de cara a la sociedad, en casos en los que no existe un reconocimiento oficial por parte del gobierno. Algunas responsabilidades referentes a la seguridad a largo plazo, por ejemplo, se pueden negociar con el gobierno a cambio de incentivos específicos (como en el caso de Servidumbres o Fideicomisos de Tierras).

Tipo D: Gobernanza por parte de pueblos indígenas y comunidades locales. Este tipo incluye dos grandes grupos: (1) áreas y territorios de pueblos indígenas, establecidas y gestionadas por ellos y (2) áreas conservadas por comunidades, establecidas y gestionadas por comunidades locales. Ambos grupos, que pueden resultar difíciles de separar, se refieren a pueblos y comunidades tanto sedentarias como móviles. La UICN define este tipo de gobernanza como áreas protegidas donde la autoridad administrativa y la responsabilidad recaen en los pueblos indigenas y/o comunidades locales bajo diversas formas de instituciones $y$ normas, consuetudinarias o legales, formales o informales. Éstas pueden resultar bastante complejas. Por ejemplo los recursos terrestres y/o marinos pueden ser propiedad y ser gestionados 
por el colectivo, mientras que otros recursos pueden ser gestionados individualmente o por clanes. Distintos pueblos indígenas o comunidades pueden estar a cargo de la misma área en distintos periodos temporales, o de distintos recursos dentro de la misma área. Las normas generalmente se entrelazan con los aspectos culturales y espirituales. Las normas y organizaciones tradicionales que gestionan los recursos naturales a menudo carecen del reconocimiento legal estatutario o poder de sanción. En otros casos, sin embargo, los pueblos indígenas y/o comunidades locales están totalmente reconocidos como la autoridad legítima a cargo de áreas protegidas identificadas por el gobierno o poseen el título legal de la tierra, el agua y los recursos. Independientemente de la estructura, las disposiciones de gobernanza requieren que el área bajo control de pueblos indígenas y/o comunidades locales tenga instituciones y regulaciones identificables, responsables de alcanzar los objetivos del área protegida.

Los cuatro tipos de gobernanza descritos anteriormente se tienen en consideración conjuntamente con las categorías de gestión en la siguiente matriz (adaptación de Borrini-Feyerabend et al. 2004).
Téngase en cuenta que los tipos de gobernanza describen los distintos tipos de autoridad administrativa y responsabilidad que pueden existir en áreas protegidas, pero no hacen una referencia especial a la propiedad. En algunos tipos de gobernanza - por ej., áreas protegidas estatales y privadas - la gobernanza y el propietario a menudo coinciden. Pero en otros casos esto dependerá de la legislación de cada país: por ej., muchas áreas protegidas por pueblos indígenas y áreas conservadas por comunidades se encuentran en tierras de propiedad del estado. En áreas protegidas extensas y complejas, particularmente en las categorías $\mathrm{V}$ y VI, puede haber múltiples tipos de gobernanza dentro del entorno de un área protegida, posiblemente bajo el paraguas de una autoridad supervisora. En el caso de la mayoría de las áreas protegidas marinas la propiedad será del estado, que administrará directamente o delegará su gestión a comunidades, ONGs u otros. Existen, de todas formas, muchas áreas marinas donde las leyes tradicionales de los pueblos indígenas son reconocidas y respetadas por la sociedad. En aguas internacionales y en el Antártico, donde no hay una autoridad estatal, las áreas protegidas tienen que estar inevitablemente bajo un tipo de gobernanza compartida.

Tabla 3. "La matriz de área protegida de la UICN": un sistema de clasificación de áreas protegidas que comprende tanto la categoría de gestión como el tipo de gobernanza

\begin{tabular}{|c|c|c|c|c|c|c|c|c|c|c|c|}
\hline \multirow{2}{*}{$\begin{array}{l}\text { Tipos de } \\
\text { gobernanza } \\
\text { Categorías de áreas } \\
\text { protegidas }\end{array}$} & \multicolumn{3}{|c|}{$\begin{array}{l}\text { A. Gobernanza } \\
\text { por parte del } \\
\text { gobierno }\end{array}$} & \multicolumn{3}{|c|}{$\begin{array}{l}\text { B. Gobernanza } \\
\text { compartida }\end{array}$} & \multicolumn{3}{|c|}{$\begin{array}{l}\text { C. Gobernanza } \\
\text { privada }\end{array}$} & \multicolumn{2}{|c|}{$\begin{array}{l}\text { D. Gobernanza por } \\
\text { parte de pueblos } \\
\text { indígenas y } \\
\text { comunidades locales }\end{array}$} \\
\hline & 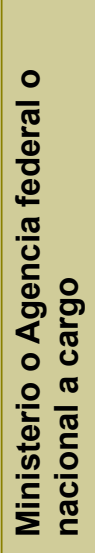 & 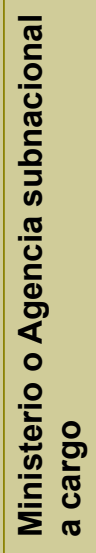 & 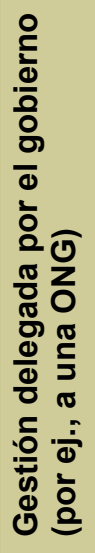 & 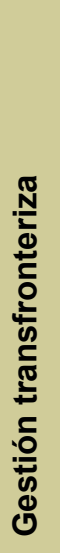 & 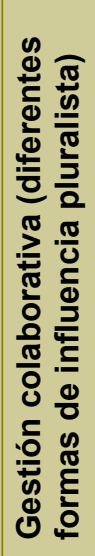 & 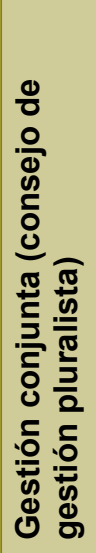 & 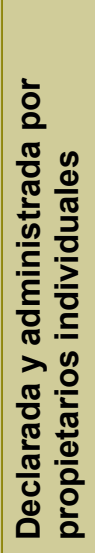 & 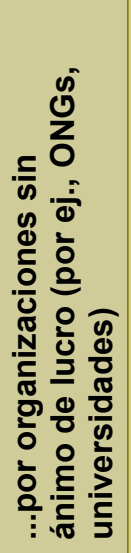 & 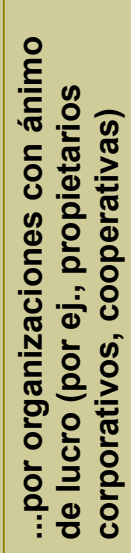 & 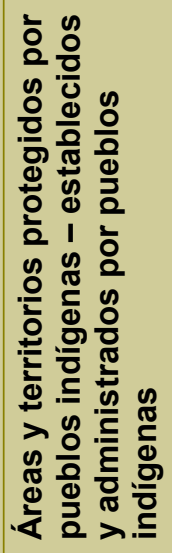 & 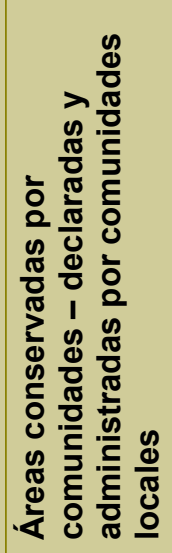 \\
\hline \multicolumn{12}{|l|}{$\begin{array}{l}\text { la. Reserva natural } \\
\text { estricta }\end{array}$} \\
\hline \multicolumn{12}{|l|}{ Ib. Área natural silvestre } \\
\hline \multicolumn{12}{|l|}{ II. Parque nacional } \\
\hline \multicolumn{12}{|l|}{ III. Monumento natural } \\
\hline \multicolumn{12}{|l|}{$\begin{array}{l}\text { IV. Area de gestión de } \\
\text { hábitats/especies }\end{array}$} \\
\hline \multicolumn{12}{|l|}{$\begin{array}{l}\text { V. Paisaje terrestre/ } \\
\text { marino protegido }\end{array}$} \\
\hline $\begin{array}{l}\text { VI. Área protegida } \\
\text { con uso sostenible de } \\
\text { recursos naturales }\end{array}$ & & & & & & & & & & & \\
\hline
\end{tabular}




\section{Registro de tipos de gobernanza}

La UICN sugiere que el tipo de gobernanza de un área protegida sea identificado y registrado al mismo tiempo que su objetivo de gestión (categoría) en estadísticas medioambientales nacionales y sistemas contables y en las bases de datos de áreas protegidas. En algunos casos puede ser tan delicado y complejo o más decidir el tipo de gobernanza que identificar la categoría y uno de ellos puede modificar e influir al otro; así mismo, muchas áreas protegidas tienden a cambiar su tipo de gobernanza con el paso del tiempo. Según se ha mencionado, en el caso de áreas protegidas muy extensas, pueden existir varios tipos de gobernanza dentro de los límites de una única área protegida.

Al considerar la gobernanza con objetivo de informar a la Base de Datos Mundial de Áreas Protegidas (WDPA según sus siglas en inglés), la UICN CMAP propone adoptar una estructura bidimensional. Aunque se pueden desarrollar y asignar los objetivos de gestión para las categorías sin tener en cuenta la gobernanza, la comparación de las áreas protegidas y de su efectividad mejorará enormemente al registrar en bases de datos futuras el tipo de gobernanza además de la categoría de gestión. Las categorías de áreas protegidas no son taxonómicas, al contrario que los tipos de gobernanza; de todos modos, una clasificación bidimensional puede fácilmente ordenar las áreas por objetivos de gestión (por ej., Categoría I-VI) y por tipo de gobernanza (por ej., A-D, según se han descrito anteriormente). Usando esta designación de letras, por ej., El Parque Nacional de Yellowstone (EEUU) se puede describir como categoría II-A; el Santuario de Vida Salvaje Mornington (Australia) puede ser II-C; el Parque Nacional Snowdonia (Reino Unido) V-B; y la Isla Coron (Filipinas) como una combinación de I-D y V-D.

\section{Calidad de la gobernanza}

Para las áreas protegidas en todas las categorías de gestión, la efectividad de la gestión proporciona una medida del avance real de las metas de conservación. La efectividad de la gestión también se ve influenciada por la calidad de la gobernanza, esto es, "hasta qué punto" un régimen de gobernanza está funcionando. En otras palabras, el concepto de calidad de gobernanza aplicado a cualquier situación específica pretende proporcionar respuestas a preguntas del tipo “¿Es esta una 'buena’ gobernanza?” y “伊uede este escenario de gobernanza ser 'mejorado' para lograr los beneficios en términos de la conservación y de sustento?"

"La buena gobernanza de un área protegida" se puede entender como "un sistema de gobernanza que responde a los principios y valores escogidos libremente por las personas de un país y reflejados en su constitución, ley de recursos naturales, legislación y normas de áreas protegidas y prácticas culturales y leyes tradicionales”. Estos principios y valores deberían reflejar principios acordados internacionalmente para la buena gobernanza (por ej., Graham et al. 2003). Distintos acuerdos y herramientas internacionales han establecido diversos principios y valores de gobernanza, tales como el CDB, la Convención de Aarhus, la
Convención de las Naciones Unidas de Lucha Contra la Desertificación, la Declaración Universal de los Derechos Humanos y la Declaración de las Naciones Unidas sobre los Derechos de los Pueblos Indígenas. Varios procesos regionales e internacionales han sido también cruciales para la elaboración de esta agenda, incluyendo el Congreso Mundial de Parques de 2003 en Sudáfrica, el Primer Congreso de Áreas Marinas Protegidas de 2003 en Australia y el Segundo Congreso Latinoamericano de Áreas Protegidas de 2007 en Argentina. Como conclusión de éstos y su experiencia de campo, la UICN ha explorado una serie de amplios principios para la buena gobernanza de áreas protegidas, incluyendo:

- Legitimidad y voz - diálogo social y acuerdos colectivos sobre los objetivos y estrategias de gestión de áreas protegidas sobre la base de libertad de asociación y expresión sin discriminación en función de género, etnia, modos de vida, valores culturales u otras características;

- Subsidiariedad - atribuir autoridad de gestión y responsabilidad a las instituciones más cercanas a los recursos en concreto;

- Equidad - compartir equitativamente los costes y beneficios de establecer y administrar áreas protegidas y proporcionar un medio de juicio imparcial en caso de conflicto relacionado;

- No hacer daño - asegurar que los costes de establecer y gestionar áreas protegidas no creen o agraven la pobreza y la vulnerabilidad;

- Dirección - fomentar y mantener una visión a largo plazo inspiradora y consistente del área protegida y sus objetivos de conservación;

- Rendimiento - conservar eficazmente la biodiversidad a la vez que responder a las preocupaciones de los grupos de interés y realizar un uso inteligente de los recursos;

- Rendición de cuentas - tener claras líneas de responsabilidad y asegurar la información y comunicación adecuadas de todos los grupos implicados acerca del cumplimiento de sus responsabilidades;

- Transparencia - asegurar que toda la información relevante esté disponible para los grupos implicados;

- Derechos humanos - respetar los derechos humanos en el contexto de la gobernanza de las áreas protegidas, incluidos los derechos de las generaciones futuras.

La gobernanza por parte de pueblos indígenas y comunidades locales y la gobernanza privada se discuten en mayor detalle a continuación.

\section{Gobernanza por parte de pueblos indígenas y comunidades locales}

Nota acerca de la terminología: los conceptos de gobernanza por parte de pueblos indígenas y comunidades locales todavía están desarrollándose y difieren a través del mundo. Algunos pueblos 
indígenas desean ver sus territorios claramente diferenciados de aquellos de las comunidades locales. En otros casos, los pueblos indígenas y comunidades locales cohabitan o cogestionan áreas, y en algunas situaciones los pueblos indígenas emplean el término “áreas conservadas por comunidades" por razones prácticas, por ejemplo cuando el término "indígena” no está reconocido. Existen diferencias similares respecto al término "territorio". Entre los pueblos indígenas y las comunidades locales hay casos en los que se usa el término "área conservada" y otros en los que se ha preferido "área protegida"; se usa un abanico de términos similares en este aspecto. La sección que sigue presenta un sumario de los conceptos e incluye una descripción de los territorios y las áreas protegidas de los pueblos indígenas.

Aunque algunas de las áreas protegidas gobernadas por los pueblos indígenas y las comunidades locales han existido durante cientos e incluso miles de años, su reconocimiento por los gobiernos y su inclusión en los sistemas nacionales de áreas protegidas es un fenómeno mucho más reciente, que merece una atención especial. Las áreas protegidas de los pueblos indígenas, los territorios conservados por pueblos indígenas y las áreas conservadas por comunidades (conjuntamente denominados en inglés Indigenous and community conserved areas, ICCAs) tienen tres características esenciales:

- Los pueblos indígenas pertinentes y las comunidades locales tienen intereses directos en los ecosistemas con los que se relacionan - y a los que normalmente están vinculados por razones culturales (por ej., por su valor como áreas sagradas) y/o porque éstos sostienen sus medios de vida y/o porque son sus territorios tradicionales según sus leyes consuetudinarias.

- Estos pueblos indígenas y/o comunidades locales son los principales agentes ("tienen el poder") para tomar decisiones y aplicarlas a la gestión de los ecosistemas en cuestión, lo cual implica que ellos poseen instituciones habilitadas para ejercer la autoridad y la responsabilidad y capaces de aplicar la normativa.

- Las decisiones y esfuerzos de gestión de los pueblos indígenas y/o comunidades locales conducen y contribuyen a la conservación de hábitats, especies, funciones ecológicas y valores culturales asociados, aunque la intención original puede haber estado relacionada con una variedad de objetivos, no necesariamente en relación directa con la protección de la biodiversidad.

Existe evidencia creciente de que las ICCAs que cumplen con la definición y los estándares de un área protegida pueden favorecer la conservación efectiva de la biodiversidad y alcanzar cualquiera de los objetivos de gestión de las categorías de la UICN, y ello en particular en lugares donde es imposible implementar, política o socialmente, áreas protegidas administradas por el gobierno, que probablemente sean gestionadas pobremente. Las ICCAs están comenzando a ser reconocidas como parte de las estrategias de planificación de la conservación, de modo complementario a las áreas protegidas gestionadas por los gobiernos, las áreas protegidas privadas y las diferentes formas de gobernanza compartida (véase http://www.iccaforum.org/). Pero esto es todavía más la excepción que la norma.

En la actualidad, la mayoría de las ICCAs no están reconocidas, protegidas o siquiera valoradas formalmente como parte de los sistemas nacionales de áreas protegidas. En algunos casos puede haber buenas razones para esto - incluida la renuencia de los pueblos indígenas o las comunidades locales relacionadas a darse a conocer o a ser molestados, por ejemplo cuando el lugar tiene valores sagrados que requieren privacidad o cuando los pueblos indígenas pertinentes prefieren gestionar sus tierras según sus leyes tradicionales únicamente. A medida que los países tienden a otorgar mayor reconocimiento a las ICCAs, es necesario tener en mente estas sensibilidades. Dependiendo de la situación específica y las principales preocupaciones de los pueblos indígenas o las comunidades locales relevantes, los planteamientos apropiados del gobierno pueden variar entre la incorporación de la ICCA en el sistema nacional de áreas protegidas, el reconocimiento "fuera del sistema", y el no reconocimiento formal de ningún tipo. Esta última opción, por supuesto, debería seleccionarse cuando el reconocimiento formal pueda minar o perturbar las ICCAs en cuestión.

La mayoría de las ICCAs se enfrentan a tremendas fuerzas de cambio, a las que pueden hacer frente mejor con la ayuda de reconocimiento y apreciación oficiales, especialmente cuando la alternativa más probable puede ser la explotación, por ej., para madera o turismo. En estos casos el reconocimiento dentro del sistema nacional de áreas protegidas, si las ICCAs cumplen con la definición y los estándares de un área protegida, u otros tipos de reconocimiento oficial, pueden proporcionar a los pueblos indígenas y comunidades locales ciertas garantías adicionales sobre sus tierras. De todas formas, esto debe emparejarse con la aceptación por parte del estado de que las ICCAs son inherentemente distintos de las áreas protegidas administradas por el gobierno - en particular respecto a sus instituciones de gobierno. Es necesario aclarar que el reconocimiento oficial de las ICCAs puede acarrear nuevos peligros, como el aumento del turismo e intereses comerciales en el lugar, o una interferencia mayor del gobierno. Los pueblos indígenas y las comunidades locales también temen que el reconocimiento oficial los pueda co-optar dentro de sistemas mayores sobre los cuales ellos no tienen ningún control.

Aunque existe un creciente reconocimiento del papel positivo que las ICCAs pueden realizar para mantener la biodiversidad, también existe la preocupación en la comunidad de conservación de que ICCAs "débiles" puedan ser incluidas en sistemas nacionales de áreas protegidas como alternativas más baratas y "políticamente convenientes" frente a otras opciones de conservación. También existen preocupaciones de que, a medida que cambian las sociedades, los enfoques de gestión por parte de la comunidad también puedan cambiar y algunos de 
los valores tradicionales y atributos que ayudaban a conservar la biodiversidad puedan perderse en el proceso. Las ICCAs reconocidas que no sean capaces de mantener sus prácticas de conservación tradicionales serían peores que las ICCAs no oficiales o reconocidas.

En última instancia, y teniendo en cuenta todos los asuntos cautelares mencionados anteriormente, el reconocimiento de las ICCAs que cumplen totalmente con la definición y los estándares de un área protegida, en las estrategias nacionales y regionales de áreas protegidas es uno de los más importantes desarrollos contemporáneos en conservación. Ya se han publicado algunas reflexiones sobre los criterios para el reconocimiento (Borrini-Feyerabend et al. 2004) y se esperan desarrollos adicionales como parte de la serie de la UICN/ CMAP Guía de Mejores Prácticas para las Áreas Protegidas.

\section{Territorios y áreas protegidas de los pueblos indígenas}

Especialmente en regiones como América Latina, Norte América, Oceanía, África, Asia y el Ártico, muchas áreas protegidas designadas formalmente son al mismo tiempo las tierras y aguas ancestrales de pueblos culturas y comunidades indígenas. La UICN desde hace tiempo ha adoptado y promovido políticas de áreas protegidas que respetan los derechos e intereses de los pueblos indígenas y ha desarrollado herramientas y enfoques para facilitar su reconocimiento e implementación.

En concordancia con sus políticas, la UICN aplica los siguientes principios de buena gobernanza en relación con áreas protegidas que se sobreponen con las tierras, aguas y recursos tradicionales de los pueblos indígenas:

- Las áreas protegidas establecidas en tierras, territorios y recursos indígenas deben respetar los derechos de los propietarios, guardianes o usuarios tradicionales de esas tierras, territorios y recursos;

- La gestión de las áreas protegidas también debe respetar las instituciones y leyes tradicionales de los pueblos indígenas;

- Por ello, las áreas protegidas deben reconocer a los propietarios o guardianes indígenas como los poseedores de los poderes estatutarios en sus áreas y por consiguiente respetar y reforzar el ejercicio de la autoridad y el control por parte de los pueblos indígenas en dichas áreas.

En los últimos años ha habido muchos desarrollos importantes en relación con las áreas protegidas que se sobreponen con tierras, aguas y recursos de los pueblos indígenas. Primero, la UICN en sus Congresos Mundiales de la Naturaleza ha adoptado políticas específicas sobre las áreas protegidas y los derechos de los pueblos indígenas. En segundo lugar, a nivel nacional, muchos países han adoptado y aplicado nuevos marcos legales y políticos relevantes para los derechos de los pueblos indígenas, con implicaciones importantes para las áreas protegidas. A nivel internacional se han adoptado varios instrumentos como el Programa de Trabajo para Áreas Protegidas del CDB, así como la Declaración de las Naciones Unidas sobre los Derechos de los Pueblos Indígenas, que han cambiado significativamente el paisaje político referente a los pueblos indígenas y las áreas protegidas.

Siguiendo estos desarrollos políticos, ha habido cambios importantes en el terreno. Muchas áreas protegidas declaradas estatalmente que se sobreponían con tierras, aguas y recursos de los pueblos indígenas han sido incluidas en arreglos de gobernanza compartida y han evolucionado hacia formas de en gestión propia por los pueblos indígenas. En países como Canadá, Australia, Nueva Zelandia, y varios países de América Latina se han creado muchas nuevas áreas protegidas por petición e iniciativa de los propietarios indígenas, o por medio de disposiciones conjuntas con los gobiernos. En estos casos, los derechos indígenas sobre las tierras y los recursos, así como el gobierno indígena del territorio, han sido factores clave.

Muchos pueblos indígenas ven las áreas protegidas como una herramienta muy útil, ya que ellas pueden reforzar la protección de sus territorios, tierras y recursos contra amenazas externas, ofrecer nuevas oportunidades para un uso sostenible, reforzar la protección de lugares críticos a través de formas basadas en la cultura, y consolidar instituciones indígenas para la gestión de la tierra. En estas condiciones, las áreas protegidas por pueblos indígenas suponen un fenómeno creciente e importante, y que es probable que aumente por todo el mundo.

No todas las tierras,,territorios y recursos indígenas se adaptan completamente a la definición de área protegida, pero algunas ciertamente sí encajan y pueden ser consideradas como "áreas protegidas". De esta forma, las áreas protegidas de los pueblos indígenas pueden definirse como:

"espacios geográficos claramente definidos, dentro de las tierras y aguas tradicionalmente ocupadas y usadas por un pueblo, nación o comunidad indígena dada, que son voluntariamente dedicadas y gestionadas, mediante medios legales $u$ otros medios efectivos incluidas sus leyes e instituciones tradicionales, para lograr la conservación a largo plazo de la naturaleza con los servicios de los ecosistemas asociados, así como la protección de las comunidades que las habitan y su cultura, medios de vidas y creaciones culturales". 
Las principales características distintivas de las áreas protegidas de los pueblos indígenas tienen que ver con las disposiciones socio-políticas establecidas entre los pueblos indígenas y las autoridades nacionales para el gobierno de las tierras y recursos en las tierras de los pueblos indígenas. Básicamente estas características son:

1. Están basadas en los derechos colectivos de los pueblos, nación o comunidad indígena respectiva sobre las tierras, territorios y recursos, bajo contextos nacionales;

2. Están establecidas como áreas protegidas en aplicación del derecho de autodeterminación, ejercido principalmente de las siguientes maneras:

- Autodeclaración del área protegida por el pueblo o nación indígena con derechos territoriales colectivos sobre el área;

- Consentimiento libre, informado y previo del pueblo, nación o comunidad con derechos territoriales sobre el área, en casos en los que la propuesta de designación se origina en agencias gubernamentales, organizaciones para la conservación u otras entidades;

3. Se basan en la ocupación ancestral o tradicional;

4. La ocupación, uso y gestión están conectadas a, y dependen de la estructura socio-cultural más amplia del pueblo o nación, que incluye sus leyes e instituciones tradicionales;

5. Son autogobernadas por instituciones indígenas dentro de sus territorios y de las áreas protegidas contenidas en ellos, en aplicación de las disposiciones establecidas con las autoridades del sistema de áreas protegidas.

La UICN reconoce que debería existir una guía específica desarrollada para la cuestión de los territorios y las áreas protegidas de los pueblos indígenas, y aspira a trabajar conjuntamente con organizaciones de pueblos indígenas de todo el mundo para hacerlo realidad.

\section{Pasos posibles para determinar si un territorio de un pueblo indígena o ICCA es un "área protegida" y cómo reconocerla dentro de un sistema nacional de áreas protegidas}

- Determinar si el área, con su sistema de gobernanza actual, encaja dentro de la definición de área protegida de la UICN.

- Determinar si el área también cumple con los criterios de área protegida según la legislación y la política nacionales.

- Si se cumple, determinar si encaja dentro de la tipología existente de categorías de áreas protegidas del país en cuestión. ¿Podría el área entrar en la categoría de parque natural, santuario, reserva de caza, u otra categoría existente? Algo que es importante: ¿haría posible esa categoría que el propio sistema de gobernanza de la comunidad continuase? ¿Permitiría la existencia de objetivos de gestión que puedan ser conceptualmente o en la práctica diferentes de la conservación por sí misma?

- Cuando las legislaciones y políticas nacionales son totalmente compatibles con las prácticas locales, las agencias de conservación deberían garantizar, o reconocer formalmente, que la autoridad y los poderes de toma de decisiones para el establecimiento y la gestión del área deberían recaer en los pueblos indígenas o comunidades locales en cuestión - un factor importante que les permitirá directamente aplicar sus decisiones (como en el caso en el que una ordenanza para el control de la pesca pueda proporcionar el respaldo legal necesario para un santuario marino declarado por la comunidad).

- Cuando exista incompatibilidad entre la gobernanza de un área valiosa de los pueblos indígenas o comunidades y las leyes y reglas de las áreas nacionales protegidas, es posible que se requieran ajustes legales y políticos en las disposiciones estatutarias de manera que los pueblos indígenas y comunidades locales involucrados puedan mantener sus sistemas de gobernanza. A menudo, lo que los pueblos indígenas y comunidades locales piden es una garantía sobre su herencia tradicional y sobre sus derechos de uso y acceso sancionados a través de la demarcación de sus territorios y recursos. Para que esto ocurra, puede ser necesario que la institución que gobierna el área sea reconocida como una entidad legalmente constituida. Ya que esto puede afectar al modo en que los pueblos indígenas y las comunidades locales se organizan y administran sus áreas y territorios, es importante que ellos determinen estas cuestiones.

- Una vez se hayan eliminado las incompatibilidades, la agencia puede emprender un proceso de negociación, que puede acabar en un acuerdo contractual entre los pueblos indígenas o locales comunidades y las autoridades 
nacionales o subnacionales. Ese acuerdo contractual podría, por ejemplo, reconocer el área y aplicar algún tipo de protección o apoyo técnico o financiero, incluido la inclusión como una parte autónoma de un sistema nacional de áreas protegidas. En otros casos, puede convertir el área en un área protegida bajo gobernanza compartida.

- Una vez el acuerdo ha sido alcanzado entre los pueblos indígenas o locales comunidades implicados y las autoridades nacionales o subnacionales acerca del reconocimiento del área como un área protegida, es posible que sea necesario clarificar y publicar las reglas y regulaciones relevantes. Esto puede significar el mero registro de las leyes tradicionales existentes, sin interferencia de las agencias estatales, o la incorporación de nuevas orientaciones, métodos y herramientas en tales normas. Las reglas deben especificar qué tipos de zonificacion de tierras y recursos existen, qué derechos comunitarios e individuales existen (incluida la propiedad), qué estructuras institucionales gestionan el área, si se puede y cómo realizar una explotación sostenible de los recursos (por ej., con límites de cantidad, especies y estaciones) y qué proceso debería seguirse para "anular el reconocimiento" del área si sus objetivos de conservación acordados no se están cumpliendo. También puede resultar útil aclarar y registrar la subdivisión de derechos y responsabilidades entre los pueblos indígenas o locales comunidades implicados y especificar medidas contra el mal uso de los derechos y el poder por parte de las autoridades en todos los niveles.

- Como parte del proceso de gobernanza, es necesario reforzar las fronteras y protegerlas frente a amenazas externas. ¿Qué tipo de mecanismos de vigilancia y de hacer cumplir las leyes, tradicionales y locales, son reconocidos por el estado? Por ejemplo, ¿pueden los miembros de los pueblos indígenas o locales comunidades implicados apresar a los infractores? ¿Se necesita ayuda del gobierno? ¿Quién juzga en caso de controversia? ¿Quién es responsable de llevar a cabo las campañas de información necesarias para que el público en general respete las ICCAs y las áreas indígenas protegidas? Las respuestas a estas preguntas son importantes para que dichas áreas resulten efectivas como áreas protegidas a lo largo del tiempo.

\section{Gobernanza privada}

Las áreas protegidas privadas suponen un subconjunto importante y creciente de las áreas protegidas del mundo que cuentan con representación en todas las categorías de la UICN, pero que hasta ahora se han visto sub-representadas en el total de áreas reconocidas por la UICN y registradas en la WDPA.

Las áreas protegidas privadas normalmente no se encuentran bajo la autoridad gubernamental directa. Existen tres tipos de entidades a cargo de áreas protegidas privadas, cada una con implicaciones específicas sobre la gestión:

- Personas físicas (el área se encuentra bajo el control de una persona física o de una familia).

- ONG (el área se encuentra bajo el control de una organización sin ánimo de lucro que tiene un objeto específico y que normalmente está controlada por un ejecutivo, un consejo y los socios)

- Cooperativas (por ej., la Comunidad de Conservación Ahuenco de Chile).

- Empresa (el área se encuentra bajo el control de una sociedad privada con ánimo de lucro o un grupo de personas autorizadas para actuar como una única entidad, normalmente controlada por un ejecutivo, un consejo de supervisión y finalmente, por todos los accionistas).

Cada uno de estos subtipos generales (así como una miríada de variaciones) tiene implicaciones sobre la gestión específica. Los pueblos indígenas y las comunidades locales también pueden ser los propietarios formales y/o tener el control de las tierras y los recursos que quieren conservar. Su caso ha sido explicado anteriormente.

\section{Áreas protegidas privadas en las categorías}

Las áreas protegidas privadas pueden encajar, y de hecho lo hacen, en todas las categorías. Algunos asumen que están mejor representadas en las categorías IV-VI; pero de hecho muchas se ajustan a los objetivos de gestión de I-III, quizás especialmente las que son propiedad de o gestionadas por ONGs. Aunque la mayoría de las aguas marinas no son propiedad privada, se está protegiendo un número creciente de islas de propiedad privada, incluyendo sus áreas costeras y marinas.

La mayoría de las áreas protegidas privadas no se encuentran registradas actualmente en la WDPA y por ello son bastante poco reconocidas por la comunidad global; a menudo también son ignoradas por los gobiernos y no se las incluye en la planificación nacional o ecoregional. Esto puede reflejar la falta de capacidad de recoger datos de áreas protegidas privadas por parte de los gobiernos, o que los gestores/propietarios de áreas protegidas privadas sean reacios a compartir información libremente.

\section{"Medios eficaces"}

En la mayoría de los casos la creación de un área protegida privada - y la gestión de la misma en función de objetivos de conservación - es un acto voluntario de los propietarios de las tierras. El creciente reconocimiento de las oportunidades de alcanzar objetivos de conservación en áreas privadas - y especialmente la proliferación de mecanismos e incentivos para dicho fin - ha resultado en un enorme incremento en el número y la extensión de áreas protegidas privadas. Entre estos mecanismos e incentivos se encuentran los siguientes:

- Sistemas de designación voluntaria de áreas protegidas, en los cuales los propietarios acuerdan ciertos objetivos o 
restricciones a cambio de asistencia u otros incentivos: las Reservas Privadas de Patrimonio Natural de Brasil son un ejemplo.

- Renuncia voluntaria a derechos legales de usos del suelo en propiedades privadas, algunas veces a cambio de ventajas (por ejemplo en tierras colindantes) concedidas por la pérdida teórica de valor, o para asegurar la protección a perpetuidad, o en calidad de mecanismos de compensación: entre los mecanismos están las servidumbres de conservación y los acuerdos y otras servidumbres conexas, y los acuerdos de gestión para la conservación.

- Donaciones con fines no lucrativos, en las que las ONGs recaudan fondos pública o privadamente para la compra de tierras para protegerlas, o reciben donaciones de tierras directamente de donantes voluntarios: aquí se incluyen grandes ONGs como The Nature Conservancy y Conservation International junto con muchos ejemplos regionales y locales.

- Asignaciones, donaciones o gestión por empresas de un área para su conservación, estimulado por un deseo de mejores relaciones públicas; como concesión o compensación por otras actividades; porque esté estipulado en alguna "certificación verde"; como inversión de futuro; o debido a intereses personales del staff.

- Renuncia involuntaria a determinados derechos de gestión por prescripción legal.

El sistema de categorías tiene el potencial de asistir a los gobiernos a la hora de monitorear las actividades privadas de conservación mediante la evaluación de los objetivos de gestión de las áreas protegidas privadas y su eficacia. Además existen salvaguardas locales y nacionales en algunos países para garantizar que las áreas protegidas privadas se gestionan de acuerdo con su designación, regulación o proclamación. El significado práctico y la implementación de estas salvaguardas pueden variar mucho de un país a otro. (Existen también ejemplos de autorregulación de áreas protegidas privadas como el programa de acreditación de fundaciones de tierras en desarrollo en Estados Unidos). La aplicación del sistema de categorías de la UICN presentado en estas directrices podría proporcionar a los gobiernos una base comparativa para monitorear las áreas protegidas privadas en el marco de sus estrategias nacionales de conservación.

La definición de área protegida de la UICN deja claro que dichas áreas deben ser gestionadas para la conservación a perpetuidad y que éste es el principal criterio para distinguir si un área terrestre o acuática de propiedad privada concreta es un área protegida o no. Un propietario que gestione con fines de conservación pero que no establezca disposiciones respecto a la futura gestión de las mismas por supuesto que contribuye a la conservación pero no mediante un área protegida reconocida. Proporcionar esta seguridad a largo plazo es uno de los retos a los que se enfrentan las áreas protegidas privadas. Algunos gobiernos nacionales han abordado esta cuestión aprobando legislación que hace de la declaración de un área protegida privada un compromiso legal vinculante para el futuro, aunque cuando este no sea el caso, otros mecanismos pueden ser necesarios. Dichos mecanismos están aún en desarrollo e incluyen varios sistemas de certificación, sistemas institucionalizados de declaración y la presión de pares con compromisos parecidos. Es urgente y necesario realizar más trabajo en relación a los pasos necesarios para integrar en mayor medida las áreas protegidas privadas en los sistemas nacionales e internacionales de áreas protegidas. 



\section{Aplicación de las categorías}

Esta sección describe los procesos para la aplicación de categorías, que incluyen: selección y aprobación de la categoría más acorde a cada situación, asignación de la categoría que cumpla la legislación nacional vigente y los estándares y normas internacionales; y registro del área protegida y su categoría ante el Centro Mundial para el Monitoreo de la Conservación del PNUMA. También se aborda la verificación de las categorías y la resolución de posibles desacuerdos. 


\section{Elección de la categoría correcta}

Una vez que un área se identifica como protegida según la definición de la UICN, el siguiente paso para su clasificación es determinar qué categoría se ajusta mejor a los objetivos generales de gestión de dicha área.

Puesto que el sistema de categorías refleja los objetivos de gestión, la categoría correcta deberá ser obvia, una vez tomada la decisión apropiada sobre la gestión de un área protegida. Esto es lo que ocurre algunas veces. Sin embargo, desafortunadamente, en otras muchas ocasiones existe mucho margen de confusión: puede que porque hay objetivos múltiples dentro de un área protegida (quizá en distintas partes del área); o porque los objetivos del área protegida van cambiando y haciéndose más complejos; o porque hay todavía dudas sobre qué enfoque concreto funciona mejor. Para acordar la categoría, es necesario no solo acordar los objetivos (quizá volviendo a evaluar los objetivos originales) sino desarrollar planes de gestión.

A la UICN se le ha pedido con frecuencia un método infalible para identificar categorías, pero esto resulta difícil. A menudo existen varias formas de enfocar la gestión de una misma área protegida, lo que puede llevar por tanto a asignar distintas categorías. ¿Qué ocurre si la mayor parte de un área protegida se gestiona de una forma, pero parte de ella de otra diferente? ¿Hay un tamaño mínimo o máximo para ciertas categorías? ¿Hay conceptos como Patrimonio Mundial o Ramsar asociados a determinadas categorías? ¿Cuánta actividad humana está "permitida" en áreas protegidas bajo diferentes categorías? A continuación se intenta dar respuesta a estas cuestiones.

Se debe recordar que muchos países tienen una legislación que define claramente los criterios para identificar los diferentes tipos de áreas protegidas, que pueden estar equiparados o no con las categorías de la UICN. En este caso, los países que quieran registrar sus áreas protegidas correctamente en la Base de Datos Mundial sobre Áreas Protegidas deben revisar las equivalencias existentes entre sus sistemas de clasificación y las categorías de la UICN - así ya lo han hecho muchos países. En otros casos, los gobiernos han adoptado las categorías de la UICN y las han mejorado para las condiciones específicas de su país. La UICN fomenta esta práctica, siempre y cuando el proceso de mejora no socave los principios básicos de un área protegida o de categorías específicas. Huelga decir que la elección de una categoría variará según las condiciones, así como de un país a otro, y que el proceso puede ser a veces complicado - en muchos casos es más arte que ciencia.

No obstante, antes de entrar en los detalles técnicos de la asignación de las categorías de área protegida, vale la pena considerar por qué se elijen las categorías. El proceso de categorización puede tener lugar en tres momentos distintos de la vida de un área protegida y aunque esto no debería influir en el resultado, puede provocar diferencias importantes en el proceso. Las categorías se pueden seleccionar:

- Antes de que se establezca el área protegida, cuando las decisiones sobre objetivos de gestión deberían ser parte del proceso de planificación.

- Después de que se haya establecido el área protegida, cuando los objetivos de gestión ya se han decido y elegir la categoría apropiada es principalmente encontrar la que mejor se ajusta a las áreas protegidas en su totalidad, aunque estudiar detalladamente las categorías en este momento puede provocar también algunos cambios en los objetivos de gestión y en las actividades.

- En un área protegida donde ya hay una categoría, pero, la gestión está cambiando para atender otras prioridades y problemas de conservación que estén surgiendo, o bien hay dudas sobre si originalmente se eligió la categoría correcta. Sin embargo, en muchos países cambiar una categoría forma parte de la legislación sobre áreas protegidas y debe seguir un proceso de valoración tan riguroso como el que se utilizó para definir la categoría previamente establecida.

\section{¿Cómo se relaciona el objetivo de gestión con la categoría?}

- La categoría debería ser la base de el/los objetivo/s principal/es del área protegida

- El objetivo de gestión principal debería ser aplicable, como mínimo, a tres cuartas partes del área protegida

LA CATEGORÍA DEBERÍA BASARSE EN EL/LOS OBJETIVO/S PRINCIPAL/ES DE GESTIÓN: tal y como se detallaba para categorías individuales en el Capítulo 2. (También debe ajustarse a la definición de área protegida). Esto da por hecho que la agencia responsable del área protegida está capacitada para decidir el objetivo principal de gestión. No es necesariamente una elección fácil; por otra parte, no aplicar la categoría correcta puede originar que la gestión en si misma sea confusa y probablemente ineficiente. En principio, un buen proceso de evaluación para identificar la categoría correcta debería involucrar a los interesados clave y a otras agencias que se ocupan de la conservación y la gestión del área protegida y debería estar basado en las mejores informaciones de ciencias naturales y sociales disponibles. Identificar el objetivo principal no significa que otros objetivos no sean importantes: casi todas las áreas protegidas tienen múltiples valores. En la práctica, no siempre resulta fácil emitir un juicio, en los siguientes ejemplos se revisan algunas de las cuestiones que surgen normalmente:

- ¿Ecosistema o hábitat - categoría II o IV? Las áreas protegidas de categoría II en teoría conservan ecosistemas enteros, mientras que la categoría IV, por lo general, tiene como objetivo conservar especies o fragmentos de 
ecosistemas. De hecho, muy pocas áreas protegidas son lo suficientemente grandes como para proteger ecosistemas enteros más sus rutas migratorias asociadas, funciones de regulación de cuencas hidrográficas, etc. Distinguir entre II y IV es por tanto, a menudo, una cuestión de gradación: un área protegida de categoría II debería tener como objetivo proteger la mayor parte de las funciones naturales del ecosistema, mientras que una zona protegida de categoría IV es por lo general un fragmento de un ecosistema (por ejemplo, fragmento de un arrecife de coral o pequeña parte de un humedal) o una zona que depende de la intervención habitual de los gestores para mantener un ecosistema artificial (por ejemplo, una zona de matorral o una zona de pradera segada habitualmente). Las áreas protegidas de categoría IV son por lo general más pequeñas que las de categoría II, pese a que esto no representa un diagnóstico ya que hay áreas protegidas de categoría IV de gran tamaño.

- ¿Intervención en la gestión o paisaje cultural-categoría IV o $V$ ? Un área protegida de categoría IV se gestiona principalmente por el valor de su fauna y su flora; y las intervenciones tipo limpieza de matorrales o vegetación, quema controlada, etc. se llevan a cabo con esto en mente, cualquier otro beneficio social derivado de estas acciones es secundario. Las intervenciones en áreas protegidas categoría $\mathrm{V}$ por el contrario tienen como objetivo sostener los medios de vida humanos, y no son tan solo parte de una estrategia de gestión de la biodiversidad. Un área protegida de categoría $\mathrm{V}$ por tanto utiliza sistemas de gestión cultural que también tienen valor para la biodiversidad, tales como los alcornocales que se gestionan principalmente para la producción de corcho, pero que también tienen gran valor para la vida silvestre si se integran en un enfoque de conservación del paisaje. En la mayor parte de las áreas protegidas bajo la categoría $\mathrm{V}$ se combina una amplia gama de formas de gestión.

- ¿Rehabilitar un paisaje cultural - categoría Vo algo más? Un paisaje cultural normalmente sería de categoría V. Pero si el objetivo de gestión es rehabilitar un antiguo paisaje cultural para hacerlo mucho más natural, entonces el objetivo de gestión y por tanto la categoría puede encajar mejor en otras, como las categorías Ib o II o IV. Por ejemplo, proteger un bosque relicto que anteriormente se usaba para pastoreo de ovejas, con el objetivo de convertirlo en algo que se parezca al ecosistema original del bosque, normalmente no se clasificaría como área protegida de categoría V. Proteger un arrecife de coral sobreexplotado con el objetivo de devolverlo a su ecosistema original tampoco estaría clasificado como categoría V.

- ¿Monumento natural o ecosistema - categoría III o II? ¿Cuándo la protección de un monumento natural es equivalente a la protección de un ecosistema? En la práctica, con frecuencia, es una cuestión de su dimensión y del enfoque de los objetivos de gestión. Un área protegida que contiene un monumento natural importante (habitualmente categoría III), pero que a pesar de todo se gestiona principalmente por sus funciones para el ecosistema (habitualmente categoría II) debería tener categoría II en lugar de III - por ejemplo, el Gran Cañón en Arizona es uno de monumentos naturales más grandes del mundo, pero el parque nacional está gestionado principalmente por las funciones de su ecosistema y por ello registrado como categoría II.

- ¿Uso sostenible o uso secundario por parte de las comunidades locales - cuándo utilizar la categoría VI? Numerosas áreas protegidas permiten un uso humano limitado, por ejemplo en muchas zonas silvestres (Ib) y ecosistemas protegidos (II) se permite a los habitantes locales desarrollar - a pequeña escala - actividades de subsistencia tradicionales que están en armonía con la naturaleza del área protegida, tales como (según acuerdos individuales de gestión) pastoreo de renos, pesca, recolección de productos forestales no madereros y caza limitada a la subsistencia. Pero en estos casos el objetivo es la conservación de zonas salvajes o ecosistemas, y la acción antrópica debería tener un impacto mínimo. En la categoría VI, el objetivo de gestión es el uso sostenible en sinergia con la conservación de la naturaleza y las actividades se gestionan de forma que no produzcan un impacto sustancial en estos ecosistemas. La diferencia en parte es una cuestión de gradación del uso.

- Paisaje cultural - ¿qué no es la categoría V? Prácticamente no existe ninguna zona terrestre que no haya sido modificada por las sociedades humanas durantes cientos o miles de años, igualmente un gran número de ecosistemas marinos también ha sido modificado. Se podría argumentar que cada área protegida en el mundo es una categoría V. Pero la UICN reconoce el papel de las comunidades humanas, al mismo tiempo que distingue las áreas en las que predominan especies naturales y ecosistemas (no habitualmente categoría V) de aquellas en que el nivel de modificación es más intenso, tales como las zonas dedicadas durante mucho tiempo a la ganadería o con procesos de gestión que ocasionan grandes cambios en la ecología y en la diversidad de las especies (generalmente categoría V).

EL PRINCIPAL OBJETIVO DEBERÍA APLICARSE AL MENOS A LAS TRES CUARTAS PARTES DEL ÁREA PROTEGIDA - LA REGLA DEL 75 POR CIENTO: muchas áreas protegidas pueden tener zonas específicas donde están permitidos otros usos, por ejemplo:

- Albergues y zonas de acampada para turistas en parques nacionales de categoría II - tal y como ocurre en muchas áreas protegidas de la sabana africana;

- Aldeas que quedan dentro de zonas estrictamente protegidas - por ejemplo, queda una aldea dentro del Parque Nacional Cat Tien en Viet Nam; 
- Pequeños núcleos estrictamente protegidos en zonas de paisaje cultural gestionados como categoría $\mathrm{V}$-por ejemplo, zonas boscosas propiedad del Fondo Nacional en el Parque Nacional de Brecon Beacons, Gales, Reino Unido;

- Zonas en las que está permitida la pesca dentro de una zona marina estrictamente protegida o un área protegida de humedal - por ejemplo, en la Reserva Natural de Kosi en KwaZulu, Natal, Sudáfrica.

La UICN reconoce esta situación y recomienda que hasta un 25 por ciento de tierras o aguas dentro de un área protegida pueda gestionarse con otros fines, siempre y cuando éstos sean compatibles con el objetivo principal del área protegida. En algunos casos, el 25 por ciento puede ser variable en el espacio y el tiempo: por ejemplo el Parque Nacional del Bosque Impenetrable de Bwindi en Uganda permite a las comunidades locales recolectar plantas medicinales y otros productos no madereros en zonas especial-mente señaladas, cuya localización varía ocasionalmente para impedir una sobre recolección de las especies.

\section{¿Cómo afecta el tamaño del área protegida a la categoría?}

- No hay reglas rápidas y sencillas pero algunas categorías tienden a tener relativamente mayor o menor tamaño

A escala global, este tamaño dependerá a menudo de otros factores como la cantidad de terreno o recursos hídricos disponibles, la densidad de población, etc. A escala relativa algunas categorías tienden a ser o más grandes o más pequeñas debido a sus objetivos específicos de gestión, pero hay excepciones en prácticamente todas las categorías. Para ayudar a esta selección, la Tabla 4 que se muestra a continuación, sugiere la escala relativa para las categorías y explica el por qué, pero además muestra algunas excepciones que ponen de relieve cómo el tamaño por si mismo no debería ser un factor determinante.

Tabla 4. Relación entre tamaño del área y la categoría

\begin{tabular}{|c|c|c|c|}
\hline Cat. & Tamaño relativo & Explicación & Excepciones \\
\hline la & $\begin{array}{l}\text { Frecuentemente } \\
\text { pequeño }\end{array}$ & $\begin{array}{l}\text { Es difícil ponerse de acuerdo sobre áreas } \\
\text { estrictamente protegidas y vedadas, } \\
\text { excepto en zonas escasamente pobladas: } \\
\text { aunque existen áreas la extensas (por } \\
\text { ej., en Australia); estas constituyen } \\
\text { probablemente la excepción. }\end{array}$ & $\begin{array}{l}\text { Zonas extensas en lugares con } \\
\text { densidad de población baja y poco } \\
\text { interés turístico. }\end{array}$ \\
\hline lb & $\begin{array}{l}\text { Generalmente } \\
\text { extensa }\end{array}$ & $\begin{array}{l}\text { Parte de la lógica de las áreas silvestres } \\
\text { es que aporten suficiente espacio } \\
\text { como para experimentar soledad y un } \\
\text { ecosistema natural a gran escala. }\end{array}$ & $\begin{array}{l}\text { Las áreas relativamente pequeñas } \\
\text { se califican como silvestres con la } \\
\text { esperanza de poder ampliarse en el } \\
\text { futuro. }\end{array}$ \\
\hline II & $\begin{array}{l}\text { Generalmente } \\
\text { extensa }\end{array}$ & $\begin{array}{l}\text { Los procesos de conservación de los } \\
\text { ecosistemas sugieren que el área } \\
\text { necesita ser suficientemente extensa } \\
\text { como para albergar todos o la mayoría de } \\
\text { tales procesos. }\end{array}$ & $\begin{array}{l}\text { Las islas pequeñas pueden ser } \\
\text { en efecto ecosistemas y por tanto } \\
\text { funcionalmente categoría II. }\end{array}$ \\
\hline III & $\begin{array}{l}\text { Generalmente } \\
\text { pequeño }\end{array}$ & $\begin{array}{l}\text { Zonas más amplias que contienen } \\
\text { monumentos naturales generalmente } \\
\text { protegerían también otros valores } \\
\text { (por ejemplo, ecosistemas y/o zonas } \\
\text { silvestres). }\end{array}$ & \\
\hline IV & $\begin{array}{l}\text { Frecuentemente } \\
\text { pequeño }\end{array}$ & $\begin{array}{l}\text { Si el lugar está preparado sólo para } \\
\text { proteger a especies individuales } \\
\text { o hábitats, esto sugiere que es } \\
\text { relativamente pequeño. }\end{array}$ & $\begin{array}{l}\text { Zonas más amplias definidas como } \\
\text { reservas naturales, pero que requieren } \\
\text { una gestión regular para mantener el } \\
\text { funcionamiento, es quizás mejor que } \\
\text { se asignen como categoría IV. }\end{array}$ \\
\hline V & $\begin{array}{l}\text { Generalmente } \\
\text { extensa }\end{array}$ & $\begin{array}{l}\text { El mosaico de diferentes enfoques que } \\
\text { se suman a la conservación de paisajes } \\
\text { sugiere una zona más extensa. }\end{array}$ & $\begin{array}{l}\text { Algunas reservas pequeñas dedicadas } \\
\text { a variedades silvestres de los cultivos } \\
\text { o a las variedades locales pueden } \\
\text { necesitar gestión cultural. }\end{array}$ \\
\hline VI & $\begin{array}{l}\text { Generalmente } \\
\text { extensa }\end{array}$ & $\begin{array}{l}\text { La naturaleza extensiva de la gestión } \\
\text { sugiere que por lo general sea una zona } \\
\text { extensa. }\end{array}$ & $\begin{array}{l}\text { Algunas áreas protegidas marinas de } \\
\text { categoría VI son pequeñas. }\end{array}$ \\
\hline
\end{tabular}




\section{¿Puede un área protegida incluir más de una categoría?}

- Las áreas protegidas marcadamente distintas comprendidas dentro de un área protegida mayor pueden tener su propia categoría;

- Distintas zonas en áreas protegidas más amplias pueden tener su propia categoría si las zonas se definen y se fijan legalmente;

- Diferentes áreas protegidas que forman un área protegida transfronteriza pueden tener categorías diferentes.

Esta es uno de las cuestiones más conflictivas en relación con las categorías. La respuesta es variable; depende de factores como la propiedad, la gobernanza y - hasta cierto punto - de lo que deseen las autoridades del área protegida.

Hay tres tipos de situaciones en las que se les pueden aplicar una categoría diferente a una o varias áreas protegidas contiguas:

Zonas anidadas con objetivos múltiples: A veces áreas protegidas de distintas categorías "anidan" dentro de otras - por ejemplo, un área protegida extensa puede tener dentro varias áreas protegidas de menor tamaño. El modelo más común sería el de un área extensa protegida a un nivel menos estricto que contenga en su interior áreas de menor tamaño más rigurosamente protegidas. Por ejemplo, muchas áreas categoría V albergan áreas categoría I y IV - seguramente bajo el control de diferentes responsables de gestión o con enfoques de gobernanza totalmente distintos. Dentro del Parque Natural Regional de Vercors en Francia (categoría V) se encuentra los Hauts Plateaux du Vercors (categoría IV). Esta situación es totalmente coherente con la aplicación del sistema de categorías. Al informar sobre áreas protegidas "anidadas" es importante evitar que se cuenten por duplicado y asegurarse de que las bases de datos no exageren la cantidad de territorio que se ha designado como protegido. Por ejemplo, en el Reino Unido, los parques nacionales (categoría V), que ocupan alrededor del 9 por ciento de la superficie de Inglaterra y Gales incluyen unas cuantas reservas naturales nacionales (categoría IV), que ocupan el 0,7 por ciento de la superficie de parques nacionales.

Zonas diferentes dentro de áreas protegidas: la zonificación es por lo general una herramienta de gestión dentro de un área protegida y habitualmente no se identificarían con una categoría separada. En algunas áreas protegidas, diferentes zonas de una unidad de gestión están clasificadas por ley con diferentes objetivos de gestión y como áreas protegidas separadas. En efecto, estas "zonas” son áreas protegidas específicas que forman una unidad mayor, aunque se encuentren bajo el control de los mismos responsables de gestión. En el caso de Australia, por ejemplo, la zonificación se utiliza igualmente como herramienta de gestión y como herramienta para designar áreas protegidas, ya que dicha práctica está amparada en su normativa. Así, al Parque Marino de la Gran Barrera de Arrecifes de Coral en Australia se le ha asignado la categoría IV en su conjunto, pero asimismo se le ha asignado oficialmente otras categorías en relación a las zonas de gestión reguladas dentro del parque. Separar las zonas en distintas categorías es una práctica que sólo debería llevarse a cabo en el caso de áreas protegidas extensas, y a discreción del gobierno interesado, teniendo en cuenta las condiciones descritas con anterioridad.

La UICN recomienda que se registren categorías múltiples dentro de una misma área protegida extensa cuando se cumplan ciertas condiciones. Estas condiciones reflejan la continuidad y los objetivos del sistema de zonificación. Hay dos escenarios posibles:

- Zona “dura": zonas a las que se puede asignar una categoría de la UICN cuando: (a) están claramente trazadas; (b) están reconocidas por un marco legal u otro medio efectivo; y (c) tienen objetivos de gestión diferentes y no ambiguos que pueden asignarse a una categoría de área protegida concreta (en este caso la regla del 75 por ciento carece de importancia);

- Zona "blanda": zonas a las que no se les asigna una categoría de la UICN cuando: (a) están sujetas a revisión periódica, tales como procesos de planificación de la gestión; (b) no están reconocidas por ningún marco legal o de otro tipo; y (c) no se corresponden con una categoría de área protegida concreta (la regla del 75 por ciento se aplica para definir la categoría general para toda el área protegida).

En resumen, la categorización separada de zonas es posible cuando la legislación básica describe y traza las zonas dentro de un área protegida, y no cuando la legislación básica simplemente permite la zonificación en un área protegida, tales como procesos de planificación de la gestión. El criterio de UICN es que en la mayoría de los casos asignar diferentes categorías a zonas de áreas protegidas, si bien puede ser pertinente en áreas protegidas más extensas en las que algunas zonas, importantes en sí mismas, constituyan áreas protegidas por derecho propio.

Áreas protegidas transfronterizas: cada vez existe un mayor número de casos de áreas protegidas situadas a ambos lados de una frontera nacional o federal, gestionadas por autoridades distintas pero con un cierto nivel de colaboración - desde planes conjuntos informales a acuerdos oficiales entre gobiernos. Estas zonas se conocen como áreas protegidas transfronterizas (Sandwith et al. 2001). En muchos casos, las áreas protegidas adyacentes pueden ser gestionadas de distinta forma y por tanto tendrán categorías diferentes. Si bien es importante que la orientación de la gestión de los distintos componentes de un área protegida transfronteriza se complemente, no existe ninguna razón por la que hayan de ser iguales.

La figura 2 muestra un ejemplo de diagrama en árbol para decidir si es apropiado que una zona tenga su propia categoría. 


\section{¿Qué impacto tiene la propiedad y la responsabilidad de la gestión en las categorías?}

- La propiedad y la gobernanza no afectan a la categoría

En cualquier categoría se puede encontrar cualquier estructura de propiedad o gobernanza, y se encuentran ejemplos de todo tipo de combinaciones a lo largo y ancho del planeta. Sin embargo, pueden describirse algunas tendencias: las áreas protegidas con grandes ecosistemas como los de categoría II son, por lo general, de propiedad y gestión estatal, mientras que las áreas conservadas a nivel de comunidad es más probable que estén en categorías menos restrictivas, V y VI; pero hay excepciones. Por ejemplo, algunas de las áreas protegidas más restrictivas del mundo son lugares naturales sagrados, donde se prohíbe la entrada al público, En cualquier categoría se puede encontrar cualquier estructura de excepto a unas cuantas personas cuidadosamente elegidas; en propiedad o gobernanza, y se encuentran ejemplos de todo tipo ciertos casos, no se permite el acceso a ninguna persona.

Figura 2. Zonas y categorías de áreas protegidas de la UICN

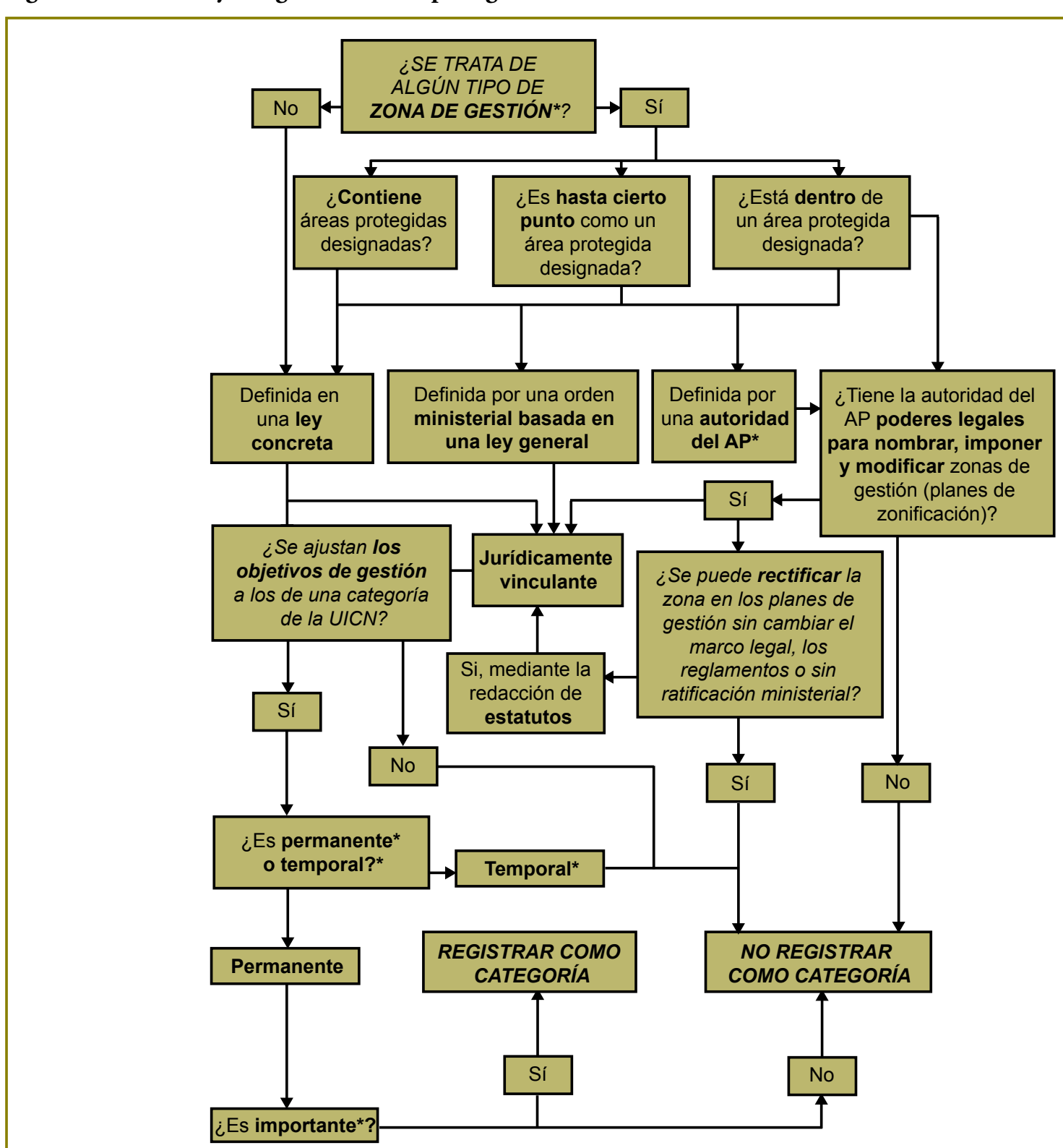

*Zona de gestión - por ejemplo, zona reguladora, zona silvestre, zona de recreo, zona vedada, zona central, etc.

Autoridad del área protegida - Departamento ministerial, agencia, ONG o una institución reconocida legalmente

Permanente - inscrita legalmente, establecida y reconocida, sometida a una visión a largo plazo (por ejemplo, zona central para la reproducción de especies clave)

Temporal - establecida sólo por motivos de gestión, temporal (por ejemplo, por un período limitado)

Importante - de naturaleza y/o proporciones razonables y reconocibles en relación a un marco más amplio 


\section{¿Qué ocurre con las zonas alrededor de las áreas protegidas?}

- Las zonas amortiguadoras, los corredores biológicos etc. pueden ser también - o no - zonas protegidas (y por tanto aptas para una categoría) dependiendo de su forma de gestión y del reconocimiento del estado

Los responsables de planificación de zonas protegidas hacen hincapié en la importancia de conectar áreas protegidas mediante corredores biológicos y zonas de apoyo (por ejemplo hábitats apropiados que usan las especies migratorias), y de aislarlas con zonas de amortiguamiento. Por desgracia, la lucha por la propiedad de la tierra, la presión poblacional y la pobre gobernanza conducen a que muchas áreas protegidas permanezcan como "islas" completamente aisladas. Abordar esta cuestión mediante proyectos de rehabilitación, indemnizaciones, reservas, acuerdos voluntarios y cambios legislativos constituye un reto a largo plazo. Que se pueda o no asignar a estas áreas una categoría depende de si cumplen o no los requisitos de área protegida según la definición de la UICN. Algunas áreas protegidas categoría $\mathrm{V}$ se han implantado para que sirvan de zonas amortiguadoras alrededor de otras áreas bajo niveles de protección más rigurosos. Otras zonas tampón y corredores biológicos no son áreas protegidas, antes bien, son zonas donde una combinación de acuerdos voluntarios y/o indemnizaciones ayudan a proteger la integridad del área protegida con enfoques de gestión del paisaje y de conectividad. Por ejemplo, en algunos países las plantaciones arbóreas comerciales o los bosques naturales gestionados ayudan a las zonas amortiguadoras ya que impiden la reconversión del terreno. Sin embargo, ninguno de estos usos reúne las condiciones de área protegida.

\section{¿Hay equivalencia entre las áreas protegidas, las categorías de la UICN y otras denominaciones internacionales de protección?}

- Buena parte del resto de denominaciones internacionales de protección no son necesariamente áreas protegidas tal y como las reconoce la UICN, si bien en la práctica muchas de ellas pueden serlo;

- Los sitios Patrimonio Mundial, Ramsar y Natura 2000 pueden tener cualquier categoría de la UICN o ninguna de ellas;

- Las reservas de la biosfera deberían tener un núcleo extremadamente protegido (categorías I-IV) y una zona de gestión sostenible alrededor (categoría V/ VI o zona no completamente protegida).
Se han sucedido una serie de iniciativas globales o regionales para definir la conservación por zonas terrestres y de agua, que incluyen:

- UNESCO Patrimonio Mundial - los sitios naturales y mixtos (naturales-culturales) inscritos por el Comité del Patrimonio Mundial tienen "el más alto valor universal";

- UNESCO el Hombre y la Biosfera (MAB) - las reservas de la biosfera son zonas en las que la conservación se combina con un uso sostenible.

- Zonas Ramsar - humedales y zonas de marea importantes reconocidas por el Convenio de Ramsar.

La definición de la relación entre estas zonas y las áreas protegidas de la UICN resulta complicada y se tratará más pormenorizadamente en una sección posterior. En algunos de los casos anteriores (como los sitios naturales de Patrimonio Mundial) las áreas con designaciones internacionales son también áreas protegidas. Algunos países interpretan estas denominaciones como áreas protegidas de forma automática, mientras que otros no. Parece ser que la tendencia general de asignar el estatus de área totalmente protegida a estas denominaciones suele ser la mejor forma de asegurar la conservación de los valores del sitio y sus valores a largo plazo. Siendo este el caso, estas y otras designaciones pueden contener, y de hecho contienen, áreas en todas las categorías de la UICN: no hay ningún tipo de vínculo específico entre una denominación de estatus de Patrimonio Mundial y una categoría o grupo de categorías de la UICN.

Una posible excepción la encontraríamos en las reservas de la biosfera MAB, que promueven el uso sostenible alrededor de un núcleo terrestre o acuático altamente protegido. En general, una reserva de la biosfera tendría: (a) un núcleo altamente protegido (por lo general categoría I-IV); (b) una zona amortiguadora que podría ser categoría V o VI, o bien territorios/aguas gestionados que no se correspondería con ninguna categoría de la UICN; y (c) una zona de transición que no se correspondería con ninguna categoría de la UICN.

\section{La asignación}

La importancia del proceso de asignación ha sido creciente a medida que las categorías se han empezado a aplicar como herramientas de políticas y como formas de medición en las estadísticas ambientales y de uso de las tierras. Por ejemplo, cuando la asignación de una categoría determinada comporta restricciones legales al uso de la tierra o el agua, o dicta quién puede o no vivir en el área, tal como pasa en algunos países, 
entonces la decisión sobre qué categoría concreta se asigna adquiere más importancia que en el caso de ser utilizada como un mero recurso estadístico. El proceso de asignación depende del país o del gobierno en cuestión, pero en la sección siguiente se describen algunos principios y se propone una metodología.

\section{Algunos principios de la asignación}

El enfoque de la UICN para la asignación de las categorías de gestión de áreas protegidas se basa en una serie de principios, detallados a continuación, relativos a la responsabilidad, a la participación de los afectados y a las garantías:

- Responsabilidad: El uso de las categorías es voluntario y nadie tiene el derecho a imponerlas. Los estados toman por lo general la última decisión legal, o al menos asumen la máxima responsabilidad sobre el uso de la tierra y el agua, por lo que parece razonable que los estados también deban decidir sobre la categoría de área protegida.

- Democracia: No obstante, la UICN impulsa a los estados a consultar con los principales actores implicados a la hora de asignar categorías. La democratización y la descentralización de los procesos han conllevado un aumento en el número de gobiernos subnacionales con responsabilidad sobre áreas protegidas; en estos casos, el gobierno local o regional debe informar al gobierno central. En la mayoría de las áreas privadas o de áreas conservadas por las comunidades, los gobiernos suelen tener discrepancias de opinión con la propiedad y los administradores respecto a la asignación de la categoría, aunque algunos países tienen políticas o legislación al respecto.

- Procedimientos de reclamación: Un gran número de interesados y actores directos apoyan la idea de que debe haber formas de apelar las decisiones sobre categorías. La UICN está de acuerdo y lo propulsa, si bien apunta que las decisiones finales sobre gestión dependen en último término de los estados o los propietarios de las áreas. Con posterioridad se detallarán algunas propuestas de posibles procedimientos de reclamación o apelación.

- Gestión de datos: La información sobre áreas protegidas deberá presentarse al Centro Mundial para el Monitoreo de la Conservación del PNUMA, que coordina la Base de Datos Mundial sobre Áreas Protegidas y recopila La Lista de la ONU de Áreas Protegidas.

- Verificación: La UICN puede aconsejar sobre asignaciones y en ocasiones organiza misiones específicas de asesoría a países e incluso áreas protegidas concretas. La UICN está también pensando en desarrollar alguna forma de sistema de verificación o certificación de la asignación de categorías de áreas protegidas, para aquellos responsables de gestión - que de forma voluntaria - quieran verificar que los objetivos de gestión se ajustan a la categoría asignada.

\section{Procedimiento para la asignación}

Se recomienda que la asignación se sustente en cuatro elementos principales:

- Buenas directrices para gobiernos y otras autoridades de áreas protegidas;

- Proceso de asignación acordado;

- Sistema de reclamación de categorías asignadas, aún por desarrollar;

- Proceso de verificación; que podría ser implementado a nivel nacional (por un panel de expertos por ejemplo) o solicitado a un organismo independiente como la UICN.

Los tres primeros se comentan a continuación: actualmente no existe un sistema de verificación aunque puede que se desarrolle más adelante.

\section{Buenas directrices para gobiernos y otras autoridades de áreas protegidas}

La base para utilizar las categorías son las directrices que contiene esta publicación. Además, otras guías más detalladas sobre temas especializados están o estarán disponibles, por ejemplo con respecto a:

- Biomas: por ejemplo, bosques (Dudley y Phillips 2006), áreas protegidas marinas y de aguas continentales, etc.;

- Categorías: similar a la guía desarrolladas para la categoría V (Phillips 2002), ya en proyecto para la categoría Ib y la categoría VI;

- Regiones: similar a las guías ya producidas en Europa (EUROPARC y UICN 1999) y en proyecto para varias regiones, bien como guías o como estudios de caso;

- Herramientas de selección: para identificar categorías y tipos de gobernanza;

- Tipos de gobernanza: hay también interés en producir información más detallada sobre áreas protegidas privadas, áreas conservadas por comunidades y áreas protegidas por poblaciones indígenas.

\section{Proceso de asignación acordado}

La Figura 3 muestra un proceso propuesto de asignación; idealmente, este debería involucrar a muchos de los actores interesados, especialmente cuando la asignación de una categoría concreta tenga impactos sobre la población que vive en el área protegida o cerca de ella, o sobre otros actores. Una opción sería tener un grupo de trabajo a nivel nacional encargado de revisar datos sobre áreas protegidas, para esto, se ha sugerido el comité nacional de la UICN como medio idóneo para esto. 
El grado de implicación de los interesados directos en la toma de decisiones depende en última instancia de los gobiernos por lo que la UICN solo puede aconsejar y alentar. Existe un numero de herramientas para identificar la mejor categoría a aplicar a una determinada área protegida. En ocasiones, las preguntas están relacionadas con una serie de sitios similares; por ejemplo cuando un departamento forestal está tratando de decidir cuales de sus reservas forestales deben ser reconocidas como áreas protegidas; cuándo áreas protegidas privadas están tratando de obtener ser reconocidas en el sistema nacional; o cuando comunidades locales están interesadas en convertir sus zonas pesqueras en áreas protegidas.

Figura 3. Proceso para la asignación de categorías de áreas protegidas

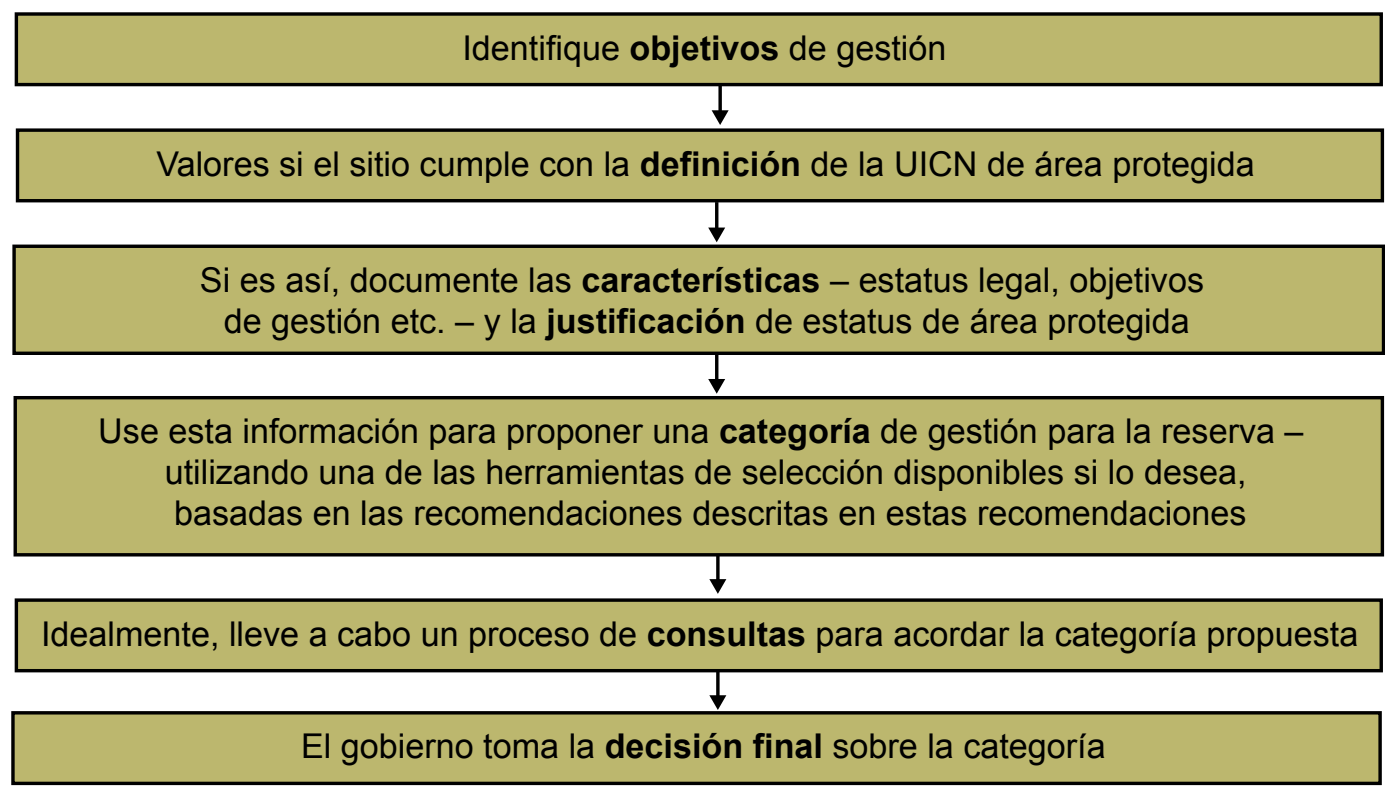

\section{Informar}

Una vez que se ha asignado la categoría, se pide a los gobiernos que informen sobre la decisión al Centro Mundial para el Monitoreo de la Conservación del PNUMA, con el fin de que la información sea incluida en la Base de Datos Mundial de Áreas Protegidas (WDPA) y en La Lista de la ONU de Áreas Protegidas. La decisión de informar es voluntaria, si bien lo solicitan varias resoluciones y políticas de Naciones Unidas, y, muy recientemente también el Convenio para la Diversidad Biológica en su Programa de Trabajo sobre Áreas Protegidas. Por ello es de esperar que los gobiernos entreguen la información regularmente y de forma precisa, utilizando el formulario que facilita el CMMC del PNUMA con objeto de garantizar que la información se transfiera de forma exacta y rápida a la base de datos.

\section{Fortalecer la asignación de categorías}

La asignación de categorías ha sido tradicionalmente responsabilidad de los gobiernos y se ha asumido que no asignarán intencionadamente una categoría incorrecta y que los gobiernos tienen la capacidad para asignar las categorías correctamente. En los últimos años, esta situación está siendo cuestionada y sometida a escrutinio, sobre todo, por algunos grupos industriales a los que les preocupa el aumento de terreno y agua "vedados" a otras formas de desarrollo, pero también por las comunidades, preocupadas por la pérdida de derechos y de acceso a los recursos. Algunos gobiernos también han pedido aclaraciones sobre la correcta asignación de una categoría a una zona específica; especialmente cuando los niveles de financiación se han fijado sobre la base de la designación de la categoría. Se ha propuesto que sería útil tener algún procedimiento de reclamación o proceso de verificación que ofreciera alguna garantía independiente de que: (1) el área es verdaderamente un área protegida; y (2) se le ha asignado la categoría correcta. Al final la elección de categorías depende de cada gobierno y la UICN no tiene ni derecho ni deseo de imponerse sobre lo que deberían ser decisiones nacionales. Sin embargo, la UICN ha recibido un fuerte apoyo para que ofrezca un marco a los gobiernos y a otros actores para que refuerce, y si fuera necesario, cuestione la asignación de categorías.

Una opción es que la UICN, o un tercero, establezca un proceso de certificación o verificación con el objetivo de examinar la asignación de categorías - estos temas se examinan 
con más detalle en la sección sobre eficacia de la gestión, sobre todo, en términos de casos concretos en los que la verificación de estándares puede ser útil para los propietarios o los propios gestores de las áreas protegidas.

Una cuestión distinta es la posibilidad de que actores externos cuestionen la asignación de una categoría. Una vez más es de esperar que tales ejemplos sean poco comunes, pero se está haciendo evidente la necesidad de contar con un sistema para abordar estos temas dentro de la UICN y CMAP. La UICN y la CMAP tienen intención de colaborar con sus asociados, incluyendo el PNUMA-CMMC, para buscar opciones prácticas para implementar algún tipo de procedimiento de reclamación en un futuro próximo.
Tal proceso puede ser sólo simbólico: los gobiernos tienen el derecho final a decir cómo se gestiona un área protegida y cuál es su categoría. Pero evaluaciones independientes de este tipo han sido de gran valor político en situaciones similares, tales como la Lista Montreux del Convenio Ramsar y el Mecanismo de Monitoreo Reactivo bajo el Convenio de Patrimonio Mundial de la UNESCO.

La UICN reconoce la necesidad de ayudar a los gobiernos y a otras instituciones a aumentar su capacidad en términos de entender y asignar las categorías. Junto con el lanzamiento de las directrices de las nuevas categorías, la UICN está desarrollando un ambicioso proyecto de desarrollo de capacidades para la mejor aplicación del sistema de categorías. 


\section{Utilización de las categorías}

Las categorías se diseñaron inicialmente como forma de clasificación y registro de áreas protegidas - lo que de por sí solo constituye una enorme tarea. Paulatinamente se han añadido otros usos, asumiendo por ejemplo un papel importante en la planificación de sistemas de áreas protegidas y en el desarrollo de políticas de conservación coherentes: después de la resistencia inicial, los propios miembros de la UICN respaldaron esta postura mediante una recomendación a los gobiernos para que prohibieran la minería en las áreas protegidas de categoría I-IV. 


\section{Utilización de las categorías de áreas protegidas de la UICN como herramienta de planificación de la conservación}

Tradicionalmente, las agencias de gestión vienen utilizando las categorías de gestión de áreas protegidas para clasificar, con distintos grados de precisión, el objetivo de un área protegida concreta después de que esta se hubiera determinado mediante un plan de conservación. La UICN recomienda que las categorías de gestión de áreas protegidas se utilicen también para ayudar a diseñar los sistemas de áreas protegidas con objetivos de gestión variantes (y distintos tipos de gobernanza) para enfrentar las necesidades de conservación de la biodiversidad del un territorio o de un espacio marino determinados. Puesto que se pide a los gobiernos que identifiquen y subsanen las carencias de sus sistemas de áreas protegidas, los responsables de la planificación deberán aplicar la gama completa de categorías de gestión de áreas protegidas a la hora de identificar, designar e iniciar la gestión de nuevas áreas protegidas.

\section{Antecedentes}

Puesto que el uso humano y el consumo dominan gran parte de los territorios y espacios marinos del mundo, existe una creciente necesidad de considerar las áreas protegidas como un conjunto de prácticas de gestión más que como lugares aislados, cerrados y restringidos. Un enfoque del tipo "una sola norma para todo" en la gestión de la biodiversidad en áreas protegidas no solo conllevará conflictos con otras necesidades sociales, sino que también limitará las opciones de gestión de los conservacionistas y la cantidad del territorio y del mar disponibles para la protección de la biodiversidad. La diversidad de las categorías de áreas protegidas puede utilizarse para abordar una necesidad ecológica de una especie o ecosistema, equilibrándose de acuerdo con las necesidades de la sociedad.

Conforme a los acuerdos de la CDB, los gobiernos han adquirido el compromiso de completar sistemas ecológicamente representativos de las áreas protegidas; dicho proceso empieza por lo general con la identificación de las vacíos del actual sistema - normalmente mediante un análisis ecológico de vacíos y omisiones en el sistema. En un contexto de conservación, el análisis de los vacíos es un método para identificar la biodiversidad (por ejemplo, especies, ecosistemas y procesos ecológicos) que no está conservada correctamente dentro de un sistema de áreas protegidas o para desarrollar otras medidas de conservación eficaces a largo plazo. Un análisis de vacíos bien diseñado logra identificar tres tipos de deficiencias en un sistema de áreas protegidas (Dudley y Parrish 2006):

- Déficits de representación: una especie o ecosistema no está suficientemente representado por las áreas protegidas;

- Déficits ecológicos: el sistema de áreas protegidas no consigue controlar lugares o fenómenos clave para la conservación de una especie o ecosistema durante su ciclo vital;
- Déficits de gestión: las áreas protegidas cubren geográficamente todos los elementos de biodiversidad pero fallan al protegerlos debido a una gestión insuficiente o incompetente.

Cuando se identifican las carencias y se ponen en marcha las consecuentes acciones - tales como proponer nuevas áreas protegidas y revisar las categorías de gestión de las áreas protegidas ya existentes - se debe tener en cuenta el conjunto de categorías en su totalidad.

Al revisar las categorías de áreas protegidas existentes para determinar el tipo de protección que mejor logre conservar la biodiversidad dentro de esa área protegida, no hay ninguna jerarquía que sugiera, por ejemplo, que un área protegida de categoría I es siempre mejor que una de categoría II o III o IV. Por otra parte, las categorías no son fácilmente intercambiables. El único principio que debería aplicarse al asignar categorías es la idoneidad del objetivo de gestión asignado al área protegida dentro del sistema en relación a las necesidades ecológicas y las amenazas para las especies o el ecosistema, en el contexto completo del territorio o medio marino donde se da la biodiversidad. Los objetivos del área protegida también deben tenerse en cuenta en el momento de revisar y asignar la categoría de gestión. En algunos casos, puede ser mejor incrementar las restricciones de protección si se da un descenso en el estatus ecológico o de conservación de una especie o ecosistema dentro de un área protegida o a través de su distribución - por ejemplo, a una parte o a toda una zona de categoría $\mathrm{V}$ se le puede reasignar una categoría Ib. En otros casos, puede ser quizá más estratégico cambiar la gestión para permitir una mayor flexibilidad en términos de uso sostenible (por ejemplo, de un área protegida de categoría II a una de categoría VI).

Por lo general, aumentar las restricciones de protección estará usualmente ligado a un descenso continuo de la biodiversidad dentro de un área protegida ya existente. ¿Cuándo podrían los gestores de recursos naturales elegir un enfoque menos riguroso respecto a un área protegida frente a otro más restrictivo?

En los siguientes casos, por ejemplo:

- Cuando la viabilidad de la población de una especie o de la integridad del ecosistema ha mejorado en toda su distribución y ya no exige reducir el uso humano ni protección intensa.

- Cuando el posible uso humano en la categoría más baja de área protegida, raramente afectará el estado de las especies o del ecosistema.

- Cuando cambiar la categoría aumenta el tamaño del área protegida para beneficio de las especies o ecosistema. Por ejemplo, en la protección de ríos y humedales puede ser más efectivo, para la función del ecosistema, gestionar la línea divisoria de aguas con una protección menos restrictiva que proteger la corriente principal del río con categoría I o II, dependiendo de cuáles sean las amenazas prioritarias para el objetivo biológico de conservación. 
- Cuando la biodiversidad se ha adaptado a los sistemas de gestión cultural y la ausencia de estas intervenciones ahora va en detrimento la supervivencia o viabilidad de las especies.

\section{Algunas consideraciones para la asignación de categorías de gestión de áreas protegidas en la planificación de sistemas de áreas protegidas}

No hay normas rápidas y eficaces para elegir una categoría en particular para un área protegida concreta. Sin embargo, un enfoque primordial debería ser el de reconocer que no todas las áreas protegidas se gestionen de la misma forma y que para elegir el enfoque de gestión es necesario sopesar las diferentes oportunidades y presiones en relación al área en cuestión. A continuación se detallan algunos principios generales:

- Comience con las necesidades ecológicas de la especie y el ecosistema. Las opciones de gestión deberían venir determinadas principalmente por las características ecológicas del ecosistema y la historia de vida de la especie. Por ejemplo, las distintas especies responden de forma diferente a las perturbaciones y, en general, las especies más sensibles pueden necesitar una protección más intensa con enfoques de gestión más restrictivos.

- Considere las amenazas a los valores de la especie y del ecosistema. Algunas amenazas se prestan a un planteamiento de gestión concreto. Por ejemplo, la pesca furtiva en áreas marinas protegidas puede abordarse mejor, permitiendo a las comunidades locales un cupo de capturas acordado (por ejemplo, en un área protegida de categoría $\mathrm{V}$ o VI), favoreciendo así que ayuden a controlar la pesca furtiva de individuos externos a la comunidad.

- Considere los objetivos del área protegida, las designaciones internacionales existentes o propuestas y cómo éstas contribuyen a los esfuerzos de conservación del paisaje, el país y la diversidad. Cada área protegida existente debería haberse establecido con objetivos concretos. Pero cuando el planteamiento de planificación se amplía a niveles del paisaje circundante y el país, puede ser necesario reconsiderar los propósitos y objetivos originales. Las denominaciones internacionales del Convenio de Patrimonio Mundial y del Convenio Ramsar son útiles para identificar la mejor forma de gestionar un sitio.

- Considere desarrollar e implementar un proceso de asignación/revisión de categorías de gestión en un país. Una agencia nacional de áreas protegidas debería desarrollar un proceso oficial de revisión y asignación de categorías de gestión. Por ejemplo, como resultado de una evaluación de vacíos ecológicos, la agencia de áreas protegidas de Panamá revisó las categorías de gestión de todas las áreas protegidas del país.

- Ninguna pérdida de naturalidad, función del ecosistema, o viabilidad de especies. La opción de gestión elegida no debería, en la mayoría de casos, tener como consecuencia una pérdida de la naturalidad actual del área protegida (por ejemplo, la UICN normalmente no propondría un área protegida de categoría V o VI a un sitio más o menos natural) pese a que puede haber excepciones.

- Considere el paisaje terrestre y marino cuando asigne categorías. La elección de la categoría debería reflejar la contribución del área protegida al conjunto de la conservación y no solo los valores del sitio específico, por ejemplo, los objetivos de gestión de un sitio concreto no deberían seleccionarse aisladamente. Por ejemplo, un lago interior podría ser importante no sólo para la población residente, sino también como punto de parada para las aves migratorias. Asimismo, recomendamos que los planificadores medioambientales desarrollen un conjunto de áreas gestionadas a través del uso de diferentes categorías de la UICN para un determinado elemento de la biodiversidad.

- Los actores directos importan. Las opciones de gestión deberían considerar las necesidades, capacidades y deseos de las comunidades locales y deberían en general seleccionarse después de tratar el tema con los actores e interesados directos - los objetivos de gestión que tienen el respaldo de las comunidades locales tienen más posibilidades de éxito que aquellos que cuentan con su oposición o son impopulares.

- Considere la eficacia de la gestión al aplicar las categorías de áreas protegidas. Los gestores deberían también tener en cuenta la efectividad de la gestión existente a la hora de recomendar objetivos de gestión (categorías de áreas protegidas). Una gestión ineficaz o inexistente en un área protegida de categoría I o II (el síndrome del "parque sobre el papel”) puede conseguir un menor impacto en la conservación que un área protegida gestionada eficazmente de categoría V o VI, incluso si las normas de gestión en estas categorías son menos restrictivas.

- Las categorías de gestión más restrictivas no son siempre mejores. Los científicos conservacionistas con frecuencia asumen que al designar áreas protegidas, las categorías I-IV suponen una conservación más eficaz que las categorías V-VI. Esto no es siempre así; por ejemplo, a veces para zonas extensas, los enfoques menos restrictivos pueden ser más eficaces.

- Use las categorías como una herramienta de planificación interna dentro de la propia área protegida. Dentro de una misma área protegida, se pueden acordar distintos objetivos de gestión para zonas distintas si con ello se consigue una mejor gestión global. Considere zonas temporales dentro de las áreas protegidas (por ejemplo, para permitir a las comunidades locales la explotación sostenible de bajo impacto de productos forestales no madereros).

- Considere los beneficios sociales de diversificar la lista de categorías. El tener en cuenta una variedad de categorías de áreas protegidas a menudo mejora la percepción pública respecto a las áreas protegidas e incrementa las probabilidades de éxito - especialmente si la población reconoce que no todas las áreas protegidas implican "el bloqueo" del uso de los recursos terrestres, hídricos o marinos. La utilización de ciertas categorías puede favorecer 
el compromiso de los actores o interesados directos con la conservación, y ampliar así las opciones para la designación de otras áreas por proteger (por ejemplo, los sitios sagrados que son considerados por la religión de poblaciones locales que también contribuyen de forma importante a la conservación de la biodiversidad, como es el caso de Parque Nacional de Tikal en Guatemala).

\section{Planificar para afrontar el cambio climático}

El calentamiento global afectará la planificación de áreas protegidas de diversas formas. El cambio climático conllevará un aumento en la temperatura media anual, cambios en el régimen del agua y, casi con seguridad, una mayor ocurrencia de fenómenos impredecibles. Es muy posible que se den cambios fundamentales en las propiedades que rigen los ecosistemas y hábitats, y en la distribución de las características de los rasgos bióticos naturales. En algunas partes del mundo, puede que se sequen los humedales, y en otras, las zonas secas pueden ser propensas a inundarse. Las islas y las zonas costeras bajas serán más vulnerables a la erosión y a la pérdida de suelo y hábitats como consecuencia de la subida del nivel del mar y el aumento de las tormentas. Las especies y los hábitats que se encuentran en los límites de su distribución geográfica se verán posiblemente afectados de forma negativa por el cambio climático global. Los ciclos estacionales de las plantas y animales también cambiarán. Es probable que muchas áreas protegidas se vean afectadas, con la consiguiente probable pérdida de especies y ecosistemas; puede que lleguen otras especies a ocupar su lugar si bien probablemente un gran número de las especies con menor capacidad de desplazamiento y adaptación se enfrentará a mayores amenazas de extinción. Pero al mismo tiempo, las áreas protegidas podrán desempeñar un papel importante para mitigar el cambio climático, sirviendo de amortiguadores contra episodios climáticos extremos (Stolton et al. 2008), proporcionando una red de hábitats naturales que servirán de rutas para el desplazamiento y migraciones rápidas, asi como una serie de espacios para la evolución y la adaptación (Dudley y Stolton 2003).

Los gestores y los responsables de las áreas protegidas están empezando a estudiar las opciones que existen para reducir el impacto que el cambio climático tendrá sobre las áreas protegidas y para optimizar los beneficios que un sistema de áreas protegidas bien diseñado pueda aportar para mitigar los impactos en la sociedad. En términos de objetivos de gestión y de categorías, esto tiene una serie de implicaciones:

- Probablemente deberían considerarse los impactos del cambio climático al diseñar sistemas de áreas protegidas para maximizar las ventajas que ofrecen los distintos enfoques de gestión, basándose en el estudio de las fortalezas y debilidades de las diferentes categorías ante el cambio climático. Se deberán identificar en la planificación de los sistemas de áreas protegidas y en las áreas protegidas actuales para prepararse para el futuro (teniendo en cuenta que aún no sabemos con certeza cuáles serán los cambios en muchos casos - por lo que la planificación debe hacerse con flexibilidad).

- Se hará cada vez más importante conectar las áreas protegidas mediante corredores y redes para facilitar el desplazamiento de las especies e incrementar los probables traslados naturales hacia lugares donde las condiciones sean más aptas para la supervivencia. Cuando sea posible, será conveniente diseñar áreas protegidas más extensas con un rango de características biogeográficas más amplio.

- Algunas especies pueden desaparecer totalmente si no hay ningún lugar dentro del rango de su expansión potencial natural en que el régimen climático sea adecuado para su supervivencia. Puede por tanto ser necesario desarrollar esquemas de desplazamiento de especies hacia zonas más apropiadas, y mejorar los vínculos entre las iniciativas y los planes de conservación "in-situ" y "ex-situ".

- El cambio climático implicará probablemente una gestión más intervencionista para evitar incidencias negativas en especies y hábitats. Esto provocará preguntas sobre la asignación de categorías y puede que una mayor utilización de los enfoques de tipo categoría IV.

- Las condiciones cambiantes pueden producir alteraciones en la gestión de algunas áreas protegidas específicas. En algunos casos, las condiciones más duras puede que conviertan paisajes culturales tradicionales en no sostenibles y también que pongan las especies restantes bajo amenaza, haciendo necesario cambiar de categoría $\mathrm{V}$ a - por ejemplo - categoría Ib, ligada al abandono por parte de la población. En otras situaciones, entornos antes prácticamente inalterados puede que sólo sobrevivan gracias a la intervención humana y un enfoque del tipo categoría Ia podría cambiar a una categoría IV. Debe tenerse en cuenta que los cambios de categoría deberían ser poco frecuentes y deberían estar sujetos a un proceso tan riguroso como el de la asignación original.

- Las áreas protegidas pueden reubicarse (por ejemplo si el nivel del mar sube) y crearse nuevas áreas protegidas; en algunos casos las áreas protegidas existentes pueden resultar inadecuadas si las especies que se debían proteger cuando fueron designadas no pueden ya sobrevivir allí. Nos hemos acostumbrado a ver las áreas protegidas cómo entes fijos que se mantienen inalterables en un futuro previsible, pero en condiciones de cambio climático puede que este no sea el modo más eficaz de implementar la conservación.

- Se debe alentar la investigación sobre cambio climático y áreas protegidas. Dicha investigación debería también ayudar a los gestores de áreas protegidas a desarrollar respuestas apropiadas y significativas para afrontar el cambio climático.

- Cuando sea posible, se deberían establecer áreas protegidas de mayor tamaño con un rango de características biogeográficas más amplio, para facilitar espacios para cambios en el rango de distribución de las especies y amortiguación contra episodios climáticos extremos. 


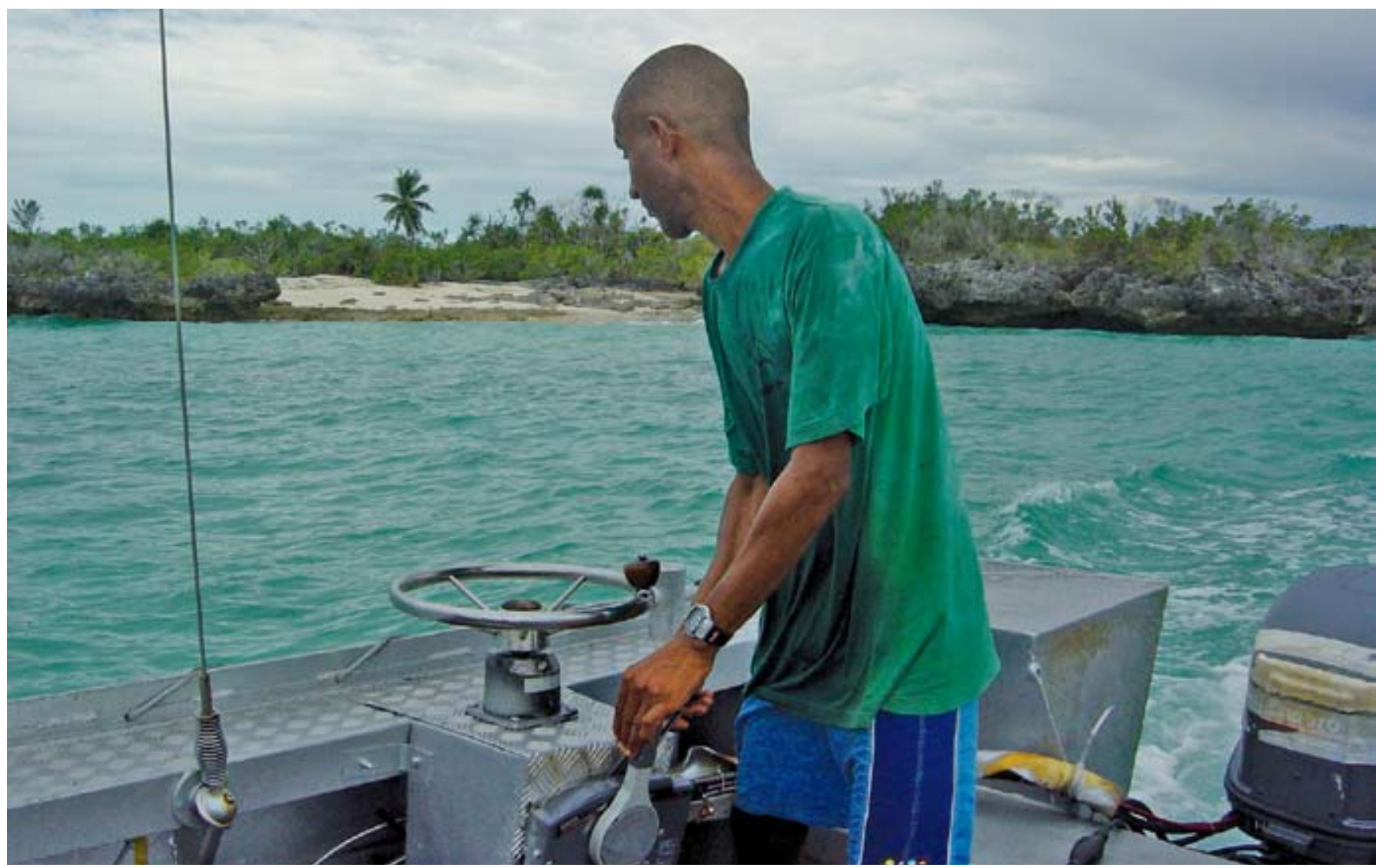

El remoto Atolón de Aldabra de las Seychelles en Océano Indico Occidental proporciona un laboratorio natural ideal para estudiar los ecosistemas marinos tropicales y sus entornos (como las praderas marinas y los manglares). (C) Sue Stolton

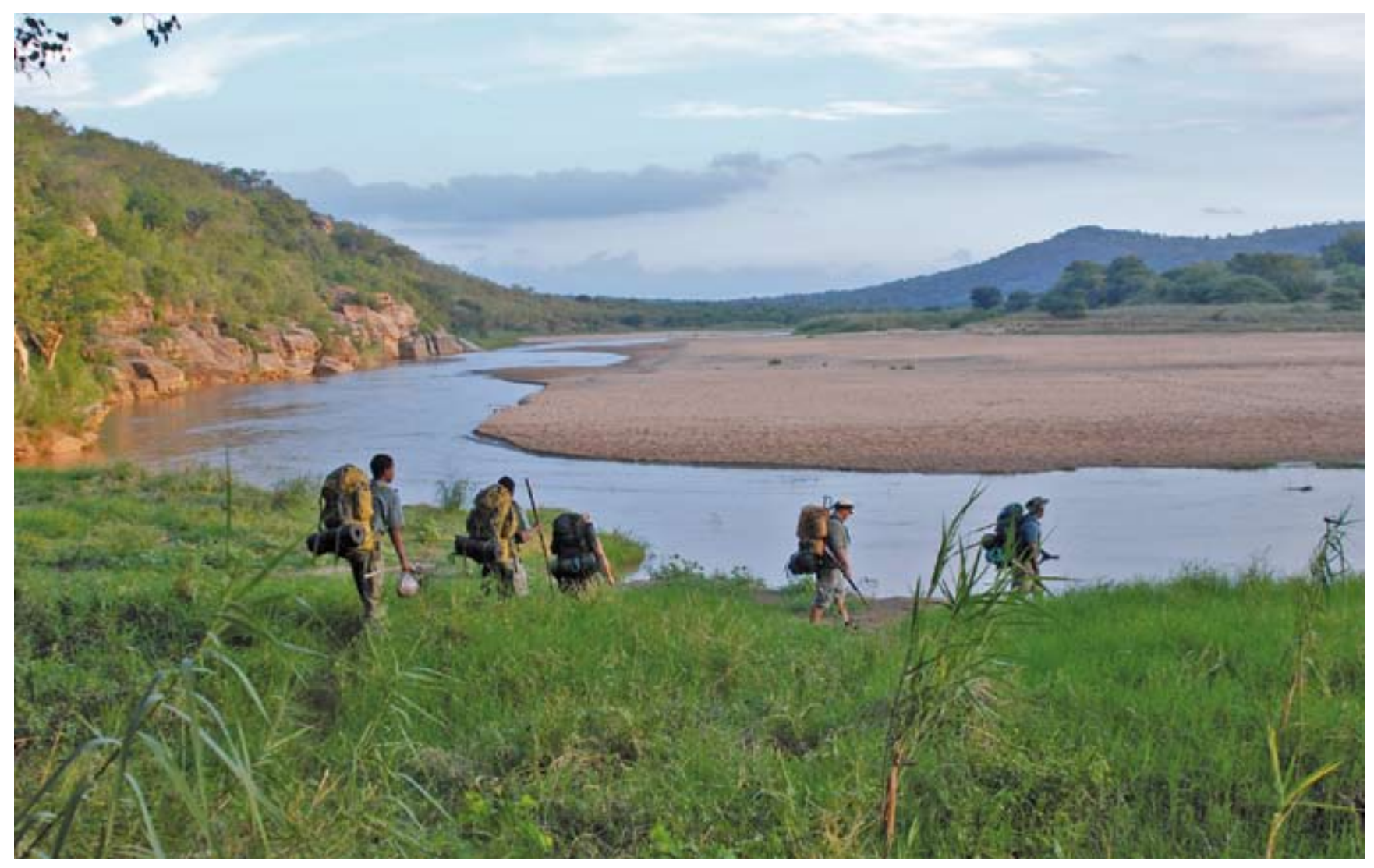

El Área Silvestre de Imfolozi (en la Reserva de Caza de KwaZulu Natal, Sudáfrica) es una área de categoría Ib, gestionada provincialmente, de la que surgieron los impulsos para crear otras áreas silvestres en África. Aquí, "rastreadores" de la Escuela de Liderazgo de Territorios Vírgenes (Wilderness Leadership School) visitan la área en una excursión a pie de cinco días que utiliza modos de acampada de bajo impacto. (C) Vance G. Martin 


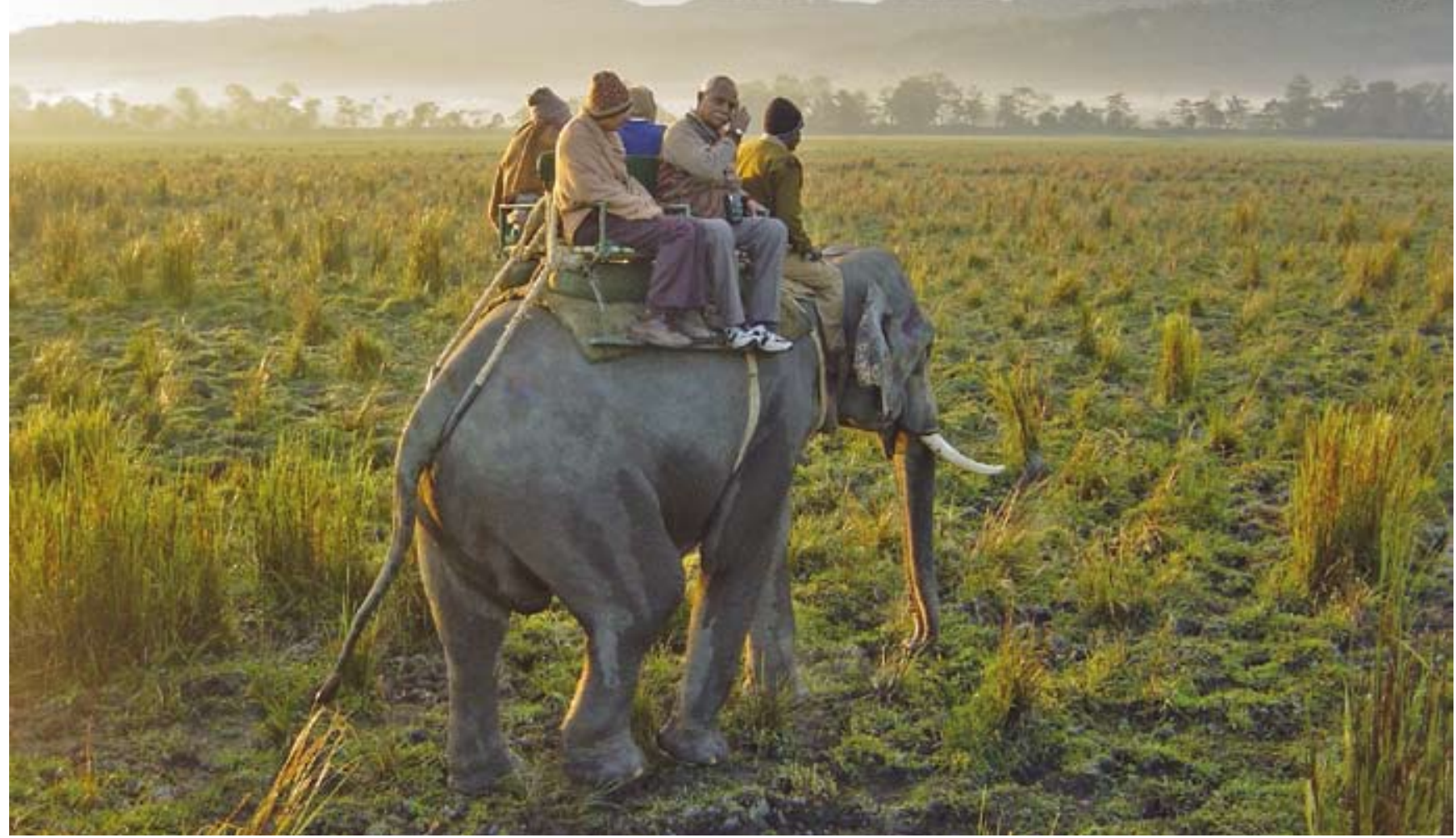

Kaziranga es un Parque Nacional clásico de categoría II. Famoso por el gran rinoceronte indio de un solo cuerno, los turistas pueden disfrutar del paisaje de Kaziranga a lomos de elefante o en viajes en barco en el Río Brahmaputra. (C) Nigel Dudley

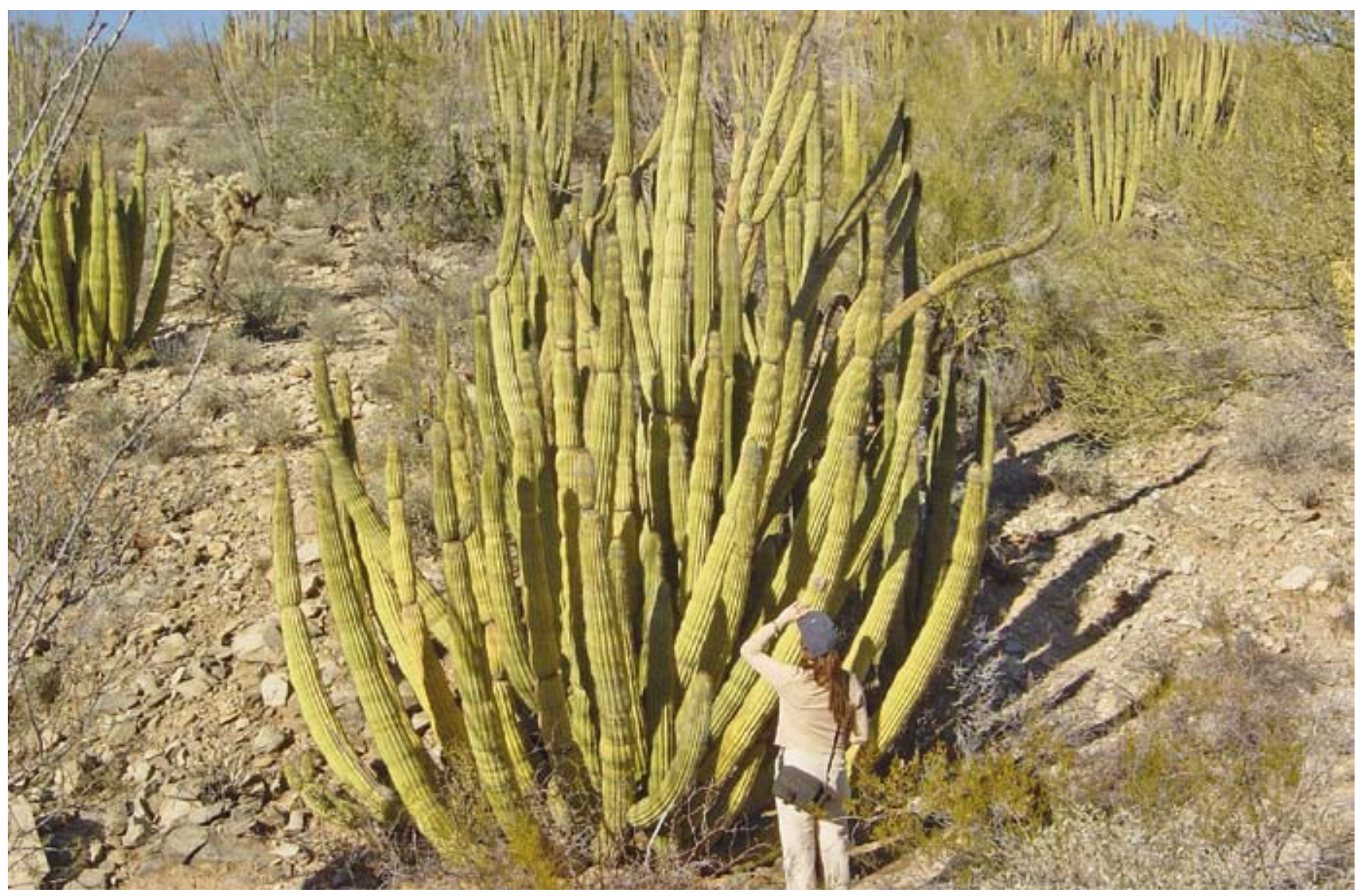

El Monumento Nacional del Cactus Saguaro (categoría III) protege la mayoría de los saguaros de los Estados Unidos. (C) Nigel Dudley 


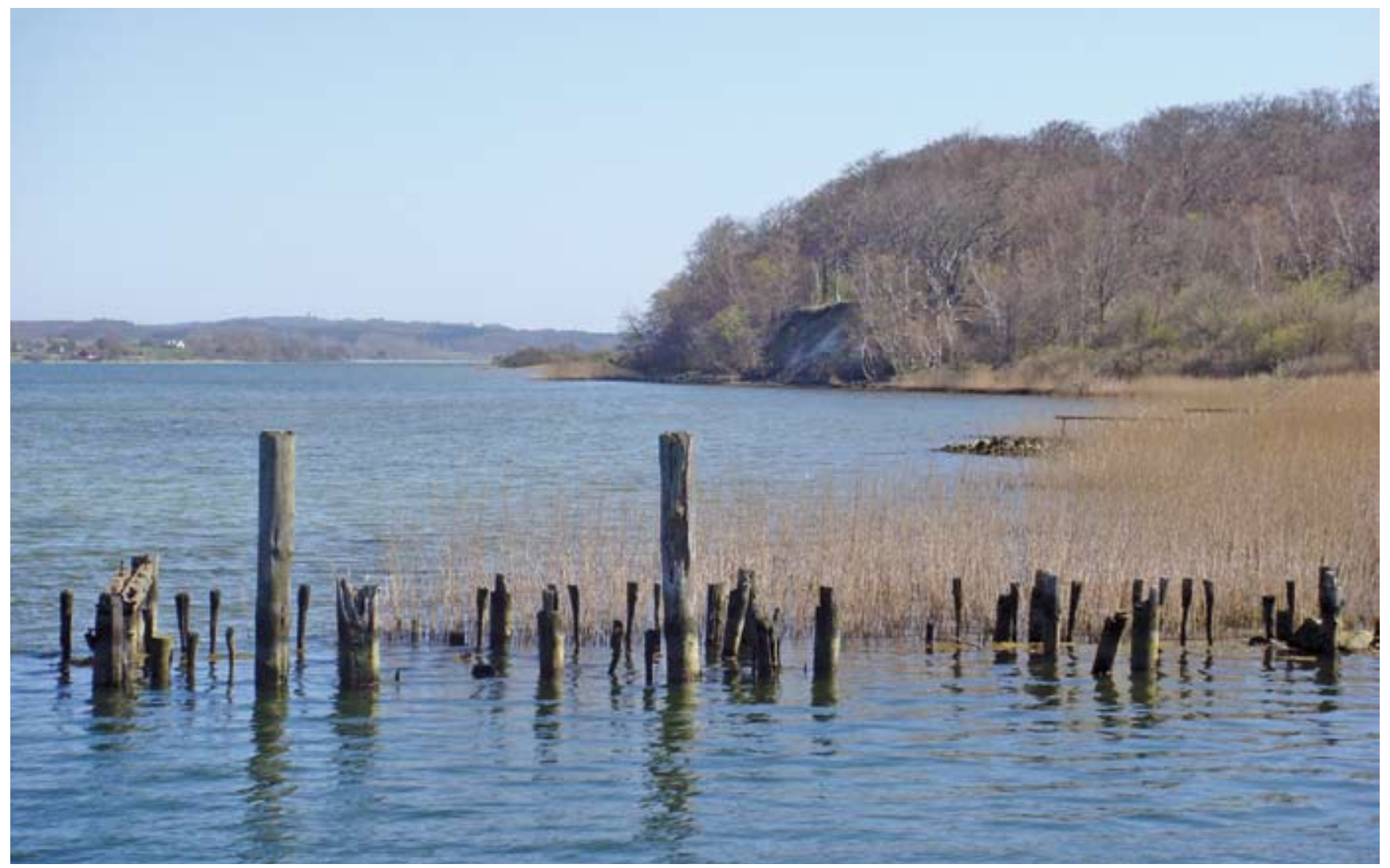

Con una superficie de menos de $1 \mathrm{~km}^{2}$, la Reserva Natural de Insel Vilm, de categoría IV, alberga algunos los robledales y hayedos más viejos de Alemania; las visitas están estrictamente controladas y gran parte de la isla está vedada a la presencia humana. C Sue Stolton

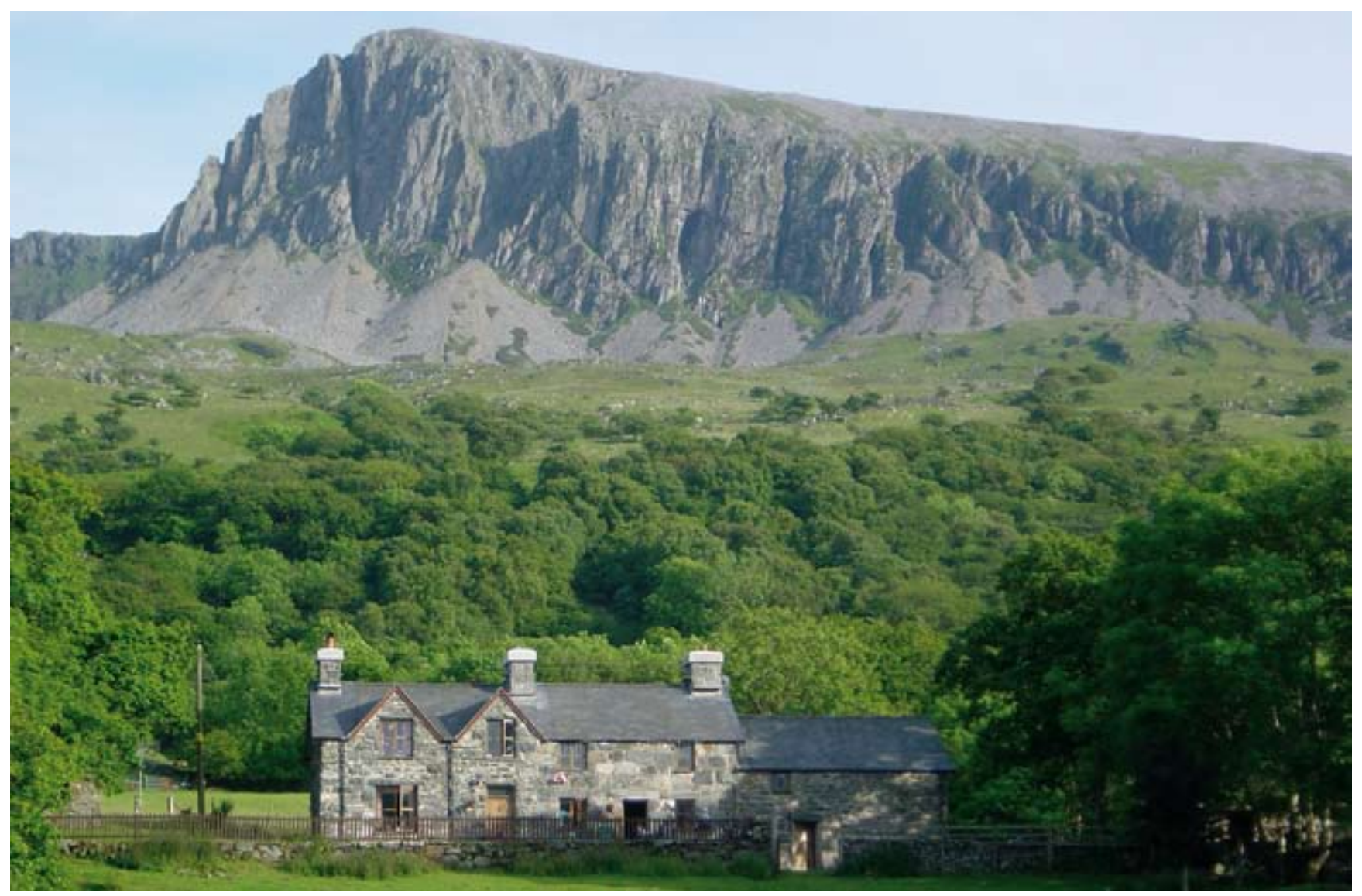

El Parque Nacional Snowdonia en Gales, de categoría V, protege extensas áreas de tierras altas, barridas por el viento y picos serrados dentro de un paisaje cultural, dominado por el impacto del pastoreo y la vieja industria minera. (C) Nigel Dudley 


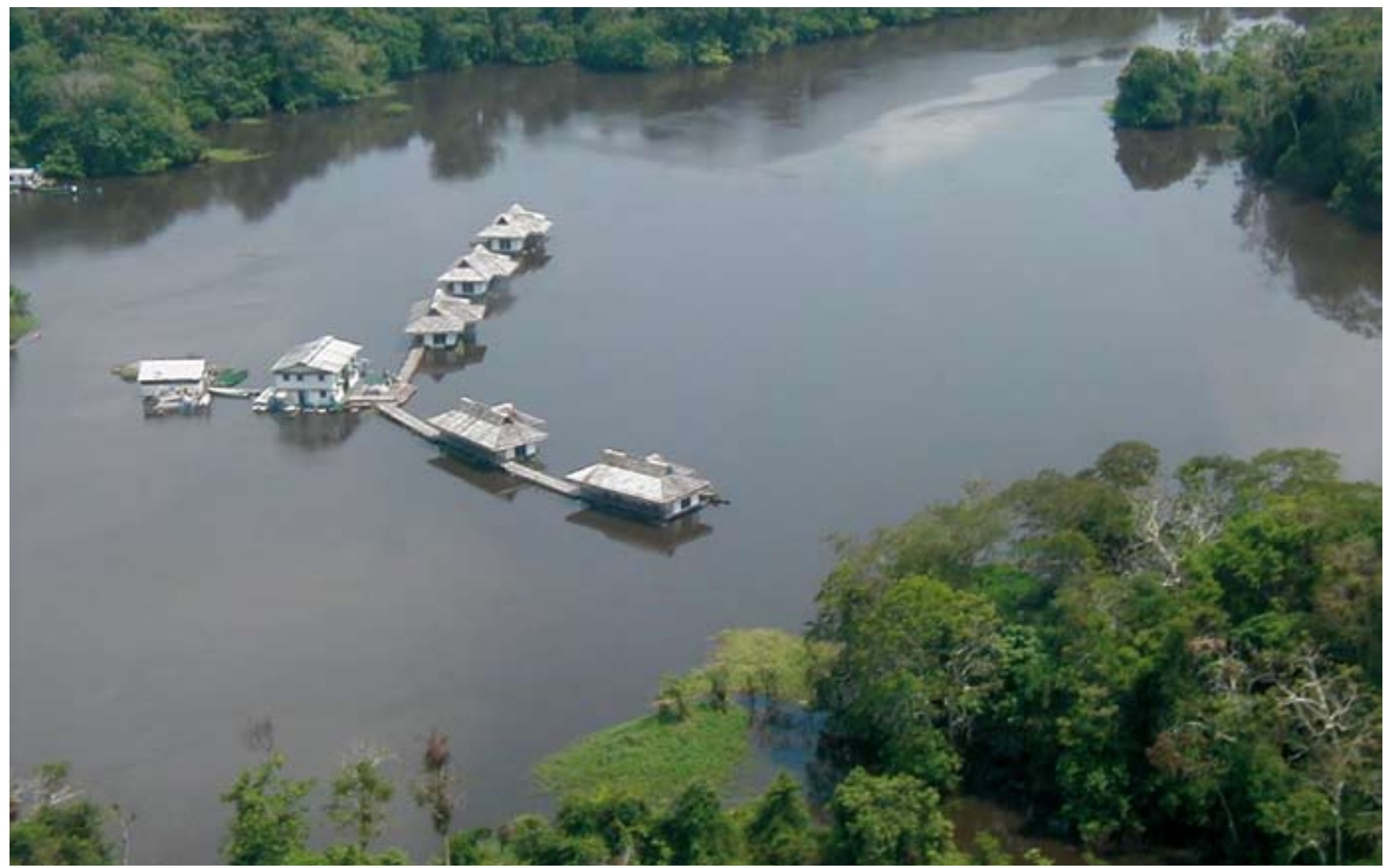

La Reserva de Desarrollo Sostenible de Mamirauá (categoría VI) en Brasil es parte de un gran complejo de conservación (más de seis millones de hectáreas) en la Cuenca Amazónica. Su gestión combina la necesidad de conservar la biodiversidad a la vez que proporciona opciones para fortalecer los modos de vida sostenibles de la población local. (C) Jim Barborak

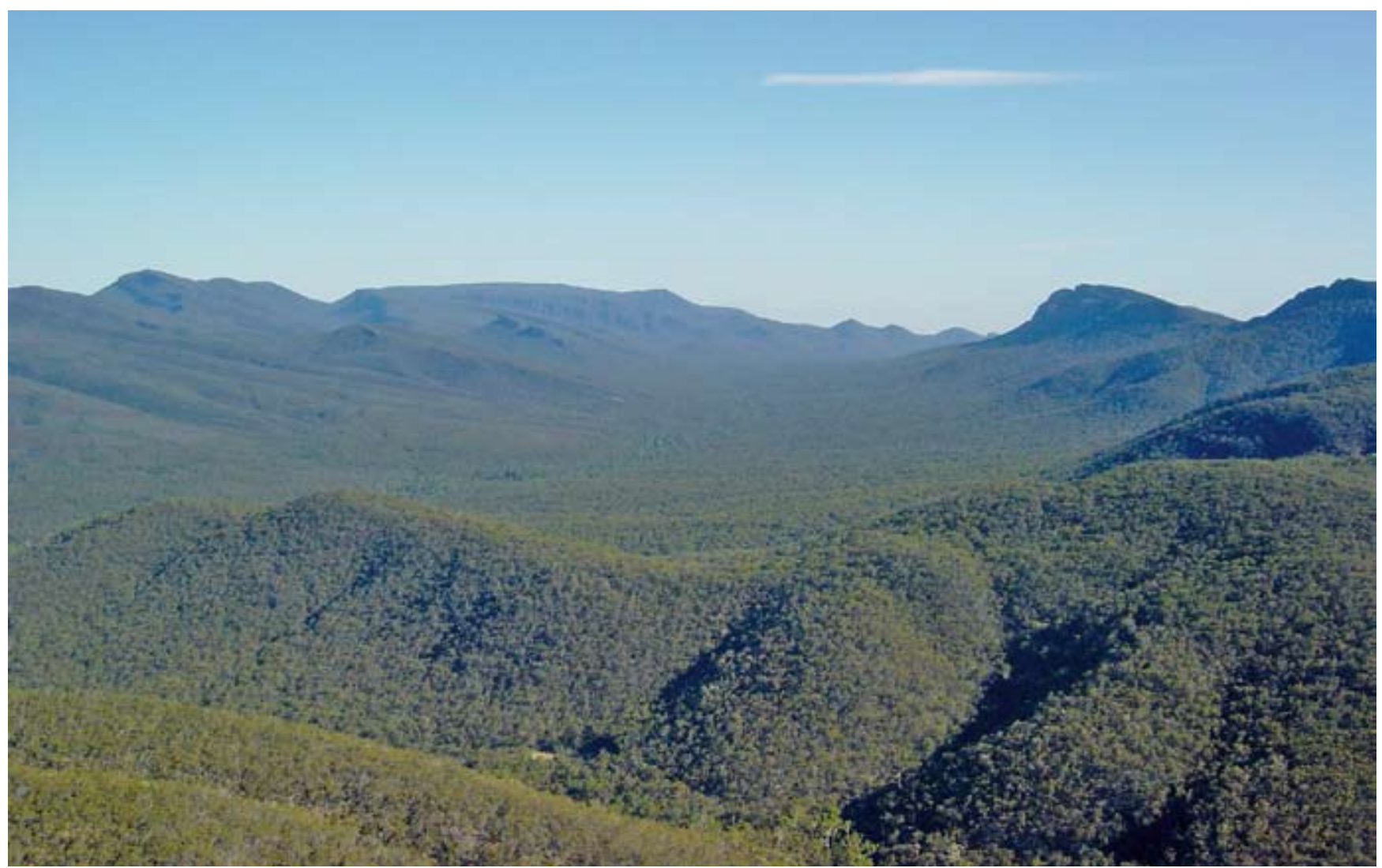

El Parque Nacional de los Montes Grampianos en Victoria, Australia, de categoría II, protege 975 especies vasculares; un tercio de la flora del Estado, 148 de las cuales están amenazadas en Victoria. (C) Nigel Dudley 


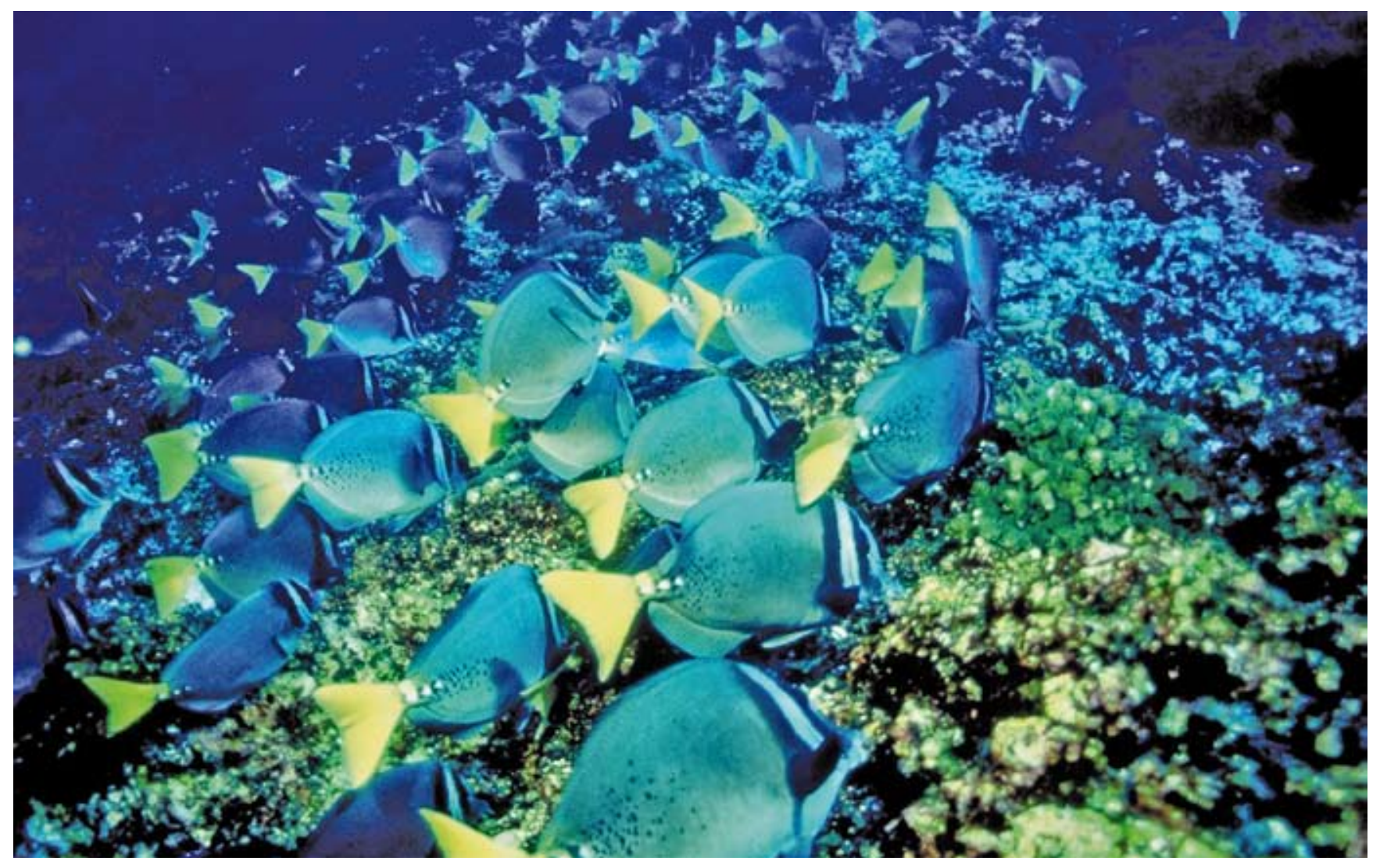

Las aguas altamente productivas protegidas por la Reserva Natural del Atolón de las Rocas (Categoría Ia, Brasil) proporciona un lugar de alimento a especies como el atún, pez espada, cetáceos, tiburones y tortugas marinas cuando migran a la costa de África en el este del Atlántico. (C) Pedro Rosabal

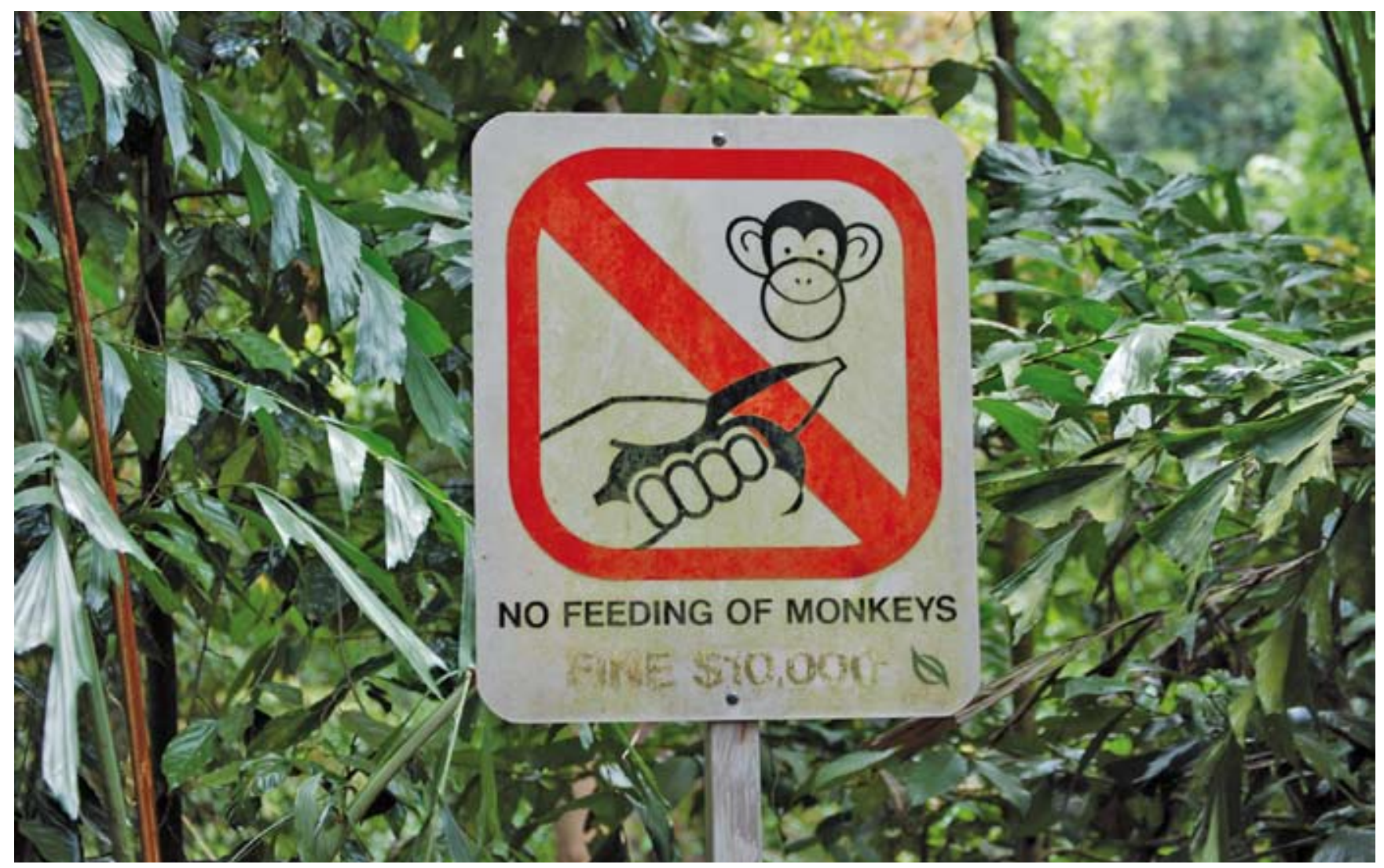

Las únicas áreas de selva que quedan en Singapur, están protegidas en la Reserva Natural de Bukit Timah (164 ha) y en la contigua Reserva Natural Central Catchment (unas 2000 ha); ambas, áreas protegidas de categoría IV. Juntas comprenden menos del 4 por ciento de la selva original. (C) Nigel Dudley 


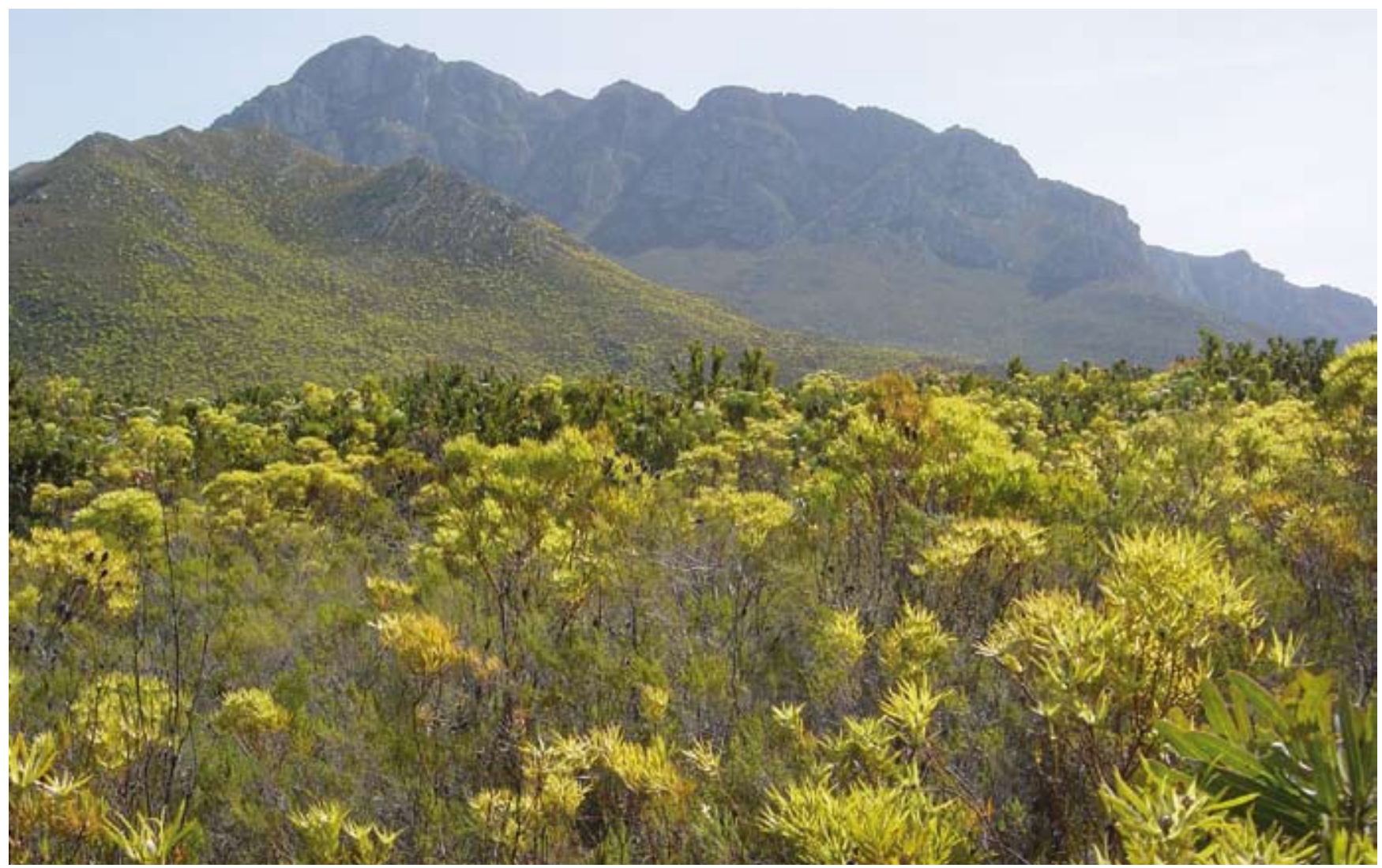

La Reserva de la Biosfera de Kogelberg fue la primera Reserva de la biosfera en ser declarada en el sur de África y forma parte de la red mundial de Reservas de la biosfera de la UNESCO. La reserva presume de 1300 especies vegetales diferentes en sus 10,000 $\mathrm{km}^{2}-\mathrm{la} \mathrm{diversidad}$ de plantas más alta del mundo. (C) Nigel Dudley

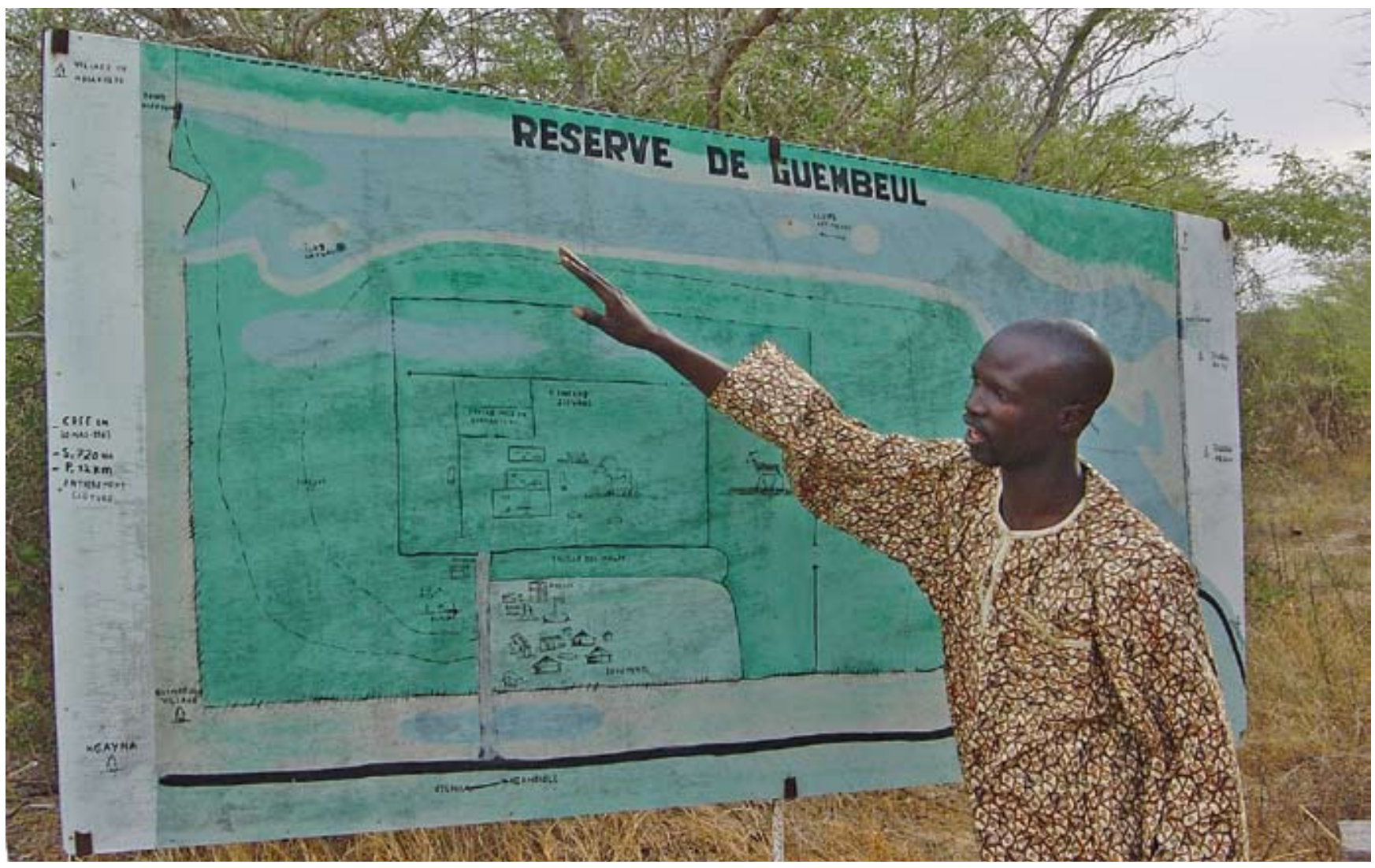

La Reserva de Geumbeul es una área pequeña conservada por la comunidad en Senegal, protegiendo manglares costeros, poblaciones de cría de una tortuga gigante y el oryx del sur (Oryx gazella). C Nigel Dudley 


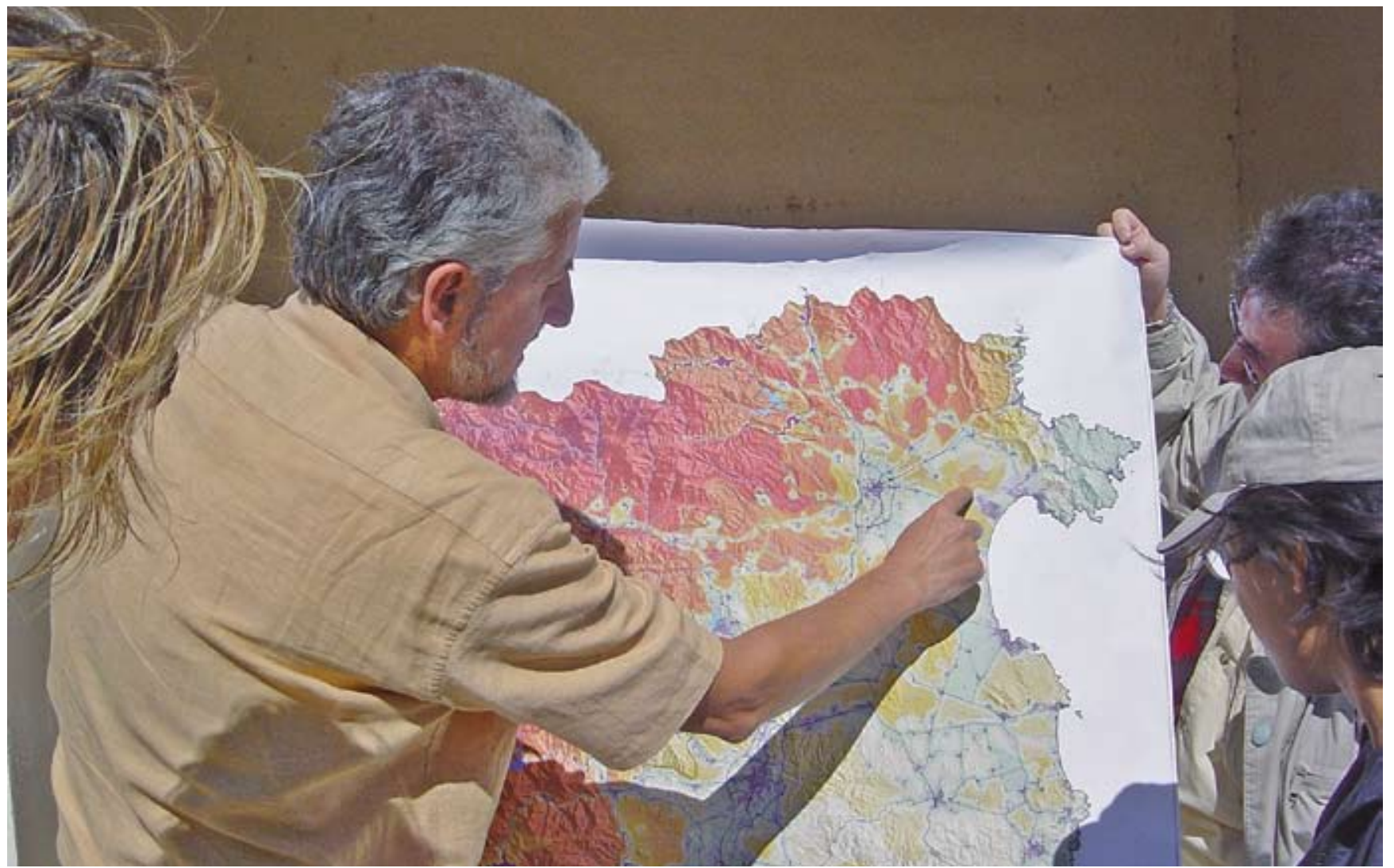

Debatiendo la zonificación de las áreas protegidas en Cataluña, España. Una red de áreas protegidas en diferentes categorías ayuda a mantener la biodiversidad de su rico paisaje mediterráneo. (C) Nigel Dudley

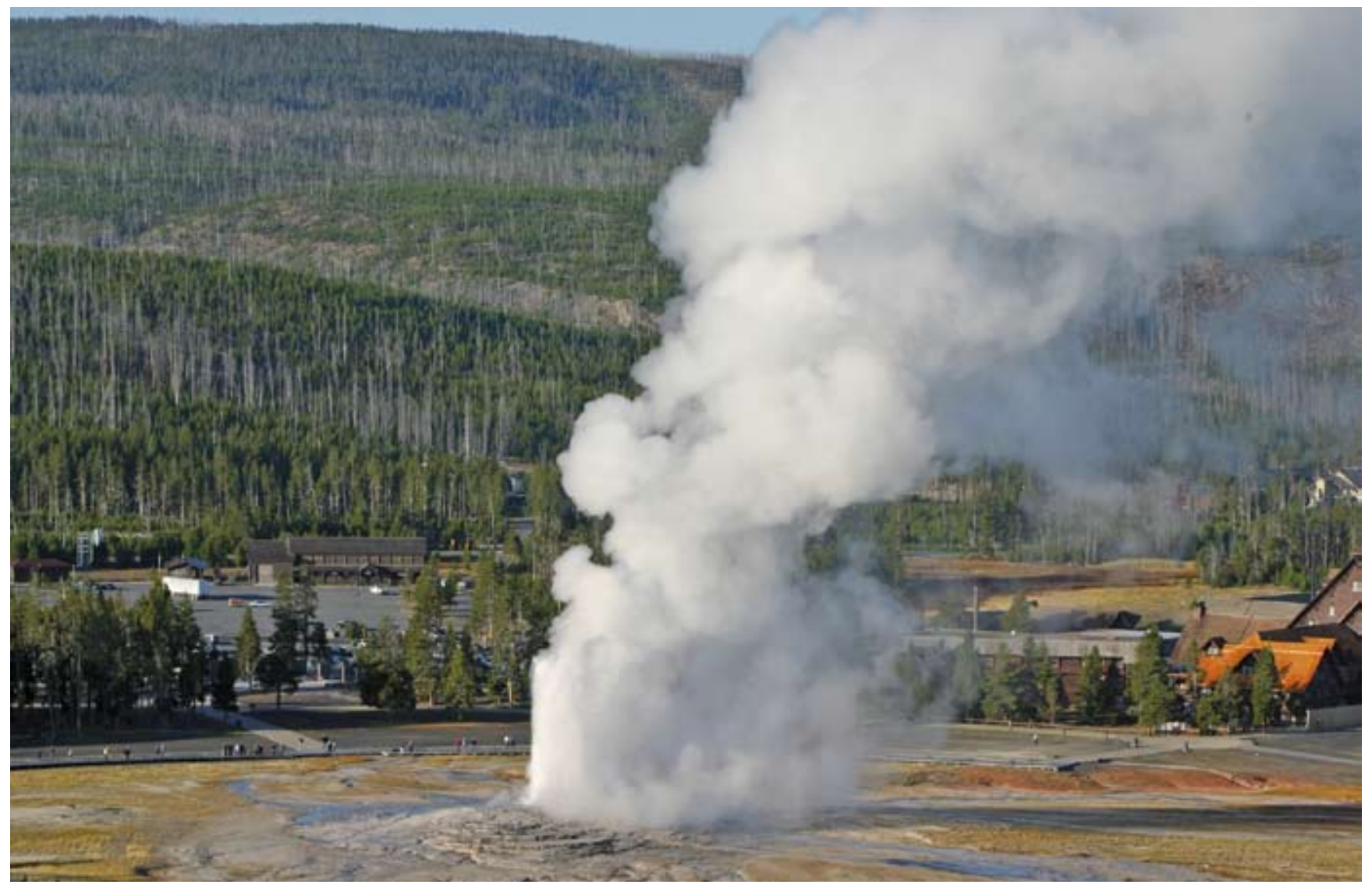

El Parque Nacional Yellowstone (category II) en los EEUU es un paisaje que está siendo moldeado continuamente por las fuerzas geológicas. Yellowstone posee el conjunto más diverso e intacto de géiseres, manantiales de agua caliente, ciénagas de barro y fumarolas del planeta.

(C) Roger Crofts 


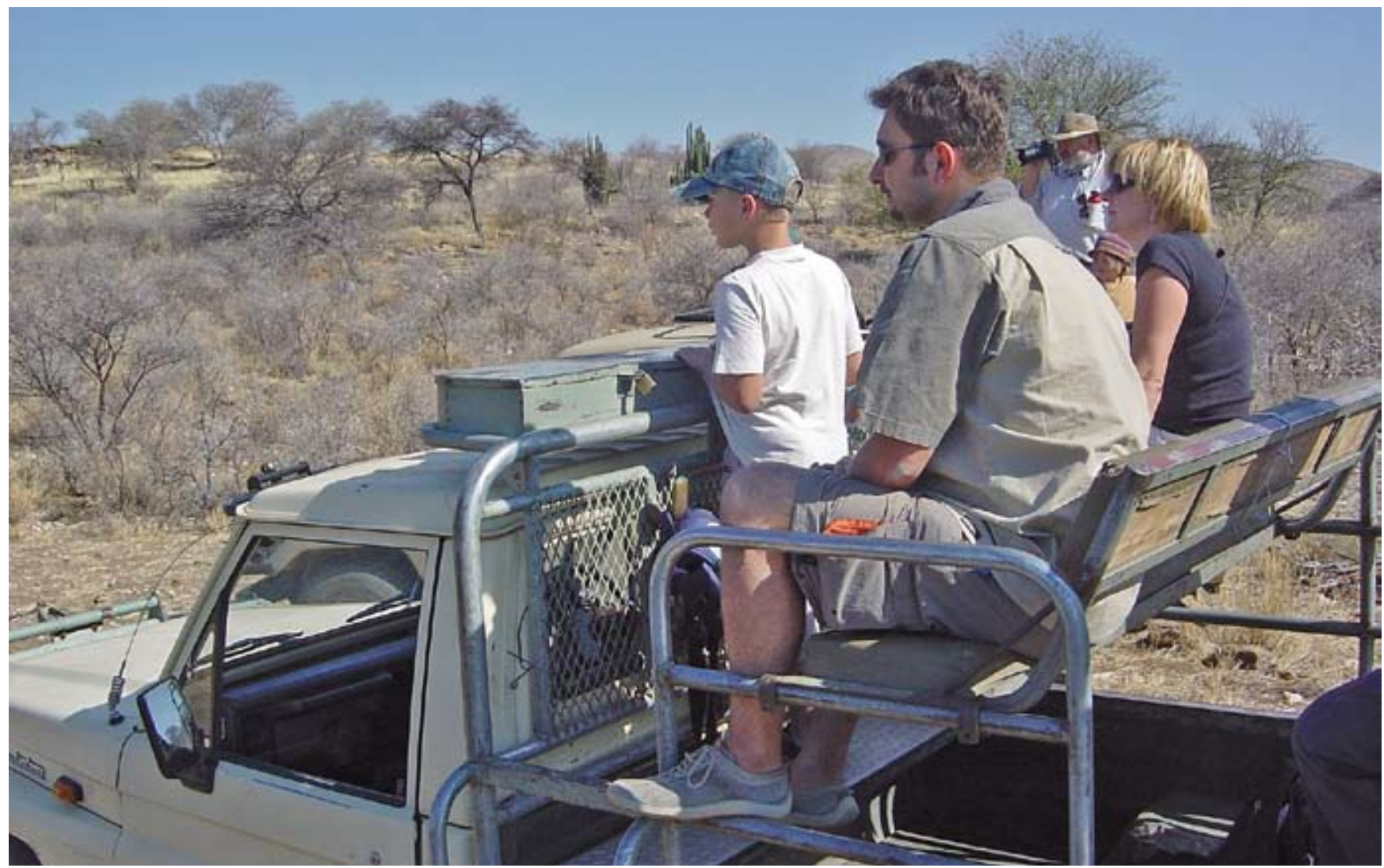

Se ha calculado que en el sur de África (Botswana, Namibia, Sudáfrica y Zimbabwe) hay unos 14 millones de ha de tierras privadas bajo alguna forma de protección de la vida silvestre o bajo una gestión sostenible de la misma. (C) Nigel Dudley

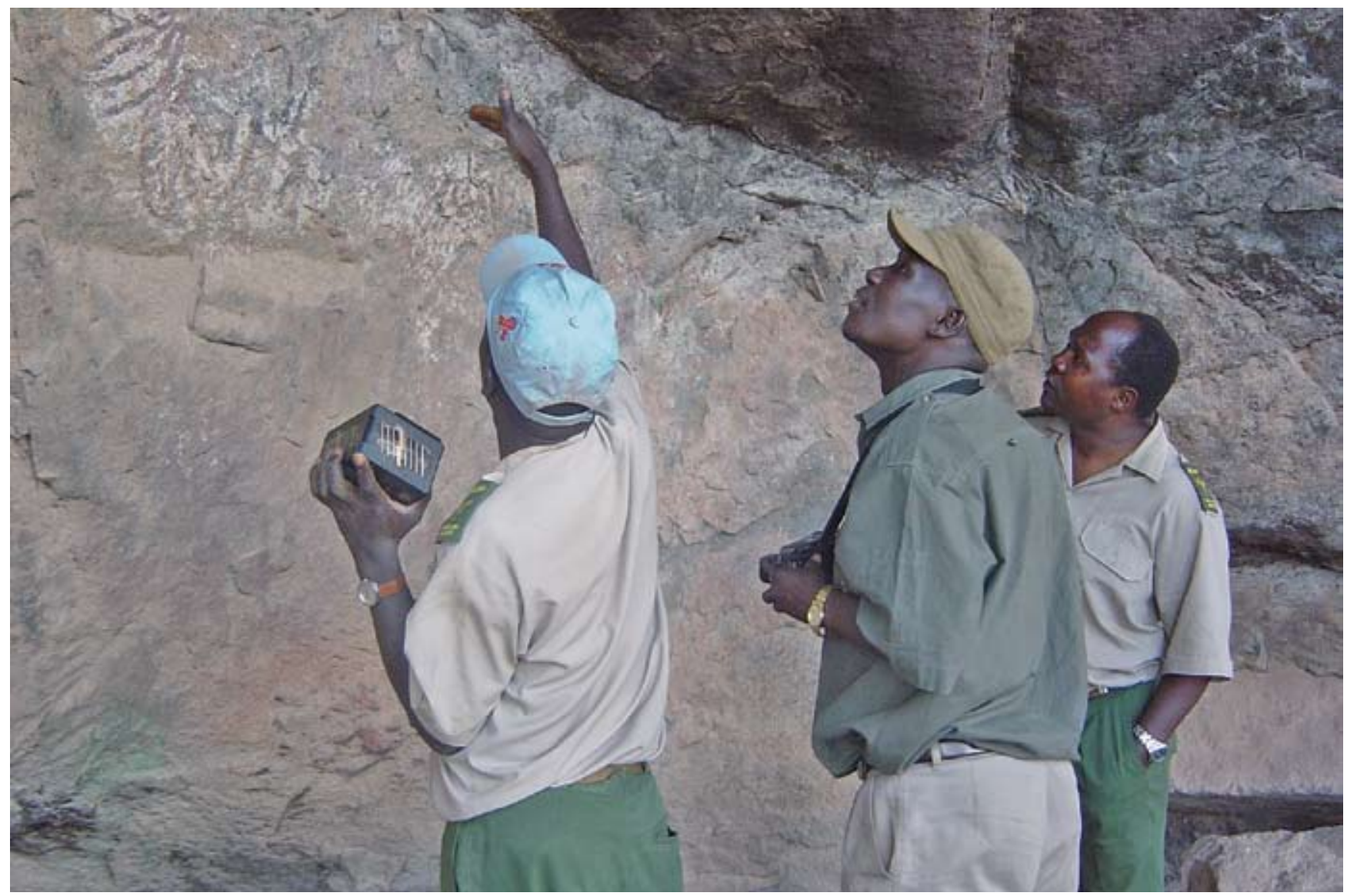

El Parque Nacional Nyika (categoría II) en Malawi contiene varios lugares naturales sagrados y también arte rupestre de las rocas, además de altos niveles de biodiversidad autóctona. (C) Nigel Dudley 
La mayoría de estas estrategias van más allá del alcance de las directrices que se recogen en esta publicación. Sin embargo, necesitamos desarrollar información sobre los meritos relativos del uso de las diferentes categorías y como las mismas pueden ser utilizadas más eficazmente como un elemento clave en las estrategias generales de respuesta al cambio climático. La tabla 5 ofrece un análisis preliminar de las fortalezas, debilidades, oportunidades y amenazas de cada categoría desde la perspectiva del cambio climático.

Tabla 5. Análisis de Fortalezas-Debilidades-Oportunidades-Amenazas por categorías en condiciones de cambio climático

\begin{tabular}{|c|c|c|c|c|}
\hline Categoría & Fortalezas & Debilidades & Oportunidades & Amenazas \\
\hline Categoría la & $\begin{array}{l}\text { La protección estricta } \\
\text { de un medio prístino } \\
\text { aporta datos básicos } \\
\text { para medir cambios y } \\
\text { planear respuestas. }\end{array}$ & $\begin{array}{l}\text { Con frecuencia } \\
\text { bastante } \\
\text { pequeño, por } \\
\text { tanto con poca } \\
\text { capacidad } \\
\text { amortiguadora. }\end{array}$ & $\begin{array}{l}\text { El estrés añadido } \\
\text { puede necesitar de una } \\
\text { mayor intervención y un } \\
\text { cambio de categoría a, } \\
\text { por ejemplo, un enfoque } \\
\text { de categoría IV. }\end{array}$ & \multirow{2}{*}{$\begin{array}{l}\text { Dejar un área protegida } \\
\text { totalmente sola a } \\
\text { expensas de los } \\
\text { procesos naturales } \\
\text { puede ser una opción } \\
\text { muy arriesgada ante un } \\
\text { cambio medioambiental } \\
\text { rápido. }\end{array}$} \\
\hline Categoría lb & \multirow{2}{*}{$\begin{array}{l}\text { Por lo general, se } \\
\text { cree que las zonas } \\
\text { extensas de hábitat } \\
\text { relativamente no } \\
\text { modificado son más } \\
\text { fuertes al absorber } \\
\text { condiciones climáticas } \\
\text { cambiantes - con la } \\
\text { ventaja de proteger } \\
\text { ecosistemas completos } \\
\text { y sus procesos } \\
\text { asociados. }\end{array}$} & & $\begin{array}{l}\text { Una oportunidad de } \\
\text { mantener áreas muy } \\
\text { amplias de hábitat } \\
\text { no modificado con } \\
\text { intervención humana } \\
\text { mínima para permitir } \\
\text { adaptación natural al } \\
\text { cambio climático. }\end{array}$ & \\
\hline Categoría II & & & $\begin{array}{l}\text { Espacio para } \\
\text { centrarse en enfoques } \\
\text { ecosistémicos, gestión } \\
\text { activa ya en marcha } \\
\text { para facilitarlo. }\end{array}$ & \multirow{2}{*}{$\begin{array}{l}\text { Muchas áreas } \\
\text { protegidas de categoría } \\
\text { II y III sobreviven } \\
\text { gracias a los ingresos } \\
\text { del turismo, que pueden } \\
\text { estar en peligro por } \\
\text { los altos precios del } \\
\text { petróleo y las campañas } \\
\text { contra los vuelos } \\
\text { vacacionales. }\end{array}$} \\
\hline Categoría III & $\begin{array}{l}\text { Por lo general sitios } \\
\text { emblemáticos con alto } \\
\text { grado de compromiso } \\
\text { y protección } \\
\text { continuada. }\end{array}$ & $\begin{array}{l}\text { Con frecuencia } \\
\text { demasiado } \\
\text { reducidos para } \\
\text { absorber los } \\
\text { impactos del } \\
\text { cambio climático. }\end{array}$ & $\begin{array}{l}\text { Pueden proporcionar } \\
\text { "islas" de protección } \\
\text { en paisajes que de } \\
\text { otra forma quedarían } \\
\text { seriamente alterados. }\end{array}$ & \\
\hline Categoría IV & $\begin{array}{l}\text { Puede que las } \\
\text { intervenciones de } \\
\text { gestión para mantener } \\
\text { los hábitats y especies } \\
\text { que se quieren } \\
\text { proteger ya hayan } \\
\text { sido recogidas en los } \\
\text { planes del sitio. }\end{array}$ & $\begin{array}{l}\text { Por lo general } \\
\text { fragmentos del } \\
\text { hábitat proclives a } \\
\text { tener resistencia } \\
\text { relativamente } \\
\text { baja al cambio } \\
\text { climático. }\end{array}$ & $\begin{array}{l}\text { Ya existe gestión } \\
\text { humana, luego } \\
\text { proporcionan un } \\
\text { laboratorio útil para } \\
\text { ensayar modificaciones } \\
\text { en la gestión. }\end{array}$ & $\begin{array}{l}\text { Pérdida de las } \\
\text { condiciones necesarias } \\
\text { para la especie concreta } \\
\text { que se está protegiendo. }\end{array}$ \\
\hline Categoría V & $\begin{array}{l}\text { Estrategias de gestión } \\
\text { a largo plazo en } \\
\text { marcha. }\end{array}$ & \multirow[t]{2}{*}{$\begin{array}{l}\text { Una parte del } \\
\text { hábitat ya está } \\
\text { alterado y puede } \\
\text { que debilitado } \\
\text { (por ejemplo } \\
\text { ante la presencia } \\
\text { de especies } \\
\text { invasoras). }\end{array}$} & $\begin{array}{l}\text { Cooperación con } \\
\text { comunidades locales } \\
\text { para desarrollar } \\
\text { estrategias de } \\
\text { gestión adaptables, } \\
\text { principalmente en } \\
\text { paisajes culturales y } \\
\text { marinos. }\end{array}$ & $\begin{array}{l}\text { Abandono de la tierra } \\
\text { debido a condiciones } \\
\text { cambiantes y por } \\
\text { tanto pérdida de } \\
\text { sistemas culturales } \\
\text { de los que depende la } \\
\text { biodiversidad. Presiones } \\
\text { adicionales sobre los } \\
\text { recursos debido a } \\
\text { condiciones más duras. }\end{array}$ \\
\hline Categoría VI & $\begin{array}{l}\text { Compromiso humano } \\
\text { con la protección a } \\
\text { largo plazo. }\end{array}$ & & $\begin{array}{l}\text { Cooperación con } \\
\text { comunidades locales } \\
\text { para desarrollar } \\
\text { estrategias de gestión } \\
\text { adaptables para una } \\
\text { gestión sostenible. }\end{array}$ & $\begin{array}{l}\text { El cambio climático hace } \\
\text { menos viables sistemas } \\
\text { de gestión antes } \\
\text { sostenibles. }\end{array}$ \\
\hline
\end{tabular}


Tabla 5. Análisis de Fortalezas-Debilidades-Oportunidades-Amenazas por categorías en condiciones de cambio climático (cont.)

\begin{tabular}{|c|c|c|c|c|}
\hline Categoría & Fortalezas & Debilidades & Oportunidades & Amenazas \\
\hline $\begin{array}{l}\text { Todas las } \\
\text { categorías }\end{array}$ & $\begin{array}{l}\text { Mantener ecosistemas } \\
\text { sanos, pues se } \\
\text { considera que son } \\
\text { los mejor adaptados } \\
\text { para hacer frente a los } \\
\text { impactos del cambio } \\
\text { climático. } \\
\text { Mantener el potencial } \\
\text { adaptativo y bancos de } \\
\text { genes in-situ. }\end{array}$ & $\begin{array}{l}\text { Fijos en una } \\
\text { ubicación y por } \\
\text { tanto susceptibles } \\
\text { a cambios } \\
\text { climáticos. }\end{array}$ & $\begin{array}{l}\text { Cambiar estrategias de } \\
\text { gestión como respuesta } \\
\text { al cambio, valiéndose de } \\
\text { la experiencia en otras } \\
\text { categorías y en gestión } \\
\text { sostenible fuera de las } \\
\text { áreas protegidas. }\end{array}$ & $\begin{array}{l}\text { El cambio climático } \\
\text { convierte al sitio en } \\
\text { no apropiado para las } \\
\text { especies y los hábitats } \\
\text { que se pretenden } \\
\text { proteger. }\end{array}$ \\
\hline
\end{tabular}

\section{Utilización de las categorías de áreas protegidas de la UICN como herramienta para las políticas de conservación}

Aunque las categorías no se pensaron en un principio como instrumentos de políticas, en la práctica a menudo se han usado como tales, tanto por la propia UICN como por gobiernos y otras instituciones. Aquellos que utilizan las categorías deben ser conscientes de esta realidad y tenerlo en cuenta al aplicarlas. Hay seis grandes tipos de uso en las políticas, con diferentes grados de estatus oficial:

- Políticas internacionales descriptivas: donde las categorías se adoptaron oficialmente para registrar e informar - uno de los objetivos originales del sistema de categorías. El sistema de la ONU ha adoptado el sistema de categorías, por ejemplo en la Lista de la ONU de Áreas Protegidas $^{8}$ y el CDB en el Programa de Trabajo sobre Areas Protegidas y en la Base de Datos Mundial sobre Áreas Protegidas. A nivel internacional, se ha hecho un uso limitado del sistema de categorías dentro de las instituciones y acuerdos mundiales como los del Grupo Intergubernamental sobre los Bosques, la Evaluación de Recursos Forestales de la ONU, y también en el contexto de las reservas de la biosfera.

- Políticas internacionales prescriptivas: con mayor controversia, las categorías se han utilizado de forma limitada para sugerir políticas internacionales incluyendo controles sobre intervenciones de gestión concretas dentro de áreas protegidas. Más significativo fue el desarrollo de una posición de la UICN sobre la exclusión de las actividades mineras en las categorías I a IV. Esta recomendación (número 2.82) fue adoptada por el Congreso mundial de la conservación de la UICN que tuvo lugar en Amán en el 2000. Recomendó, inter alia que: "Los miembros de la UICN que probiban por ley, toda explotación y extracción de recursos minerales en áreas protegidas que correspondan a las Categorias I a IV de Gestión de Areas Protegidas". Esta recomendación desempeñó un papel importante para que Shell y el CIMM adoptaran un compromiso de zonas de exclusión de la minería en sitios naturales Patrimonio Mundial. Supuso una nueva aplicación del sistema de categorías de la UICN pues vinculaba restricciones al uso de recursos con el propio sistema, y además provocó un debate importante sobre si el sistema era lo suficientemente riguroso para estos propósitos.

- Políticas regionales: dos convenios regionales y acuerdos han aplicado las categorías de la UICN (Dillon 2004). Estos son la Conservación de la Flora y la Fauna del Ártico (CAFF en sus siglas en inglés) - Red Circumpolar de Áreas Protegidas Estrategia y Plan de Acción en 1996, y el Convenio Africano Revisado sobre la Conservación de la Naturaleza y los Recursos Naturales en 2003. En el caso del Convenio Africano, las categorías de la UICN tuvieron una gran influencia sobre el desarrollo del Convenio revisado y aportó un referente para un número de secciones, inicialmente apoyadas por un grupo de trabajo en el que participaron diferentes agencias y que después fueron presentadas a un número de gobiernos africanos, que adaptaron el texto al contexto africano. El artículo V del Convenio define un Área de Conservación como cualquier área protegida designada y gestionada principalmente para una serie de objetivos, y a continuación detalla los objetivos haciendo referencia a las seis categorías de la UICN. Hay otro ejemplo de aplicación a nivel regional en Europa, donde la CMAP/Federación EUROPARC preparó una publicación sobre La Interpretación y Aplicación en Europa de las Categorías de Gestión de Áreas Protegidas que sirvió de guía en el contexto europeo.

- Políticas nacionales descriptivas: un número de países han realizados esfuerzos deliberados para alinear sus propios sistemas de categorización de áreas protegidas con el sistema de UICN, ya sea cambiando las categorías para que encajaran directamente en el sistema, o bien

8 Las Categorías de 1994 se utilizaron como base para recopilar las versiones de 1997 y 2003 de la Lista de la ONU. 
acordando equivalencias para que compararlas sea fácil. Aunque el uso de las categorías es voluntario, una mayoría de países actualmente las aplican a algunas de sus áreas protegidas, si no a todas. Alrededor del 10 por ciento de la legislación sobre áreas protegidas desde 1994 ha utilizado las categorías de la UICN. Entre otras la legislación de Australia, Brasil, Bulgaria, Cambodia, Cuba, Georgia, Hungría, Kuwait, México, Níger, Eslovenia, Uruguay y Viet Nam.

- Políticas nacionales prescriptivas: un pequeño subgrupo de países ha vinculado explícitamente sus políticas a las categorías, incluyendo el nivel de financiación (por ejemplo, Austria) o políticas sobre asentamientos en áreas protegidas. En algunos casos, los países han elaborado información sobre lo que las categorías significan en el contexto nacional, manteniendo el marco original, pero aportando detalles de las políticas - como en el caso de Madagascar.

- Políticas de ONG: el uso por parte de las ONGs es menos oficial, pero aún así es importante. Por ejemplo, varias ONG han considerado sólo las categorías I-IV como áreas protegidas influyendo así en muchos planes ecoregionales o bioregionales. Las ONGs también han utilizado las categorías para apoyar sus fines, por ejemplo presionando por una determinada forma de gestión en áreas protegidas.

\section{Lecciones aprendidas de la aplicación del sistema de categoría en las políticas}

La experiencia hasta la fecha, proporciona diversas enseñanzas acerca del uso de las categorías como políticas:

- Las categorías tienen un potencial significativo para influir a todos los niveles en la spolíticas y lalegislación, y su grado de aplicación ha experimentado un gran avance desde la publicación de las directrices en 1994;

- Se prevé que la influencia del sistema de categorías en las decisiones políticas aumente, particularmente a nivel nacional, según se vaya aplicando de una manera más amplia y efectiva el Programa de Trabajo sobre Áreas Protegidas del CDB;

- Las ventajas de incluir el sistema de categorías en la toma de decisiones políticas residen en que imprimen al sistema un peso y credibilidad adicionales, y permiten mejorar la concienciación y el entendimiento de los valores de las áreas protegidas;

- Se ha conseguido un uso más eficaz del sistema de categorías al aplicarse de una forma flexible, de acuerdo con las circunstancias regionales o nacionales específicas;

- La aplicación del sistema de categorías también otorga reconocimiento en términos de estándares internacionales.

Existen, sin embargo, ciertas limitaciones en la aplicación efectiva de las categorías en las decisiones políticas. Éstas incluyen:

- Se han cuestionado la validez y precisión de los procesos utilizados para la asignación de áreas protegidas a las categorías de la UICN, especialmente las categorías I-IV: en particular, los relativos a las recomendaciones de la política de la UICN sobre la exclusión de las actividades mineras en áreas protegidas de categoría I-IV, sugiriendo que su uso en políticas implica un mayor rigor en su aplicación de la que ha existido en el pasado;

- Existe una falta de concienciación y/o entendimiento del sistema de categorías de la UICN;

- La precisión y fiabilidad de los datos sobre áreas protegidas en la Base de Datos Mundial sobre Áreas Protegidas y en la Lista de la ONU de Áreas Protegidas es variable en muchos casos;

- Existe una falta de comprensión y concienciación sobre cómo el sistema de categorías puede ser aplicado no solo a nivel nacional sino en biomas concretos.

De todo ello se deriva que los futuros esfuerzos en el uso de las categorías en las decisiones políticas deben basarse en una comprensión más rigurosa y una aplicación objetiva de las categorías. 

6. Aplicaciones especializadas

Las áreas protegidas abarcan una gama muy amplia de biomas, modos de propiedad y motivaciones todos ellos influyen en la forma de establecer los objetivos de gestión y por lo tanto en las categorías que se aplican posteriormente. Este capítulo analiza con más detalle algunos casos particulares que han causado confusión en el pasado: bosques, áreas marinas y de agua dulce protegidas, lugares naturales sagrados y el papel de la restauración en la protección. 


\section{Áreas protegidas forestales}

Han existido confusiones sobre las áreas forestales protegidas, y en concreto sobre qué es lo que tiene importancia como área protegida en el bioma forestal, especialmente cuando dicha información se incorpora a un proceso de recogida de datos más amplio sobre recursos forestales. Las siguientes directrices (basadas en Dudley y Phillips 2006) abordan una serie de cuestiones entre las que se encuentran:

- Definición de bosque en el contexto de las áreas protegidas forestales;

- Aplicación del sistema de categorías de la UICN a los bosques;

- Cálculo de la superficie de las áreas protegidas forestales;

- ¿Qué áreas quedan fuera de la definición de área protegida forestal de la UICN?

- Distinción entre corredores biológicos, puntos conectores y zonas de amortiguamiento.

\section{Definición de bosque en el contexto de las áreas protegidas forestales}

La definición se ha tomado de la UNECE/FAO e incorpora la interpretación de la UICN:

\section{Definición de bosque de la UNECE/FAO}

Bosque: Tierras con una cobertura de copas (o la densidad de población equivalente) de más del 10 por ciento y superficie de más de 0,5 ha. Los árboles deberán alcanzar una altura mínima de $5 \mathrm{~m}$ en su madurez in situ. Un bosque puede consistir de formaciones cerradas en las que árboles de diferentes estratos y sotobosque cubren una buena parte del suelo, o formaciones forestales abiertas con una cubierta vegetal continua en la que la cobertura de copas supera el 10 por ciento. Se consideran bosque las poblaciones naturales jóvenes y todas las plantaciones realizadas con fines forestales que aún no han alcanzado una densidad de copas del 10 por ciento o una altura $5 \mathrm{~m}$, al igual que las áreas que normalmente forman parte natural de la zona boscosa carecen temporalmente de árboles como resultado de la intervención humana o de causas naturales pero que se espera que vuelvan a convertirse en bosque.

Incluye: Los viveros forestales y los huertos de semillas que constituyen parte integral del bosque; los caminos forestales, las zonas desbrozadas, los cortafuegos y otras áreas abiertas de superficie reducida; los bosques de los parques nacionales, las reservas naturales y otras áreas protegidas, como las de especial interés científico, histórico, cultural o espiritual; los cortavientos y cinturones de protección de árboles con un área de más de 0,5 ha y anchura superior a $20 \mathrm{~m}$; las plantaciones utilizadas principalmente con fines forestales, incluyendo las plantaciones de caucho y los alcornoques.
Excluye: Las tierras utilizadas predominantemente para fines agrícolas.

Otras tierras arboladas: Las tierras con cobertura de copas (o densidad de población equivalente) del 5-10 por ciento de árboles susceptibles de alcanzar una altura de $5 \mathrm{~m}$ en su madurez in situ; o una cobertura de copas (o densidad de población equivalente) de más del 10 por ciento de árboles incapaces de alcanzar los una altura de $5 \mathrm{~m}$ en su madurez in situ (por ej., árboles enanos o atrofiados); o con cubierta de matorral o arbusto superior al 10 por ciento.

Directriz política: La definición de la UNECE/FAO debería utilizarse para los bosques situados en áreas protegidas forestales con las siguientes advertencias:

- Los bosques de plantación cuyo objetivo de gestión principal es la obtención industrial de madera, caucho/resina o fruta no deben contabilizarse;

- Las tierras que están siendo restauradas a bosque natural deberían contabilizarse si el objetivo principal de la gestión es el mantenimiento y la protección de la biodiversidad y los valores culturales asociados;

- Los "bosques culturales" deberían incluirse si están siendo protegidos principalmente por su biodiversidad y sus valores culturales asociados.

\section{Aplicación del sistema de categorías de la UICN a los bosques}

Se puede evitar gran parte de la confusión posible sobre lo que es un área protegida o no si se subraya la naturaleza jerárquica de la definición y el sistema de categorías se aplica de forma secuencial. En resumen, las categorías se deben aplicar sólo a áreas protegidas forestales si el área en cuestión cumple previamente la definición de área protegida. Incluso después de haber identificado correctamente un área protegida, es posible equivocarse al decidir qué categoría se le asigna. Surgen dos cuestiones:

- ¿Qué proporción del área protegida debería ser boscosa para ser contabilizada como área protegida forestal? Algunos bosques importantes situados en áreas protegidas son de hecho hábitats minoritarios, como bosques relictos, bosques de ribera y manglares. Esto crea problemas de interpretación y de disponibilidad de datos. ¿Deberían los estadísticos forestales diferenciar las fracciones de las áreas protegidas que contienen bosque?

- ¿Son todos los bosques situados en un área protegida automáticamente un área protegida forestal? Algunas áreas protegidas especialmente de las categorías $\mathrm{V}$ y VI contienen zonas arboladas que no son bosques protegidos, 
como las plantaciones exóticas existentes en muchas áreas de categoría V de Europa. Estas no se ajustan a la definición de bosque propuesta para su utilización en áreas protegidas indicada anteriormente pero de hecho a veces se registran como "protegidos" - y por ello pueden aparecer en las estadísticas oficiales como "áreas protegidas forestales".

Es importante seguir un procedimiento estandarizado para determinar la superficie de las áreas protegidas forestales de manera que proporcione datos significativos y fieles. El cálculo debería seguir la secuencia que se muestra a continuación. Las áreas protegidas forestales pueden calcularse como un subconjunto no ambiguo en las estadísticas nacionales de áreas protegidas, recogiendo la información de todos los bosques protegidos pero eliminando las plantaciones que entren en las categorías de protección menos estrictas.

Orientación e interpretación para las políticas: el proceso de asignación debería por tanto comenzar por la definición de área protegida de la UICN y luego se debería depurar con referencia a las categorías de la UICN:

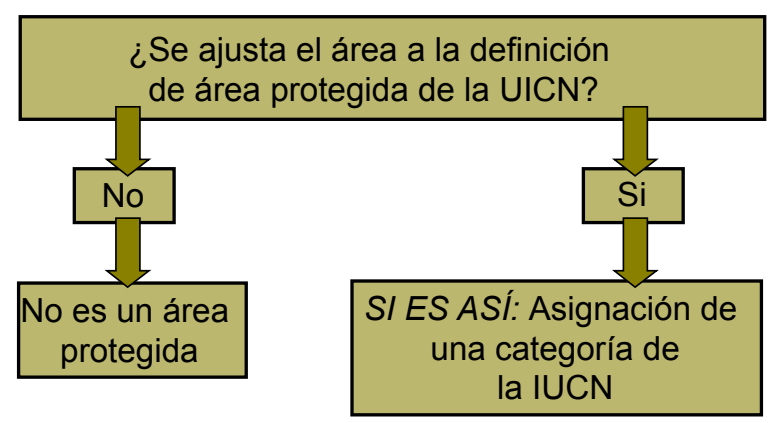

De aquí se deduce que un área que parece encajar en una de las categorías basándonos únicamente en las prácticas de gestión, pero que no se ajusta a la definición general de área protegida no debería ser considerada como área protegida según la define la UICN.

\section{Cálculo de la superficie de las áreas protegidas forestales}

Cuando se buscan estadísticas específicas a los bosques, es necesario identificar la porción de las áreas protegidas que contiene bosque. Esto rara vez será fácil y directo: muchas áreas protegidas contienen algo de bosque, incluso las "áreas protegidas forestales" a menudo no están compuestas exclusivamente por bosque y además a veces los cálculos tienen que tener en cuenta los bosques dentro de una protección más amplia a escala de paisaje que no cumplen los criterios de identificación indicados anteriormente.

Orientación para las políticas: el cálculo de la superficie de bosque protegido comprende los siguientes pasos:

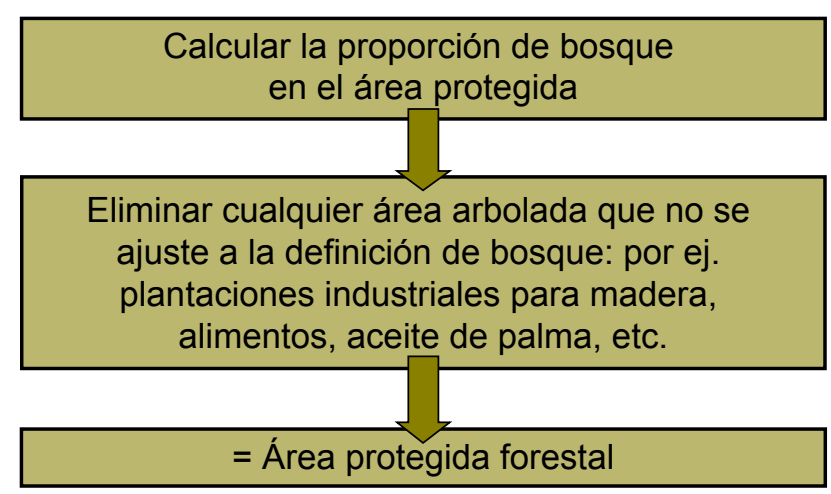

\section{¿Qué áreas quedan fuera de la definición de área protegida forestal de la UICN?}

Existen muchos usos forestales - algunos con valores sociales y ecológicos o biológicos grandes - que quedan fuera de la definición de la UICN.

Orientación para las políticas: las siguientes no son automáticamente áreas protegidas forestales:

- Bosques gestionados para la protección de recursos distintos a la biodiversidad - por ej. bosques protegidos para la protección de las vertientes o de agua potable, control de avalanchas, cortafuegos, cortavientos y control de la erosión;

- Bosques gestionados principalmente como recurso de la comunidad - por ej. bosques gestionados para la obtención de productos no madereros, leña y forraje, con fines recreativos o religiosos;

- Bosques gestionados como recurso estratégico - por ej. para suministro de madera en casos de emergencia en tiempos de conflicto;

- Bosques con objetivos de gestión primarios no claros lo que significa que la protección de la biodiversidad es una prioridad igual o menor que otros usos;

- Bosques protegidos por accidente - por ej. terrenos boscosos en la mediana o los bordes de autopistas, bosques mantenidos con fines militares o de seguridad.

A continuación la Tabla 6 ofrece algunos ejemplos. 
Tabla 6. Ejemplos de Áreas Protegidas Forestales, y también de bosques bien conservados que no son Áreas Protegidas Forestales

\begin{tabular}{|c|c|c|}
\hline Tipo de bosque & Ejemplo & Notas \\
\hline \multicolumn{3}{|c|}{ Ejemplos de Áreas Protegidas Forestales } \\
\hline $\begin{array}{l}\text { Área protegida de } \\
\text { categoría I de la } \\
\text { UICN }\end{array}$ & $\begin{array}{l}\text { Reserva Natural de } \\
\text { Wolong, Sichuan, } \\
\text { China }\end{array}$ & $\begin{array}{l}\text { Área estrictamente protegida establecida principalmente para } \\
\text { proteger el panda gigante, incluyendo un centro de cría en } \\
\text { cautividad. }\end{array}$ \\
\hline $\begin{array}{l}\text { Área protegida de } \\
\text { categoría II de la } \\
\text { UICN }\end{array}$ & $\begin{array}{l}\text { Parque Nacional de } \\
\text { Huerquehue, Chile }\end{array}$ & $\begin{array}{l}\text { Este parque nacional está enteramente protegido (existen algunas } \\
\text { edificaciones en el mismo pero están excluidas del área protegida } \\
\text { que están dedicadas al ecoturismo). Se estableció principalmente } \\
\text { para la conservación de los bosques de araucarias únicos. }\end{array}$ \\
\hline $\begin{array}{l}\text { Categoría III de la } \\
\text { UICN }\end{array}$ & $\begin{array}{l}\text { Área de Usos } \\
\text { Múltiples de } \\
\text { Monterrico, } \\
\text { Guatemala }\end{array}$ & $\begin{array}{l}\text { Es un área costera con la masa compacta de manglares más } \\
\text { extensa que queda en el país, junto con playas de tortugas y } \\
\text { varias comunidades marinas. Los manglares se gestionan para la } \\
\text { protección de la pesca artesanal. }\end{array}$ \\
\hline $\begin{array}{l}\text { Categoría IV de la } \\
\text { UICN }\end{array}$ & $\begin{array}{l}\text { Reserva de Fauna } \\
\text { de Dja, Camerún }\end{array}$ & $\begin{array}{l}\text { Situada en el sureste de Camerún en la cuenca del río Congo. } \\
\text { Vive mucha gente dentro del área protegida y en sus alrededores, } \\
\text { incluyendo tribus de pueblos baka (pigmeos). Es necesaria una } \\
\text { gestión activa para controlar el comercio de carne de caza y ayudar a } \\
\text { restaurar áreas de bosque. }\end{array}$ \\
\hline $\begin{array}{l}\text { Categoría V de la } \\
\text { UICN }\end{array}$ & $\begin{array}{l}\text { Sugarloaf Mountain, } \\
\text { Parque Nacional de } \\
\text { Brecon Beacons, RU }\end{array}$ & $\begin{array}{l}\text { Los bosques de la falda de la montaña son propiedad de y están } \\
\text { gestionados por el National Trust, una importante ONG del Reino } \\
\text { Unido, aunque se permite el pastoreo limitado de ovejas dentro del } \\
\text { área forestal protegida. Las colinas circundantes son utilizadas como } \\
\text { pastos para ovejas. }\end{array}$ \\
\hline $\begin{array}{l}\text { Categoría VI de la } \\
\text { UICN }\end{array}$ & $\begin{array}{l}\text { Reserva } \\
\text { Antropológica de } \\
\text { Talamanca Cabécar, } \\
\text { Costa Rica }\end{array}$ & $\begin{array}{l}\text { Se permiten algunos usos forestales en esta área protegida, } \\
\text { especialmente por pueblos indígenas, pero la mayor parte está bajo } \\
\text { protección estricta. }\end{array}$ \\
\hline \multicolumn{3}{|c|}{ Ejemplos de bosques que no son Áreas Protegidas Forestales } \\
\hline $\begin{array}{l}\text { Bosque en la } \\
\text { categoría V de la } \\
\text { UICN }\end{array}$ & $\begin{array}{l}\text { Bosque de plantación } \\
\text { en el Parque Nacional } \\
\text { de Snowdonia, Gales, } \\
\text { RU }\end{array}$ & $\begin{array}{l}\text { Aunque la plantación se encuentra en un área protegida de categoría } \\
V \text {, es una plantación de madera propiedad del estado de especies } \\
\text { exóticas con fines comerciales y como tal no constituye un área } \\
\text { forestal protegida. }\end{array}$ \\
\hline $\begin{array}{l}\text { Bosque } \\
\text { gestionado para } \\
\text { control ambiental }\end{array}$ & $\begin{array}{l}\text { Vertiente de } \\
\text { Brisbane, } \\
\text { Queensland, } \\
\text { Australia }\end{array}$ & $\begin{array}{l}\text { Partes de la cuenca de captación que rodea Brisbane están protegidas } \\
\text { de la tala y otras perturbaciones para mantener el suministro de agua } \\
\text { de la ciudad. El bosque está estrictamente conservado pero no como } \\
\text { área protegida ya que no cuenta con el objetivo específico de la } \\
\text { protección de la biodiversidad, aunque existen áreas protegidas que } \\
\text { también forman parte de la cuenca de captación. }\end{array}$ \\
\hline $\begin{array}{l}\text { Bosque } \\
\text { gestionado por la } \\
\text { comunidad }\end{array}$ & $\begin{array}{l}\text { Comunidad local de } \\
\text { Kribi, suroeste de } \\
\text { Camerún }\end{array}$ & $\begin{array}{l}\text { Los pueblos locales gestionan un bosque con un proyecto apoyado } \\
\text { por WWF. El objetivo del bosque es proporcionar beneficios tanto a } \\
\text { la población local como al medio ambiente, pero no está designada } \\
\text { área protegida (y no cuenta con objetivos específicos de protección } \\
\text { de la biodiversidad). }\end{array}$ \\
\hline $\begin{array}{l}\text { Bosque } \\
\text { gestionado para } \\
\text { fines múltiples }\end{array}$ & $\begin{array}{l}\text { Bosques de las } \\
\text { montañas del Jura, } \\
\text { Suiza }\end{array}$ & $\begin{array}{l}\text { La política forestal suiza subraya la gestión con objetivos múltiples, } \\
\text { la tala selectiva y la conservación. El Jura es un recurso valioso } \\
\text { tanto para las comunidades locales como para la vida silvestre. Sin } \\
\text { embargo, la región en su conjunto no es un área protegida, aunque } \\
\text { existen algunas áreas protegidas (de varias categorías) en ella. }\end{array}$ \\
\hline $\begin{array}{l}\text { Bosques } \\
\text { protegidos por } \\
\text { accidente }\end{array}$ & $\begin{array}{l}\text { Bosques situados } \\
\text { en la frontera entre } \\
\text { ambas Coreas (la } \\
\text { zona desmilitarizada) }\end{array}$ & $\begin{array}{l}\text { Grandes áreas de bosque que están conservadas por exclusión con } \\
\text { fines de defensa, pero la situación podría alterarse si hay cambios } \\
\text { políticos. }\end{array}$ \\
\hline
\end{tabular}




\section{Distinción entre corredores biológicos, puntos conectores y zonas de amortiguamiento dentro y fuera de las áreas protegidas forestales}

La UICN también propone una serie de directrices para identificar cuando algunos hábitats de conexión - como corredores y zonas de amortiguamiento - se ajustan o no a la definición de área protegida (ver Tabla 7 a continuación).

Tabla 7. Distinción entre áreas de conservación de conectividad como corredores biológicos, puntos conectores y zonas de amortiguamiento dentro y fuera de las áreas protegidas forestales

\begin{tabular}{|c|c|c|}
\hline Elemento & Descripción & Ejemplos \\
\hline Corredor biológico & $\begin{array}{l}\text { Área de hábitat adecuado, o } \\
\text { que está siendo restaurado } \\
\text { que conecta dos o más áreas } \\
\text { protegidas (o que conecta } \\
\text { hábitats importantes no } \\
\text { protegidos) que permiten } \\
\text { el intercambio de especies, } \\
\text { migraciones, intercambio de } \\
\text { genes, etc. }\end{array}$ & $\begin{array}{l}\text { Áreas protegidas } \\
\text { - Designación de un bosque que conecta dos bosques } \\
\text { protegidos siendo un área enteramente protegida con } \\
\text { una categoría de la UICN } \\
\text { Áreas no protegidas } \\
\text { - Áreas de bosque con buena gestión certificada entre } \\
\text { áreas forestales protegidas } \\
\text { - Área arbolada que conecta dos áreas protegidas } \\
\text { gestionadas de forma voluntaria para la vida silvestre } \\
\text { por el propietario y de forma temporal } \\
\text { Áreas de bosque sujeta a servidumbre de conservación } \\
\text { gestionadas por el gobierno u organizaciones privadas } \\
\text { de conservación }\end{array}$ \\
\hline Puntos conectores & $\begin{array}{l}\text { Área de hábitat adecuado, o } \\
\text { que está siendo restaurado } \\
\text { entre dos áreas protegidas } \\
\text { u otros tipos de hábitats } \\
\text { importantes que proporciona } \\
\text { un hábitat temporal a las aves } \\
\text { migratorias y otras especies. }\end{array}$ & $\begin{array}{l}\text { Áreas protegidas } \\
\text { - Bosques relictos gestionados para proporcionar puntos } \\
\text { de descanso para las aves migratorias } \\
\text { Áreas no protegidas } \\
\text { - Bosques conservados por los agricultores mediante } \\
\text { acuerdos voluntarios y compensación del estado } \\
\text { para proporcionar hábitats temporales para las aves } \\
\text { migratorias }\end{array}$ \\
\hline $\begin{array}{l}\text { Zona de } \\
\text { amortiguamiento }\end{array}$ & $\begin{array}{l}\text { Área alrededor de un área } \\
\text { protegida central gestionada } \\
\text { para ayudar a proteger los } \\
\text { valores del área protegida. }\end{array}$ & $\begin{array}{l}\text { Áreas protegidas } \\
\text { - Bosque situado en los límites de un área protegida } \\
\text { que está abierto a usos comunitarios bajo controles } \\
\text { respetuosos con el medio ambiente que no afectan al } \\
\text { objetivo de conservación. Normalmente área protegida } \\
\text { de categoría } \mathrm{V} \text { o VI que rodea a un núcleo protegido } \\
\text { más estrictamente (I-IV). En algunos países las zonas } \\
\text { tampón son oficialmente declaradas parte del área } \\
\text { protegida. } \\
\text { Áreas no protegidas } \\
\text { - Área de bosque situada fuera de una área protegida } \\
\text { que se gestiona sensiblemente mediante acuerdos } \\
\text { con las comunidades locales, con o sin pagos de } \\
\text { compensación. }\end{array}$ \\
\hline
\end{tabular}

\section{Áreas marinas protegidas}

Las áreas marinas protegidas (AMPs) presentan por su propia naturaleza una serie de retos de gestión que pueden requerir enfoques distintos a los de las áreas protegidas en entornos terrestres. Algunas de las características específicas de las áreas protegidas en el ámbito marino, que a menudo están ausentes o son poco frecuentes en tierra son las siguientes:

- Las AMPs están designadas en un entorno fluido tridimensional; en algunos casos se pueden considerar distintos enfoques de gestión a distintas profundidades (ver punto 3 a continuación); 
- Normalmente existen flujos multi-direccionales (por ej. mareas, corrientes);

- El régimen de tenencia raramente resulta de aplicación al entorno marino; lo más frecuente es que las áreas marinas sean consideradas "zonas comunes", en las que todos los usuarios tienen derecho de uso y de paso;

- La protección completa puede ser necesaria solo en ciertas épocas del año, por ejemplo para proteger lugares de cría de peces o mamíferos marinos;

- El control del acceso a las AMPs y de las actividades desarrolladas en ellas a menudo resulta especialmente difícil (a veces imposible) de regular e implantar, y raramente se pueden aplicar límites o restricciones a las influencias externas;

- Las AMPs están más sujetas a su entorno especialmente las que se encuentran "corriente abajo" de otras influencias, que a menudo ocurren fuera del área de control de la gestión. Por otra parte resulta aún más difícil gestionar áreas marinas como unidades separadas de lo que resulta en tierra;

- Las escalas a las que se produce la conectividad marina pueden ser muy extensas.

Hoy en día existen alrededor de 5.000 AMPs que han sido asignadas a una o varias categorías de la UICN. Sin embargo, la aplicación de categorías en el medio marino a menudo es inadecuada. Además, en situaciones en las que las áreas protegidas abarcan zonas terrestres y marinas, a menudo no se consideran los objetivos de la parte marina cuando se asigna la categoría al lugar. Dichas inconsistencias entre las AMPs reducen la eficacia y relevancia del sistema de categorías como esquema global de clasificación. El objetivo de esta sección de las directrices es ayudar a mejorar el grado de exactitud para la asignación y la realización de informes.

\section{Principios generales para la aplicación de las categorías a las AMPs (o a una zona dentro de un AMP)}

1. Distinción entre AMPs y otras áreas gestionadas bajo alguna forma de conservación

Para que un área sea considerada área protegida marina, tiene que cumplir la definición general de área protegida de la UICN; algunas áreas que son establecidas principalmente con otros fines (por ej. defensa) pueden tener valor para la biodiversidad marina, pero no serían clasificadas como áreas marinas protegidas.

La definición de AMP empleada por la UICN desde 1999 ha sido: "Cualquier área del territorio intermareal o submareal, cuyos fondos, aguas, flora y fauna asociadas, asi como sus rasgos históricos y culturales, han sido preservados por las leyes o cualquier otra medida efectiva para proteger todo o parte del medio ambiente comprendido en ella" (Kelleher 1999).
La nueva definición general de área protegida de la UICN (ver página 10) ha reemplazado a la definición de AMP de la UICN en las áreas marinas. Aunque se haya perdido la referencia específica al medio ambiente marino, se asegura una demarcación más clara entre espacios destinados a la conservación y aquellos en los que el objetivo primario es extractivo, como por ej. las áreas de gestión de pesca. Esto no excluye la inclusión de las correspondientes zonas de protección de pesca, pero las mismas deberán ajustarse a la nueva definición para ser incluidas como AMP por UICN/CMAP. Así, todas las áreas de mar que de alguna forma están dedicadas a la conservación podrán recibir la denominación, y para aquellas que no lo hacen ahora queda claro cómo han de avanzar para conseguir el reconocimiento formal de la UICN como AMP.

Como en las áreas terrestres protegidas, existe una amplia gama de tipos de gobernanza. Por ejemplo, se han establecido muchas AMPs gestionadas por comunidades, especialmente en el Pacífico y en el Sudeste Asiático. Estas no han sido siempre reconocidas por las agencias nacionales, y por ello pueden no aparecer en las listas nacionales o internacionales, ni se les ha adjudicado una categoría. Un ejemplo es Samoa Occidental, donde se ha establecido una red de más de 50 reservas de pesca de pequeñas poblaciones dentro del marco del Plan de Gestión de Pesca de Poblaciones (Sulu et al. 2002). Se pretende que las categorías de la UICN se apliquen a cualquier enfoque de gestión, tanto legal como a cualquier otro tipo que sea eficaz, y las áreas marinas protegidas gestionadas por las comunidades pueden ser reconocidas como áreas protegidas y catalogadas según sus objetivos de gestión siempre que se ajusten a la definición de área protegida.

\section{Protección temporal}

Algunos espacios, como las zonas de concentración de peces para la reproducción o las rutas migratorias pelágicas, son de importancia crucial y las especies correspondientes son especialmente vulnerables en períodos del año concretos y predecibles, mientras que durante el resto del año no necesitan ningún tipo de gestión diferente al de las áreas circundantes. Por ejemplo, el Coto de Bacalao del Mar de Irlanda está diseñado para conservar las reservas de bacalao en el Mar de Irlanda restringiendo la actividad pesquera durante la época de reproducción. La UE ha fomentado la creación de estas "cajas" de conservación, en los que se establecen controles estacionales, a tiempo completo, temporales o permanentes sobre los métodos de pesca y/o los accesos. Éstas podrían cumplirían los requisitos para ser AMPs si se ajustan a la definición de área protegida.

\section{Aplicación de las categorías en las AMPs con zonifi- cación vertical}

En un entorno marino tridimensional algunas jurisdicciones han introducido una zonificación vertical (por ej. con una normativa diferente en la columna de agua de las que se aplican al lecho marino) que da como resultado diferentes categorías 
de la UICN a distintas profundidades de la columna de agua. Mientras que esto puede ser una forma de conseguir una mayor protección bentónica a la vez que se permite la pesca pelágica, plantea retos para su aplicación, y la zonificación vertical no se muestra fácilmente mediante las bases de datos bidimensionales o sobre los mapas. Lo que es más importante, los vínculos entre los sistemas y las especies bentónicas y pelágicas pueden no ser bien conocidos, de forma que la explotación de las pesquerías de superficie o medias aguas puede tener efectos ecológicos desconocidos sobre las comunidades bentónicas subyacentes. Los expertos sobre el tema marino de la CMAP desaconsejan la zonificación tridimensional por estas razones. Para las escasas AMPs en las que se da esta situación, el consejo actual de la UICN es que las AMPs se deberían categorizar de acuerdo con el menos restrictivo de los regímenes de gestión. Por ejemplo, si el sistema bentónico está estrictamente protegido y el área pelágica permite un uso de los recursos compatible con la categoría VI, se debe asignar la categoría VI al área en su conjunto. Esto minusvalora el nivel de protección superior otorgado (y oscurece el objetivo de protección bentónica original). Sin embargo, sólo unas pocas áreas se ven afectadas de esta manera y el uso de la categoría menos restrictiva probablemente refleja la incertidumbre ecológica respecto a si los niveles de protección bentónica más altos son eficaces en estas circunstancias.

\section{Empleo de la zonificación en AMPs de usos múltiples}

Las AMPs normalmente abarcan ecosistemas marinos fluidos y dinámicos, cuentan con una gran diversidad de hábitats y especies dentro de un área y contienen especies marinas altamente migratorias. Esta complejidad a menudo determina la necesidad de objetivos múltiples y sistemas de gestión complejos. En el entorno marino esto resulta especialmente importante y en las directrices de mejores prácticas de la UICN para las AMPs se recomienda la zonificación como mejor fórmula para la gestión de áreas marinas de usos múltiples (Kelleher 1999; Day 2002).

Las AMPs de usos múltiples contienen un espectro de zonas, cada una de ellas con objetivos diferentes y algunas de ellas permiten un mayor uso y extracción de recursos que otras (por ej. las zonas de veda normalmente están designadas como una de las zonas internas de una AMP de usos múltiples).

La CMAP ha reconocido el problema de gestionar las zonas dentro del sistema de categorías. Como en las áreas protegidas terrestres, se pueden registrar y contabilizar distintas áreas de gestión en las AMPs siempre y cuando:

- las correspondientes áreas estén definidas en la legislación general o en el plan de gestión normativo;
- dichas áreas se encuentren claramente definidas y cartografiadas;

- los objetivos de gestión de cada una las zonas no son ambiguos y permiten la asignación a una categoría de área protegida concreta.

Se ha propuesto que este enfoque se debe emplear sólo en las AMPs de usos múltiples de gran extensión, en las que las zonas están legalmente definidas y suponen más del 25 por ciento de la superficie total (ver página 43 para la explicación de la "regla del 75 por ciento").

La identificación de zonas dentro de las AMPs debería estar basada en los mejores conocimientos científicos y criterios disponibles, y también deberían desarrollarse después de consultas con las partes y actores interesados.

A título de ejemplo la Tabla 8 muestra la inscripción modificada de la Gran Barrera de Arrecifes en la Lista de la ONU de Areas Protegidas editada por el PNUMA-CMMC:

Tabla 8. Categorización de la Gran Barrera de Arrecifes

\begin{tabular}{|l|l|r|}
\hline Área & $\begin{array}{l}\text { Categoría de } \\
\text { la UICN }\end{array}$ & $\begin{array}{l}\text { Superficie } \\
\text { (ha) }\end{array}$ \\
\hline $\begin{array}{l}\text { Parque Marino de } \\
\text { la Gran Barrera } \\
\text { de Arrecifes que } \\
\text { comprende: }\end{array}$ & & 34.440 .000 \\
\hline $\begin{array}{l}\text { Gran Barrera de } \\
\text { Arrecifes }\end{array}$ & la & 86.500 \\
\hline $\begin{array}{l}\text { Gran Barrera de } \\
\text { Arrecifes }\end{array}$ & II & 11.453 .000 \\
\hline $\begin{array}{l}\text { Gran Barrera de } \\
\text { Arrecifes }\end{array}$ & IV & 1.504 .000 \\
\hline $\begin{array}{l}\text { Gran Barrera de } \\
\text { Arrecifes }\end{array}$ & VI & 21.378 .000 \\
\hline $\begin{array}{l}\text { Islas } \\
\text { Commonwealth }\end{array}$ & & 18.500 \\
\hline
\end{tabular}

\section{Aplicación de las diferentes categorías en las AMPs}

Cualquiera de las categorías puede aplicarse en el entorno marino, aunque algunas pueden ser más apropiadas que otras. La Tabla 9, aunque no es definitiva, ofrece algunas indicaciones de la amplia gama de enfoques de gestión y dónde pueden aplicarse. Esta orientación adicional debería ser interpretada en conjunto con las descripciones más amplias para cada categoría de las presentes directrices.

9 Téngase en cuenta que las Islas Commonwealth son legalmente parte del Parque Marino de la Gran Barrera de Arrecifes, mientras que la mayoría de las demás islas, que están bajo jurisdicción de los Estados, no lo son. 
Tabla 9. Aplicación de las diferentes categorías en las áreas marinas protegidas

\begin{tabular}{|c|c|}
\hline Categoría & Notas relativas a su empleo en las AMPs \\
\hline la & $\begin{array}{l}\text { El objetivo en estas AMPs es la conservación de la biodiversidad y de otros valores en un } \\
\text { área estrictamente protegida. Las áreas vedadas/reservas marinas son el tipo concreto de } \\
\text { AMP que consigue este resultado. Se han convertido en una herramienta importante tanto } \\
\text { para la protección de la biodiversidad marina como para las gestión de la pesca (Palumbi } \\
2001 ; \text { Roberts and Hawkins } 2000 \text { ). Pueden abarcar un área completa, o más frecuentemente } \\
\text { ser zonas separadas de una AMP de usos múltiples. Cualquier extracción de especies } \\
\text { marinos y modificación, extracción o recogida de recursos marinos (por ej. mediante pesca, } \\
\text { la recolección, dragado, minería o perforación) es incompatible con esta categoría, con } \\
\text { excepciones como la investigación científica. Las visitas están limitadas para asegurar la } \\
\text { preservación de los valores de conservación. El establecimiento de áreas estrictamente } \\
\text { protegidas en el entorno marino es de importancia crucial, especialmente para proteger } \\
\text { la reproducción y cría de peces y proporcionar zonas de estudio científicas que estén tan } \\
\text { poco alteradas como sea posible. Sin embargo, dichas áreas son extremadamente difíciles } \\
\text { de delinear (las boyas pueden actuar como dispositivos de congregación de peces, con } \\
\text { lo que el área dejaría de estar inalterada) y por ello es difícil hacer cumplir la normativa. } \\
\text { Siempre que se considere posible, el establecimiento de áreas de categoría la, los usos de } \\
\text { las aguas circundantes, y especialmente las influencias "corriente arriba" y las cuestiones } \\
\text { de conectividad marina deberían ser parte de los criterios de evaluación. Las áreas de } \\
\text { categoría la deberían ser consideradas como "núcleos" rodeados por otras áreas protegidas } \\
\text { adecuadamente (por ej. el área que rodea a un área de categoría la debería estar protegida } \\
\text { de manera que complemente y garantice la protección de la biodiversidad del área nuclear de } \\
\text { categoría la.). }\end{array}$ \\
\hline lb & $\begin{array}{l}\text { Las áreas de categoría lb en el medio marino deberían ser espacios de paisaje marino } \\
\text { relativamente inalterado, significativamente libres de perturbaciones, estructuras o } \\
\text { instalaciones humanas y capaces de permanecer en dicha situación con una gestión eficaz. } \\
\text { La cuestión del carácter "silvestre" del medio marino está menos clara que en las áreas } \\
\text { protegidas terrestres. Siempre que dichas áreas estén relativamente libres de perturbaciones } \\
\text { e influencias humanas, cualidades como la "soledad", el "disfrute silencioso" o el "disfrute } \\
\text { de áreas naturales que retienen características silvestres" pueden alcanzarse en cuanto se } \\
\text { bucea bajo la superficie. La cuestión del acceso motorizado no es tan crítica como en las de } \\
\text { áreas silvestres terrestres debido a la enorme extensión de los océanos y el hecho de que } \\
\text { de no ser así, muchas de dichas áreas serían inaccesibles; sin embargo, es más importante } \\
\text { minimizar la densidad de uso para asegurar que la "sensación silvestre" se mantiene en las } \\
\text { áreas consideradas adecuadas para su designación como categoría lb. Por ejemplo, los } \\
\text { puntos de amarre fijos pueden ser una forma de gestionar la densidad y limitar los impactos } \\
\text { sobre el lecho marino a la vez que se proporciona acceso. }\end{array}$ \\
\hline II & $\begin{array}{l}\text { Las áreas de categoría II suponen un reto especial en el medio marino, ya que se gestionan } \\
\text { para la "protección del ecosistema" permitiéndose las visitas, las actividades recreativas } \\
\text { y el turismo de naturaleza. En el medio marino, los usos extractivos (de material vivo o } \\
\text { inerte) son actividades clave que generalmente no se ajustan a los objetivos de las áreas } \\
\text { de categoría II. Esto es así porque hoy en día se considera que muchas actividades } \\
\text { humanas, incluso cuando se desarrollan a bajo nivel (como la pesca), suponen un drenaje } \\
\text { ecológico de recursos, y por lo tanto se consideran incompatibles con una protección eficaz } \\
\text { del ecosistema. Cuando dichos usos no se pueden gestionar activamente en un área de } \\
\text { categoría II para garantizar que los objetivos generales de protección del ecosistema, } \\
\text { se debería considerar la posibilidad de no permitir ninguno de ellos, o considerar si los } \\
\text { objetivos de la reserva, o de la zona dentro de la reserva, quizás se ajustarían de forma más } \\
\text { realista a otra categoría (por ej. las categorías } \mathrm{V} \text { o } \mathrm{VI} \text { ) y por tanto deberían modificarse. La } \\
\text { conservación de la naturaleza en las áreas de categoría II en el medio marino debería poder } \\
\text { alcanzarse mediante la protección y no requerir una gestión activa o una manipulación del } \\
\text { hábitat sustanciales. }\end{array}$ \\
\hline III & $\begin{array}{l}\text { La protección de monumentos o rasgos naturales en el medio marino puede atender a una } \\
\text { serie de objetivos. La protección localizada de rasgos como las montañas submarinas tiene } \\
\text { un importante valor para la conservación, mientras que otros rasgos marinos pueden tener un } \\
\text { valor cultural o recreativo para grupos concretos, incluyendo paisajes sumergidos históricos/ } \\
\text { arqueológicos. Probablemente, la categoría III es una designación relativamente infrecuente } \\
\text { en los ecosistemas marinos. }\end{array}$ \\
\hline
\end{tabular}


Tabla 9. Aplicación de las diferentes categorías en las áreas marinas protegidas (cont.)

\begin{tabular}{|c|c|}
\hline Categoría & Notas relativas a su empleo en las AMPs \\
\hline IV & $\begin{array}{l}\text { Las áreas de categoría IV en el medio marino debería jugar un papel importante en la } \\
\text { protección y supervivencia de las especies (incorporando, cuando corresponda, áreas } \\
\text { de cría, áreas de freza, áreas de alimentación/pasto) o características esenciales para el } \\
\text { bienestar de la flora de importancia nacional o local y de la fauna residente o migratoria. La } \\
\text { categoría IV está dirigida a la protección de especies o hábitats concretos, a menudo con } \\
\text { intervenciones de gestión activas (por ej. protección de hábitats bentónicos fundamentales } \\
\text { frente a la pesca de arrastre o el dragado). Los regímenes de protección dirigidos a especies } \\
\text { o grupos de especies concretas, cuando no hay limitación de otras actividades, normalmente } \\
\text { se clasificarían como categoría IV, por ej. los santuarios de ballenas. La protección limitada } \\
\text { en el tiempo, como en el caso de las vedas estacionales o la protección de las playas de } \\
\text { puesta de las tortugas, también encajaría en la categoría IV. A diferencia de lo que ocurre en } \\
\text { tierra, donde la categoría IV puede incluir fragmentos de ecosistemas, en el medio marino } \\
\text { el empleo de esta categoría cuenta con un potencial significativo para una protección del } \\
\text { sistema a mayor escala, con frecuencia incluyendo zonas de categoría la o Ib y zonas de } \\
\text { interés de categoría II. }\end{array}$ \\
\hline V & $\begin{array}{l}\text { La interpretación del concepto de paisaje marino en áreas protegidas atrae un interés } \\
\text { creciente. Las áreas protegidas de categoría } \vee \text { subrayan la importancia de la "interacción de } \\
\text { los seres humanos y la naturaleza a lo largo del tiempo" y en el entorno marino, podríamos } \\
\text { esperar que la categoría } \bigvee \text { se diese típicamente en áreas costeras. El mantenimiento de } \\
\text { prácticas de pesca locales antiguas y sostenibles, o la recolección sostenible en arrecifes de } \\
\text { coral, quizás en presencia de hábitats costeros modificados culturalmente (por ej. mediante } \\
\text { la plantación de cocoteros) podría ser un mosaico de gestión adecuado para considerarse } \\
\text { como categoría V. }\end{array}$ \\
\hline VI & $\begin{array}{l}\text { Las AMPs que mantienen hábitats predominantemente naturales pero permiten la recolección } \\
\text { sostenible de elementos concretos, como ciertas especies para alimentación o pequeñas } \\
\text { cantidades de coral o conchas para su venta a los turistas podrían ser identificadas como } \\
\text { categoría VI. El punto en que un área gestionada para la extracción de recursos se convierte } \\
\text { en un área protegida marina de categoría VI puede resultar a veces difícil de enjuiciar y en } \\
\text { último término se determinará por la referencia a si el área se ajusta a la definición general de } \\
\text { área protegida o no, así como si el área consigue una sostenibilidad ecológica verificable con } \\
\text { los mecanismos de medida adecuados. }\end{array}$ \\
\hline
\end{tabular}

La extensión de las actividades extractivas y el nivel al cual están reguladas es una consideración importante a la hora de determinar la categoría de la UICN más adecuada para un AMP (o una zona dentro de un AMP). Los usos extractivos, incluyendo cualquier tipo de pesca, no se ajusta a los objetitos de las categorías Ia y Ib y es poco probable que se ajuste a la categoría II.

\section{Clasificación de las AMPs por lo que hacen y no por el} título de la categoría

La asignación de una AMP a una categoría de la UICN debería basarse en los objetivos de gestión más que en el nombre de las categorías. El mismo nombre o titulo para una AMP puede significar cosas distintas en distintos países. Por ejemplo, el término "santuario", tal como se utiliza en Estados Unidos, designa un AMP de usos múltiples que está registrada dentro del Programa Nacional de Santuarios Marinos (por ej. el Santuario Marino de los Cayos de la Florida). Sin embargo, el término "santuario" tiene un significado muy diferente en otros lugares - en el Reino Unido el término se utiliza para designar reservas marinas estrictamente protegidas en las que están prohibidos todos los usos extractivos. Tal como ocurre en las áreas protegidas terrestres y de aguas continentales, las categorías son independientes de los nombres de las AMPs.

\section{Áreas protegidas de aguas terrestres}

Los ecosistemas acuáticos terrestres ocupan únicamente una pequeña área del planeta, pero quizás sean los más amenazados por las actividades humanas de entre todos los biomas y hábitats. Los gobiernos y la comunidad de la conservación han realizado compromisos para conservar las especies y hábitats acuáticos terrestres iguales a los de los ámbitos terrestres y marinos, pero dichos compromisos aún están por cumplirse. Además, cuando se conservan estos hábitats de calidad, se está prestando un servicio crucial a las personas que se enfrentan a una escasez creciente de agua potable/utilizable. Por lo tanto, las consideraciones relativas a las aguas terrestres deben integrarse en la gestión de todas las áreas protegidas relevantes, que por su parte deben ser gestionadas en función de su contexto bioregional y de cuenca hidrográfica en el sentido más amplio. 


\section{Definiciones: Humedales terrestres, sistemas de agua dulce y humedales}

Los términos aguas terrestres (humedales terrestres), sistemas de agua dulce, y simplemente, humedales, a menudo se usan de forma intercambiable, pero existen ciertas diferencias. Aguas terrestres o humedales terrestres se refiere a todos los ecosistemas acuáticos no marinos, incluyendo los sistemas terrestres de agua salada o salobre; si los sistemas de transición como los estuarios están incluidos o no es cuestión de interpretación. El término humedales terrestres es el empleado por el CDB. De agua dulce se define como "de, o relacionado con, o viviendo en, o consistente de agua no salina".Por lo tanto, técnicamente excluye los sistemas de aguas saldas y salobres terrestres, pero en la práctica el término se usa como equivalente de humedales terrestres. El Convenio Ramsar define los humedales como "marismas, pantanos, turberas o aguas, ya sean naturales o artificiales, permanentes o temporales, con agua estática o fluyendo, dulce, salobre o salada, incluyendo áreas de aguas marinas cuya profundidad no excede de seis metros en marea baja". En algunas regiones del mundo se entiende que el término humedales excluye todos los sistemas acuáticos sin vegetación como corrientes, lagos y aguas subterráneas. Para los fines de las presentes directrices utilizaremos el término aguas terrestres para describir toda la variedad de hábitats acuáticos y semiacuáticos, y las especies asociadas a los mismos, que no se incluyen en las clasificaciones marinas. Los humedales de aguas terrestres incluyen (modificado de la Evaluación de Ecosistemas del Milenio, Informe de Síntesis de Humedales y Aguas, Tabla 3.1):

- Ríos y corrientes de agua permanentes y temporales;

- Lagos permanentes;

- Lagos, pantanos y ciénagas temporales, incluyendo Ilanuras aluviales;

- Humedales, pantanos y ciénagas forestales, incluyendo llanuras aluviales;

- Humedales alpinos y de tundra;

- Fuentes, oasis y humedales geotermales;

- Humedales subterráneos, incluyendo cuevas y sistemas de aguas subterráneas.

\section{Complejidades en la protección de aguas terrestres}

La relación entre las áreas protegidas y la conservación de aguas terrestres es compleja. Existen muchas incompatibilidades y retos, reales y percibidos que surgen al considerar esta relación, entre ellos los siguientes:
- Relación y papel en el paisaje. Los sistemas acuáticos terrestres forman parte de un paisaje terrestre más amplio y cada una de sus partes está unida a su cuenca de captación ${ }^{10}$ que está aguas arriba mediante una serie de procesos hidrológicos superficiales o subterráneos. La perspectiva de "vallar" los sistemas de humedales resulta en la mayoría de los casos técnicamente inviable por las razones que a continuación se indican. Las áreas protegidas más eficaces para la conservación de aguas continentales serían siempre parte de una gestión integrada de las cuencas fluviales (GICF), también denominada a veces gestión integral de la cuenca de captación o de las vertientes. La GICF conlleva una estrategia a escala de paisaje para alcanzar de forma concurrente objetivos ambientales, económicos y sociales. La GICF es una forma de Enfoque de Ecosistema que las Partes Signatarias del CDB se han comprometido a implementar. Los gobiernos de todo el mundo también se han comprometido a planificar e implementar una gestión integrada de recursos hídricos (GIRH), que es similar en teoría a la GICF, pero no está sujeta a cuencas fluviales. En la práctica, lamentablemente ni la GIRH ni la GICF han dedicado la atención necesaria a la conservación de la biodiversidad de las aguas continentales.

- Procesos hidrológicos. El "propulsor fundamental" en los sistemas continentales de aguas corrientes (ecosistemas lóticos o asociados al flujo de las aguas) es el régimen del caudal:11 la magnitud, frecuencia, distribución temporal, duración y tasa de cambio del caudal de agua. En los sistemas acuáticos de aguas estancadas (lénticos), la variable principal suele ser el período hídrico: el patrón estacional y cíclico del agua. Tanto el régimen de caudal como el período hídrico caracterizan el "patrón hídrico" de un sistema. En casi todos los sistemas de aguas continentales el agua se genera "fuera" de los propios sistemas y entra en ellos a través de vías superficiales o subterráneas y afluentes. La protección del patrón hídrico requiere una protección o gestión que se extiende aguas arriba y a cotas superiores y a menudo también a las cuencas subterráneas. 12 En muchos casos puede ser necesaria una gestión hídrica transfronteriza, incluso cuando el área protegida se encuentra dentro de un único estado. En el caso de la mayoría de las áreas protegidas existentes, esto supone trabajar con agentes y socios para gestionar los regímenes de caudal fuera de los límites del área protegida.

- Conectividad longitudinal. Las corrientes de agua y las redes de corrientes tienen una dimensión lineal o longitudinal junto con dimensiones laterales, verticales y temporales. La protección de la conectividad longitudinal - los vínculos entre hábitats, especies, comunidades y procesos

10 Una cuenca de captación se define como todo el territorio rodeado por una divisoria de aguas superficiales continua y que se encuentra aguas arriba de un punto o una corriente concretos; o en el caso de sistemas de cuencas cerradas, todo el territorio que drena a un lago.

11 El caudal se define aquí como el volumen de agua que pasa por un punto dado por unidad de tiempo.

12 El equivalente subterráneo a una cuenca de aguas superficiales. 
ecológicos entre las partes altas y bajas del cauce de una corriente o de una red de ellas - es a menudo un objetivo esencial de la conservación de aguas continentales y conlleva el impedir o eliminar las barreras físicas y químicas. La protección de la conectividad longitudinal es también crucial para mantener sistemas flexibles y resistentes ante el cambio climático. Por otra parte, una conectividad artificial adicional, como ocurre con los trasvases entre cuencas, puede ser negativa debido a la invasión de especies foráneas. A menudo se considera que las áreas protegidas son polígonos más que estructuras lineales y pocas veces se diseñan teniendo en cuenta la protección y gestión de la conectividad longitudinal de los canales de corrientes de agua. A menudo se emplean las corrientes de agua para marcar los límites de las áreas protegidas sin que dichas corrientes reciban una protección especial.

- Conectividad lateral. Las conexiones laterales entre las corrientes de agua y el paisaje circundante son esencial para la salud ecológica tanto de las corrientes como de las comunidades ribereñas y de las llanuras aluviales asociadas. Estas conexiones están regidas en gran medida por los procesos hidrológicos descritos anteriormente; siendo la interacción entre los caudales de la corriente y las tierras ribereñas la que crea las condiciones dinámicas que son la base de los ricos y únicos hábitats existentes en las llanuras aluviales y los humedales ribereños. Estas tierras también aportan materiales orgánicos e inorgánicos cruciales a las corrientes y pueden proteger a los hábitats acuáticos de los contaminantes. La anchura de estas áreas es muy variable, desde las franjas relativamente estrechas de las laderas inclinadas a las llanuras aluviales extremadamente grandes. Las áreas protegidas también pueden jugar un papel importante en la conservación de los hábitats ribereños y de las llanuras aluviales y su conectividad con los canales fluviales.

- Interacciones aguas subterráneas-aguas superficiales. La protección de las especies y hábitats de las aguas superficiales terrestres exige normalmente mirar más allá de la hidrología de superficie. los sistemas alimentados por aguas subterráneas son comunes en muchas áreas, y requieren la protección de las aguas tanto subterráneas como superficiales. La mayoría de las aguas superficiales dependen también de las aguas subterráneas (el nivel freático) para su funcionamiento, independientemente de que sean alimentadas por aguas subterráneas o no. Las aguas subterráneas, como por ejemplo en las zonas kársticas, proporcionan un hábitat para especies a menudo especializadas, así como agua para millones de personas. Las cuencas de áreas subterráneas y las de aguas superficiales pueden no coincidir espacial o geopolíticamente, añadiendo un nivel adicional de complejidad a la protección de los caudales de entrada.

- Amenazas exógenas. Las aguas continentales normalmente están en las zonas más bajas del paisaje, y en consecuencia reciben perturbaciones que se propagan entre cuencas y se transmiten por el agua (por ej., contaminación, erosión del suelo y eutrofización). Mientras que todas las áreas protegidas se tienen que enfrentar a amenazas que se originan fuera de sus límites, aquellas que protegen sistemas acuáticos tienen que abordar de forma explícita amenazas que se plantean aguas arriba e incluso aguas abajo (como las especies invasoras).

- Exclusión de los recursos hídricos continentales. Las comunidades humanas siempre se han asentado en la proximidad de sistemas acuáticos continentales, que proporcionan una amplia gama de servicios ecosistémicos esenciales. El derecho fundamental de acceso a agua potable, tanto dentro de las áreas protegidas como aguas arriba de ellas puede entrar en conflicto con los objetivos de algunas categorías de áreas protegidas que limitan el uso de los recursos por los humanos.

- Autoridades de gestión múltiples. En muchos si no en todos los países existen responsabilidades superpuestas y a menudo en conflicto de distintas agencias gubernamentales en lo que se refiere a gestión de recursos hídricos, de especies que habitan en humedales, hábitats acuáticos, paisajes circundantes y áreas protegidas. En consecuencia, la gestión de las especies y hábitats acuáticos continentales dentro de un área protegida - que como se señaló anteriormente requiere también la gestión de territorios y aguas fuera del área protegida - puede resultar complicada por la necesidad de coordinar actividades entre múltiples autoridades, algunas de ellas con mandatos que entran en conflicto con la conservación de la biodiversidad.

En resumen, los retos abundan. Mientras que lo ideal sería que las áreas protegidas establecidas para conservar ecosistemas acuáticos continentales deberían comprender cuencas completas, con mucha frecuencia es necesario aplicar combinaciones innovadoras de áreas protegidas y otras estrategias dentro del marco de la GICF. Las áreas protegidas existentes están diseñadas para proteger ecosistemas terrestres y sin duda proporcionan beneficios para la conservación de la biodiversidad de los humedales mediante la gestión paisajística, pero hay oportunidades significativas de mejorar dicha protección. El diseño de nuevas áreas protegidas puede y debe incluir consideraciones del agua y caudales externos para lograr una integración mejor. Las siguientes páginas proporcionan unas directrices introductorias sobre cómo la gama de enfoques de gestión de áreas protegidas que representan las categorías pueden ayudar a la conservación de los humedales continentales.

\section{Aplicación de la nueva definición de AP}

La nueva definición de $\mathrm{AP}$ - Un espacio geográfico claramente definido, reconocido, dedicado y gestionado, mediante medios legales $u$ otros tipos de medios eficaces, para conseguir la conservación a largo plazo de la naturaleza con los servicios ecosistémicos y valores culturales asociados - es más inclusiva con respecto a las aguas dulces que la definición adoptada anteriormente mediante la sustitución de "superficie de tierra y/o mar" por "un espacio geográfico claramente definido". Las áreas protegidas dedicadas principalmente a 
la conservación de elementos de las aguas continentales como los cauces de los ríos o los lagos están ahora mejor cubiertas por la definición. Entre ellas se encuentran algunos tipos de área protegidas que son únicas entre los ecosistemas de aguas continentales como los ríos que fluyen libremente. ${ }^{13}$ Una amplia variedad de estrategias de conservación de aguas continentales dirigidas a la protección de la calidad y la cantidad de agua, como la gestión de los caudales ambientales ${ }^{14}$ y la aplicación de prácticas sensatas en la gestión hídrica, normalmente quedan fuera de la definición de área protegida. Se mencionan aquí porque en muchos casos sólo se podrá conseguir una conservación eficaz de los sistemas de aguas terrestres dentro de las áreas protegidas mediante el uso coordinado de dichas estrategias más allá de los límites de las áreas protegidas.

\section{Aplicación de las categorías de AP}

En principio cualquiera de las categorías es aplicable a áreas con objetivos específicos de conservación de humedales y aguas terrestres. Ejemplos de áreas protegidas con objetivos claros relativos a la conservación de humedales y aguas terrestres se encuentran en todas las categorías de la UICN (Tabla 10):

Tabla 10. Ejemplos de áreas protegidas de distintas categorías destinadas a la protección de aguas terrestres

\begin{tabular}{|c|c|c|}
\hline Categoría & Ejemplo & Descripción \\
\hline la & $\begin{array}{l}\text { Reserva Natural } \\
\text { de Srebarna } \\
\text { (Bulgaria) }\end{array}$ & $\begin{array}{l}\text { Reserva de la biosfera de } 600 \text { ha, sitio de Patrimonio Mundial y sitio Ramsar } \\
\text { para proteger el Lago Srebarna, en la llanura aluvial del Danubio. La reserva } \\
\text { fue establecida principalmente para proteger a la rica avifauna, especialmente } \\
\text { aves acuáticas. }\end{array}$ \\
\hline $\mathrm{lb}$ & $\begin{array}{l}\text { Parque de Vida } \\
\text { Silvestre de Avon } \\
\text { (Australia) }\end{array}$ & $\begin{array}{l}\text { Parque de vida silvestre de } 39.650 \text { ha que abarca cuencas de captación } \\
\text { enteras de la cabecera del Río Avon, establecido para la conservación y usos } \\
\text { recreativos sin infraestructuras bajo la Ley de Parques Nacionales. }\end{array}$ \\
\hline II & $\begin{array}{l}\text { Parque Nacional } \\
\text { del Pantanal } \\
\text { (Brasil) }\end{array}$ & $\begin{array}{l}\text { Parque nacional (y sitio Ramsar) de } 135.000 \text { ha situado en una extensa } \\
\text { depresión que funciona como un delta interior. El área consiste en una vasta } \\
\text { región de sabanas inundadas estacionalmente, islas de matorral xerofítico y } \\
\text { bosques caducifolios húmedos. }\end{array}$ \\
\hline III & $\begin{array}{l}\text { Lago Ganga } \\
\text { (Mongolia) }\end{array}$ & $\begin{array}{l}\text { Rasgo natural (y sitio Ramsar) de } 32.860 \text { ha que comprende un pequeño lago } \\
\text { de agua salobre y otros lagos asociados en Mongolia oriental con un paisaje } \\
\text { único que combina humedales, estepa y dunas de arena. El distrito lacustre es } \\
\text { de gran importancia para la reproducción y como punto de descanso de aves } \\
\text { acuáticas. }\end{array}$ \\
\hline IV & $\begin{array}{l}\text { Koshi Tappu } \\
\text { (Nepal) }\end{array}$ & $\begin{array}{l}\text { Reserva de vida silvestre de } 17.500 \text { ha situada a lo largo del río Sapta Kosi } \\
\text { consistente en grandes llanuras cenagosas y pantanos a su alrededor. La } \\
\text { reserva contiene la última población superviviente de de búfalos de agua } \\
\text { salvajes de Nepal. }\end{array}$ \\
\hline V & $\begin{array}{l}\text { Big South Fork } \\
\text { (EEUU) }\end{array}$ & $\begin{array}{l}\text { Esta área nacional fluvial y recreativa comprende } 50.585 \text { ha de la Meseta de } \\
\text { Cumberland y protege el tramo denominado Big South Fork del río Cumberland } \\
\text { y sus afluentes. El área ha sido protegida principalmente con fines recreativos. }\end{array}$ \\
\hline VI & Titicaca (Perú) & $\begin{array}{l}\text { Reserva nacional de } 36.180 \text { ha establecida para proteger el lago navegable a } \\
\text { mayor altitud del mundo. }\end{array}$ \\
\hline
\end{tabular}

Las aguas terrestres pueden ser divididas en zonas para permitir distintos niveles de uso. Por ejemplo, en el Parque Nacional del Lago Malawi (Malawi), se permiten en zonas limitadas métodos de pesca tradicionales para la captura de peces migratorios, mientras que en la mayoría del parque no se pueden pescar los peces residentes.

Cuando y como se pueden vincular las categorías de áreas protegidas con la protección de sitios específicos requiere ser analizada caso a caso. La Tabla 11 indica una serie de estrategias basadas en la protección de sitios específicos e identifica cuándo resultan especialmente compatibles o incompatibles con las categorías de áreas protegidas de la UICN. Estas asignaciones representan generalizaciones ya que existirán sin duda excepciones. Los sitios naturales de Patrimonio Mundial, los sitios Ramsar y las reservas de la biosfera están incluidos porque han sido ampliamente utilizados para proteger aguas terrestres y porque han hecho de la división en zonas una herramienta de gestión.

13 En algunos países hay una legislación específica sobre ríos pintorescos y en estado natural.

14 La calidad, cantidad y distribución temporal de los caudales necesarios para mantener los elementos, funciones, procesos y la resiliencia de los ecosistemas acuáticos que proporcionan bienes y servicios a la población. 
Tabla 11. Compatibilidad de distintas estrategias de protección de aguas terrestres con las categorías de la UICN

\begin{tabular}{|c|c|c|c|c|c|c|c|c|c|}
\hline \multirow{2}{*}{$\begin{array}{l}\text { Tipo de área protegida: } \\
\text { las descripciones normalmente } \\
\text { se refieren a estos tipos como } \\
\text { entidades aisladas - todas } \\
\text { pueden formar parte de reservas } \\
\text { de mayor tamaño }\end{array}$} & \multicolumn{7}{|c|}{$\begin{array}{l}\text { Compatibilidad con las } \\
\text { categorías de áreas protegidas }\end{array}$} & \multirow{2}{*}{$\begin{array}{l}\text { Si estuvieran fuera } \\
\text { de I-VI, potencial } \\
\text { de contribución a } \\
\text { la conservación en } \\
\text { la GICF* }\end{array}$} & \multirow{2}{*}{ Ejemplos } \\
\hline & la & Ib & II & III & IV & $\mathbf{V}$ & VI & & \\
\hline \multicolumn{10}{|c|}{ Designación/reconocimiento por un convenio o programa internacional } \\
\hline Sitio de Patrimonio Mundial & & & & & & & & Bajo & Lago Malawi (Malawi) \\
\hline Sitio Ramsar & & & & & & & & Muy alto & $\begin{array}{l}\text { Área de Conservación de } \\
\text { Upper Navua (Fiyi) }\end{array}$ \\
\hline Reserva de la biosfera & & & & & & & & Alto & Lago Dalai (China) \\
\hline \multicolumn{10}{|c|}{ Mecanismos de protección de aguas dulces basados en el lugar } \\
\hline Río sin obstáculos & & & & & & & & Alto & $\begin{array}{l}\text { Curso superior del río } \\
\text { Delaware (EEUU) }\end{array}$ \\
\hline Reserva ribereña/tampón & & & & & & & & Alto & $\begin{array}{l}\text { Área de Conservación } \\
\text { Douglas River/Daly River } \\
\text { Esplanade (Australia) }\end{array}$ \\
\hline Reserva de llanura aluvial & & & & & & & & Alto & Pacaya-Samiria (Perú) \\
\hline Reserva de pesca/recolección & & & & & & & & Alto & Lubuk Sahab (Indonesia) \\
\hline Reserva de caza en humedal & & & & & & & & Moderado & $\begin{array}{l}\text { Reserva de Caza de } \\
\text { Ndumo (Sudáfrica) }\end{array}$ \\
\hline $\begin{array}{l}\text { Área con pesca recreativa } \\
\text { restringida }\end{array}$ & & & & & & & & Moderado & Río Onon (Mongolia) \\
\hline $\begin{array}{l}\text { Cuenca de suministro de agua } \\
\text { protegida }\end{array}$ & & & & & & & & Alto & $\begin{array}{l}\text { Parque Nacional de } \\
\text { los Montes Ruwenzori } \\
\text { (Uganda) }\end{array}$ \\
\hline $\begin{array}{l}\text { Área de recarga de acuífero } \\
\text { protegida }\end{array}$ & & & & & & & & Alto & $\begin{array}{l}\text { Humedal de Susupe } \\
\text { (Saipan) }\end{array}$ \\
\hline \multicolumn{10}{|c|}{ Otros mecanismos basados en el lugar con beneficio potencial para las aguas dulces } \\
\hline $\begin{array}{l}\text { Reserva marina/área de gestión } \\
\text { costera }\end{array}$ & & & & & & & & Bajo & $\begin{array}{l}\text { Delta del Danubio } \\
\text { (Rumania) }\end{array}$ \\
\hline Pesquería con veda estacional & & & & & & & & Moderado & Lago Santo Antonio (Brasil) \\
\hline Reserva forestal & & & & & & & & Moderado & $\begin{array}{l}\text { Reserva Forestal de los } \\
\text { Sundarbans (Bangladesh) }\end{array}$ \\
\hline Área forestal certificada & & & & & & & & Moderado & $\begin{array}{l}\text { Curso Superior del Río St. } \\
\text { John (EEUU) }\end{array}$ \\
\hline
\end{tabular}

Especialmente compatible con la categoría de área protegida

No incompatible con la categoría de área protegida No especialmente o nunca apta con la categoría de área protegida
*GICF = gestión integrada de cuenca fluvial, ver texto 
No todas las áreas protegidas diseñadas en todo o en parte para la protección de las aguas terrestres, incluyendo la mayoría de los sitios Ramsar, tienen asignada una categoría. Además, muchas áreas protegidas que contribuyen a la conservación de ecosistemas de aguas terrestres carecen de estatus Ramsar. En consecuencia, no es posible evaluar globalmente en estos momentos cuáles de las áreas protegidas existentes tienen objetivos relativos a las aguas terrestres, o cómo se han aplicado las categorías de la UICN. Distintos tipos de sistemas de aguas terrestres, con distintos niveles de naturalidad, pueden prestarse mejor a alguna de las categorías de áreas protegidas que a otras: En la tabla 12 se hacen algunas sugerencias.

\section{Protección integrada de sistemas de humedales de aguas interiores}

A menudo resulta difícil identificar un "área protegida de aguas interiores" y la influencia de un área protegida sobre los sistemas acuáticos puede tener tanto que ver con sus objetivos de gestión como con los hábitats que la componen. Las áreas marinas protegidas son fácilmente identificables por su ubicación. Sin embargo los sistemas de aguas interiores se extienden por todo el paisaje terrestre y se dan en casi todas las áreas terrestres protegidas. Ciertas áreas protegidas, como los ríos que fluyen sin

Tabla 12. Categorías de áreas más adecuadas para distintos tipos de ecosistemas de humedales terrestres

\begin{tabular}{|c|c|c|c|c|c|c|c|c|}
\hline \multirow{2}{*}{$\begin{array}{l}\text { Tipo de ecosistema de } \\
\text { agua dulce }\end{array}$} & \multicolumn{7}{|c|}{ Categoría de la UICN } & \multirow[t]{2}{*}{ Ejemplos } \\
\hline & la & lb & II & III & IV & $\mathbf{V}$ & VI & \\
\hline \multicolumn{9}{|l|}{ Sistemas fluviales } \\
\hline Cuencas completas & & & & & & & & Parque Nacional Kakadu (Australia) \\
\hline $\begin{array}{l}\text { Río/corriente completo o } \\
\text { secciones sustanciales }\end{array}$ & & & & & & & & Río Patrimonio Fraser (Canadá) \\
\hline Cabecera & & & & & & & & Reserva Forestal de los Adirondacks (Estados Unidos) \\
\hline Curso medio e inferior & & & & & & & & Parque Nacional de Doñana (España) \\
\hline Zonas ribereñas & & & & & & & & $\begin{array}{l}\text { Área de Conservación Douglas River/Daly River } \\
\text { Esplanade (Australia) }\end{array}$ \\
\hline Secciones de cauces de ríos & & & & & & & & Monumento Nacional de Hippo Pool (Zambia) \\
\hline Gargantas & & & & & & & & $\begin{array}{l}\text { Área de Conservación del Cañón del Río Fish } \\
\text { (Namibia) }\end{array}$ \\
\hline Saltos de agua & & & & & & & & Parque Nacional de Iguazú (Argentina/Brasil) \\
\hline \multicolumn{9}{|l|}{ Humedales y lagos } \\
\hline $\begin{array}{l}\text { Humedales de llanuras } \\
\text { aluviales }\end{array}$ & & & & & & & & Reserva de Desarrollo Sostenible de Mamirauá (Brasil) \\
\hline Lagos & & & & & & & & Lago Balatón (Hungría) \\
\hline Partes de lagos & & & & & & & & Parque Nacional de la Isla de Rubondo (Tanzania) \\
\hline Deltas interiores & & & & & & & & $\begin{array}{l}\text { Área de Gestión de Vida Silvestre del Delta del } \\
\text { Okavango (Botswana) }\end{array}$ \\
\hline Deltas costeros & & & & & & & & Reserva de la Biosfera del Delta del Danubio (Rumanía) \\
\hline Humedales costeros & & & & & & & & Parque Nacional de Doñana (España) \\
\hline Humedales geotermales & & & & & & & & Lago Bogoria (Kenia) \\
\hline Fuentes & & & & & & & & $\begin{array}{l}\text { Refugio Nacional de la Vida Silvestre de Ash } \\
\text { Meadows (EEUU) }\end{array}$ \\
\hline $\begin{array}{l}\text { Humedales alpinos y de la } \\
\text { tundra }\end{array}$ & & & & & & & & Humedal de Bitahai (China) \\
\hline Ciénagas de agua dulce & & & & & & & & Ciénaga de Busanga (Zambia) \\
\hline Turberas & & & & & & & & Reserva Natural Nacional de Silver Flowe (RU) \\
\hline \multicolumn{9}{|l|}{ Humedales subterráneos } \\
\hline Aguas kársticas y cuevas & & & & & & & & Polje de Mira Minde y las fuentes conexas (Portugal) \\
\hline
\end{tabular}


obstáculos y muchos sitios Ramsar, podrían cumplir claramente los criterios para ser "áreas protegidas de aguas interiores", pero la designación de los demás espacios puede ser ambigua. Algunas han incluido objetivos de gestión tanto para ecosistemas terrestres como de aguas interiores desde el principio, mientras que otras áreas protegidas establecidas originalmente para proteger rasgos terrestres con el tiempo han incorporado objetivos de gestión de aguas interiores. El Parque Nacional Kruger de Sudáfrica es un ejemplo: originalmente fue establecido para proteger a la fauna de grandes mamíferos, pero se estima que las zonas ribereñas y fluviales soportan alrededor del 50 por ciento de la biota del parque por lo que se dedica actualmente alrededor del 30 por ciento de la gestión a las aguas interiores.

Aunque algunas áreas protegidas benefician a los sistemas de humedales terrestres situados dentro de ellas, existen muchos otros ejemplos en los que éste no es el caso. En muchos casos, los ecosistemas de humedales situados dentro de áreas protegidas han sido alterados deliberadamente para suministrar agua y electricidad, e incluso para facilitar la observación de animales salvajes y otros fines recreativos. Es necesario integrar las consideraciones relativas a la conservación de humedales en la gestión de todas las áreas protegidas que los contengan, incluyendo las AMPs costeras. La gestión de las áreas protegidas terrestres podría abordar mejor las aguas interiores, por ejemplo mediante:

- Protección o restauración de la conectividad longitudinal y lateral de las corrientes de agua (por ej. eliminando barreras, reconectando los ríos con las llanuras aluviales, asegurándose de que las carreteras e infraestructuras asociadas dentro de las áreas protegidas no fragmenten los sistemas fluviales);

- Protección de la fauna nativa (por ej. prohibiendo la introducción de peces exóticos o la sobrepesca);

- Protegiendo la flora nativa - especialmente en las zonas ribereñas que pueden no ser debidamente atendidas en el entorno más amplio del área protegida;

- Gestión de las actividades recreativas acuáticas (por ej. restringiendo las embarcaciones de motor y los vertidos desde las mismas);

- Protección prioritaria de la calidad del agua (por ej. gestión cuidadosa de los vertidos puntuales desde las instalaciones recreativas);

- Proteger los caudales de las cabeceras de rios y fuentes fluviales de forma que los usuarios situados aguas abajo puedan disfrutar de las ventajas de los servicios de este ecosistema;

- Protección o restauración de las zonas de amortiguamiento ribereñas tanto dentro del parque como a lo largo del límite del parque si es un río el que sirve de delimitación (y ampliando los límites de las AP cuando sea posible empleando los criterios de gestión de ecosistemas apropiados a los humedales - por ej. empleando los límites entre cuencas y no los lechos fluviales para demarcar las áreas);

- Protección especial para las fuentes o cuerpos de agua sagrados con importancia cultural.
Debido en parte a la continua ambigüedad sobre si un área es un "área protegida de aguas interiores" o no, separar estos componentes al registrar estas áreas en la Base de Datos Mundial de Áreas Protegidas sigue siendo un reto. La medición y la interpretación del tamaño de muchos humedales puede ser difícil y en muchos casos los humedales pueden variar mucho debido a factores naturales (por ej. inundaciones estacionales), y actualmente la Base de Datos Mundial de Áreas Protegidas no tiene en mente las mediciones de longitud. Hasta que la conservación de las aguas interiores se incorpore de forma más eficaz a los planes de gestión de áreas protegidas, y dichos planes de gestión reconozcan los procesos y amenazas externas a los límites de estas áreas protegidas, la extensión de los sistemas de aguas interiores dentro de las áreas protegidas nos dice más sobre el potencial de conservación de estos ecosistemas que sobre su conservación real.

\section{Lugares naturales sagrados}

Los lugares sagrados (incluyendo los lugares y paisajes naturales sagrados) que se ajustan a las definiciones nacionales e internacionales de área protegida pueden se reconocidos potencialmente como componentes legítimos de los sistemas de áreas protegidas y pueden ser clasificados en cualquiera de las seis categorías de áreas protegidas de la UICN. Al mismo tiempo, los valores culturales y espirituales de las áreas protegidas deberían estar reflejados en todo el rango de categorías, en las cuales están actualmente ausentes o insuficientemente reconocidos.

Muchas áreas protegidas contienen lugares de importancia para alguno y a veces varios sistemas de valores espirituales o de creencias, incluyendo tanto lugares naturales sagrados como monumentos construidos como monasterios, templos, altares y rutas de peregrinación. Incluso en los sistemas de áreas protegidas en los países más secularizados de Europa, que fueron establecidos empleando únicamente criterios ecológicos, se estima que entre el 20 y el 35 por ciento contienen valores culturales o espirituales significativos. Hay países y territorios en los que toda la naturaleza es sagrada y las áreas protegidas pueden formar entidades más pequeñas como parte de paisajes sagrados más extensos. Los gestores deben asegurar que estos valores espirituales son protegidos junto con el patrimonio natural. Sin embargo, actualmente los lugares sagrados no están reflejados eficazmente en los diseños y planes de gestión de áreas protegidas, y los marcos legales y políticos existentes no apoyan adecuadamente los lugares (naturales) sagrados. Existe una evidencia razonable y general de que los lugares naturales sagrados han estado proporcionando una conservación eficaz de la biodiversidad, a menudo durante siglos. Los lugares sagrados existen en ecosistemas más o menos naturales, paisajes culturales o paisajes gestionados y cuando existen en áreas protegidas tienen que ser incluidos completamente en las estrategias de gestión en conformidad con los correspondientes grupos religiosos o comunitarios. La Tabla 13 ofrece algunos ejemplos. 
Tabla 13. Ejemplos de lugares sagrados en las categorías de la UICN

la Reserva natural estricta: área protegida gestionada principalmente con fines científicos

\begin{tabular}{|l|l|l}
\hline Sri Lanka & $\begin{array}{l}\text { Parque Nacional de } \\
\text { Yala }\end{array}$ & $\begin{array}{l}\text { Importante para Budistas e Hinduistas y requiere altos niveles de } \\
\text { protección por razones religiosas. }\end{array}$ \\
\hline $\begin{array}{l}\text { Federación } \\
\text { Rusa }\end{array}$ & Yuganskiy Kanthy & $\begin{array}{l}\text { Importante para el Cristianismo. El área protegida se ha establecido } \\
\text { alrededor del Lago Numto - un lugar sagrado para los Khanty y } \\
\text { Nenets - en la región de Beloyarsk. }\end{array}$ \\
\hline
\end{tabular}

Ib Área silvestre: área protegida gestionada principalmente para la protección de la vida silvestre

\begin{tabular}{|l|l|l|}
\hline Mongolia & Montaña Bogd Khan & $\begin{array}{l}\text { La montaña es importante para el Budismo y anteriormente para } \\
\text { el chamanismo. La montaña ha sido declarada oficialmente por el } \\
\text { estado montaña sagrada. Hay evidencias de la declaración de área } \\
\text { silvestre desde 1294. }\end{array}$ \\
\hline Mongolia & Dornod Mongol & $\begin{array}{l}\text { Importante para el Budismo. Vangiin Tsagaan Uul (la Montaña Blanca } \\
\text { de Vangi) es una montaña sagrada budista dentro de la reserva. }\end{array}$ \\
\hline
\end{tabular}

II Parque nacional: área protegida gestionada principalmente para la protección del ecosistema y usos recreativos

\begin{tabular}{|l|l|l|}
\hline Malawi & $\begin{array}{l}\text { Parque Nacional de } \\
\text { Nyika }\end{array}$ & $\begin{array}{l}\text { Área extensa que contiene cuatro lugares sagrados, que la población } \\
\text { local sigue utilizando para las ceremonias de invocación de la lluvia. }\end{array}$ \\
\hline Japón & $\begin{array}{l}\text { Parques nacionales } \\
\text { de Kii Mountains y } \\
\text { sitio de Patrimonio } \\
\text { Mundial (PM) }\end{array}$ & $\begin{array}{l}\text { Varios templos sintoístas y budistas, lugares sagrados y rutas de } \\
\text { peregrinación para ambas religiones con un uso continuado de más } \\
\text { de un milenio. }\end{array}$ \\
\hline India & $\begin{array}{l}\text { Gran Parque } \\
\text { Nacional del } \\
\text { Himalaya }\end{array}$ & Incluye muchos lugares de importancia religiosa para el Hinduismo. \\
\hline
\end{tabular}

III Monumento natural: área protegida gestionada principalmente para la conservación de rasgos naturales concretos

\begin{tabular}{|c|c|c|c|}
\hline & Camboya & $\begin{array}{l}\text { Santuario Silvestre } \\
\text { de Phnom Prich }\end{array}$ & $\begin{array}{l}\text { Una pequeña zona del santuario es un bosque sagrado y con ello un } \\
\text { monumento natural (otro ejemplo son los bosques Kaya de Kenia). }\end{array}$ \\
\hline & $\begin{array}{l}\text { Federación } \\
\text { Rusa }\end{array}$ & $\begin{array}{l}\text { Montañas Doradas } \\
\text { del Altai }\end{array}$ & $\begin{array}{l}\text { Sagrado para los indígenas del Altai y muchas otras religiones } \\
\text { incluyendo el Budismo, el Cristianismo y el Islam. }\end{array}$ \\
\hline & Grecia & $\begin{array}{l}\text { Península del Monte } \\
\text { Athos - sitio de PM }\end{array}$ & $\begin{array}{l}\text { Baluarte del Cristianismo Ortodoxo que incluye } 20 \text { monasterios dentro } \\
\text { de un estado monástico y cientos de asentamientos monásticos, } \\
\text { ermitas y cuevas menores con más de un milenio de actividad } \\
\text { monástica ininterrumpida. }\end{array}$ \\
\hline & España & $\begin{array}{l}\text { Reserva Natural y } \\
\text { Parque Natural de } \\
\text { Montserrat }\end{array}$ & $\begin{array}{l}\text { Montaña sagrada que contiene ermitas antiguas y un monasterio } \\
\text { cristiano que ha sido centro de peregrinación desde el siglo XIV. Hoy } \\
\text { en día es el área protegida más visitada de España. }\end{array}$ \\
\hline IV & \multicolumn{3}{|c|}{$\begin{array}{l}\text { Área de gestión de hábitat/especies: área protegida gestionada principalmente para la conservación } \\
\text { mediante intervenciones de gestión }\end{array}$} \\
\hline & Líbano & $\begin{array}{l}\text { Valle de Qadisha y } \\
\text { los Bosques de los } \\
\text { Cedros de Dios - } \\
\text { sitio de PM }\end{array}$ & $\begin{array}{l}\text { Bosque sagrado para la iglesia cristiana maronita que incluye un } \\
\text { importante monasterio, ermitas y la residencia de las autoridades } \\
\text { religiosas. }\end{array}$ \\
\hline & Borneo & Jardines tembawang & $\begin{array}{l}\text { Algunos lugares sagrados requieren intervención continua e incluso } \\
\text { ser replantados como los jardines tembawang que contienen altos } \\
\text { niveles de biodiversidad. }\end{array}$ \\
\hline & Sri Lanka & $\begin{array}{l}\text { Parque Silvestre del } \\
\text { Pico Adams, (Sri } \\
\text { Pada-Adams Peak) }\end{array}$ & $\begin{array}{l}\text { Lugar sagrado para el Islam, Budismo, Hinduismo y Cristianismo que } \\
\text { atrae muchos peregrinos de todas estas religiones. }\end{array}$ \\
\hline
\end{tabular}


Tabla 13. Ejemplos de lugares sagrados en las categorías de la UICN (cont.)

\begin{tabular}{|c|c|c|}
\hline \multicolumn{3}{|c|}{$\begin{array}{l}\text { Paisaje terrestre/marino protegido: área protegida gestionada principalmente para la conservación del } \\
\text { paisaje terrestre/marino y usos recreativos }\end{array}$} \\
\hline China & $\begin{array}{l}\text { Parque Nacional } \\
\text { Xishuangbanna }\end{array}$ & $\begin{array}{l}\text { Paisaje con varios lugares sagrados (bosques y montañas) } \\
\text { gestionados por la comunidad desde hace mucho tiempo. }\end{array}$ \\
\hline Rumanía & $\begin{array}{l}\text { Parque Natural } \\
\text { Vanatori Neamt }\end{array}$ & $\begin{array}{l}\text { El corazón espiritual de Rumanía, incluye } 16 \text { monasterios cristianos } \\
\text { junto con una vida silvestre extraordinaria: Bisonte europeo, oso } \\
\text { pardo y poblaciones de lobos. }\end{array}$ \\
\hline \multicolumn{3}{|c|}{$\begin{array}{l}\text { Área protegida de gestión de recursos: área protegida gestionada principalmente para el uso } \\
\text { sostenible de los ecosistemas naturales }\end{array}$} \\
\hline Ecuador & Cayapas Mataje & $\begin{array}{l}\text { Área de usos sostenibles que se dice contiene los manglares } \\
\text { más altos del mundo y conocida porque en ella residen espíritus } \\
\text { importantes adorados por los pueblos locales. }\end{array}$ \\
\hline EEUU & $\begin{array}{l}\text { Bosque Nacional } \\
\text { de los Picos de San } \\
\text { Francisco }\end{array}$ & Sagrado para más de una decena de tribus nativas americanas. \\
\hline Egipto & $\begin{array}{l}\text { Área de Santa } \\
\text { Catalina - sitio de } \\
\text { PM - y Monte Sinaí }\end{array}$ & $\begin{array}{l}\text { El Monte Sinaí es sagrado para el Judaísmo, el Cristianismo y el } \\
\text { Islam. El antiguo Monasterio de Santa Catalina es Patrimonio Mundial }\end{array}$ \\
\hline
\end{tabular}

Cuando sea posible, los custodios de los lugares sagrados deben participar en su gestión. Los custodios tradicionales de lugares sagrados deberían comunicar y transmitir los valores culturales y espirituales de los lugares sagrados para ayudar a determinar los objetivos de gestión. Los lugares sagrados ofrecen una oportunidad excelente para entablar este diálogo y desarrollar sinergias que sean sostenibles ambientalmente y equitativas en términos sociales.

\section{Lugares sagrados y categorías de áreas protegidas}

La inclusión o no de un lugar sagrado concreto en el sistema de áreas protegidas depende de los deseos del grupo religioso involucrado y de si los objetivos de gestión del lugar se ajustan a la definición de área protegida de la UICN y los requisitos de alguna de las categorías. Esto implica que el grupo religioso reconozca y acepte la importancia de mantener la biodiversidad junto a los valores sagrados del lugar.

Hay que tener cuidado de asegurarse que los valores culturales y espirituales no ponen en riesgo los valores de biodiversidad y a su vez, que la gestión del área protegida no atenta contra los valores sagrados del lugar. La integración de lugares sagrados, o más ampliamente, la percepción del carácter sagrado de la naturaleza, en los planes de conservación sólo es posible si se aborda conjuntamente sin fronteras ideológicas, físicas o institucionales. En resumen, este es un proceso que integra el conocimiento y la sabiduría en la conservación de la biodiversidad. Por lo tanto, la inclusión de lugares sagrados en todas las categorías de áreas protegidas fomenta los valores interculturales y transversales, que a su vez pueden producir sinergias equitativas entre la diversidad espiritual, cultural y natural en apoyo de objectivos de conservación más holísticos.

\section{Geodiversidad}

"La Geodiversidad es la variedad de rocas, minerales, fósiles, formas terrestres, sedimentos y suelos, junto con los procesos naturales que los forman y modifican".

Muchas áreas protegidas contienen una importante geodiversidad y algunas áreas protegidas han sido establecidas especialmente por sus valores de geodiversidad; en ambos casos el mantenimiento de dichos valore requiere una atención especial en las políticas de gestión. La geodiversidad está incluida en el término "conservación de la naturaleza" en la definición de área protegida de la UICN.

La geodiversidad proporciona los cimientos para la vida sobre la tierra y para la diversidad de hábitats y paisajes naturales. Muchos rasgos y formaciones geológicas tienen valores culturales o icónicos para los seres humanos, que influyen en la forma en que miramos a los hábitats naturales y seminaturales que nos rodean. La geodiversidad también tiene gran influencia sobre muchos aspectos de los paisajes culturales, los entornos construidos y las actividades económicas. La protección de la geodiversidad puede ser una respuesta a una serie de intereses, incluyendo los asociados a yacimientos importantes de fósiles; lugares de referencia para las geociencias; rasgos espectaculares vinculados al turismo; y formaciones del relieve que cuentan con valores culturales o espirituales especiales. La geodiversidad puede contribuir al desarrollo económico 
sostenible mediante el turismo asociado a los rasgos geológicos. La comprensión de los vínculos funcionales entre la geodiversidad y la biodiversidad resulta especialmente importante para la conservación y gestión de medios dinámicos, en los que los procesos naturales (por ej. inundaciones, erosión y deposición) mantienen la diversidad de hábitats y las funciones ecológicas. Esto está implicito en el enfoque de gestión de ecosistemas y resulta fundamental en un momento en que muchos ecosistemas se enfrentan a los impactos del cambio climático. La geodiversidad es por lo tanto una cuestión clave en la gestión sostenible de la tierra, los ríos y las costas. Requiere enfoques integrados de gestión del patrimonio natural, tierra y agua a escala de paisaje/ecosistema, basados en el entendimiento de que estamos trabajando con procesos naturales y sus probables respuestas al cambio climático.

Aunque la categoría III destaca como la más obvia para la protección de rasgos o formaciones geológicas concretas, la geodiversidad puede estar, y de hecho se encuentra protegida bajo todas las categorías y todos los tipos de gobernanza. La Tabla 14 proporciona algunos ejemplos.
Tabla 14. Ejemplos de geodiversidad en distintas categorías de áreas de la UICN

\begin{tabular}{|l|l|l|}
\hline Categoría & Ejemplo & País \\
\hline Ia & $\begin{array}{l}\text { Parque Nacional del } \\
\text { Gran Cañón }\end{array}$ & $\begin{array}{l}\text { Estados } \\
\text { Unidos }\end{array}$ \\
\hline Ib & $\begin{array}{l}\text { Reserva de } \\
\text { Conservación del Karst } \\
\text { de Jenolan }\end{array}$ & Australia \\
\hline III & $\begin{array}{l}\text { Parque Nacional de } \\
\text { Brecon Beacons }\end{array}$ & Reino Unido \\
\hline IV & & \\
\hline V & & \\
\hline VI &
\end{tabular}

Aunque no pretende ser definitiva, la Tabla 15 ofrece algunas indicaciones de cuándo los valores de geodiversidad pueden ajustarse a las categorías concretas de la UICN.

Tabla 15. Indicaciones de posibles categorías de áreas protegidas de la UICN para distintos aspectos de la geodiversidad

Aspecto concreto de la geodiversidad considerado

La protección se dirige principalmente a un rasgo de interés concreto (monumento natural como un salto de agua o una cueva) o un lugar de valor nacional o internacional para la geociencia.

Conjunto de formaciones del relieve (por ej. un sistema de valles glaciares) y/o procesos o rasgos geológicos.

Rasgos con potencial para la interpretación y el geoturismo.

La geodiversidad es por sí misma la base de los hábitats y las especies (por ej. plantas calcícolas o especies adaptadas a cuevas).

La geodiversidad tiene importantes vínculos con paisajes culturales (por ej. cuevas utilizadas como viviendas o formaciones del relieve adaptadas a la agricultura en terrazas).

La geodiversidad es la base para la gestión sostenible (actividades asociadas a procesos naturales, como el turismo espeleológico).

\section{Categoría/categorías posibles}

Principalmente categoría III

Principalmente categorías la, Ib, II y V

Principalmente categorías II y III

Principalmente categorías la, Ib, II, IV, V y VI

Principalmente categoría $\mathrm{V}$ y también categorías II y III

Principalmente compatible con categorías $\mathrm{V}$ y $\mathrm{VI}$

\section{Restauración y categorías de áreas protegidas de la UICN}

La categoría de áreas protegidas de la UICN se escoge principalmente en función del objetivo de gestión, por ej., está relacionado con los objetivos de gestión más que con el estado actual de los recursos, de forma que en cualquier categoría las áreas protegidas pueden estar sujeta a restauración. Sin embargo, en la práctica la categoría también suele indicar algo sobre el estado de un área protegida y normalmente la restauración activa no se ajusta a todas las categorías de áreas protegidas. Por ejemplo, la categorización en función de los valores silvestres (Ib) no suele ser adecuada para un área que vaya a requerir intervenciones activas y continuas de gestión para mantener dichos valores. En algunas situaciones la restauración de un área protegida puede consistir en una intervención limitada en el tiempo para revertir daños causados anteriormente mientras que en otros casos los cambios han sido tan profundos que será necesaria una intervención continuada a largo plazo: esto es a menudo cierto si algunos elementos ecológicos como especies importantes, han desaparecido. Algunas intervenciones, como el control de especies invasoras y en ciertos hábitats las quemas prescritas pueden resultar necesarias en todas las categorías. Los consejos siguientes describen la situación general, pero siempre habrá excepciones: 
- Restauración mediante procesos naturales como resultado de la protección (mise en défens): por ejemplo la restauración de bosques antiguos mediante la eliminación de la presión maderera y del pastoreo; recuperación de las reservas de peces o arrecifes de coral restringiendo la pesca; prohibición de impactos por pisoteo en comunidades de flora alpina - adecuada para todas las categorías de aguas protegidas.

- Restauración mediante intervenciones limitadas en el tiempo para revertir daños pasados: una o varias intervenciones pueden ser necesarias para restaurar daños; por ejemplo reintroducción de especies extirpadas; replantación para acelerar la recuperación forestal; selección de plantones; clareado; eliminación de especies invasoras normalmente no son adecuados en las áreas estrictamente protegidas de categoría Ia y Ib, pero pueden ser adecuados en las demás categorías. ${ }^{15}$

- Restauración como proceso continuo para la conservación de la biodiversidad: por ejemplo mantenimiento artificial de los niveles de agua en un humedal o una cuenca que hayan sufrido cambios hidrológicos sustanciales; acopado (poda regular) de árboles para mantener un bosque cultural importante; utilizar el pastoreo de ganado para mantener valores de biodiversidad - generalmente adecuado para las categorías IV-VI.

- Restauración como proceso continuo tanto para los recursos naturales como para la biodiversidad: por ejemplo recuperar la productividad tras la erosión del suelo, proporcionando recursos para el sustento humano - adecuado para las categorías V-VI.

Tabla 16. Guía indicativa para la restauración en diferentes categorías de la UICN

\begin{tabular}{|c|c|c|c|c|c|c|}
\hline \multicolumn{7}{|c|}{ Categoría de la UICN } \\
\hline la & lb & II & III & IV & $\mathbf{V}$ & VI \\
\hline \multicolumn{7}{|c|}{ Restauración mediante procesos naturales como resultado de la protección } \\
\hline & & \multicolumn{5}{|c|}{ Restauración activa limitada en el tiempo } \\
\hline & & & & \multicolumn{3}{|c|}{ Restauración continua para la biodiversidad } \\
\hline & & & & & \multicolumn{2}{|c|}{$\begin{array}{l}\text { Restauración continua para la } \\
\text { biodiversidad y las necesidades humanas }\end{array}$} \\
\hline
\end{tabular}

En los casos en que la destrucción general del hábitat es tan avanzada que las mismas áreas protegidas requieren una restauración sustancial, puede ser sensato esperar a ver el éxito final de los proyectos de restauración antes de asignar una categoría.
El grado de restauración necesario y la gestión activa pueden aumentar en muchas áreas protegidas en condiciones de cambio climático.

15 Es posible cambiar la categoría de un área protegida a Ia o Ib si la restauración ha tenido éxito. 



\section{Iniciativas internacionales de conservación}

Existe una serie de tentativas paralelas para proteger importantes hábitats por parte de las Naciones Unidas o por acuerdos regionales. Cabe destacar el Convenio sobre la Diversidad Biológica, sitios naturales de Patrimonio Mundial de la UNESCO, Reservas del Hombre y la Biosfera de la UNESCO y los sitios de Ramsar. La siguiente sección analiza en particular la relación entre Ramsar y Patrimonio Mundial y las categorías de la UICN. 


\section{Convención del Patrimonio Mundial}

Los sitios del Patrimonio Mundial suponen los más importantes lugares culturales y naturales del mundo reconocidos por la Convención sobre la protección del Patrimonio Mundial, Cultural y Natural de la UNESCO y bajo protección especial de las naciones donde se encuentran. Incluyen montañas con Angkor Wat en Camboya o las Pirámides de Egipto, y adicionalmente áreas naturales excepcionales, como el Parque Nacional del Serengeti en Tanzania o el Parque Nacional de Canaima en Venezuela. Los gobiernos nominan lugares para su posible inclusión en la Lista de Patrimonio Mundial, cuyo reconocimiento depende de una evaluación técnica ${ }^{16}$ seguida de una revisión y decisión final de los miembros del Comité del Patrimonio Mundial. La toma en consideración se basa en que el sitio tenga Valores Universales Excepcionales (VUE), término referido a la combinación de los valores patrimoniales del sitio que demuestran por qué son de significación global, así como el requisito de que el lugar tenga integridad y una gestión efectiva. La UICN está reconocida oficialmente en el texto de la Convención como el Órgano Asesor para todos sitios naturales y los sitios mixtos naturales y culturales. Esto conlleva llevar a cabo las evaluaciones técnicas de todos los sitios nominados para su inclusión en la Lista de Patrimonio y también realizar misiones de monitoreo requeridas para los sitios que puedan estar amenazados. Prácticamente, todos los sitios naturales de Patrimonio Mundial son también áreas protegidas. En el pasado, los sitios de Patrimonio Mundial estaban registrados aparte, en la Lista de la ONU de Áreas Protegidas, pero esto inducía a duplicidad de información ya que muchos sitios aparecían también registrados bajo su categoría de la UICN.

\section{¿Qué requiere la Convención del Patrimonio Mundial de los sitios naturales de la Lista del Patrimonio Mundial?}

Las siguientes notas intentan ayudar a los gobiernos a considerar la relación de los sitios naturales de Patrimonio Mundial con el sistema de categorías de áreas protegidas de la UICN. No se incluyen los sitios de patrimonio cultural, ya que la mayoría de ellos no están ubicados dentro de áreas protegidas (o si lo están, puede ser accidentalmente).

\section{Relación, en teoría, entre el Patrimonio Mundial y las áreas protegidas}

La versión del 2008 de las Directrices Operacionales (DO) de la Convención del Patrimonio Mundial explica qué se requiere de los sitios de Patrimonio Mundial (PM). Se explica que un área se puede inscribir en la lista de PM únicamente si el lugar cumple con los criterios pertinentes de Patrimonio Mundial y si se cumplen las condiciones estrictas de integridad y conservación (párrafo 88), o lo que es lo mismo, está obligada a:
- Incluir todos los elementos necesarios para expresar los Valores Universales Excepcionales por los que se la nomina para su inscripción en la lista de PM;

- Ser de una extensión adecuada para asegurar la representación total de las rasgos y procesos que conlleva la relevancia del sitio:

- No sufrir efectos adversos derivados del desarrollo o de la negligencia.

Los sitios de PM potenciales se juzgan en función de varios criterios, dos de los cuales (ecosistemas y biodiversidad) son particularmente relevantes para las áreas protegidas. Los párrafos 94-95 describen la integridad para estos dos criterios:

- Criterio ix (ecosistemas): el sitio "debe tener extensión suficiente y contener los elementos necesarios para demostrar los aspectos fundamentales de los procesos que resultan esenciales para la conservación a largo plazo del ecosistema y la diversidad biológica que estos contienen".

- Criterio x (biodiversidad): el sitio "debe contener hábitats para mantener la más diversa fauna y flora características de la provincia biogeográfica y el ecosistema en consideración".

Las DO reconocen que "ningún área es totalmente virgen y de que todas las áreas naturales están en un estado dinámico, y de algún modo conllevan el contacto con las personas. Las actividades humanas, incluidas las de sociedades tradicionales y comunidades locales, a menudo tienen lugar en áreas naturales. Estas actividades pueden estar en sintonía con los VUE del área dónde sean sostenibles ecológicamente" (párrafo 89).

Finalmente las DO incluyen una sección titulada Protección y Gestión (párrafos 96-118), que enumera medidas para la conservación a largo plazo de áreas nominadas para su consideración como PM. Específicamente, el párrafo 97 dice que: "Todos los sitios inscritos en la Lista del Patrimonio Mundial tienen que disponer a largo plazo de la protección y gestión legislativa, reguladora, institucional y/o tradicional para asegurar su salvaguarda. Esta protección debe incluir límites adecuadamente delineados". El párrafo 98 de las DO añade además que: "Medidas legislativas y reguladoras a nivel nacional y local deben asegurar la supervivencia del sitio y su protección contra el desarrollo y el cambio que puedan tener un impacto negativo en su valor universal excepcional, o en su integridad. Los Estados Partes deben asegurar la implementación total y efectiva de estas medidas".

Respecto a la relación entre los sitios nominados y las áreas protegidas existentes, las DO indican, en el párrafo 102, que: "Los límites del sitio nominado pueden coincidir con una o más áreas protegidas existentes o propuestas, como parques nacionales o reservas naturales, reservas de la biosfera [...]. Mientras que estas

16 Todos los sitios naturales son evaluados por UICN y todos los sitios culturales por ICOMOS (Consejo internacional de monumentos y sitios - International Council on Monuments and Sites). 
áreas establecidas para su protección pueden contener varias zonas de gestión, tan sólo alguna de estas zonas puede llegar a satisfacer los criterios para su inscripción". Esta afirmación implica que algunas áreas con protección legal pueden no llegar a calificarse con PM, por ej., algunas formas de protección legal no son lo suficientemente restrictivas para cumplir los requisitos de las DO.

Por ello, aunque las DO no especifican que un lugar tiene que ser un "área protegida", o estar referido a las categorías de áreas protegidas de la UICN, se puede deducir en conclusión que aquellas áreas sin ningún régimen particular de protección deberían excluirse de los sitios de PM (por ej. Párrafos 97 y 102 de las DO): de este modo, se espera que los sitios naturales de Patrimonio Mundial sean gestionados de forma equivalente a la gestión que se realiza en áreas protegidas, estén formalmente protegidas o no. Esta es la interpretación aplicada por la UICN en su función asesora.

\section{Relación, en la práctica, entre sitios de Patrimonio Mundial y áreas protegidas}

Se requiere una gestión eficaz para el registro en la Lista del Patrimonio Mundial y en la práctica esto ha significado que la amplia mayoría de los sitios naturales de Patrimonio Mundial sean áreas protegidas. El PNUMA-CMCM prepara relaciones de datos de todos los sitios propuestos para Patrimonio Mundial y registra explícitamente la categoría de AP de la UICN que corresponde al área nominada. Esto supone un claro vínculo entre los sitios naturales de Patrimonio Mundial y el sistema de categorías.

Esta situación se ha desarrollado con el paso del tiempo. En los primeros años de la Convención, algunos sitios naturales de Patrimonio Mundial incluían desarrollos que hoy no serían aceptados por el Comité del Patrimonio Mundial. Como resultado, algunos sitios de PM contienen áreas de usos incompatibles, lo bastante grandes para ser consideradas como zonas claramente definidas dentro de un sitio Patrimonio Mundial y no simplemente como intrusiones "preexistentes" a un área protegida, de otro modo, estaría relativamente poco perturbada. Los Estados Partes podrían en teoría proponer enmiendas para retirar algunas de estas zonas de los sitios de patrimonio existentes. Esto ocurre en unos pocos casos, pero es necesario considerarlo con cautela, caso por caso. ${ }^{17}$

La mayoría de los sitios de PM incluidos en la lista de patrimonio o nominados para su inscripción coinciden con los límites de áreas protegidas existentes. En aquellos casos donde existen grandes espacios entre áreas protegidas de valores similares y complementarios existe la posibilidad de inscribir una nominación en serie y este tipo de nominaciones se están volviendo cada vez más comunes. (por ej. Las Reservas de la Selva Atlántica de la Costa de los Descubrimientos en Brasil y las Áreas Protegidas de la Región Floral del Cabo en Sudáfrica). Los estudios resumidos en la Tabla 17 demuestran cómo se ha fortalecido la relación entre los sitios de PM y las áreas protegidas durante los últimos 25 años. Los nuevos sitios de PM han ido ajustándose gradualmente de un modo más estricto a la definición de área protegida de la UICN, y se han ido excluyendo aquellas áreas que no se benefician de un régimen de protección. De todas formas, continúan dándose algunas excepciones (por ej. Península Valdés en Argentina) y todavía no es un requisito para los sitios naturales de Patrimonio Mundial que sean áreas protegidas oficialmente establecidas, si se puede proporcionar una protección y gestión adecuada por otros medios.

Tabla 17. Cambios de relación entre los sitios naturales Patrimonio Mundial y las áreas protegidas con el tiempo

\begin{tabular}{|l|l|l|l|l|}
\hline $\begin{array}{l}\text { Nombre del } \\
\text { sitio }\end{array}$ & $\begin{array}{l}\text { Criterios } \\
\text { PM }\end{array}$ & Cat. UICN & $\begin{array}{l}\text { Año } \\
\text { inscr. }\end{array}$ & Discusión \\
\hline $\begin{array}{l}\text { Islas Galápagos } \\
\text { ECUADOR }\end{array}$ & $\begin{array}{l}\text { vii, viii, } \\
\text { ix, } x\end{array}$ & $\begin{array}{l}\text { II (terrestre) } \\
\text { IV (marino) }\end{array}$ & 1978 & $\begin{array}{l}\text { Se encuentra entre el primer grupo de nominaciones } \\
\text { formuladas para su inscripción en la lista del PM de todos } \\
\text { los tiempos, los límites terrestres no excluyen las áreas } \\
\text { agrícolas y asentamientos, lo que da lugar a un sitio PM } \\
\text { que incluye extenso ranchos de ganado y áreas urbanas } \\
\text { densamente pobladas. Se amplió el sitio para incluir un área } \\
\text { protegida marina en 2001, que incluye una mezcla de zonas } \\
\text { de baja intensidad y uso múltiple (buceo, pesca artesanal). }\end{array}$ \\
\hline $\begin{array}{l}\text { Gran Barrera de } \\
\text { Coral } \\
\text { AUSTRALIA }\end{array}$ & $\begin{array}{l}\text { vii, viii, } \\
\text { ix, } x\end{array}$ & V & 1981 & $\begin{array}{l}\text { Una zona de uso múltiple, con una variedad de usos } \\
\text { permitidos, desde la conservación estricta al uso recreativo } \\
\text { incluida la pesca. En su informe de evaluación de la } \\
\text { nominación, la UICN sugirió que los límites concretos } \\
\text { de PM estuviesen limitados al área crucial totalmente } \\
\text { protegida (estos comentarios no fueron tenidos en cuenta } \\
\text { en la evaluación de la nominación de las Galápagos), } \\
\text { pero acabó recomendando en el mismo informe que la } \\
\text { nominación se inscribiese según se propuso originalmente. }\end{array}$ \\
\hline
\end{tabular}

17 Por ejemplo se está estudiando retirar las estaciones de esquí del sitio Patrimonio Mundial en el Parque Nacional de Pirin en Bulgaria. 
Tabla 17. Cambios de relación entre los sitios naturales Patrimonio Mundial y las áreas protegidas con el tiempo (cont.)

\begin{tabular}{|c|c|c|c|c|}
\hline $\begin{array}{l}\text { Nombre del } \\
\text { sitio }\end{array}$ & $\begin{array}{l}\text { Criterios } \\
\text { PM }\end{array}$ & Cat. UICN & $\begin{array}{l}\text { Año } \\
\text { inscr. }\end{array}$ & Discusión \\
\hline $\begin{array}{l}\text { Lago Baikal } \\
\text { RUSIA }\end{array}$ & $\begin{array}{l}\text { vii, viii, } \\
\text { ix, x }\end{array}$ & la, II, IV & 1996 & $\begin{array}{l}\text { Este sitio consta de varias entidades distintas } \\
\text { gestoras de la conservación, además de tierras de no } \\
\text { conservación (por ej. Zonas de protección costeras) de } \\
\text { valor de conservación limitado. Se da un abanico de } \\
\text { usos potencialmente incompatibles, incluidos la pesca } \\
\text { comercial, la industria maderera, la agricultura, la caza } \\
\text { y el turismo. También existen varios asentamientos } \\
\text { pequeños. Las recomendaciones originales para los } \\
\text { límites del sitio PM incluían un área mucho más amplia, } \\
\text { incluidas ciudades importantes, pero finalmente se } \\
\text { inscribió una área más pequeña con menos usos } \\
\text { conflictivos. }\end{array}$ \\
\hline $\begin{array}{l}\text { Rennell Oriental } \\
\text { SALOMÓN } \\
\text { ISLANDS }\end{array}$ & ix & $\mathrm{n} / \mathrm{a}$ & 1998 & $\begin{array}{l}\text { Aproximadamente } 800 \text { personas de origen indonesio } \\
\text { residen en el sitio. Se desarrolla una subsistencia } \\
\text { basada en la agricultura la pesca y la caza. La } \\
\text { población local depende de los productos del bosque } \\
\text { para la mayoría de los materiales de construcción. } \\
\text { La tierra está repartida según la tradición y existe un } \\
\text { lago de aqua dulce de propiedad común. Este fue } \\
\text { el primer sitio natural Patrimonio Mundial inscrito en } \\
\text { la Lista del Patrimonio Mundial bajo un régimen de } \\
\text { gestión tradicional. En este caso, el Comité del PM, } \\
\text { bajo recomendación de la UICN, hizo constar que el } \\
\text { régimen de gestión tradicional era lo suficientemente } \\
\text { efectivo como para asegurar la protección de los valores } \\
\text { naturales. }\end{array}$ \\
\hline $\begin{array}{l}\text { Península } \\
\text { Valdés } \\
\text { ARGENTINA }\end{array}$ & $x$ & II, IV, VI & 1999 & $\begin{array}{l}\text { Una colección de siete áreas protegidas distintas además } \\
\text { de una parte importante (más del } 50 \text { por ciento) de tierras } \\
\text { privadas. Se anima a los propietarios a colaborar en un } \\
\text { ejercicio de planificación de gestión conjunta, aunque } \\
\text { no tienen obligación legal aparente de hacerlo. Las } \\
\text { amenazas actuales incluyen la subdivisión de la tierra } \\
\text { para el desarrollo residencial de costa. Esto parece ser } \\
\text { un experimento en tierras de propiedad privada dentro de } \\
\text { un sitio natural PM. }\end{array}$ \\
\hline $\begin{array}{l}\text { Reservas } \\
\text { de la Selva } \\
\text { Atlántica de la } \\
\text { Costa de los } \\
\text { Descubrimientos } \\
\text { BRASIL }\end{array}$ & $i x, x$ & la, II & 1999 & $\begin{array}{l}\text { Una serie de ocho áreas protegidas distintas esparcidas } \\
\text { por } 450 \mathrm{~km} 2 \text { y anidadas en una reserva de la biosfera } \\
\text { de un millón ha - los terrenos intersticiales son en su } \\
\text { mayoría propiedad privada. }\end{array}$ \\
\hline $\begin{array}{l}\text { Áreas } \\
\text { Protegidas de } \\
\text { la Región Floral } \\
\text { del Cabo } \\
\text { SUDÁFRICA }\end{array}$ & ix, $x$ & Ib, II, IV & 2004 & $\begin{array}{l}\text { La inscripción de este sitio en serie es el resultado de } \\
\text { un proceso plurianual a lo largo del cual la nominación } \\
\text { inicial del Estado Parte no fue aceptada debido a la } \\
\text { carencia de un régimen de gestión consolidado para la } \\
\text { totalidad de las siete áreas protegidas. Como resultado, } \\
\text { se formuló una nominación final que cumplía con los } \\
\text { requisitos técnicos de la UICN, y el Comité del PM la } \\
\text { inscribió. }\end{array}$ \\
\hline $\begin{array}{l}\text { Reservas de } \\
\text { Pandas de } \\
\text { Sichuan } \\
\text { CHINA }\end{array}$ & $x$ & $\mathrm{n} / \mathrm{a}$ & 2006 & $\begin{array}{l}\text { Los límites originales propuestos por el Estado Parte } \\
\text { incluían localidades, áreas agrícolas e infraestructuras } \\
\text { públicas. Las revisiones de la nominación inicial tuvieron } \\
\text { lugar durante más de } 10 \text { años. La UICN requirió la } \\
\text { revisión de los límites de manera que sólo se incluyeran } \\
\text { las áreas principales. Los límites finales reflejan los } \\
\text { requisitos de la UICN. }\end{array}$ \\
\hline
\end{tabular}




\section{Relación entre los sitios de Patrimonio Mundial y las categorías de área protegida de la UICN}

Presuntamente, si los sitios naturales de Patrimonio Mundial no son todos áreas protegidas, no todos tendrán categorías UICN. Pero en la práctica, la mayoría son áreas protegidas y la mayoría sí tienen una categoría asignada. Existen sitios naturales de Patrimonio Mundial en todas las categorías de la UICN, pero con una distintiva tendencia hacia los objetivos de gestión más estricta de las categorías Ia, Ib y II. A fecha de junio de 2008, existen 166 sitios de Patrimonio Mundial naturales y 25 mixtos. De ellas, 139 están inscritos bajo los criterios ix y/o x (y por ello enfocados a cuestiones de biodiversidad y especies), bien en exclusividad, o bien en combinación con los criterios vii y vii no directamente enfocados a la biodiversidad; no obstante son considerados como sitios de patrimonio natural de biodiversidad. La Figura 4 ilustra la frecuencia en la incidencia de una categoría particular de área protegida de la UICN dentro los sitios naturales de PM. ${ }^{18}$

Figura 4. Frecuencia de la incidencia de las categorías de Áreas Protegidas de la UICN en los sitios naturales de Patrimonio Mundial de biodiversidad y de no-biodiversidad

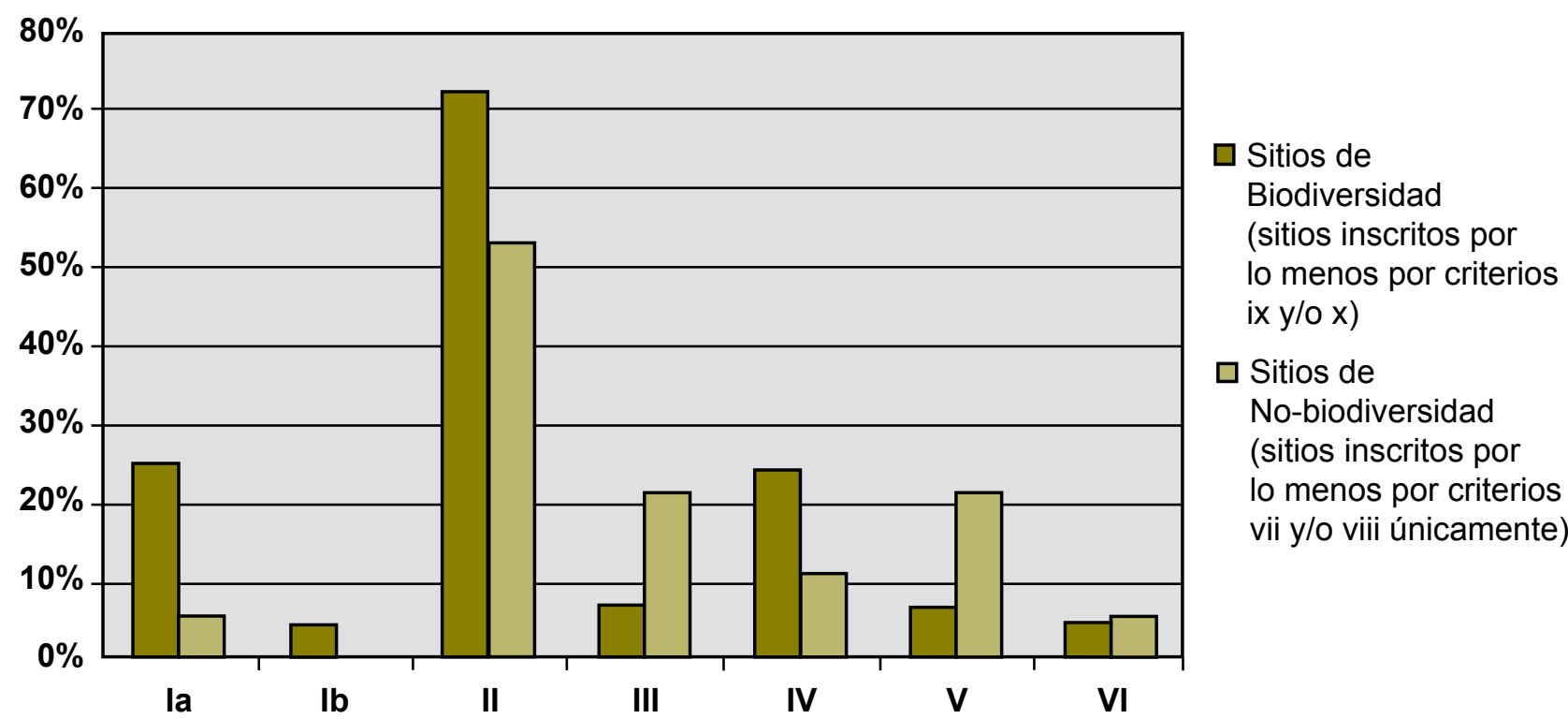

Más del 70 por ciento de los sitios de Patrimonio Mundial inscritos por sus valores de biodiversidad contienen (parcial o totalmente) un área protegida de categoría II. Algunos de estos mismos sitios también pueden contener áreas de otras categorías (por ejemplo, Te Wahipounamu en Nueva Zelanda está compuesta de distintas áreas protegidas que representan a cinco categorías de áreas protegidas distintas). La figura muestra que muy pocos sitios de PM de biodiversidad tienen áreas protegidas de categoría V o VI (estas categorías están representadas en ocho y seis sitios de PM respectivamente de los 128 sitios a los que la base de datos del PNUMA-CMMC ha atribuido una categoría de área protegida). De éstos, sólo tres (2 por ciento de todos los sitios de biodiversidad) están compuestos exclusivamente por un área protegida de categoría V o VI - siendo éstos la Gran Barrera de Arrecifes de Coral de Australia el Parque Nacional de Banc d'Arguin de Mauritania (normalmente considerado bajo la categoría II) y el Área de Conservación del Ngorongoro en Tanzania. Éstos son normalmente sitios extensos: $348.700 \mathrm{~km}^{2}$, $12.000 \mathrm{~km}^{2}$ y $8.288 \mathrm{~km}^{2}$ respectivamente.

\section{Conclusiones}

Para los gobiernos que consideran nominar un sitio natural de Patrimonio Mundial:

- Todos los sitios de Patrimonio Mundial tienen que tener un régimen efectivo de gestión. Esto implica que estas áreas serán designadas como áreas protegidas en prácticamente todos los casos.

- No existe una regla que diga que esas áreas tienen que tener asignadas a una categoría de la UICN, pero de nuevo, es muy recomendable y de hecho todos los informes de datos del CMMC de áreas nominadas como sitios naturales de PM incluyen una categoría UICN, que corresponde al sitio nominado. La mayoría de los sitios inscritos bajo los criterios (ix) o (x) corresponden a las categorías I o II de UICN, de todos modos, existen excepciones y cualquier categoría puede ser aceptable.

18 Debido a que un sitio de PM puede comprender más de un AP, a las que se asignan categorías diferentes, los porcentajes no suman cien. Además, solo a 128 de los 139 sitios de biodiversidad, y a 38 de los 49 de no biodiversidad se les ha atribuido una categoría de AP en la Base de Datos Mundial de Áreas Protegidas (WDPA). 


\section{Convención Ramsar}

La Convención Ramsar anima a las partes a designar y gestionar humedales importantes de un modo que no afecte a su carácter ecológico. Las 158 Partes Contratantes (gobiernos) se han comprometido al uso inteligente (uso sostenible) de todos los humedales de su territorio (incluidos los ríos), a la conservación de "humedales de importancia internacional" (sitios Ramsar) y a la cooperación internacional. Cada parte se compromete a realizar un inventario de sus humedales y preparar un "marco de trabajo estratégico para la lista de Ramsar" que permita la designación nacional sistemática y representativa de los tipos de hábitats húmedos así como su gestión. La Convención tiene múltiples beneficios para la conservación de los humedales ya que crea una presión moral para que los estados miembros establezcan y gestionen áreas protegidas húmedas; establece estándares, proporciona orientación y facilita la colaboración sobre el uso inteligente de los humedales; tiene un sistema global trienal de comunicación y monitoreo y apoya la participación de ONGs, comunidades locales y pueblos indígenas.

Mientras que muchos Humedales de Importancia Internacional (Sitios Ramsar) también tienen algún otro estatus de protección (por ej. son áreas protegidas bajo legislación nacional, sitios Patrimonio Mundial o reservas de la biosfera de la UNESCO), no existe obligación alguna de que los sitios Ramsar sean áreas protegidas legales bajo la legislación nacional. De hecho, esto a veces ayuda a persuadir a los gobiernos a que designen lugares como Sitios Ramsar cuando estarían poco dispuestos a convertirlos en áreas protegidas nacionales.

La protección ofrecida por la propia Convención es ya un apoyo legal, pero bajo leyes "blandas" y no siempre articuladas claramente. Por ejemplo, los Criterios para la Identificación de Humedales de Importancia Internacional no hacen referencia alguna al estatus de protección. La Hoja Informativa de los Humedales Ramsar implica que no es obligatorio un estatus de protección, con frases como: "Si se ha establecido una reserva". El Manual de la Convención Ramsar (2006) es explícito: " $L a$ designación de un humedal en la lista Ramsar no requiere que el sitio haya sido declarado previamente área protegida". De hecho, pertenecer a la lista de la Convención Ramsar, especialmente en los casos de lugares sujetos a uso intensivo de comunidades humanas - bien para extraer recursos, bien para beneficiarse de las funciones naturales del humedal - puede proporcionar la protección necesaria que asegure su sostenibilidad a largo plazo. Esto se puede lograr preparando e implementando un plan de gestión apropiado, con la participación activa de todos los actores.

Se implica de lo anteriormente expuesto, que estar incluido en la lista de la Convención Ramsar, especialmente en los casos de sitios sujetos al uso intensivo de comunidades humanas, debería proporcionar la protección necesaria para asegurar su sostenibilidad a largo plazo. Pertenecer a la lista Ramsar eleva el sitio a un estatus superior, atrae mayor atención hacia él, y debería contribuir a su conservación y uso inteligente a largo plazo - si el estatus Ramsar conlleva o no una protección internacional adicional depende de decisiones de los gobiernos nacionales y locales. Los usos de los humedales por parte humana son compatibles con estar incluido en la lista Ramsar, siempre que se cumpla el concepto Ramsar de "uso inteligente" (uso sostenible) y no lleve a un cambio negativo en el carácter ecológico del sitio.

El Secretariado de Ramsar ha considerado la Lista Ramsar como un conjunto de "áreas protegidas": por ejemplo el documento Las soluciones de emergencia rara vez conducen a la sostenibilidad ofrece "una introducción al concepto de Humedales de Importancia Internacional como una red de áreas protegidas" (énfasis añadido). Algunos gobiernos Partes de la Convención consideran la inclusión en la lista como si, de facto, el sitio se convirtiera en un área protegida (tenga una categoría UICN o no), mientras que otros gobiernos no lo consideran así.

\section{El sistema de categorías y los sitios Ramsar}

En la versión original de las categorías de gestión, se identificaba a las reservas de la biosfera y sitios de Patrimonio Mundial como una categoría por derecho propio, pero los sitios Ramsar no estaban identificados. Por consiguiente, las directrices de 1994 no trataban una designación internacional como una categoría aparte. Se acordó en la Novena Convención Ramsar de las Partes (Resolución IX.22) incluir datos acerca de la categoría UICN dentro de la base de datos de los sitios Ramsar. De los 84 sitios designados desde el 1 de enero de 2007, 37 (el 44 por ciento) incluyen información de la categoría UICN. Los sitios Ramsar se designan a nivel nacional. El sistema de categorías de la UICN es un método para clasificarlas en función de sus objetivos de gestión. Los sitios Ramsar rompen totalmente con este planteamiento ya que por su propio concepto postulan la idea de un abanico de objetivos de gestión. Por otro lado, algunos sitios Ramsar a menudo contienen una serie de zonas de gestión con objetivos de gestión diferentes, cada una de las cuales puede corresponder a una categoría del sistema UICN. Algunos pueden constar de una serie de categorías de uso diferentes.

Las directrices de la UICN proporcionan varias maneras por las cuales las distintas situaciones que se encuentran en los sitios Ramsar puedan conciliarse con el sistema de categorías. Una vez que se haya detectado que un sitio cumple con la definición de la UICN de área protegida, se recomienda un enfoque en dos fases:

- Fase I: identificar si todo el sitio Ramsar debería ser clasifcado bajo una, o más de una categoría.

Para ello es necesario establecer a cuál de las tres posibilidades teóricas corresponde: 
1. Sólo existe una autoridad de gestión para todo el sitio Ramsar y por razones legales, todo el sitio Ramsar está clasificado por ley en tener un único objetivo de gestión.

\section{Al área se le asignaría una única categoría}

Mientras que las directrices requieren que la asignación de una categoría se base en el propósito principal de la gestión, también reconocen que los planes de gestión a menudo contienen zonas de gestión por una variedad de razones que tienen en cuenta las condiciones locales. Para establecer la categoría apropiada, por lo menos las tres cuartas partes, y preferiblemente más, tienen que ser gestionados para un objetivo principal de gestión; y la gestión del área restante no puede entrar en conflicto con el propósito principal.

2. Existe una autoridad de la gestión responsable de dos o más áreas que forman el sitio Ramsar, pero cada una de estas áreas tiene objetivos de gestión independientes definidos por ley.

Las directrices reconocen esta situación a sabiendas de que "las áreas protegidas de diferentes categorías son a menudo contiguas, y a veces una categoría 'anida' dentro de otra". Por ello muchas áreas protegidas de categoría $\mathrm{V}$ contienen dentro de ellas áreas de categoría Ia y Ib: algunas podrán colindar con áreas de categoría II. Del mismo modo algunas áreas de categoría II contienen áreas de categoría Ia y Ib.

\section{En este caso las distintas partes del sitio Ramsar se categorizarán de modo diferente.}

3. Existen dos o más autoridades de gestión responsables de distintas áreas con objetivos de gestión diferentes, que en conjunto forman el sitio Ramsar.

En este caso otra vez, la correcta interpretación de las directrices permitirá categorizar estas áreas por separado.

- Fase 2: asignación de partes del sitio Ramsar a categorías individuales.

El sistema de categorías puede aplicarse a un conjunto de situaciones legales y de gestión diferentes que caracterizan a los sitios Ramsar en los distintos países. Esto está totalmente en línea con el modo en que se pretende que se aplique el sistema. La UICN especifica que las áreas protegidas deberían establecerse para cumplir objetivos consistentes con los fines y las necesidades nacionales, locales o privadas (o una combinación de éstas) y sólo ser etiquetadas con una categoría UICN en función de los objetivos de gestión. Estas categorías han sido diseñadas para facilitar la comunicación y la información, no para dirigir el sistema.

\section{Beneficios}

Los beneficios de un sistema que puede ser aplicado internacionalmente, de un modo transparente, son importantes. La ventaja principal es que permite el análisis global de los sitios Ramsar actuales. Además facilita el desarrollo y posterior establecimiento de un sistema de sitios Ramsar en el que cada país pueda mantener su red particular de sitios Ramsar individuales, y a la vez, formar parte del marco de trabajo global de áreas protegidas. También permite que la red de sitios Ramsar esté en relación y contribuya al desarrollo de un sistema global de áreas protegidas integral, adecuado y representativo.

Se pretende elaborar una guía más detallada sobre los vínculos entre los sitios Ramsar y las categorías de áreas protegidas de la UICN.

\section{Convenio sobre la Diversidad Biológica}

En la séptima reunión de la Conferencia de las Partes del CDB en 2004, 188 Partes contratantes del convenio acordaron un Programa de Trabajo en Áreas Protegidas, una de las más ambiciosas estrategias de la historia. El Programa pretende, para 2010 (terrestre) y 2012 (marino), establecer "sistemas inclusivos, gestionados eficazmente y representativos ecológicamente, de áreas protegidas a nivel nacional y regional". Este programa contiene más de 90 acciones específicas a realizar en un tiempo limitado por los estados miembros y otras partes interesadas.

Específicamente, el Programa "reconoce el valor de un único sistema internacional de clasificación para las áreas protegidas y el beneficio de proporcionar información comparable por todos los paises y regiones y por consiguiente da la bienvenida a los continuados esfuerzos del CMAP de la UICN de depurar el sistema de categorías de la UICN y anima a las partes, a otros gobiernos y a las organizaciones correspondientes a asignar categorias de gestión de áreas protegidas a sus áreas protegidas, proporcionando información consistente con las categorias depuradas de la UICN con el propósito de información y comunicación."

El CDB ha acordado su propia definición de un área protegida como un: área geográfica definida designada o regulada y gestionada para lograr objetivos de conservación especificos. Existe un acuerdo tácito entre el Secretariado del CDB y la UICN de que las dos definiciones efectivamente significan lo mismo. De un modo importante, el Programa de Trabajo del $\mathrm{CDB}$ explícitamente reconoce las categorías de área protegida de la UICN:

Explorar el establecimiento de un sistema armonizado y una planificación temporal para la comunicación y la información sobre sitios designados bajo la Convención de Humedales, la Convención del Patrimonio Mundial, y el programa MAB de la UNESCO, y otros sistemas regionales, según proceda, teniendo en cuenta el trabajo continuado del PNUMA-CMMC sobre la armonización de informes y el sistema de categorías de gestión de áreas protegidas de UICN (énfasis añadido) para los objetivos de información. 
En la novena Conferencia de las Partes del CDB en 2008, se reafirmó y confirmó el apoyo a las categorías:

"9. Reafirma el párrafo 31 de la decisión VII/28, que reconoce el valor de un único sistema de clasificación internacional de áreas protegidas y el beneficio de proporcionar información que es comparable en distintos paises y regiones y por ello da la bienvenida al esfuerzo a la Comisión Mundial sobre Áreas Protegidas de la UICN de depurar el sistema de categorías de la UICN y anima a las partes, otros gobiernos y organizaciones correspondientes a asignar categorías de gestión de áreas protegidas a sus propias áreas protegidas, proporcionando información consistente con las categorias depuradas de la UICN con propósitos de información y comunicación".

Por ello existe una clara iniciativa del CDB de que los países usen el sistema de categorías de la UICN al informar del progreso en el establecimiento y mantenimiento de los sistemas de áreas protegidas. 


\section{Efectividad de las categorías de la UICN}

La UICN siempre ha hecho especial hincapié en que la categoría se basa en el objetivo y es independiente de la efectividad: esto es, si un área protegida no logra lograr sus objetivos no es excusa para cambiarla a otra categoría (más bien para incrementar la capacidad de gestión). Pero muchos grupos de interés vienen demandando una relación más estrecha entre las categorías y la efectividad en la gestión: la siguiente sección explora algunas opciones. 


\section{Evaluación de la gestión y las categorías de la UICN}

La efectividad de la gestión de áreas protegidas ha obtenido una creciente atención como un elemento esencial para el mantenimiento de un sistema de áreas protegidas, y ahora se ve la evaluación o valoración de la gestión como un método muy útil para incrementar la efectividad, proporcionando información concisa y práctica para los administradores y gestores de áreas protegidas y otros actores. Se define la evaluación de la efectividad de la gestión como lo bien que las áreas protegidas están siendo gestionadas - principalmente los logros alcanzados en la protección de los valores existentes y el nivel alcanzado en el cumplimiento de las metas y objetivos de conservación. El término "efectividad de gestión" refleja tres grandes "temas" en la gestión de áreas protegidas:

- asuntos de diseño relacionados tanto con áreas protegidas individuales como sistemas de áreas protegidas;

- adecuación y ajuste de los sistemas y procesos de gestión;

- consecución de los objetivos de las áreas protegidas, incluida la conservación de los valores.

Actualmente la evaluación es reconocida como un componente de las gestión reactiva y preventiva de las áreas protegidas que ayudan a los gestores a la toma de decisiones en el día a día acerca de la asignación y reparto del tiempo y los recursos y más recientemente como una etapa del progreso de información y comunicación en el contexto internacional, mediante convenios y acuerdos como el CDB. En el Programa de Trabajo sobre Areas Protegidas del CDB, por ejemplo, los estados firmantes se han comprometido a desarrollar sistemas de evaluación de la efectividad de la gestión y de informar sobre el 30 por ciento de sus áreas protegidas hasta el 2010.

La evaluación sobre la efectividad de la gestión puede:

- Permitir y apoyar un enfoque adaptativo de la gestión;

- Asistir en la designación y distribución efectiva de recursos;

- Promover la responsabilidad y la transparencia;

- Involucrar a la comunidad y fomentar el apoyo a las áreas protegidas.

El abanico de razones para llevar a cabo una evaluación combinado con la gran diversidad de áreas protegidas - con distintos valores y objetivos, razones culturales, regímenes de gestión y desafíos - significa que no resulta práctico desarrollar una única herramienta de evaluación. Por esta razón, la UICN-CMAP, decidió desarrollar un marco de trabajo común (2a Edición, Hockings et al. 2006), que proporciona una base consistente para diseñar sistemas de evaluación, y provee una guía sobre qué así como amplios criterios a utilizar en la evaluación. El proceso de evaluación recomendado por la IUCN se resume en la Tabla 18 siguiente. Basados en este marco de trabajo, se pueden usar una serie de "herramientas" evaluadoras para realizar evaluaciones a distintas escalas y profundidades.

Tabla 18. Elementos del marco de trabajo del CMAP para la evaluación de la eficacia de la gestión de áreas protegidas

\begin{tabular}{|l|l|l|l|l|l|l|}
\hline & \multicolumn{2}{|c|}{ Diseño } & Conveniencia/Adecuación & \multicolumn{2}{c|}{ Resultados } \\
\hline & Contexto & Planificación & $\begin{array}{l}\text { Entrada de } \\
\text { información }\end{array}$ & Proceso & $\begin{array}{l}\text { Salida de } \\
\text { información }\end{array}$ & Valoraciones \\
\hline $\begin{array}{l}\text { Objetivo } \\
\text { de la } \\
\text { evaluación }\end{array}$ & $\begin{array}{l}\text { Importancia } \\
\text { Amenazas } \\
\text { Ambiente } \\
\text { político }\end{array}$ & $\begin{array}{l}\text { Diseño y } \\
\text { planificación }\end{array}$ & $\begin{array}{l}\text { Recursos a } \\
\text { gestionar }\end{array}$ & $\begin{array}{l}\text { Cómo se } \\
\text { desarrolla } \\
\text { la gestión }\end{array}$ & $\begin{array}{l}\text { Implementación } \\
\text { de programas } \\
\text { y acciones de } \\
\text { gestión }\end{array}$ & $\begin{array}{l}\text { Nivel de los } \\
\text { objetivos } \\
\text { alcanzados }\end{array}$ \\
\hline $\begin{array}{l}\text { Criterios } \\
\text { que se } \\
\text { evalúan }\end{array}$ & $\begin{array}{l}\text { Valores } \\
\text { Amenazas } \\
\text { Vulnerabilidad } \\
\text { Grupos de } \\
\text { Interés } \\
\text { Contexto } \\
\text { Nacional }\end{array}$ & $\begin{array}{l}\text { Legislación y } \\
\text { políticas } \\
\text { Diseño del } \\
\text { sistema } \\
\text { Planificación } \\
\text { de la gestión }\end{array}$ & $\begin{array}{l}\text { Adecuación } \\
\text { de los } \\
\text { recursos } \\
\text { disponibles } \\
\text { para su } \\
\text { gestión }\end{array}$ & $\begin{array}{l}\text { ldoneidad } \\
\text { de los } \\
\text { procesos } \\
\text { de gestión }\end{array}$ & $\begin{array}{l}\text { Resultados de } \\
\text { las acciones de } \\
\text { gestión }\end{array}$ & $\begin{array}{l}\text { Efectos de } \\
\text { la gestión en } \\
\text { relación a los } \\
\text { objetivos }\end{array}$ \\
\hline
\end{tabular}

Durante los últimos 10 ó 15 años se han desarrollado un gran número de sistemas para la evaluación de la efectividad de la gestión, aunque muchos se han aplicado sólo en algunas áreas protegidas. Más del 90 por ciento de las evaluaciones realizadas han usado sistemas compatibles con los propuestos en el marco de evaluación de UICN-CMAP. Esto significa que dichas evaluaciones comparten un enfoque y criterios de evaluación comunes, aunque algunos de los indicadores y métodos de evaluación pueden variar. Los sistemas se pueden dividir en dos grandes tipos: (1) sistemas que emplean principalmente los conocimientos de expertos y (2) sistemas que emplean el monitoreo de datos, encuestas a los grupos de interés y otras fuentes de información cuantitativas o cualitativas. Algunos sistemas combinan los dos métodos de evaluación dependiendo de qué aspecto de gestión se está analizando. Los sistemas basados en los conocimientos de expertos generalmente utilizan un método de preguntas, pidiendo a las personas con conocimiento detallado del área protegida y su gestión que evalúen una serie de aspectos 
de la gestión, características del lugar y su naturaleza así como la importancia de los valores naturales y de las amenazas sobre los mismos. Estas evaluaciones pueden apoyarse en una base de conocimientos considerable compuesta por los resultados del monitoreo y la investigación llevada a cabo en el área protegida. Este enfoque de evaluación se suele aplicar al evaluar la gestión de un gran número de áreas protegidas, a menudo todas las áreas protegidas de un país, ya que es más rápido y requiere menos recursos que el método basado en el monitoreo.

\section{Relación entre la evaluación y la asignación de la categoría}

La evaluación puede cubrir dos aspectos distintos de las áreas protegidas:

- Si los objetivos acordados para el área protegida coinciden con la categoría asignada. Esto va más allá de un interés académico si la política o legislación nacional enlazan la toma de decisiones con la designación de la categoría (respecto a, por ej., financiación, uso permitido del terreno, derechos de caza, etc.).

- Si se están cumpliendo esos objetivos eficazmente.

El primero es básicamente una evaluación de las intenciones de gestión. El propósito de esta evaluación no es evaluar la efectividad de la gestión sino clarificar los objetivos expresos a alcanzar por la gestión. Este enfoque ha sido desarrollado por la UICN-CMAP en Europa y ha sido empleado para "certificar" que un a área protegida se le ha asignado la correcta categoría (según la legislación y normativa del gobierno) y si se está gestionando el área en concordancia con los objetivos de gestión pertinentes a dicha categoría. Hasta ahora, no existe ninguna metodología escrita y el sistema está todavía en desarrollo. Se centra particularmente en los dos primeros elementos del marco de trabajo del CMAP - contexto y planificación - y prácticamente no considera los elementos de productos y resultados alcanzados por la gestión.

El segundo profundiza en si se han cumplido estos objetivos en la práctica. Estos objetivos se especifican normalmente a nivel nacional en la legislación pertinente u otro método de gobernanza (por ej., áreas protegidas por la autoridad tradicional o por comunidades) que proporciona unas directrices generales de la gestión del lugar. Por ejemplo, la designación de un área de categoría II significa que el área debería ser gestionada principalmente para la conservación de la biodiversidad sin uso de los recursos o en su caso, muy limitado. En algunos casos, los administradores tienen dificultades al gestionar un lugar estrictamente en línea con los objetivos. Se ha asumido que los resultados de la evaluación de la efectividad de gestión no deberían usarse como base para destinar o cambiar la categoría que se ha asignado a un área protegida. Así, por ejemplo, la respuesta apropiada a una evaluación de la efectividad de gestión que revela el mal control de la explotación de recursos de un área protegida de categoría II no es cambiarla a la categoría $\mathrm{V}$ (que permite un nivel substancial de utilización de recursos) sino más bien intentar adaptar la gestión para lograr más eficazmente los objetivos de gestión especificados por la ley.

En el futuro, la UICN investigará la necesidad de evaluación más rigurosa de la efectividad de gestión, dentro del contexto del sistema de categorías y teniendo en cuenta las implicaciones prácticas de estas evaluciones. 



\section{Apéndice. Tipología y glosario}

Los usuarios leerán esto línea a línea, intentando tomar decisiones difíciles, frecuentemente en una lengua que no será la materna. Así que las directrices deben ser tan claras como sea posible pero se vuelve difícil precisar debido a que muchas palabras usadas en ecología y conservación están difusamente definidas y sujetas a interpretaciones múltiples. Se incluye el glosario en el Tabla 19 para aportar claridad y debería ser usado conjuntamente con la definición y las descripciones de las categorías siguientes. Las fuentes utilizadas han sido descritas en la medida de lo posible en las definiciones de la UICN o del CDB existentes y deberían resultar familiares a los gobiernos u otras entidades que usen las categorías.

Tabla 19. Definición de los términos usados en las directrices

\begin{tabular}{|c|c|c|}
\hline Término & Definición & Fuentes y notas \\
\hline Agrobiodiversidad & $\begin{array}{l}\text { Incluye a las plantas silvestres en parentesco } \\
\text { directo con las cosechas (los parientes } \\
\text { silvestres de las cosechas), plantas } \\
\text { cultivadas (especies domésticas) variedades } \\
\text { de ganado. Agrobiodiversidad puede ser } \\
\text { un objetivo de gestión de áreas protegidas } \\
\text { para plantas silvestres emparentadas } \\
\text { con las cosechas, especies tradicionales } \\
\text { o amenazadas, particularmente aquellas } \\
\text { dependientes de las prácticas culturales } \\
\text { tradicionales, y/o especies de ganado } \\
\text { tradicionales amenazadas, especialmente si } \\
\text { dependen de sistemas de gestión culturales } \\
\text { y tradicionales y son compatibles con la } \\
\text { "biodiversidad salvaje". }\end{array}$ & $\begin{array}{l}\text { Fuente: Amend, T., J. Brown, A. Kothari, A. } \\
\text { Phillips y S. Stolton (Eds). 2008. Protected } \\
\text { Landscapes and Agrobiodiversity Values. } \\
\text { Volume } 1 \text { in the series Values of Protected } \\
\text { Landscapes and Seascapes. Heidelberg: } \\
\text { Kasparek Verlag, en nombre de la UICN y } \\
\text { GTZ. }\end{array}$ \\
\hline $\begin{array}{l}\text { Área conservada } \\
\text { por la comunidad }\end{array}$ & $\begin{array}{l}\text { Ecosistemas naturales y modificados, } \\
\text { incluidos biodiversidad, servicios ecológicos } \\
\text { y valores culturales, conservados } \\
\text { voluntariamente por pueblos indígenas y } \\
\text { comunidades locales y móviles mediante de } \\
\text { leyes tradicionales u otros medios efectivos. }\end{array}$ & $\begin{array}{l}\text { Fuente: Borrini-Feyerabend, G., A. Kothari } \\
\text { y G. Oviedo. 2004. Indigenous and Local } \\
\text { Communities and Protected Areas: Towards } \\
\text { Equity and Enhanced Conservation. Best } \\
\text { Practice Protected Area Guidelines Series No. } \\
\text { 11. Gland y Cambridge: UICN. }\end{array}$ \\
\hline $\begin{array}{l}\text { Área protegida } \\
\text { de gobernanza } \\
\text { compartida }\end{array}$ & $\begin{array}{l}\text { Área protegida designada por el gobierno } \\
\text { donde el poder de toma de decisiones, } \\
\text { responsabilidad y rendición de cuentas están } \\
\text { compartidos entre agencias gubernamentales } \\
\text { y otros grupos de interés, en particular de } \\
\text { pueblos indígenas y comunidades locales y } \\
\text { móviles que dependen del área culturalmente } \\
\text { y/o por su medio de vida. }\end{array}$ & $\begin{array}{l}\text { Fuente: Borrini-Feyerabend, G., A. Kothari } \\
\text { y G. Oviedo. 2004. Indigenous and Local } \\
\text { Communities and Protected Areas: Towards } \\
\text { Equity and Enhanced Conservation. Best } \\
\text { Practice Protected Area Guidelines Series No. } \\
\text { 11. Gland y Cambridge: UICN. }\end{array}$ \\
\hline Bioma & $\begin{array}{l}\text { Una gran parte del entorno vivo de una } \\
\text { región en particular (como un bosque } \\
\text { de abetos o pastos), caracterizada por } \\
\text { su vegetación distintiva y mantenida } \\
\text { principalmente por las condiciones climáticas } \\
\text { locales. }\end{array}$ & $\begin{array}{l}\text { Fuente: From the Biodiversity Glossary of the } \\
\text { CBD Communication, Education and Public } \\
\text { Awareness (CEPA) Toolkit: http://www.cbd.int/ } \\
\text { cepa/toolkit/2008/cepa/index.htm }\end{array}$ \\
\hline $\begin{array}{l}\text { Calidad de la } \\
\text { gobernanza }\end{array}$ & $\begin{array}{l}\text { Nivel de satisfacción del gobierno de un área } \\
\text { protegida - el grado en que responde a los } \\
\text { principios y criterios de "buena gobernanza" } \\
\text { identificados y elegidos por los pueblos, } \\
\text { comunidades y gobiernos pertinentes (como } \\
\text { parte del sentido de moralidad, identidad } \\
\text { cultural y orgullo) y generalmente vinculado } \\
\text { a los principios expuestos por agencias y } \\
\text { convenios internacionales. }\end{array}$ & $\begin{array}{l}\text { Fuente: Borrini-Feyerabend, G. } 2004 \text {. } \\
\text { "Governance of protected areas, participation } \\
\text { and equity", pp. 100-105 in Secretariat of the } \\
\text { Convention on Biological Diversity, Biodiversity } \\
\text { Issues for Consideration in the Planning, } \\
\text { Establishment and Management of Protected } \\
\text { Areas and Networks. Technical Series no. 15. } \\
\text { Montreal: Secretariado del CDB (SCDB). }\end{array}$ \\
\hline
\end{tabular}


Tabla 19. Definición de los términos usados en las directrices (cont.)

\begin{tabular}{|c|c|c|}
\hline Término & Definición & Fuentes y notas \\
\hline $\begin{array}{l}\text { Conservación } \\
\text { in-situ }\end{array}$ & $\begin{array}{l}\text { La conservación de ecosistemas y hábitats } \\
\text { naturales y el mantenimiento y recuperación } \\
\text { de poblaciones de especies viables en su } \\
\text { entorno natural y, en el caso de especies } \\
\text { domesticadas o cultivadas, en el entorno } \\
\text { donde hayan desarrollado sus propiedades } \\
\text { distintivas. }\end{array}$ & $\begin{array}{l}\text { Fuente: CDB, Artículo 2. Uso de términos } \\
\text { http://www.cbd.int/convention/articles. } \\
\text { shtml?a=cbd-02 } \\
\text { Traducciones: Árabe, Chino, Español, } \\
\text { Francés, Inglés, Ruso. }\end{array}$ \\
\hline Corredor & $\begin{array}{l}\text { Medio para mantener conectividad ecológica } \\
\text { o medioambiental manteniendo conexiones } \\
\text { físicas entre áreas protegidas. }\end{array}$ & $\begin{array}{l}\text { Fuente: Source: Bennett, G. y K.J. Mulongoy. } \\
\text { 2006. Review of experience with ecological } \\
\text { networks, corridors and buffer zones. } \\
\text { Technical Series no. 23. Montreal: SCDB. }\end{array}$ \\
\hline $\begin{array}{l}\text { Diversidad } \\
\text { biológica }\end{array}$ & $\begin{array}{l}\text { La variedad de organismos vivos de todas } \\
\text { las formas incluidos, inter alia, terrestres, } \\
\text { marinos y de otros sistemas acuáticos y los } \\
\text { complejos ecológicos de los que forman } \\
\text { parte; esto incluye la diversidad dentro de } \\
\text { las propias especies, entre especies y entre } \\
\text { ecosistemas }\end{array}$ & $\begin{array}{l}\text { Fuente: CBD, Article } 2 \text {. Uso de términos } \\
\text { http://www.cbd.int/convention/articles. } \\
\text { shtml?a=cbd-02 } \\
\text { Traducciones: Árabe, Chino, Español, } \\
\text { Francés, Inglés, Ruso. }\end{array}$ \\
\hline Ecosistema & $\begin{array}{l}\text { Un complejo dinámico de comunidades } \\
\text { plantas, animales y microorganismos y } \\
\text { su entorno inerte interactuando como una } \\
\text { unidad funcional. }\end{array}$ & $\begin{array}{l}\text { Fuente: CDB, Artículo 2. Uso de términos } \\
\text { http://www.cbd.int/convention/articles. } \\
\text { shtml?a=cbd-02 } \\
\text { Traducciones: Árabe, Chino, Español, } \\
\text { Francés, Inglés, Ruso. }\end{array}$ \\
\hline $\begin{array}{l}\text { Eficacia de la } \\
\text { gestión }\end{array}$ & $\begin{array}{l}\text { Nivel de satisfacción de la gestión de un } \\
\text { área protegida - principalmente el grado } \\
\text { en el que se está protegiendo los valores } \\
\text { y consiguiendo las metas y objetivos de } \\
\text { conservación propuestos para el área. }\end{array}$ & $\begin{array}{l}\text { Fuente: Hockings, M., S. Stolton, F. } \\
\text { Leverington, N. Dudley y J. Courrau. } 2006 . \\
\text { Evaluating Effectiveness: A framework for } \\
\text { assessing management effectiveness of } \\
\text { protected areas. 2nd edition. Best Practice } \\
\text { Protected Area Guidelines Series No. } 14 . \\
\text { Gland y Cambridge: UICN. } \\
\text { Traducciones: Próximamente en Francés y } \\
\text { Español. }\end{array}$ \\
\hline Geodiversidad & $\begin{array}{l}\text { La diversidad de minerales, rocas ("sólidas" } \\
\text { o "sueltas"), fósiles, formas geográficas, } \\
\text { sedimentos y sustratos, conjuntamente con } \\
\text { los procesos naturales que constituyen la } \\
\text { topografía, el paisaje y la estructura bajo la } \\
\text { superficie de la tierra. }\end{array}$ & $\begin{array}{l}\text { Fuente: McKirdy, A., J. Gordon y R. Crofts. } \\
\text { 2007. Land of Mountain and Flood: the } \\
\text { geology and landforms of Scotland. Edinburgh: } \\
\text { Birlinn. }\end{array}$ \\
\hline Gobernanza & $\begin{array}{l}\text { En el contexto de áreas protegidas, } \\
\text { se puede definir la gobernanza como: } \\
\text { "las interacciones entre las estructuras, } \\
\text { procesos y tradiciones que determinan } \\
\text { cómo se ejerce el poder, como se toman las } \\
\text { decisiones en temas de interés público, y } \\
\text { cómo expresan su opinión los ciudadanos } \\
\text { y otros grupos de interés". Los acuerdos } \\
\text { de gobernanza se expresan mediante } \\
\text { marcos de trabajo legales y políticos, } \\
\text { estrategias y planes de gestión; incluyen } \\
\text { las disposiciones organizacionales para el } \\
\text { seguimiento de políticas y planes y para } \\
\text { monitorizar el desempeño. La gobernanza } \\
\text { engloba las normas de toma de decisiones, } \\
\text { incluido quién tiene acceso a la información } \\
\text { y participa en el proceso de toma de } \\
\text { decisiones, así como las decisiones en sí. }\end{array}$ & $\begin{array}{l}\text { Fuente: Borrini-Feyerabend, G., A. Kothari } \\
\text { y G. Oviedo. 2004. Indigenous and Local } \\
\text { Communities and Protected Areas: Towards } \\
\text { Equity and Enhanced Conservation. Best } \\
\text { Practice Protected Area Guidelines Series No. } \\
\text { 11. Gland y Cambridge: UICN. }\end{array}$ \\
\hline
\end{tabular}


Tabla 19. Definición de los términos usados en las directrices (cont.)

\begin{tabular}{|c|c|c|}
\hline Término & Definición & Fuentes y notas \\
\hline Grupos de Interés & $\begin{array}{l}\text { Las personas u organizaciones que resultan } \\
\text { vitales para el éxito o fracaso de que una } \\
\text { organización o proyecto cumpla sus objetivos. } \\
\text { Los grupos de interés principales son (a) los } \\
\text { necesarios para el respaldo financiero, de } \\
\text { permisos y de aprobaciones y (b) aquellos } \\
\text { afectados directamente por las actividades } \\
\text { de la organización o proyecto. Los grupos } \\
\text { de interés secundarios son los afectados } \\
\text { indirectamente. Los terciarios son aquellos no } \\
\text { afectados o involucrados, pero que pueden } \\
\text { influenciar opiniones a favor y en contra. }\end{array}$ & $\begin{array}{l}\text { Fuente: Herramientas de Comunicación, } \\
\text { Educación y Concienciación Pública del CDB } \\
\text { (CECP): http://www.cbd.int/cepa/toolkit/2008/ } \\
\text { cepa/index.htm } \\
\text { Esta definición viene del Glosario del CECP; } \\
\text { que es una versión actualizada de un glosario } \\
\text { de comunicación desarrollado por el CEC } \\
\text { de Grupo de Productos de la UICN sobre } \\
\text { Comunicación Corporativa, editado por Frits } \\
\text { Hesselink en } 2003 .\end{array}$ \\
\hline $\begin{array}{l}\text { Lugar natural } \\
\text { sagrado }\end{array}$ & $\begin{array}{l}\text { Áreas naturales marinas o terrestres con } \\
\text { especial significado espiritual para pueblos o } \\
\text { comunidades. }\end{array}$ & $\begin{array}{l}\text { Fuente: Wild, R. y C. McLeod. 2008. Sacred } \\
\text { Natural Sites: Guidelines for Protected Area } \\
\text { Managers. Best Practice Protected Area } \\
\text { Guidelines Series No. 16. Gland y Cambridge: } \\
\text { UICN. }\end{array}$ \\
\hline Lugar sagrado & $\begin{array}{l}\text { Un área de especial significado espiritual } \\
\text { para pueblos o comunidades. }\end{array}$ & \\
\hline Marco de trabajo & $\begin{array}{l}\text { Una estructura de alto nivel que subyace } \\
\text { bajo un propósito y dirección común para } \\
\text { planes y programas. }\end{array}$ & $\begin{array}{l}\text { Fuente: Herramientas de Comunicación, } \\
\text { Educación y Concienciación Pública del CDB } \\
\text { (CECP): http://www.cbd.int/cepa/toolkit/2008/ } \\
\text { cepa/index.htm Esta definición viene del } \\
\text { Glosario del CECP; que es una versión } \\
\text { actualizada de un glosario de comunicación } \\
\text { desarrollado por el CEC de Grupo de } \\
\text { Productos de la UICN sobre Comunicación } \\
\text { Corporativa, editado por Frits Hesselink en } \\
2003 \text {. }\end{array}$ \\
\hline $\begin{array}{l}\text { Pueblos indígenas } \\
\text { y tribales }\end{array}$ & $\begin{array}{l}\text { (a) Pueblos tribales en países } \\
\text { independientes cuyas condiciones sociales, } \\
\text { culturales y económicas les distinguen de } \\
\text { otras secciones de la comunidad nacional, y } \\
\text { cuyo estatus es regulado total o parcialmente } \\
\text { por sus propias costumbres o tradiciones o } \\
\text { por leyes o normas especiales; } \\
\text { (b) Pueblos en países independientes que } \\
\text { son reconocidos como indígenas en función } \\
\text { de su descendencia de las poblaciones que } \\
\text { habitaban el país, o región a la que el país } \\
\text { pertenece, en el momento de la conquista } \\
\text { o colonización o el establecimiento de los } \\
\text { límites estatales y que, independientemente } \\
\text { de su estatus legal, mantienen todas o } \\
\text { parte de sus propias instituciones sociales, } \\
\text { económicas, culturales y políticas. }\end{array}$ & $\begin{array}{l}\text { Fuente: Definición aplicada a la convención de } \\
\text { la Organización Internacional del Trabajo (OIT) } \\
\left(n^{\circ} 169\right) \text { acerca de los Pueblos Indígenas y } \\
\text { Tribales en Países Independientes. } \\
\text { Los pueblos indígenas también reclaman } \\
\text { que hay cierto grado de autodefinición al } \\
\text { determinar que supone ser un pueblo indígena } \\
\text { o tribal específico. }\end{array}$ \\
\hline $\begin{array}{l}\text { Servicios } \\
\text { ecosistémicos }\end{array}$ & $\begin{array}{l}\text { Los beneficios que la sociedad obtiene de } \\
\text { los ecosistemas. Estos incluyen servicios } \\
\text { de aprovisionamiento, como comida y } \\
\text { agua; servicios de regulación, como la } \\
\text { regulación de las inundaciones, sequías, } \\
\text { degradación del terreno y enfermedades; } \\
\text { servicios de sustento como la formación del } \\
\text { sustrato y el reciclaje de los nutrientes; y } \\
\text { servicios culturales, ya sean recreacionales, } \\
\text { espirituales, religiosos u otros beneficios no } \\
\text { materiales. }\end{array}$ & $\begin{array}{l}\text { Source: Hassan, R., R. Scholes y N. Ash } \\
\text { (Eds). 2005. Ecosystems and Human Well- } \\
\text { Being: Current State and Trends: Findings } \\
\text { of the Condition and Trends Working Group } \\
\text { v. } 1 \text { (Millennium Ecosystem Assessment). } \\
\text { Washington DC: Island Press. } \\
\text { Definiciones en: Capítulo 1: MA Marco de } \\
\text { Trabajo Conceptual. }\end{array}$ \\
\hline
\end{tabular}


Tabla 19. Definición de los términos usados en las directrices (cont.)

\begin{tabular}{|c|c|c|}
\hline Término & Definición & Fuentes y notas \\
\hline $\begin{array}{l}\text { Tipo de } \\
\text { Gobernanza }\end{array}$ & $\begin{array}{l}\text { Los tipos de gobernanza han sido definidos } \\
\text { en función de "quién ostenta la autoridad } \\
\text { y responsabilidad de la gestión y tiene que } \\
\text { rendir cuentas" para un área protegida } \\
\text { específica. }\end{array}$ & $\begin{array}{l}\text { Fuente: "Governance of protected areas, } \\
\text { participation and equity", pp. 100-105 } \\
\text { in Secretariat of the Convention on } \\
\text { Biological Diversity, Biodiversity Issues for } \\
\text { Consideration in the Planning, Establishment } \\
\text { and Management of Protected Areas and } \\
\text { Networks. Technical Series no. 15. Montreal: } \\
\text { SCDB. }\end{array}$ \\
\hline Uso sostenible & $\begin{array}{l}\text { El uso de los componentes de diversidad } \\
\text { biológica de un modo y a un ritmo que } \\
\text { no conlleve al declive a largo plazo de la } \\
\text { diversidad biológica, por ello manteniendo } \\
\text { su potencial para cubrir las necesidades y } \\
\text { aspiraciones de las generaciones presentes } \\
\text { y futuras. } \\
\text { (Esta definición del CDB es específica al uso } \\
\text { sostenible de la biodiversidad). }\end{array}$ & $\begin{array}{l}\text { Fuente: CDB, Artículo } 2 \text {. Uso de Términos } \\
\text { http://www.cbd.int/convention/articles. } \\
\text { shtml?a=cbd-02 } \\
\text { Traducciones: Árabe, Chino, Español, } \\
\text { Francés, Inglés, Ruso. }\end{array}$ \\
\hline $\begin{array}{l}\text { Zona de } \\
\text { amortiguamiento }\end{array}$ & $\begin{array}{l}\text { Área entre las áreas protegidas y las } \\
\text { extensiones de tierra y marinas circundantes } \\
\text { que protegen a la red de influencias } \\
\text { externas potencialmente dañinas y que son } \\
\text { esencialmente áreas de transición. }\end{array}$ & $\begin{array}{l}\text { Fuente: Bennett, G. y K.J. Mulongoy. } \\
\text { 2006. Review of experience with ecological } \\
\text { networks, corridors and buffer zones. } \\
\text { Technical Series no. 23. Montreal: SCDB. }\end{array}$ \\
\hline
\end{tabular}




\section{Bibliografía}

Bishop, K., N. Dudley, A. Phillips y S. Stolton. 2004. Speaking a Common Language - the uses and performance of the IUCN System of Management Categories for Protected Areas. Cardiff University, UICN y PNUMA/CMMC.

Borrini-Feyerabend, G., A. Kothari y G. Oviedo. 2004. Indigenous and Local Communities and Protected Areas: Towards equity and enhanced conservation. Best Practice Protected Area Guidelines Series No. 11. Gland y Cambridge: UICN.

Bridgewater, P., A. Phillips, M. Green y B. Amos. 1996. Biosphere Reserves and the IUCN System of Protected Area Management Categories. Canberra: Australian Nature Conservation Agency.

Brockman, C.F. 1962. "Supplement to the Report to the Committee on Nomenclature". In: Adams, A.B. (Ed.) First World Conference on National Parks. Washington, DC: National Park Service.

CDB. 2004. http://www.cbd.int/programmes/cross-cutting/ecosystem/default.shtml. Accessed 24 August 2007.

Chape, S., S. Blyth, L. Fish, P. Fox y M. Spalding. (Eds). 2003. 2003 United Nations List of Protected Areas. Gland y Cambridge: UICN y PNUMA-CMMC.

Davey, A.G. 1998. National System Planning for Protected Areas. Best Practice Protected Area Guidelines Series No. 1. Gland y Cambridge: UICN.

Day, J. 2002. "Zoning: Lessons from the Great Barrier Marine Park”. Ocean and Coastal Management 45: 139-156.

Dillon, B. 2004. "The Use of the Categories in National and International Legislation and Policy". PARKS 14(3): 15-22.

Dudley, N., L. Higgins-Zogib y S. Mansourian. 2006. Beyond Belief: Linking faiths and protected area networks to support biodiversity conservation. Gland y Bath: WWF International y Alliance on Religions and Conservation.

Dudley, N. y J. Parrish. 2006. Closing the Gap: Creating ecologically representative protected area systems. Technical Series no. 24. Montreal: SCDB.

Dudley, N. y A. Phillips. 2006. Forests and Protected Areas: Guidance on the use of the IUCN protected area management categories. Best Practice Protected Area Guidelines Series No. 12. Gland y Cambridge: UICN.

Dudley, N. y S. Stolton. 2003. "Ecological and socio-economic benefits of protected areas in dealing with climate change". In: Hansen, L.J., J.L. Biringer y J.R. Hoffman (Eds) Buying Time: A user's guide to building resistance and resilience to climate change in natural systems, pp. 217-233. Washington, DC: WWF US.

Eidsvik, H. 1990. A Framework for Classifying Terrestrial and Marine Protected Areas. Based on the Work of the CNPPA Task Force on Classification, UICN/CNPPA. Unpublished.

Elliott, H.B. (Ed). 1974. Second World Conference on National Parks, Proceedings. Morges: UICN.

EUROPARC y UICN. 1999. Guidelines for Protected Area Management Categories - Interpretation and Application in Europe. Grafenau: EUROPARC.

Graham, J., B. Amos y T. Plumptre. 2003. Principles for Good Governance in the 21st Century. Policy Brief Number 15. Ottawa: Institute on Governance.

Hockings, M., S. Stolton, F. Leverington, N. Dudley y J. Courrau. 2006. Evaluating Effectiveness: A framework for assessing management effectiveness of protected areas. 2nd edition. Gland y Cambridge: UICN.

Holdaway, E. Undated. Making the Connection between Land and Sea: The place for coastal protected landscapes in the marine environment. Wadebridge y Bangor: EUROPARC Atlantic Isles y The Countryside Council for Wales.

Holdgate, M. 1999. The Green Web. London: Earthscan.

Kelleher, G. 2002. Guidelines for Marine Protected Areas. Best Practice Protected Area Guidelines Series No. 3. Gland y Cambridge: UICN.

Palumbi, S.R. 2001. "The ecology of marine protected areas". In: Bertness, M.D, S.M. Gaines y M.E. Hixon (Eds). Marine Community Ecology, pp.509-530. Sunderland, MA: Sinauer Associates.

Phillips, A. 2002. Management Guidelines for IUCN Category V Protected Areas: Protected Landscapes/Seascapes. Best Practice Protected Area Guidelines Series No. 9. Gland y Cambridge: UICN.

Phillips, A. 2007. "A short history of the international system of protected area management categories". Paper prepared for the WCPA Task Force on protected area categories.

Sandwith. T., C. Shine, L. Hamilton y D. Sheppard. 2001. Transboundary Protected Areas for Peace and Cooperation. Best Practice Protected Area Guidelines Series No. 7. Gland y Cambridge: UICN.

Stolton, S., N. Dudley y J. Randall. 2008. Natural Security: Protected areas and hazard mitigation. The Arguments for Protection Series. Gland: WWF International. 
Sulu, R., R. Cumming, L. Wantiez, L. Kumar, A. Mulipola, M. Lober, S. Sauni, T. Poulasi y K. Pakoa. 2002. "Status of Coral Reefs in the Southwest Pacific Region to 2002: Fiji, Nauru, New Caledonia, Samoa, Solomon Islands, Tuvalu and Vanuatu”. In: Wilkinson, C.R. (Ed.) Status of Coral Reefs of the World 2002. Townsville, Queensland: Australian Institute of Marine Science.

UICN. 1974. Classification and Use of Protected Natural and Cultural Areas. IUCN Occasional Paper No. 4. Morges: UICN. UICN. 1978. Categories, Objectives and Criteria: Final Report of the Committee and Criteria of the CNPPA/IUCN. Morges: UICN.

UICN/CMMC. 1994. Guidelines for Protected Area Management Categories. Gland y Cambridge: UICN.

UICN. 2004. PARKS 14. (includes 10 papers). 


\section{UICN}

UNIÓN INTERNACIONAL PARA

LA CONSERVACIÓN DE LA NATURALEZA

SEDE MUNDIAL

Rue Mauverney 28

1196 Gland

Suiza

mail@iucn.org

Tel +41229990000

Telefax +41229990002

www.iucn.org

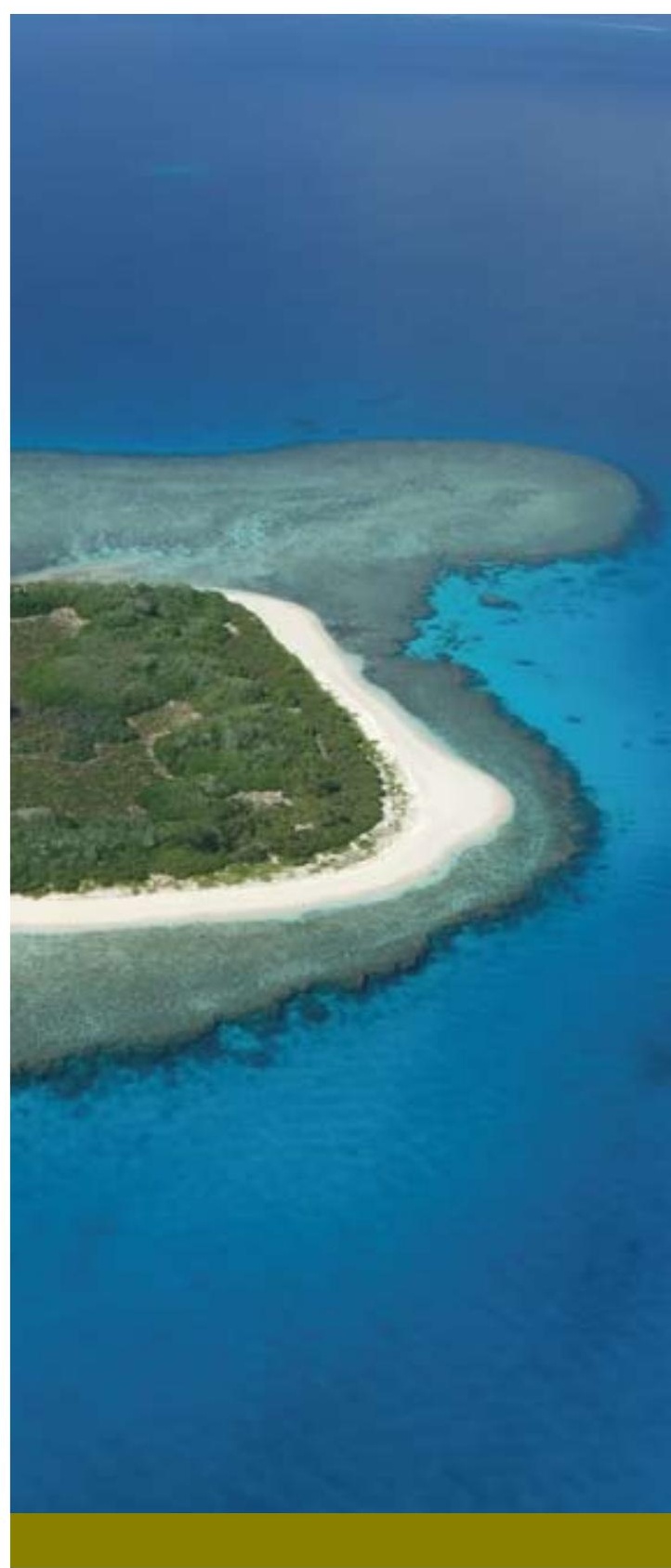

